\title{
RELAÇÃO ENTRE CARACTERÍSTICAS MICROESTRUTURAIS E O COMPORTAMENTO MACROSCÓPICO DE SOLOS GRANULARES
}

ROBINSON ANDRÉS GIRALDO ZULUAGA

TESE DE DOUTORADO EM GEOTECNIA

DEPARTAMENTO DE ENGENHARIA CIVIL E AMBIENTAL

\section{FACULDADE DE TECNOLOGIA UNIVERSIDADE DE BRASÍLIA}


UNIVERSIDADE DE BRASÍLIA

FACULDADE DE TECNOLOGIA

DEPARTAMENTO DE ENGENHARIA CIVIL E AMBIENTAL

\section{RELAÇÃO ENTRE CARACTERÍSTICAS MICROESTRUTURAIS E O COMPORTAMENTO MACROSCÓPICO DE SOLOS GRANULARES}

ROBINSON ANDRÉS GIRALDO ZULUAGA

ORIENTADOR: MÁRCIO MUNIZ DE FARIAS, Ph.D. CO-ORIENTADOR: NICOLÁS ESTRADA MEJIA, Ph.D.

TESE DE DOUTORADO EM GEOTECNIA

PUBLICAÇÃO: G.TD-118/16

BRASÍLIA / DF: MAIO DE 2016 


\title{
UNIVERSIDADE DE BRASÍLIA \\ FACULDADE DE TECNOLOGIA \\ DEPARTAMENTO DE ENGENHARIA CIVIL E AMBIENTAL
}

\author{
RELAÇÃO ENTRE CARACTERÍSTICAS \\ MICROESTRUTURAIS E O COMPORTAMENTO \\ MACROSCÓPICO DE SOLOS GRANULARES
}

\section{ROBINSON ANDRÉS GIRALDO ZULUAGA}

TESE DE DOUTORADO SUBMETIDA AO DEPARTAMENTO DE ENGENHARIA CIVIL E AMBIENTAL DA UNIVERSIDADE DE BRASÍLIA COMO PARTE DOS REQUISITOS NECESSÁRIOS PARA A OBTENÇÃO DO GRAU DE DOUTOR.

APROVADA POR:

MÁRCIO MUNIZ DE FARIAS, Ph.D. (UnB)

(ORIENTADOR)

NICOLÁS ESTRADA MEJIA, Ph.D. (UNIANDES-Colômbia) (CO-ORIENTADOR)

MANOEL PORFÍRIO CORDÃO NETO, D.Sc. (UnB) (EXAMINADOR INTERNO)

HERNÁN EDUARDO MARTÍNEZ CARVAJAL , D.Sc. (UnB) (EXAMINADOR INTERNO)

LUIS MARCELO MARQUES TAVARES, Ph.D. (COOPE-UFRJ) (EXAMINADOR EXTERNO)

IRVIN PABLO PÉREZ MORALES, Ph.D. (UCLV-Cuba) (EXAMINADOR EXTERNO)

DATA: BRASÍLIA/DF, MAIO DE 2016 


\section{FICHA CATALOGRÁFICA}

\section{ZULUAGA, ROBINSON ANDRÉS GIRALDO}

Relação entre características microestruturais e o comportamento macroscópico de solos granulares.

xxi 150 p., 297 mm (ENC/FT/UnB, Doutor, Geotecnia, 2016)

Tese de Doutorado - Universidade de Brasília. Faculdade de Tecnologia. Departamento de Engenharia Civil e Ambiental
1. Micromecânica
2. Quebra de partículas
3. Elementos discretos
4. Partículas

I. ENC/FT/UnB

II. Título (série)

\section{REFERÊNCIA BIBLIOGRÁFICA}

ZULUAGA, R.A.G. (2016). Relação entre características microestruturais e o comportamento macroscópico de solos granulares. Tese de Doutorado, Publicação G.TD-190/16, Departamento de Engenharia Civil e Ambiental, Universidade de Brasília, Brasília, DF, 150 p.

\section{CESSÃO DE DIREITOS}

NOME DO AUTOR: Robinson Andrés Giraldo Zuluaga

TÍTULO DA TESE DE DOUTORADO: Relação entre características microestruturais e o comportamento macroscópico de solos granulares.

GRAU / ANO: Doutor / 2016

É concedida à Universidade de Brasília a permissão para reproduzir cópias desta tese de doutorado e para emprestar ou vender tais cópias somente para propósitos acadêmicos e científicos. O autor reserva outros direitos de publicação e nenhuma parte desta dissertação de mestrado pode ser reproduzida sem a autorização por escrito do autor.

\section{Robinson Andrés Giraldo Zuluaga}

roangizu@gmail.com 


\section{DEDICATÓRIA}

Aos meus pais, Orlando e Marina, os quais sempre me ensinaram a prosseguir sem importar as dificuldades encontradas no caminho, além do apoio e confiança permanente durante todas as fases da minha vida. À minha irmãzinha, Milena, a flor de nossa família, a qual ilumina nosso tracejar e incentiva a sermos melhores pessoas a cada dia. 


\section{AGRADECIMENTOS}

À Deus, por me ajudar em todos os momentos frente às adversidades encontradas nesta fase de minha vida, sendo a maior fonte de ânimo e fortaleza nos momentos de fraqueza.

À toda minha família, pelo carinho e apoio durante esta caminhada, sempre me motivando a dar o meu melhor para finalizar este trabalho.

Ao professor Márcio Muniz de Farias pela orientação, confiança permanente, e por seu exemplo como docente e pesquisador na engenharia geotécnica. Agradeço pela forma humana com a qual entendeu minhas dificuldades, me apoiando e incentivando nas etapas mais críticas deste trabalho.

Ao professor Nicolás Estrada pelo suporte e orientação durante minha estadia na Universidade de Los Andes (Bogotá-Colômbia). Sou muito grato pelas acertadas recomendações feitas no decorrer das nossas conversas.

Ao Doutor Irvin Pérez Morales pelo assessoramento nas analises micromecânicas e no uso da ferramenta numérica de elementos discretos YADE.

Ao professor Bernardo Caicedo da Universidade de Los Andes (Bogotá-Colômbia) pelo bom recebimento no grupo de pesquisa, permitindo-me participar de forma ativa nas suas atividades. Agradeço pelos ensinamentos recebidos, especialmente, a metodologia com a qual aborda suas pesquisas experimentais.

Aos meus grandes amigos Marcelo, Tubal, Marcola, Julian, Hernán, Ramon, Paulo André, Alex, Diego, Luis Carlos, Pancho e Ewerton pelas inumeráveis experiências e pelos bons momentos vividos durante todo este tempo.

À Ivonne e ao Jaime pela amizade sincera. Muito obrigado pelo apoio constante ao longo desta fase da minha vida.

Ao Cristhian Mendoza pela amizade e a colaboração na minha estadia em Bogotá, acolhendo-me de forma calorosa dentro de seu lar, com a boa companhia da Lida e da Juana.

Aos meus amigos Eduardo, Julieth, Enzo, William, Camilo Perico, Mauro, Natalia, Gabriel, Jairo, Catalina, Jose, Alberto e Jairo que ajudaram para que as coisas fossem bem mais tranquilas durante a minha estadia na Universidade de Los Andes.

Aos meus amigos do Laboratório, Juan, Alejandra, Ivan, Marcus e Ferney, pela agradável companhia e pelos conhecimentos transmitidos. 
À Cíntia, uma pessoa especial, que com seu carinho fez com que a última fase deste trabalho se tornasse mais tranquila.

Ao Engenheiro Kay Mootz da SymaTec pela colaboração na realização dos ensaios de granulometria e índices de forma mediante tecnologia Laser.

Agradeço ao Laboratório de Infraestruturas (InfraLab) da UnB pelos diferentes recursos providos para a realização desta pesquisa.

Agradeço ao Programa de Pós-Graduação em Geotecnia da Universidade de Brasília e ao seu corpo de professores, que transmitiram seus conhecimentos, contribuindo na minha formação como Engenheiro Geotécnico.

À Universidade de Los Andes, por todo o suporte de infraestrutura e humano durante o período sanduíche do doutorado.

Agradeço à Coordenação de Aperfeiçoamento de Pessoal de Nível Superior (Capes) e ao Centro de Apoio ao Desenvolvimento Tecnológico (CDT) da UnB, pelo apoio econômico para o desenvolvimento deste trabalho.

A todas as pessoas que de uma ou outra forma participaram deste processo,

\section{MUITO OBRIGADO!}

MUCHAS GRACIAS! 


\section{RESUMO}

O entendimento do comportamento dos solos, comumente, tem sido interpretado com base na mecânica do meio contínuo. Para isso, modelos constitutivos fenomenológicos devem ser formulados, a fim de representar o comportamento dos materiais em escala macroscópica, sem considerar a influência de fatores tais como a forma, a distribuição granulométrica, a quebra das partículas etc. Outra abordagem para esse problema é a mecânica dos meios descontínuos, a qual baseia-se na interação explícita dos elementos (partículas). Nesta abordagem é possível considerar diferentes caraterísticas na escala micro para a avaliação do comportamento de materiais granulares. Neste trabalho é estudada a influência de algumas caraterísticas em nível de partícula no comportamento de materiais granulares. São abordados, principalmente, os fenômenos de fragmentação de partículas e desestruturação de materiais cimentados. Para isto, foram executados ensaios de compressão confinada com esferas de vidro secas, com e sem cimentação artificial. Além disso, foi feito o monitoramento das emissões acústicas para compreender melhor os processos micromecânicos. Como complemento, foram registradas imagens microscópicas das partículas, úteis para as análises da evolução da forma do grão com o processo de quebra. Simulações numéricas simplificadas foram feitas com o objetivo de verificar a capacidade do Método dos Elementos Discretos reproduzir os fenômenos de quebra de partículas. Os resultados experimentais obtidos mostraram as mudanças de comportamentos de materiais granulares com e sem cimentação. Observou-se que o início da quebra das partículas ocorre para níveis de tensão elevados e não depende das condições iniciais de índice de vazios. Além disso, a evolução de quebra pode ser representada por vários índices propostos na literatura. Foram observados diferentes estágios de evolução da quebra de grãos e da cimentação, identificados com base em níveis de tensão e energia acústica acumulada emitida. Cada estágio pode ser delimitado por pontos de mudança, os quais estão relacionados com certos valores de índice de quebra e relação de aspecto. 


\begin{abstract}
The overall behavior of soil has been commonly interpreted within the framework of continuum mechanics. Phenomenological constitutive models have been formulated to represent the observed behavior at the macroscopic scale, without taking into consideration the influence of important factors such as grain shape, grain size distribution and particle breakage. An alternative approach is provided by the discrete analysis, which is based on the explicit interactions between particles. Using this approach, it is possible to consider the influence of different grain characteristics on the behavior of granular materials. The research carried out in this thesis focuses on the phenomena of particle breakage and destructuration due to debonding. Strain controlled one-dimensional compression tests were carried out on glass spheres with and without artificial cementation. Acoustic emissions were monitored during these tests in order to gain further insight about the micromechanical processes. To complement the analyses, the fragmented glass spheres were subjected to laser scanning in order to evaluate the evolution of grain shape due to particle breakage. Simplified numerical simulations using the Discrete Element Method were performed in order to verify the effectiveness of this method to reproduce the phenomenon of particle breakage. The experimental results showed the gradual change of behavior of the material with and without cementation. It was observed that particle breakage takes place at relative high stress levels, and does not depend on the initial void ratio of the package. Furthermore, the evolution of this phenomenon can be represented using most of the particle breakage indices proposed in the literature. Different stages of fragmentation and debonding were identified based on the evolution of stress and accumulated acoustic energy emission. These stages are associated with critical points, which should be related to changes in breakage indices and aspect ratio.
\end{abstract}




\section{ÍNDICE}

1 INTRODUÇÃO ........................................................................................................... 1

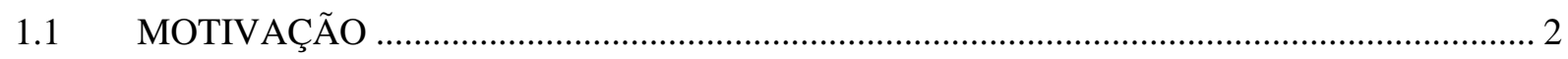

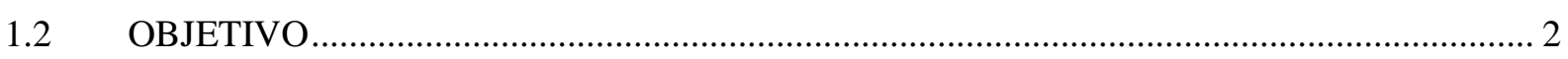

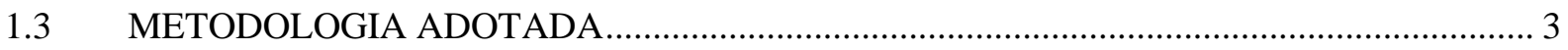

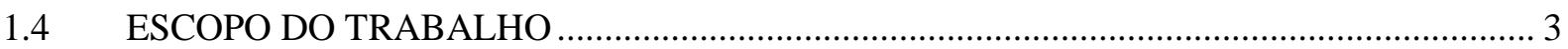

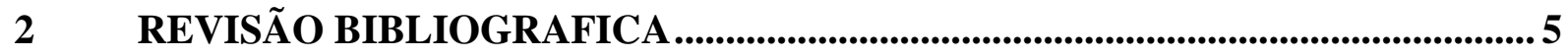

2.1 COMPORTAMENTO DE MATERIAIS GRANULARES ……….................................. 5

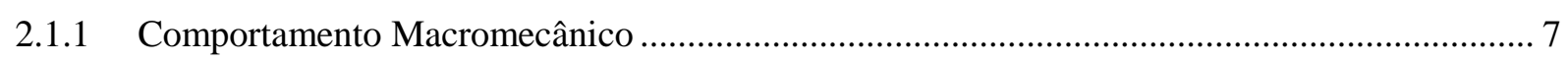

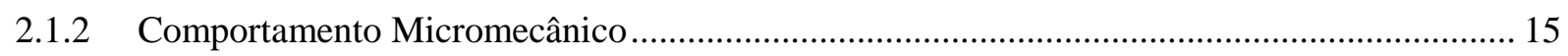

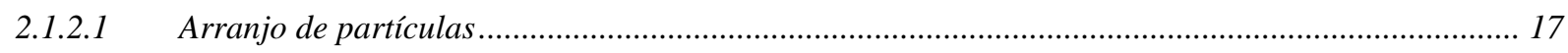

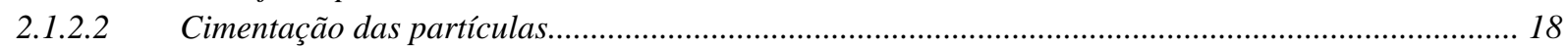

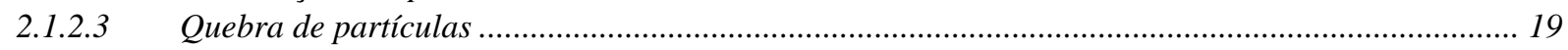

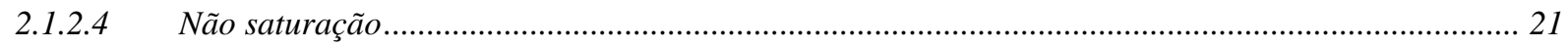

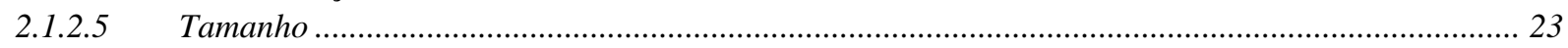

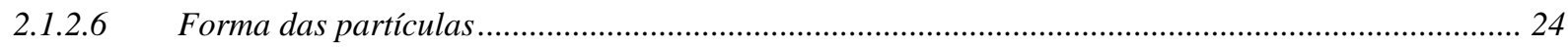

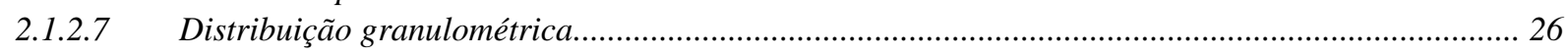

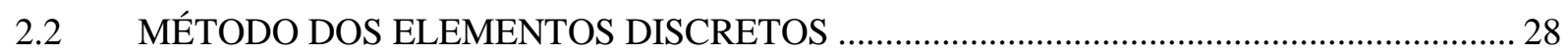

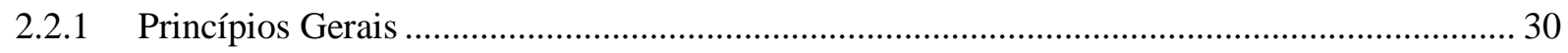

2.2.2 Interpretação Micromecânica dos Resultados ................................................................... 34

2.2.3 Alguns Desenvolvimentos na Modelagem Micromecânica ...................................................... 36

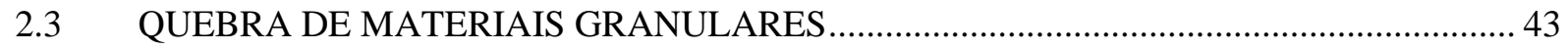

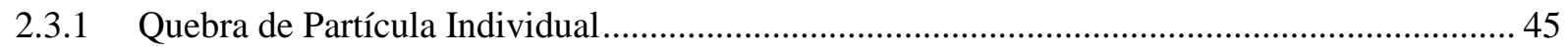

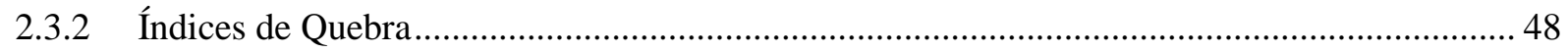

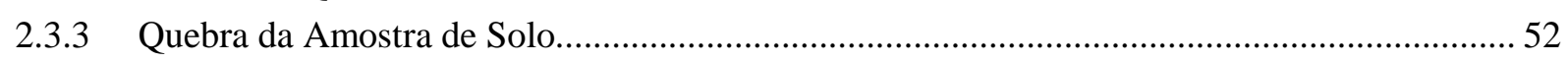

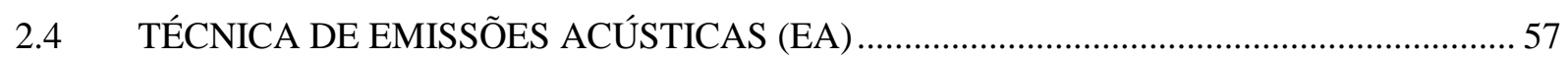

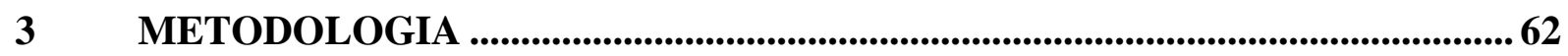

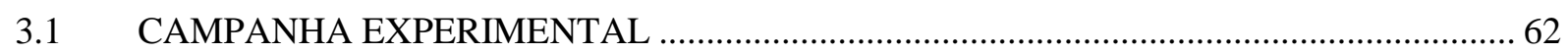

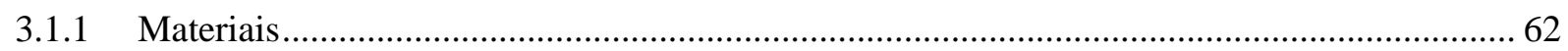

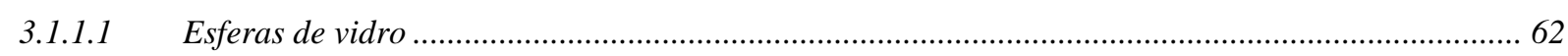

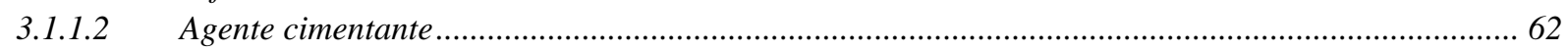

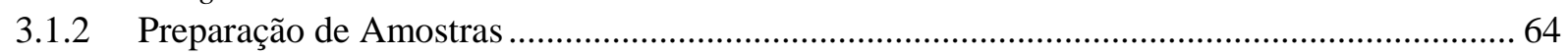

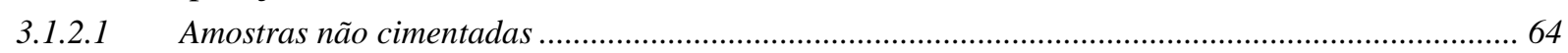

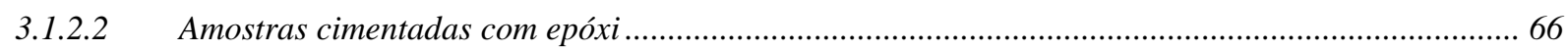

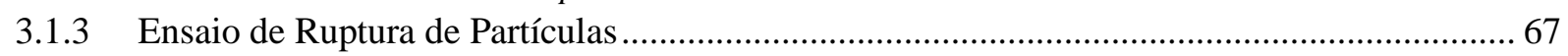

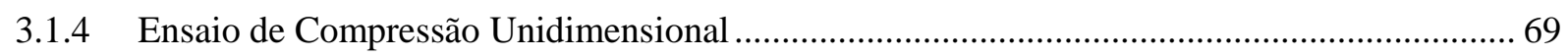

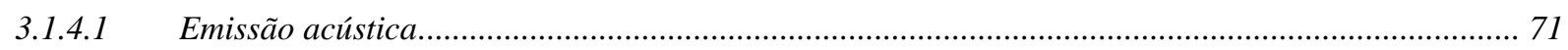

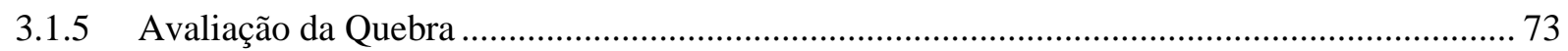

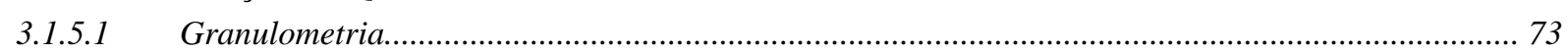

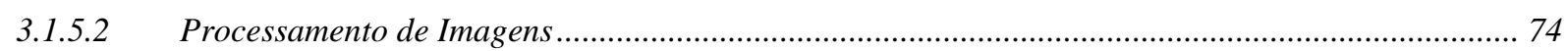




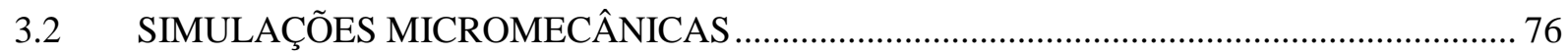

4 APRESENTAÇÃO E ANÁLISE DE RESULTADOS........................................ 81

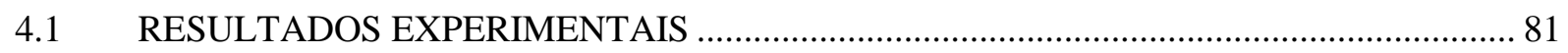

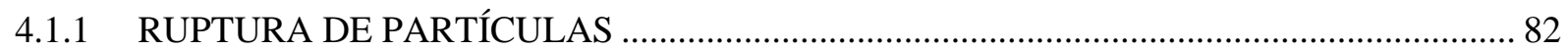

4.1.2 COMPRESSÃO CONFINADA - MATERIAL SOLTO ……........................................... 94

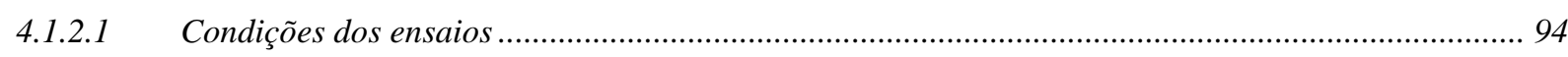

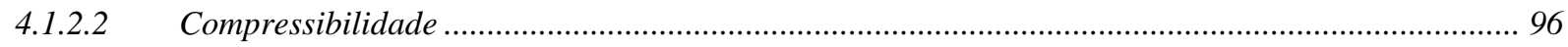

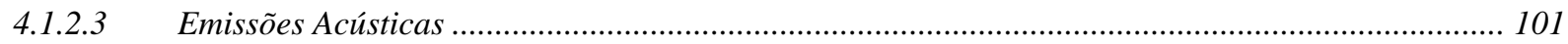

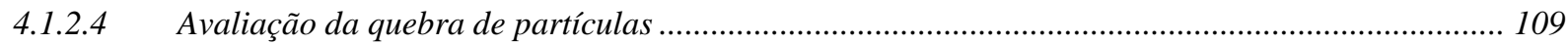

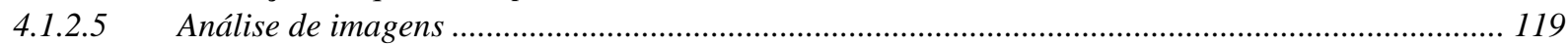

4.1.3 COMPRESSÃO CONFINADA - MATERIAL CIMENTADO …....................................... 126

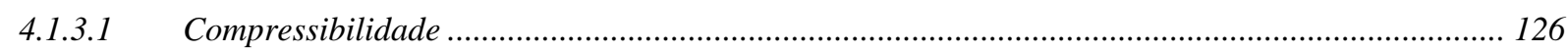

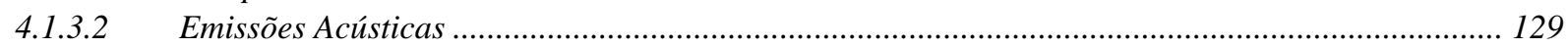

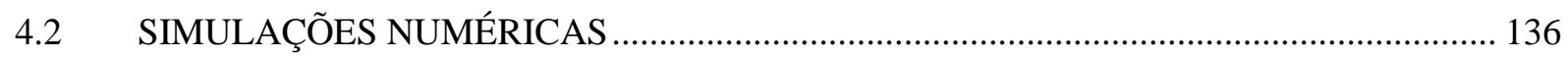

5 CONCLUSÕES E SUGESTÕES ....................................................................................... 140

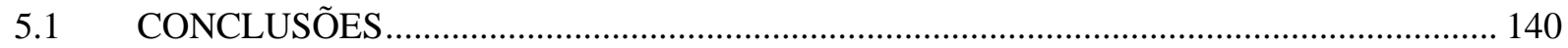

5.2 SUGESTÕES PARA FUTURAS PESQUISAS …......................................................... 142 


\section{ÍNDICE DE TABELAS}

Tabela 2.1. Classificação de solos granulares com a compacidade (Lambe \& Whitman, 1969). 8

Tabela 2.2. Descrição das características dos tipos de curvas de compressibilidade............... 14

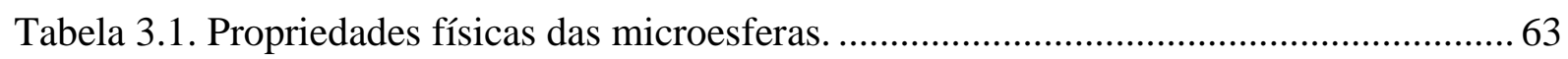

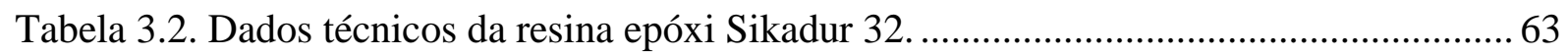

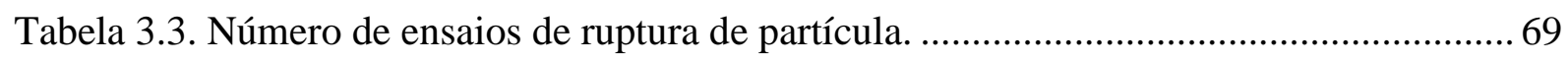

Tabela 3.4. Relação de Ensaio para material solto................................................................. 70

Tabela 3.5. Relação de Ensaio para material cimentado........................................................ 71

Tabela 3.6. Configuração da substituição por 14 esferas, em que $R$ representa o raio da "esfera mãe", enquanto $r$ representa o raio das "esferas filhas" (Ciantia et al., 2015)......... 78

Tabela 4.1. Estatística dos resultados primários do ensaio de compressão diametral dos grãos.

Tabela 4.2. Parâmetros da distribuição de Weibull para cada faixa de tamanhos. …............... 87

Tabela 4.3. Resultados do modelo geral de distribuição de resistência da partícula. .............. 92

Tabela 4.4. Evolução da relação de aspecto do material A170 ............................................ 122

Tabela 4.5. Propriedade usadas para a simulação .............................................................. 136 


\section{ÍNDICE DE FIGURAS}

Figura 1.1. Metodologia adotada.

Figura 2.1. Mecânica de materiais particulados como um ramo especial da mecânica (Modificado Feda, 1982).

Figura 2.2. Meio contínuo vs. Meio descontínuo (Modificado Biarez \& Hicher, 1994).....

Figura 2.3. (a) Ensaios triaxiais em areia fofa e densa sob baixos níveis de tensão confinante (Taylor, 1948). (b) Variação do ângulo de atrito de pico com a compacidade, em ensaios triaxiais em areia (Rowe, 1962)......

Figura 2.4. Ilustração da dilatação e contração da amostra.

Figura 2.5. Comportamento de areia em ensaios triaxiais sob diferentes estados de tensão confinante para uma areia fofa (Lee, 1965 apud Ortigão, 2007).

Figura 2.6. Comportamento de areia em ensaios triaxiais sob diferentes estados de tensão

confinante para uma areia densa (Lee, 1965 apud Ortigão, 2007). 12

Figura 2.7. Curva de compressibilidade tipo A (Nakata et al., 2001b). 13

Figura 2.8. Curva de compressibilidade tipo B (De Beer, 1963).

Figura 2.9. Curva de compressibilidade tipo C (Pestana \& Whittle, 1995).

Figura 2.10. Curva de compressibilidade da areia cimentada estruturada de Cambria (Yamamuro et al., 1996). .15

Figura 2.11. Resultados do estudo fotoelástico de discos carregados (Jong \& Verruijt, 1969). 16

Figura 2.12. Elementos micromecânicos que influenciam o comportamento macroscópico. . 17

Figura 2.13. Influência do arranjo das partículas do solo na sua compacidade (Neves, 2009). 18

Figura 2.14. . Detalhe da cimentação entre as partículas calcárias, cimentadas com (a) Calcita, (b) Gesso, e (c) Cimento Portland (Ismail et al., 2002), e entre as esferas de vidro cimentadas com epóxi(Zuluaga, 2011). . 19

Figura 2.15. Detalhe da quebra de microesferas de vidro. 20

Figura 2.16. Comportamento de compressão unidimensional de areias com várias composições mineralógicas para dois tamanhos de grão (Chuhan et al., 2003).

Figura 2.17. Influência da sucção no contato entre os grãos de solo: (a) detalhe do menisco entre duas partículas reais (Alonso \& Gens, 2010); (b) ilustração das forças atuantes no contato(Ibañez, 2008).

Figura 2.18. Forma dos meniscos de água sobre grãos de areia: (a), (c) e (d) mostram meniscos predominantemente côncavos; (B) mostra menisco convexo. As 'rugas' das interfaces ar / água são claros em (b) (Toll et al., 2012). 
Figura 2.19. Forma do Menisco de água em microesferas. A imagem mostra que meniscos côncavos (cv) e convexos (cx) coexistem num material com a mesma umidade relativa (Toll et al., 2012).

Figura 2.20. Representação esquemática dos efeitos da não saturação no comportamento. ... 23

Figura 2.21. Influência do tamanho das partículas na compressibilidade de uma areia sílica (Nakata et al., 2001b).

Figura 2.22. Determinação da forma das partículas: (a) Carta de esfericidade $S$ e arredondamento $R$. As linhas tracejadas correspondem à constante de regularidade das partículas $\rho=(\mathrm{S}+\mathrm{R}) / 2$. (b) ilustração das medidas necessárias para a obtenção das características da forma das partículas (Cho et al., 2006). 25

Figura 2.23. Efeitos da variação da forma dos grãos para areias bem graduadas ricas em quartzo (Chuhan et al., 2003).....

Figura 2.24. Algumas influências da forma das partículas no comportamento mecânico de materiais granulares (Cho et al., 2006). 26

Figura 2.25. Efeito da graduação sobre a quebra das partículas de granito para ensaios de compressão isotrópica conduzido até 7,8 MPa (Lee \& Farhoomand, 1967 apud Hardin, 1985).

Figura 2.26. Efeitos da variação do coeficiente de uniformidade $\left(c_{u}\right)$ durante a compressão unidimensional de areias (Chuhan et al., 2003).

Figura 2.27. Ilustração das categorias de técnicas numéricas discretas, segundo a abordagem no contato (O'Sullivan, 2011). 28

Figura 2.28. (a)-(c) Resultados experimentais do estudo fotoelástico de discos (Jong \& Verruijt, 1969); (b)-(d) Resultados das simulações numéricas com o método dos elementos discretos (Cundall \& Strack, 1979). 29

Figura 2.29. Princípios de modelagem MED (O’Sullivan, 2011).......................................... 31

Figura 2.30. Procedimento do método de elementos discretos (Sadd et al., 2000).................. 32

Figura 2.31. Mapeamento usado para a determinação dos contatos num problema 2D

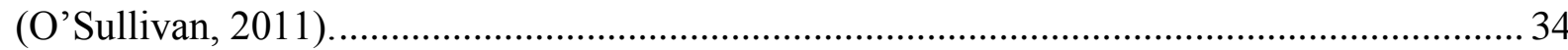

Figura 2.32. Linhas de força no ensaio de cisalhamento (Lobo-Guerrero \& Vallejo, 2006).. 35

Figura 2.33. Número de publicações a longo do tempo (O’Sullivan, 2014).

Figura 2.34. (a,b) Clusters (Mcdowell \& Ferellec, 2010). (c,d) Poliedros esféricos (GalindoTorres \& Pedroso, 2010). Esferopolígonos: (e) ilustração da geração de uma forma complexa, e (f) visualização da interação de 400 vacas numa caixa retangular confinada (AlonsoMarroquín, 2008).

Figura 2.35. Número de publicações com uso de partículas $2 \mathrm{D}$ e $3 \mathrm{D}$ ao longo do tempo (O'Sullivan, 2014). 38 
Figura 2.36. Modelo de contato simplista proposto para simular o efeito da agua capilar (CW) no MED (Jiang et al., 2004).

Figura 2.37. (a) Geometria idealizada do menisco; (b) força capilar no menisco; (c) processos de transferência de massa partícula-menisco-poro (Ibañez, 2008). 40

Figura 2.38. Abordagens para simular a quebra de partículas: (a) substituição por fragmentos menores (Lobo-guerrero, 2006) e (b) usando cluster de esferas (Harireche \& Mcdowell, 2002). (c) aplicação de clusters para a simulação de ensaios de compressão (Lim \& McDowell, 2005). 41

Figura 2.39. Modelo de cimentação de Jiang et al (2005). 41

Figura 2.40. Modelo de conexões paralelas para material cimentado(Potyondy \& Cundall, 2004): (a,b) mostram os detalhes da concepção do modelo, e (c) mostra a aplicação feita por Wang e Leung (2008).

Figura 2.41. Curvas da distribuição de probabilidade acumulada de Weibull (Nakata et al., 1999). 46

Figura 2.42. Probabilidade de sobrevivência normalizada (Nakata et al., 1999). 46

Figura 2.43. Comparação dos dados observado com a função de Weibull para uma areia de quartzo (Nakata et al., 1999).

Figura 2.44. Tensão de tração média em função do diâmetro da partícula (McDowell \& Bolton, 1998). .48

Figura 2.45. Avaliação do índice $B_{g}$ 49

Figura 2.46. Metodologia para a obtenção do índice de quebra relativo $B_{r}$ (modificado Cantor et al., 2015). .50

Figura 2.47. Determinação da dimensão fractal de um solo real (Ghanbarian \& Daigle, 2015). .52

Figura 2.48. Efeito da quebra para diferentes tamanho de partículas iniciais (Lee \& Farhoomand, 1967). .53

Figura 2.49. Efeito da quebra para diferentes condições de carregamento (Lee \& Farhoomand, 1967). .53

Figura 2.50. Variação volumétrica com o nível de confinamento (Lo \& Roy, 1973). 54

Figura 2.51. Relação entre o incremento da área superficial e o trabalho plástico para ensaios de compressão triaxial drenados (Miura \& O-hara, 1979). .55

Figura 2.52. Quebra em função da energia total do sistema (Lade et al., 1996)..................... 56

Figura 2.53. Processo de fratura do grão (modificado Cheng et al., 2001)............................. 56

Figura 2.54. Componentes da técnica de emissões acústicas (Michlmayr et al., 2012). ......... 57

Figura 2.55. Algumas caraterísticas das emissões acústicas............................................... 58

Figura 2.56. Ensaio triaxial como monitoramento acústico (Koerner et al., 1981).................59 
Figura 2.57. Resultados de um ensaio oedométrico em areia seca (Koerner et al., 1984)....... 60

Figura 2.58. Evolução do índice de vazios e da contagem de emissões acústicas acumuladas para um ensaio de compressão isotrópica (Tanimoto \& Tanaka, 1986).

Figura 2.59. Evolução da tensão axial, do índice de quebra $\left(B_{r}\right)$ e a contagem de emissões acústicas acumuladas para um ensaio de compressão confinada (Fernandes et al., 2010)...... 61

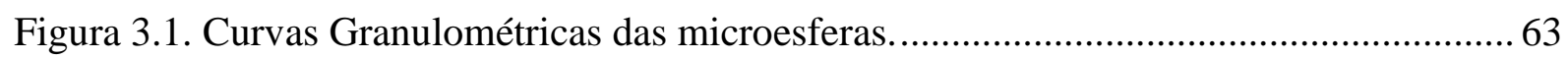

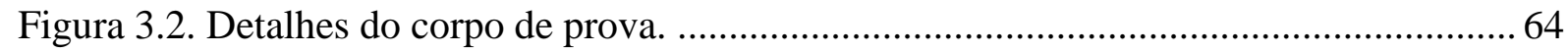

Figura 3.3. Processo de fabricação de amostras com material solto...................................... 65

Figura 3.4. Detalhes do corpo de prova para material solto................................................. 66

Figura 3.5. Processo de fabricação de amostras com material cimentado. .............................. 67

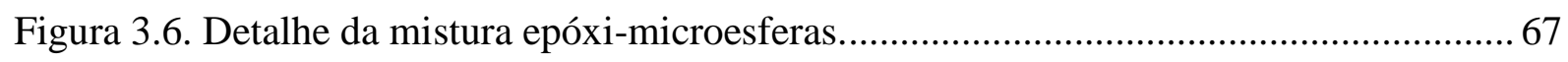

Figura 3.7. Ensaio de compressão diametral de uma partícula. ............................................. 68

Figura 3.8. Equipamento de compressão unidimensional com deformação controlada. ......... 70

Figura 3.9. Detalhe da localização dos sensores acústicos. ................................................ 71

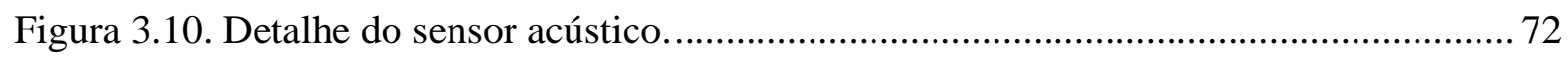

Figura 3.11. Detalhe do pré-amplificador de sinais acústicas................................................. 72

Figura 3.12. Placa de aquisição de dados........................................................................ 72

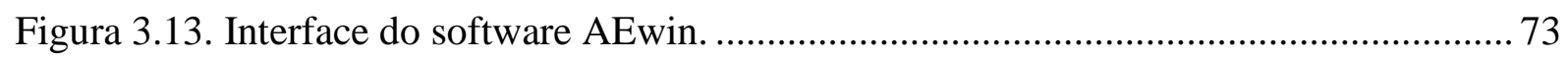

Figura 3.14. Sistema QICPIC com o dispersor: (a) tipo Gradis e (b) tipo Rodos

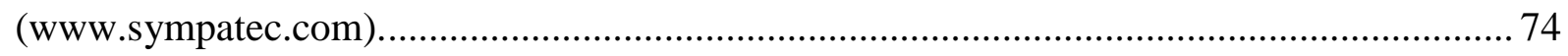

Figura 3.15. Princípios físicos dos dispersores (www.sympatec.com) .................................. 75

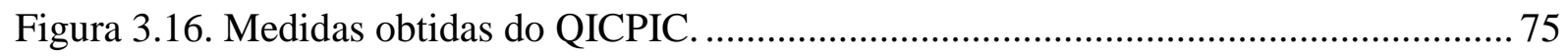

Figura 3.17. Configurações da quebra da partícula (Ciantia et al., 2014).............................. 77

Figura 3.18. Resposta macroscópica num ensaio de compressão confinada para diferentes configurações de substituição da partícula mãe (Ciantia et al., 2015).................................... 77

Figura 3.19. Hipóteses de critério de ruptura de uma partícula. ............................................. 79

Figura 3.20. Condições de contorno iniciais da simulação................................................. 80

Figura 4.1. Detalhes do ensaio de compressão diametral e da quebra do grão......................... 83

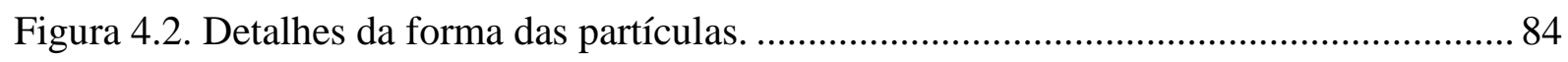

Figura 4.3. Ensaios de compressão diametral para esferas com diâmetros entre 1,00-1,18 mm. .84

Figura 4.4. Ensaios de compressão diametral para esferas com diâmetros entre 1,18-1,40 mm. 
Figura 4.5. Ensaios de compressão diametral para esferas com diâmetros entre 1,40-1,68 mm.

Figura 4.6. Ensaios de compressão diametral para esferas com diâmetros entre 1,68-2,00 mm. .85

Figura 4.7. Ensaios de compressão diametral para esferas com diâmetros entre 2,00 -2,38 mm .85

Figura 4.8. Curvas de probabilidade de sobrevivência. 86

Figura 4.9. Curvas de probabilidade de sobrevivência normalizada pela tensão caraterística. 87

Figura 4.10. Curvas para a obtenção do modulo de Weibull dos materiais. 88

Figura 4.11. Obtenção do modulo de Weibull do conjunto de partículas 89

Figura 4.12. Efeito do tamanho da partícula na tensão de quebra do material A170. .90

Figura 4.13. Modulo de Weibull da areia de quartzo da pesquisa feita por Nakata et al (1999).

Figura 4.14. Efeito do tamanho da partícula na tensão de quebra para a areia de quartzo da pesquisa feita por Nakata et al (1999). 92

Figura 4.15. Curvas de probabilidade de sobrevivência: dados experimentais vs. Modelos calibrados. .93

Figura 4.16. Modelo geral de probabilidade de sobrevivência. 94

Figura 4.17. Influência do atrito lateral na compressão confinada. 95

Figura 4.18. Curvas com compressibilidade com sistema plástico-vaselina nas paredes........ 95

Figura 4.19. Imagem do plástico após o ensaio de compressão. .96

Figura 4.20. Influencia da velocidade de deslocamento no comportamento. .96

Figura 4.21. Influência do tamanho da partícula na compressão confinada. .97

Figura 4.22. Curva de compressibilidade normalizada das microesferas tipo A170. .98

Figura 4.23. Curva de compressibilidade normalizada das microesferas tipo A072..............98

Figura 4.24. Curva de compressibilidade normalizada das microesferas tipo AC. .99

Figura 4.25. Compressibilidade de microesferas tipo A170. .99

Figura 4.26. Compressibilidade de microesferas tipo A072. 100

Figura 4.27. Compressibilidade de microesferas tipo AC. 100

Figura 4.28. Compressibilidade a níveis altos de tensão confinante. 101

Figura 4.29. Medições obtidas da técnica de EA para as microesferas A170.... 103

Figura 4.30. Energia PAC com a variação do tamanho de partícula. 103

Figura 4.31. Variação da energia PAC com o tipo de partícula. 104 
Figura 4.32. Relação entre a compressibilidade e as emissões acústicas para o material A170.

Figura 4.33. Relação entre a compressibilidade e as emissões acústicas para o material A072.

Figura 4.34. Relação entre a compressibilidade e as emissões acústicas para o material AC. 108

Figura 4.35. Imagens das microesferas após compressão confinada, para vários níveis de tensão- A170. 109

Figura 4.36. Imagens das microesferas após compressão confinada, para vários níveis de tensão- A072.

Figura 4.37. Curva de compressibilidade para vários níveis de tensão. Esferas A170.

Figura 4.38. Curva de compressibilidade para vários níveis de tensão. Esferas A072.

Figura 4.39. C urva de compressibilidade para vários níveis de tensão. Esferas AC.

Figura 4.40. Curva granulométrica para vários níveis de tensão. Esferas A170.

Figura 4.41. Curva granulométrica para vários níveis de tensão. Esferas A072.

Figura 4.42. Curva granulométrica para vários níveis de tensão. Esferas AC.

Figura 4.43. Índices de quebra para o material A170.

Figura 4.44. Índices de quebra para o material A072.

Figura 4.45. Índices de quebra para o material AC.

Figura 4.46. Índices de quebra em função do tipo de material.

Figura 4.47. Granulometria do material A170 para os quais foram feitas analise de imagens.

Figura 4.48. Distribuição acumulada da relação de aspecto para o material A170.

Figura 4.49. Relação de Aspecto em função do tamanho da partícula.

Figura 4.50. Algumas imagens do material A170.

Figura 4.51. Granulometria do material A072 para os quais foram feitas analise de imagens.

Figura 4.52. Granulometria do material AC para os quais foram feitas analise de imagens. 124

Figura 4.53. Distribuição acumulada da relação de aspecto para o material A072. 125

Figura 4.54. Distribuição acumulada da relação de aspecto para o material AC. 125

Com estes gráficos de distribuição acumuladas é possível determinar a quantidade de material com relação de aspecto superior a um valor de interesse. No caso do material A072 original, $90 \%$ do material (10\% de material que passa) tem relações de aspecto superiores a 0,9. Quando este material é carregado (quebrado) a porcentagem de material com $\mathrm{AR} \geq 90 \%$ diminui para 35\% (ver Figura 4.53). No caso do material AC, para uma relação de aspecto de 
0,9 , a porcentagem passa de $80 \%$ para o material original para $70 \%$ nas partículas quebradas

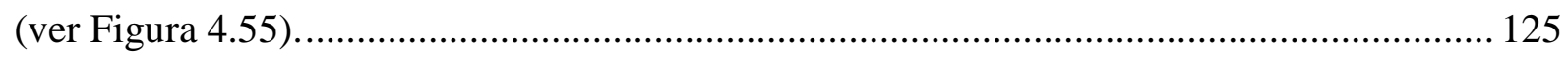

Figura 4.56. Curvas de compressibilidade para materiais cimentados. ............................... 127

Figura 4.57. Curvas de compressibilidade normalizadas do material cimentado. .................. 128

Figura 4.58. Diferenças entre as emissões acústicas para material solto e cimentado........... 129

Figura 4.59. Compressibilidade e as emissões acústicas com a porcentagem de cimento. ... 131

Figura 4.60. Relação entre a compressibilidade e as emissões acústicas para o material A170

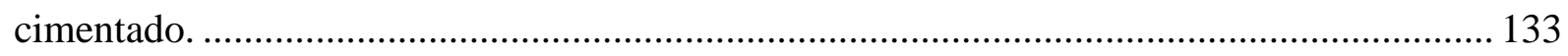

Figura 4.61. Relação entre a compressibilidade e as emissões acústicas para o material A072

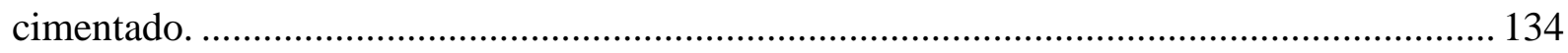

Figura 4.62. Relação entre a compressibilidade e as emissões acústicas para o material AC cimentado 135

Figura 4.63. Resultado da simulação do ensaio de compressão confinada, com o método de elementos discretos, ilustrando a evolução do fenômeno de quebra.................................... 137

Figura 4.64. Curva de compressibilidade obtida da simulação com MED............................ 138

Figura 4.65. Evolução da tensão e dos eventos de quebra ao longo do ensaio....................... 138

Figura 4.66. Evolução da curva Granulométrica com o processo de quebra. ........................ 139 


\section{LISTA DE ABREVIATURAS E SÍMBOLOS}

\section{ABREVIATURAS}

AR

Relação de Aspecto

DDA

Analise de Deformação Descontínua

DEM

Método dos Elementos Discretos (Discrete Element Method-DEM)

EA

Emissões Acústicas

MEF

Método dos Elementos Finitos

NCL

"Normal Consolidation Line". Para este trabalho será chamada de Linha de Compressão Normal.

PAC

"Physical Acoustic Corporation"

\section{SÍMBOLOS}

\section{Letras Arábicas}

$C_{c}$

Coeficiente de curvatura

$C_{u}$

Coeficiente de uniformidade

F

Força

$M_{i}^{(e)}$

Momentos

$D_{r}$

Densidade Relativa

$e$

Índice de Vazio do Material

$e_{\min }$

Índice de Vazio Mínimo do Material

$e_{\text {máx }}$

Índice de Vazio Máximo do Materia

M

Módulo Volumétrico

$S$

Esfericidade

$R$

Arredondamento

Z

Número de Coordenação

$N c$

Números de Contato do Sistema

$N p$

Número de Partículas 


$\begin{array}{ll}N m & \text { Número de Coordenação Mecânico } \\ C W & \text { Ação da Água Capilar } \\ P_{s} & \text { Probabilidade de Sobrevivência } \\ V_{0} & \text { Volume da partícula } \\ d & \text { Diâmetro } \\ B & \text { Índice de Quebra Relativa } \\ r & \text { Abertura da Peneira } \\ R_{m a ́ x} & \text { Abertura Máxima da Peneira } \\ k N & \text { Quilo Newton } \\ d B & \text { Decibeis } \\ D m i ́ n & \text { Tamanho Mínimo } \\ A_{F} & \text { Área de Contato da Placa com a Esfera num Ensaio de Compressão } \\ & \text { Diametral da Partícula } \\ & \text { Modulo de Weibull }\end{array}$

\section{Letras Gregas}

$\sigma$

$\varepsilon$

$\delta_{i}^{(e)}$

$\theta_{i}^{(e)}$

$\phi^{\prime}$

$\phi_{c r}^{\prime}$

$\sigma$

$\varepsilon$

$\rho$
Tensão

Deformação

Deslocamentos

Rotações

Ângulo de Atrito

Ângulo Atrito do Estado Crítico

Tensão Vertical Efetiva

Deformação Axial

Constante de Regularidade das Partículas 


\section{INTRODUÇÃo}

O entendimento do comportamento dos solos ao longo do tempo tem sido concebido com base na mecânica do meio contínuo, geralmente com o auxílio de técnicas numéricas para sua solução, como o Método dos Elementos Finitos (MEF), por exemplo. Para isso, modelos constitutivos fenomenológicos foram formulados a fim de representar o comportamento dos materiais, em escala macroscópica, sem considerar a estrutura granular ou cristalina do material. Em outras palavras, modelos matemáticos foram gerados para a relação causa-efeito, sem detalhar o que ocorre no interior do material.

Esse tipo de técnica apresenta dificuldades para capturar a influência de fatores tais como a forma, a distribuição granulométrica, a quebra das partículas etc. Além disso, a descrição do material como um meio contínuo encontra limitações para grandes deformações e também para a propagação de fraturas no meio (Donzé et al., 2009).

O relativo fracasso da abordagem contínua deve-se, principalmente, ao desajuste de escalas, isto é, enquanto os fenômenos comportamentais típicos dos solos estão enraizados nas suas características mineralógicas e feições microestruturais, a mecânica do contínuo procura modelá-los por meio de ajustes matemáticos do comportamento global observado na macroescala (Ibañez, 2008).

Outra abordagem para esse problema é a mecânica dos meios descontínuos, a qual está baseada na interação explícita dos elementos (partículas no caso do solo). Esta teoria é baseada na mecânica clássica de Newton e na definição de algumas leis de interação nos contatos entre os diferentes elementos. O fato de levar em consideração, de forma explícita, a natureza discreta do material, faz desta abordagem uma ferramenta válida e potente para ser utilizada em problemas da engenharia geotécnica. Além disso, com o avanço tecnológico e científico das últimas décadas, novas técnicas experimentais e computacionais foram desenvolvidas para aperfeiçoar as análises. Ferramentas como tomógrafos, microscópios de alta resolução, processamento de imagens em 2D e 3D, entre outras, são instrumentos disponíveis para a coleta de informações das caraterísticas micromecânicas dos meios descontínuos. Em relação à vertente numérica, o método dos elementos discretos (MED) ganhou bastante notoriedade no meio científico nos últimos anos, devido ao aumento da capacidade computacional, sendo cada vez mais accessível. Existem duas grandes vantagens para a utilização deste método (O’Sullivan, 2008): a primeira, está relacionada com o ganho de conhecimento sobre o comportamento de solos em nível de partícula. Já a segunda, 
relaciona-se com a possibilidade de resolver problemas de grandes deformações e deformações localizadas.

Uma das tendências para o uso do MED é como ferramenta para o entendimento das relações mecânicas das partículas (microscópica) com os resultados observados na escala macroscópica. A maioria das aplicações é feita para materiais granulares. Seu uso para materiais argilosos é reduzido devido à complexidade não apenas das forças de superfície, mas também da geometria das partículas (O’Sullivan, 2008).

A presente tese visa estudar a influência de algumas caraterísticas em nível de partícula que ajudem a melhorar o entendimento do comportamento de materiais granulares. Para tanto serão realizados ensaios laboratoriais e simulações numéricas, com a técnica numérica MED.

\subsection{MOTIVAÇÃO}

A motivação desta pesquisa fundamenta-se na potencialidade da abordagem descontínua para melhorar o entendimento do comportamento mecânico de geomateriais. A grande vantagem da abordagem discreta está na possibilidade de representar fenômenos na escala em que eles ocorrem. Com as avaliações feitas em laboratório desses processos, existe a possibilidade de simular diferentes características microestruturais com o uso do método dos elementos discretos. Tal ferramenta possui limitações com respeito à necessidade de capacidade computacional elevada, porém o aumento do poder de processamento computacional tem minimizado essa limitação e potencializado o uso dessa ferramenta dentro da comunidade geotécnica. Além disso, essa técnica permite o entendimento das interações entre as partículas, as quais nem sempre podem ser medidas em ensaios de laboratório, mas que podem ser facilmente monitoradas em ensaios virtuais, de forma a ajudar a melhorar o entendimento dos fenômenos geomecânicos.

\subsection{OBJETIVO}

O objetivo principal deste trabalho é avaliar a influência das características microestruturais de solos granulares sobre o comportamento geomecânico macroscópico, mediante a realização de uma campanha de ensaios experimentais, mas também de simulação numérica com o Método dos Elementos Discretos. Serão abordados, principalmente, os fenômenos de fragmentação de partículas e desestruturação de materiais cimentados. As indagações a serem abordadas ao longo deste trabalho são: 
- Quais são as variáveis micromecânicas que regem o processo de fragmentação de partículas e como elas influenciam no comportamento macroscópico?

- Quais são as variáveis micromecânicas que regem o comportamento de materiais cimentados estruturados e a evolução da sua desestruturação?

- Quais são as características micromecânicas que podem fornecer informações importantes para melhorar a interpretação física das variáveis internas dos modelos constitutivos macroscópicos?

\subsection{METODOLOGIA ADOTADA}

Para tentar responder às indagações supracitadas, este trabalho divide-se em três fases de execução. A primeira fase está relacionada com a execução de uma campanha de ensaios experimentais, com a finalidade de obter evidências sobre os fenômenos. A segunda fase corresponde à simulação numérica dos ensaios experimentais, na tentativa de reproduzir os fenômenos estudados e obter informações relevantes para o entendimento do comportamento do material. A última fase relaciona-se com as análises dos resultados, experimentais e numéricos, a fim de identificar as variáveis capazes de melhorar a representação dos fenômenos macroscópicos estudados para materiais granulares. Na Figura 1.1, ilustra-se a metodologia adotada para a execução deste estudo. No capítulo 3, serão abordadas cada uma destas fases com maior nível de detalhe.

\subsection{ESCOPO DO TRABALHO}

Este trabalho é dividido em três partes gerais, a primeira trata da revisão bibliográfica pertinente para o desenvolvimento desta pesquisa. Posteriormente é apresentada de forma detalhada a metodologia usada para a execução de cada uma das partes. Por último, são apresentados e analisados os resultados obtidos. A seguir se apresenta um breve resumo dos capítulos componentes deste trabalho.

No presente Capítulo 1 faz-se uma introdução da importância da abordagem descontínua para o entendimento dos geomateriais. No Capítulo 2 é apresentada uma breve revisão bibliográfica do comportamento de solos granulares, mostrando as principais características micro e macro mecânicas. Posteriormente aborda-se o método dos elementos discretos, fazendo uma explicação sucinta dos fundamentos teóricos, dos aspectos computacionais mais importantes e dos desenvolvimentos mais relevantes com aplicação na engenharia geotécnica. Por último, é apresentada uma revisão mais detalhada do fenômeno de 
quebra de partículas, por ser um dos principais assuntos trabalhados nesta pesquisa, e da técnica de emissões acústicas (ferramenta usada para complementar os ensaios laboratoriais).

No Capítulo 3 descreve-se a metodologia usada neste trabalho, mostrando os diferentes materiais, equipamentos, procedimentos e ferramentas utilizadas. No Capítulo 4 apresentamse os resultados e as análises dos comportamentos observados para as diferentes configurações de ensaios e caraterísticas microestruturais. No Capítulo 5 são apresentadas as conclusões do trabalho e as sugestões para pesquisas futuras.

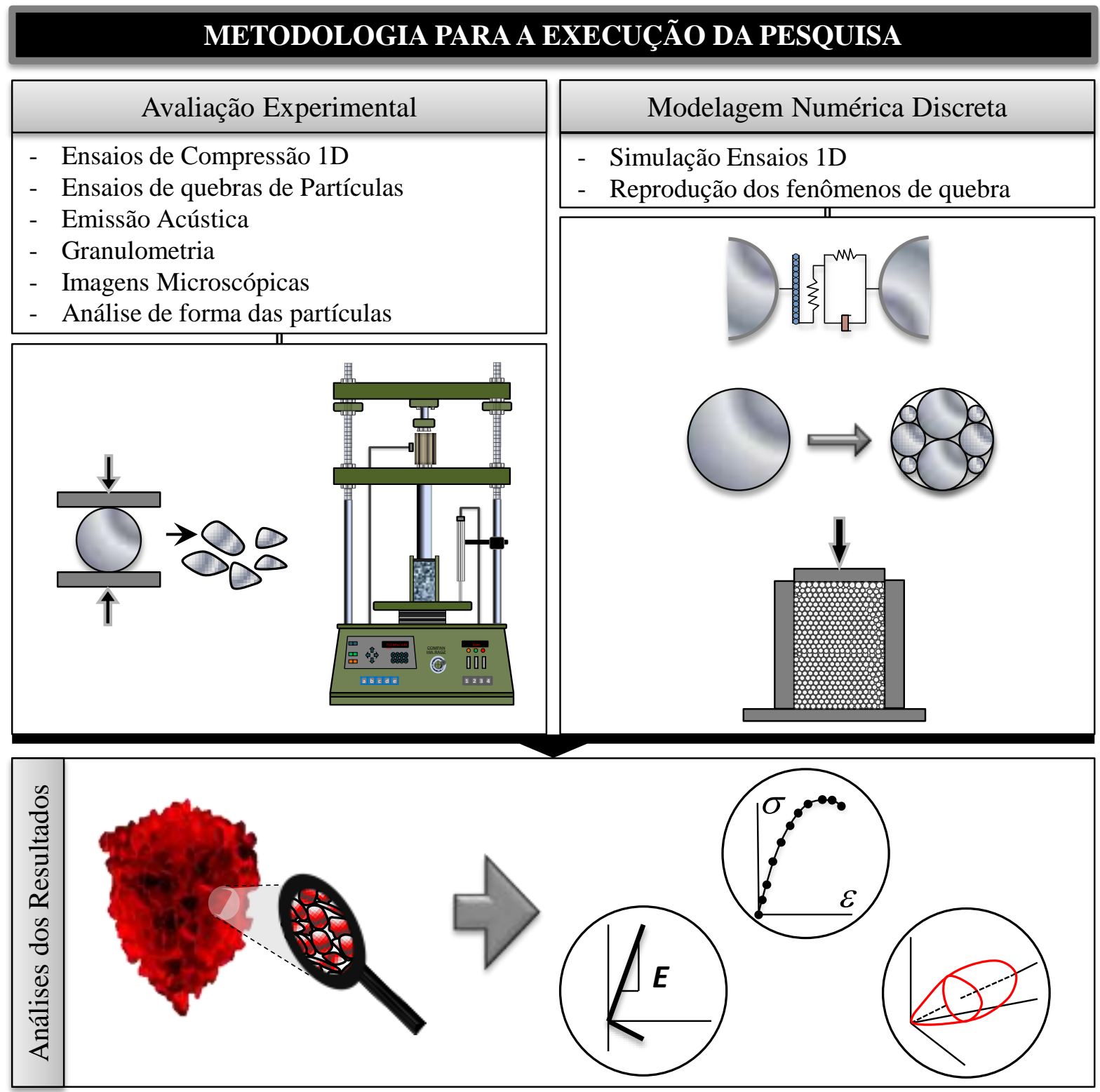

Figura 1.1. Metodologia adotada. 


\section{REVISÃO BIBLIOGRAFICA}

Neste capítulo será apresentada a visão geral dos conceitos teóricos necessários para entender os temas abordados nesta tese. $\mathrm{Na}$ primeira parte, são descritas as principais características macro e micro do comportamento de materiais granulares. Em seguida, é feita uma descrição da modelagem micromecânica, com ênfase no método dos elementos discretos e as suas principais características. Posteriormente, é apresentado um levantamento do estado da arte do fenômeno de fragmentação de materiais granulares, mostrando mais detalhes das implicações na engenharia geotécnica e as diferentes abordagens para sua avaliação. Por último, é apresentada uma breve revisão da técnica de emissões acústica e suas aplicações na engenharia geotécnica.

\subsection{COMPORTAMENTO DE MATERIAIS GRANULARES}

A mecânica de materiais particulados tem sido motivo de estudo de várias áreas do conhecimento. A Figura 2.1 mostra que esta disciplina é um ramo especial da mecânica, além disso, ilustra a relação com varias áreas aplicadas, destacando assim a sua importância. No caso específico da mecânica de solos, abordada na geomecânica, observasse a confluência de várias áreas, as quais tem interesse nessa temática. Assim, fica ilustrado que mesmo que cada área tenha a suas especificidades, que depende de cada aplicação, os conceitos e fenômenos físicos que acontecem são comuns entre todas.

Nos problemas de engenharia são feitas idealizações para a obtenção de soluções. Entre estas está a forma como vai ser representado o material. Na Figura 2.2 ilustra-se as duas abordagens que podem ser utilizadas para a representação do comportamento mecânico do material. A primeira, chamada de abordagem descontinua ou discreta, coloca de forma explícita os diferentes elementos que constituem o meio (no caso de solo, as partículas) e analisa suas interações. A outra forma de atacar o problema, chamada de abordagem contínua, é representar o meio mediante uma porção idealizada do material, cujo comportamento possa representar as propriedades médias da matéria como um todo. A diferença principal entre estas duas abordagens é o fato da primeira representar de forma explícita o material, enquanto que a segunda trabalha com a medida média de um conjunto de partículas. Outra diferença é o fato de trabalhar com grandezas primárias (força, deslocamento, etc) no caso do meio discreto e com medidas secundárias ou derivadas (tensão, deformação, etc) no caso do meio contínuo.

A seguir serão apresentadas as principais caraterísticas geotécnicas de comportamento de materiais granulares, sob a perspectiva contínua e discreta. 


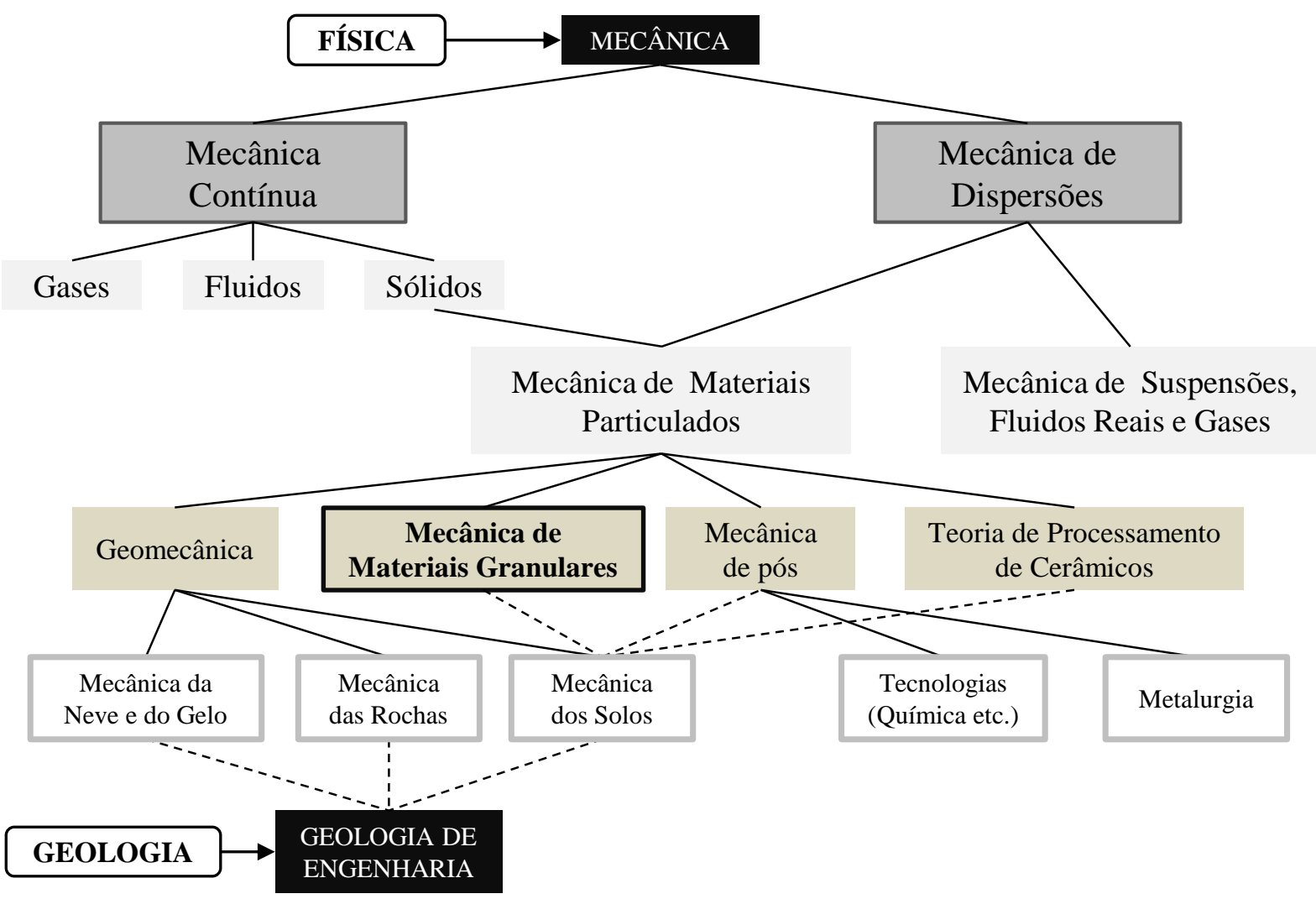

Figura 2.1. Mecânica de materiais particulados como um ramo especial da mecânica (Modificado Feda, 1982).

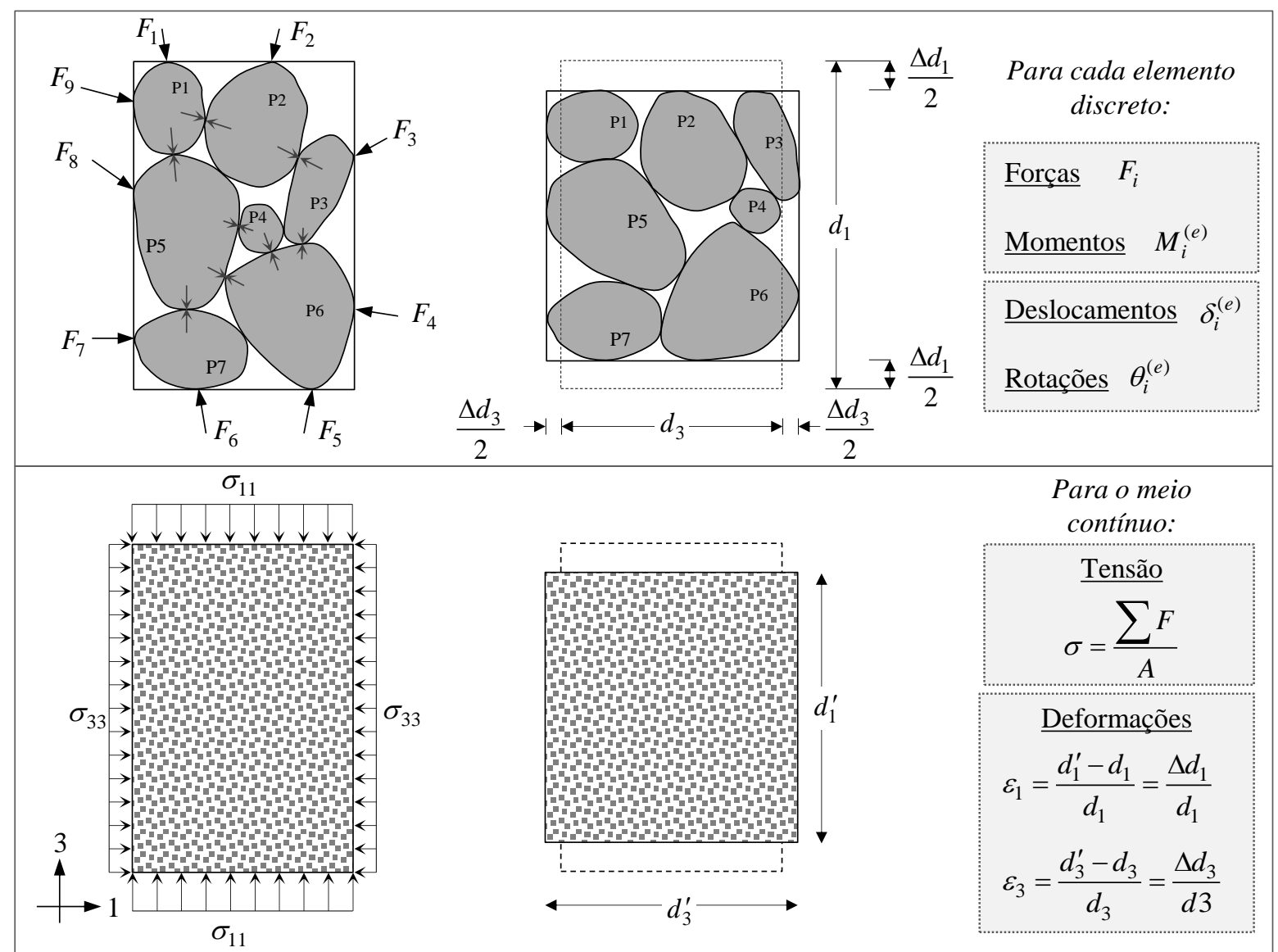

Figura 2.2. Meio contínuo vs. Meio descontínuo (Modificado Biarez \& Hicher, 1994) 


\subsubsection{Comportamento Macromecânico}

Os materiais granulares normalmente são denominados em função do tamanho de seus grãos, sendo classificados como areias ou pedregulhos. Estes materiais, quando interatuam em conjunto com as partículas individualmente soltas, apoiam-se apenas entre si e são altamente permeáveis. Isto se deve ao fato de existirem, entre as partículas, espaços vazios relativamente grandes e intercomunicados entre si. Esta é uma importante característica para o entendimento do comportamento mecânico desses materiais, já que devido a esta condição, os materiais granulares comportam-se com características de drenagem livre. Assim, os ensaios realizados para a caracterização mecânica desses materiais geralmente são executados sob condições drenadas (com amostras secas ou saturadas), exceto no caso de carregamentos transientes ou cíclicos (para simular terremotos, por exemplo), em que pode haver acréscimos de poropressão e liquefação de areias finas e fofas (Ortigão, 2007). Neste estudo, serão tratadas apenas as feições típicas de solos granulares sob condições drenadas. Outra característica importante desse material é que não existe influência de forças químicas na interação entre as partículas, a qual é a principal diferença com relação aos solos finos argilosos. Assim, pode-se afirmar que o atrito entre as partículas é uma característica fundamental no entendimento do comportamento de solos granulares.

A resposta do material granular a solicitações dependerá do "estado" no qual o mesmo se encontra. Este "estado" é a combinação das condições da estrutura do material (índice de vazios) e de carregamento (tensão de confinamento). Em relação às condições da estrutura do material, ou compacidade, normalmente se trabalha com índices que refletem a quantidade de vazios que o material pode possuir, já que estas condições proporcionam uma medida da capacidade de deformação (fechamento de vazios). O índice usado para descrever as condições da estrutura, que tem maior aceitação no meio técnico, é a densidade relativa $\left(D_{r}\right)$, a qual é definida como:

$$
D_{r}=\frac{e_{\max }-e}{e_{\text {máx }}-e_{\text {min }}}
$$

onde $e, e_{\max }$ e $e_{\text {mín }}$ são os índices de vazios atual, máximo e mínimo do material, respectivamente. A densidade relativa varia entre 0 e 1 (ou de 0 a 100\%), de forma a proporcionar uma fácil medida para a interpretação física da compacidade desses materiais. Na Tabela 2.1, mostra-se a classificação de solos granulares, a partir dos valores de densidade relativa (compacidade). 
Tabela 2.1. Classificação de solos granulares com a compacidade (Lambe \& Whitman, 1969).

\begin{tabular}{cc}
\hline Densidade relativa $(\%)$ & Denominação \\
\hline $0-15$ & Muito Fofo \\
$15-35$ & Fofo \\
$35-65$ & Médio \\
$65-85$ & Denso \\
$85-100$ & Muito Denso \\
\hline
\end{tabular}

A influência da compacidade no comportamento mecânico de solos granulares, pode ser observada na Figura 2.3-a, na qual se apresentam os resultados de um ensaio triaxial com nível de confinamento de $200 \mathrm{kPa}$ para uma areia fofa e outra densa. Observa-se que o comportamento para ambos estados é bastante distinto. Note-se que os valores de resistência são maiores, quando a areia encontra-se no estado denso. Destaca-se também que após o pico o valor de resistência decresce e se tende gradativamente ao valor máximo obtido no ensaio em que a areia estava na condição solta (amolecimento).

Outra diferença no comportamento, evidenciada na Figura 2.3-a, é a variação das curvas de deformações volumétricas contra a deformação axial, em função da compacidade. Quando areias densas são ensaiadas, a deformação volumétrica aumenta durante todo ensaio, de modo que no final do mesmo há tendência de estabilização. $\mathrm{O}$ aumento do volume sob cisalhamento é chamado de dilatância. No caso de material fofo, ocorre a diminuição do volume no início do ensaio (contração), que posteriormente é recuperada e mantida, mais ou menos, no mesmo valor. Na Figura 2.4, os processos de dilatância e contração são ilustrados, de forma a ressaltar a importância da compacidade no entendimento do comportamento mecânico de materiais granulares. No estado denso, a tendência é de as partículas deslizarem e rolarem umas sobre as outras, aumentando assim o volume da amostra de ensaio, enquanto no estado fofo, as partículas se encaixam nos vazios existentes, o que resulta na diminuição do volume da amostra de ensaio.

Outra forma de visualizar o fenômeno de dilatância é mediante a evolução do ângulo de atrito máximo ou de pico $\left(\phi^{\prime}\right)$, obtido a partir de ensaios triaxiais de um mesmo material, com diferentes compacidades (ver Figura 2.3-b). Nesta figura pode-se observar que o aumento da porosidade leva a tendência de um valor de ângulo de atrito constante, normalmente chamado de ângulo atrito do estado crítico $\left(\phi_{c r}^{\prime}\right)$. Os resultados de ângulo de atrito de pico mostram a dependência deste com respeito à compacidade. Não obstante, a determinação dos ângulos de atrito para todos os ensaios na última fase da curva, resulta em valores muito similares ao $\phi_{c r}^{\prime}$. 
Assim, o $\phi_{c r}^{\prime}$ pode ser interpretado como uma propriedade do material granular, já que não depende de sua compacidade.

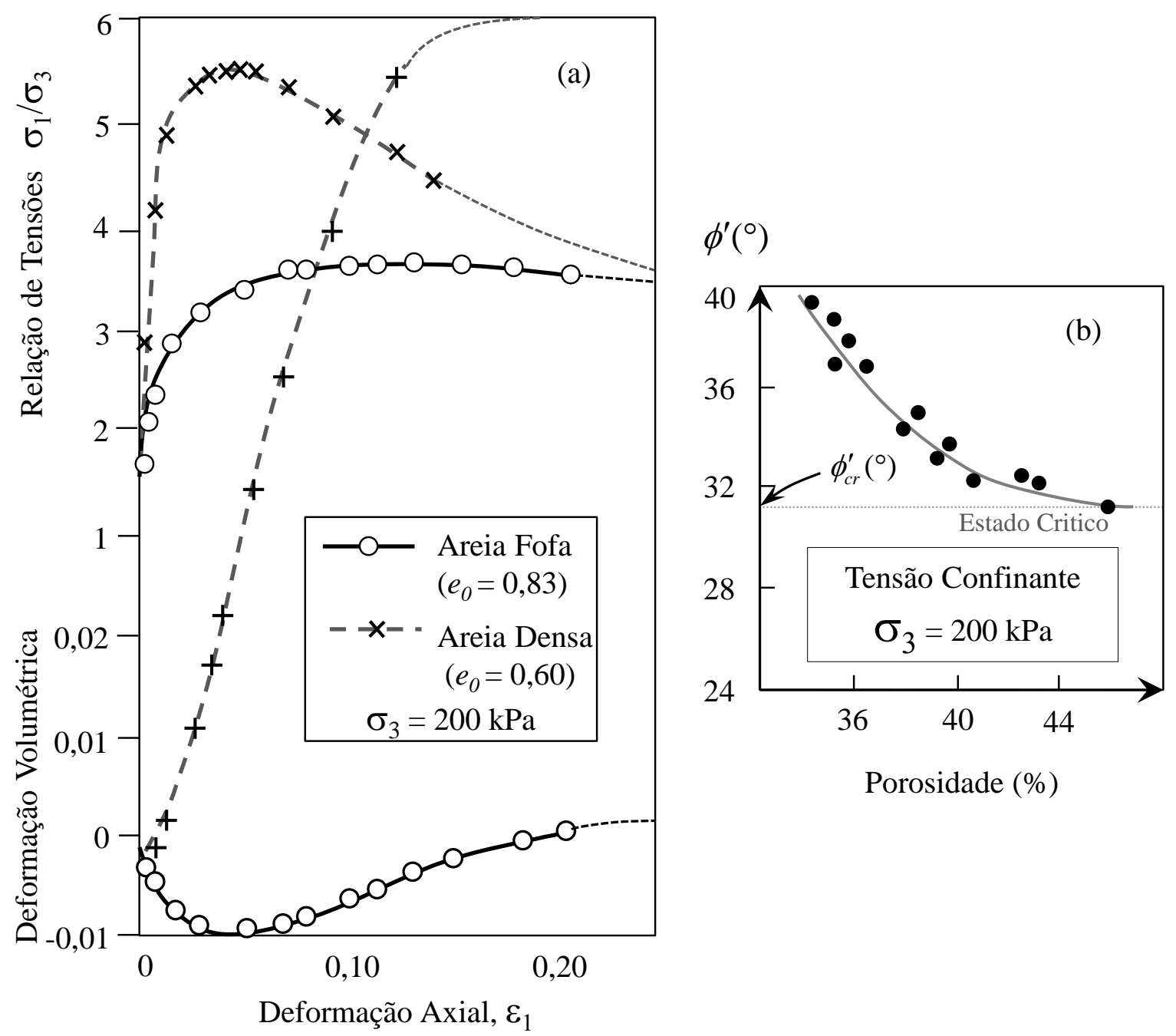

Figura 2.3. (a) Ensaios triaxiais em areia fofa e densa sob baixos níveis de tensão confinante (Taylor, 1948). (b) Variação do ângulo de atrito de pico com a compacidade, em ensaios triaxiais em areia (Rowe, 1962).
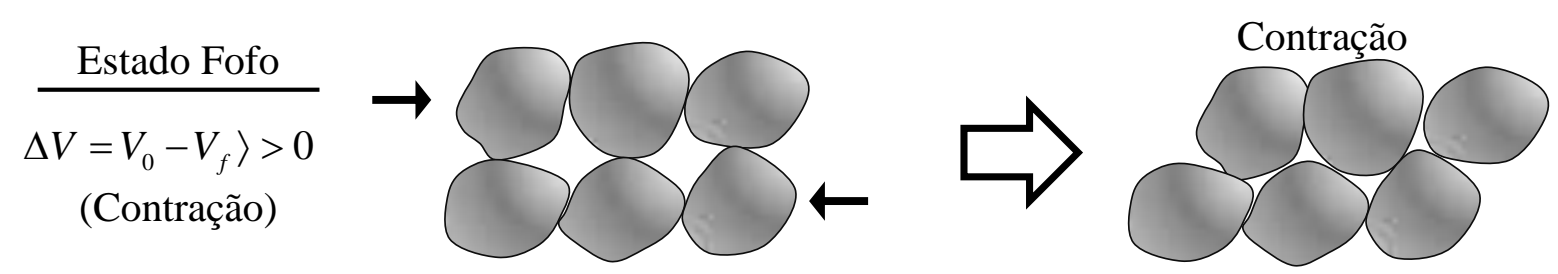

Dilatação

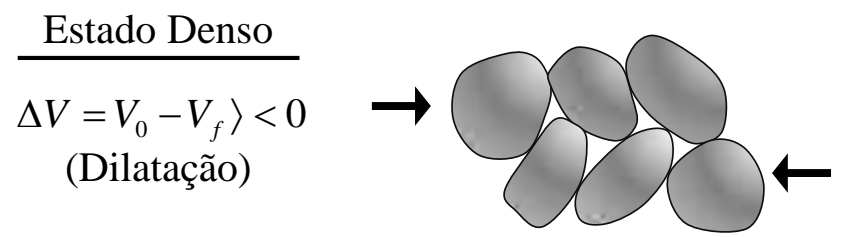

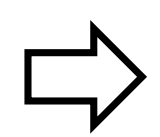

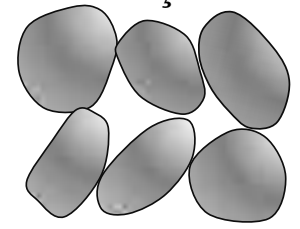

Figura 2.4. Ilustração da dilatação e contração da amostra. 
A dilatância depende da compacidade, a qual é função do estado do material, que pode ser fofo ou denso, no caso de níveis de confinamento baixos (100 a $300 \mathrm{kPa}$ ). Não obstante, o comportamento dilatante também depende do nível de tensões. Na Figura 2.5 e Figura 2.6 são apresentados os resultados do estudo feito por (Lee, 1965) e publicados por (Ortigão, 2007), referentes a ensaios triaxiais realizados com areia, submetida a diferentes estados de tensão confinantes e considerando-se os estados fofo e denso.

A dependência do nível de tensões na curva tensão-deformação mostra que para solos compactos o aumento da tensão confinante leva ao desaparecimento gradual do pico da resistência e da dilatância durante o cisalhamento. No caso de material fofo, observa-se que para o material atingir a ruptura, é necessário que haja uma deformação axial maior.

As deformações volumétricas sofrem muito a influência do nível de confinamento também. Pode-se notar que, para materiais na condição densa, o incremento de tensões faz com que o material passe da dilatação para a contração volumétrica. As deformações volumétricas no material fofo aumentam proporcionalmente com o nível de tensão.

Outra característica importante dos solos granulares é a compressibilidade. Neste trabalho, será descrita unicamente a compressão primária, a fim de focar, principalmente, nos processos existentes que ajudam a entender os tipos de curvas de compressibilidade que normalmente são obtidas.

Mesri e Vardhanabhuti (2009) descrevem o comportamento à compressão de solos granulares e ressaltam a importância do arranjo estrutural no processo de deslizamentos e rotações e dos danos nas partículas. Os danos são divididos em três tipos. O tipo I correspondente à trituração e à abrasão de asperezas superficiais das partículas. O tipo II está relacionado com a quebra e o esmagamento das saliências superficiais, dos cantos e das arestas das partículas. Por último, o tipo III correspondente à fratura, divisão e ruptura da partícula.

Para o entendimento da compressão em solos granulares, os processos internos entre as partículas são divididos em mecanismos de bloqueio (locking) e desbloqueio. O desbloqueio corresponde às ações que favorecem a deformação do material, entre as quais estão o deslizamento e a rotação interpartículas e os danos das partículas. Já o bloqueio é o mecanismo que obedece às dinâmicas internas que favorecem o intertravamento dos grãos, capaz de proporcionar ao material o aumento de sua rigidez. 

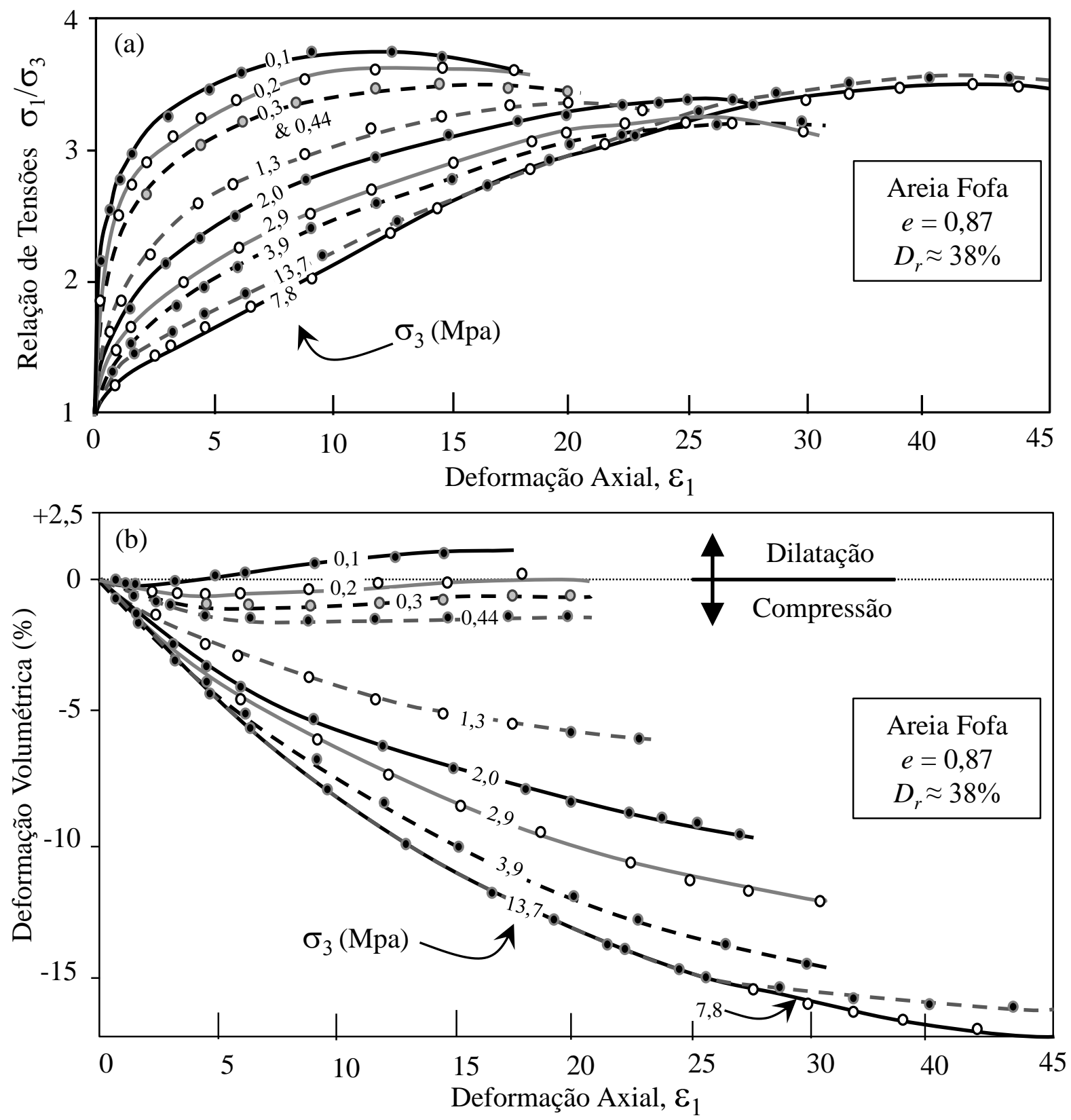

Figura 2.5. Comportamento de areia em ensaios triaxiais sob diferentes estados de tensão confinante para uma areia fofa (Lee, 1965 apud Ortigão, 2007).

As curvas de compressibilidade de solos granulares podem ser resumidas em três tipos (A, B, C), de acordo com o comportamento da curva tensão efetiva versus índice de vazios analisadas por Mesri e Vardhanabhuti (2009), onde 98 tipos de areias foram avaliadas por meio de 182 ensaios oedométricos e 17 ensaios de compressão isotrópica.

O comportamento à compressão das curvas tipo A se caracteriza por possuir três estágios. Durante o primeiro estágio, pequenos deslizamentos, pequenas rotações interpartículas e pequenos danos do tipo I e II ocorrem. Não obstante, os mecanismos de bloqueio predominam sobre os mecanismos de desbloqueio, o que ocasiona o aumento dos 
módulos volumétricos $(M)$ com o incremento das tensões. No segundo estágio, o dano tipo III passa a ser predominante, sendo dominantes os mecanismos de desbloqueio. O módulo volumétrico decresce com o aumento das tensões. No último estágio, o material apresenta poucos espaços para o movimento, assim o intertravamento é o mecanismo dominante, capaz de produzir o aumento gradual do módulo volumétrico com o aumento das tensões. A Figura 2.7 ilustra o comportamento típico de curvas de compressibilidade tipo A, além de mostrar a curva de tensão versus módulo volumétrico.
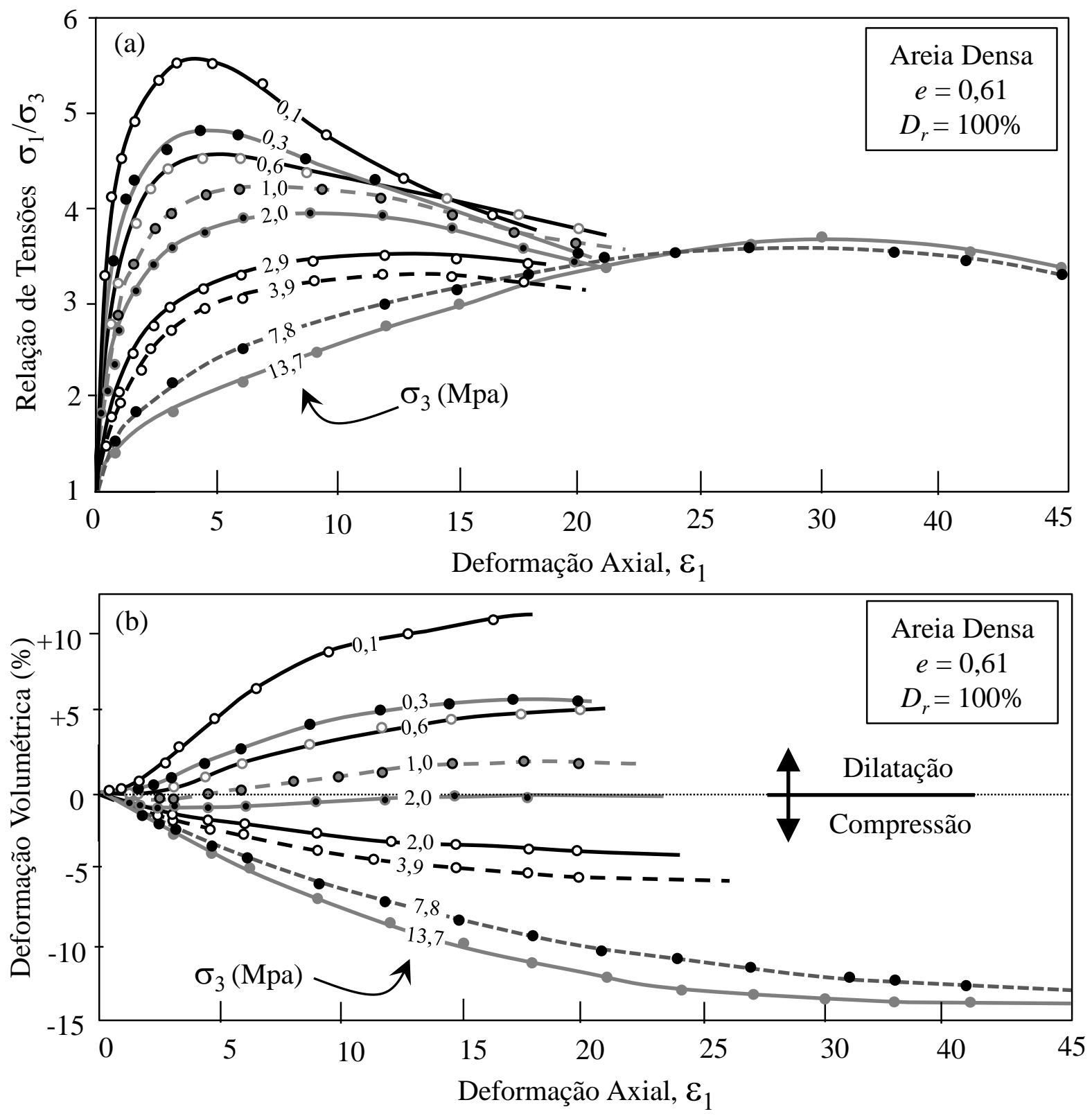

Figura 2.6. Comportamento de areia em ensaios triaxiais sob diferentes estados de tensão confinante para uma areia densa (Lee, 1965 apud Ortigão, 2007). 

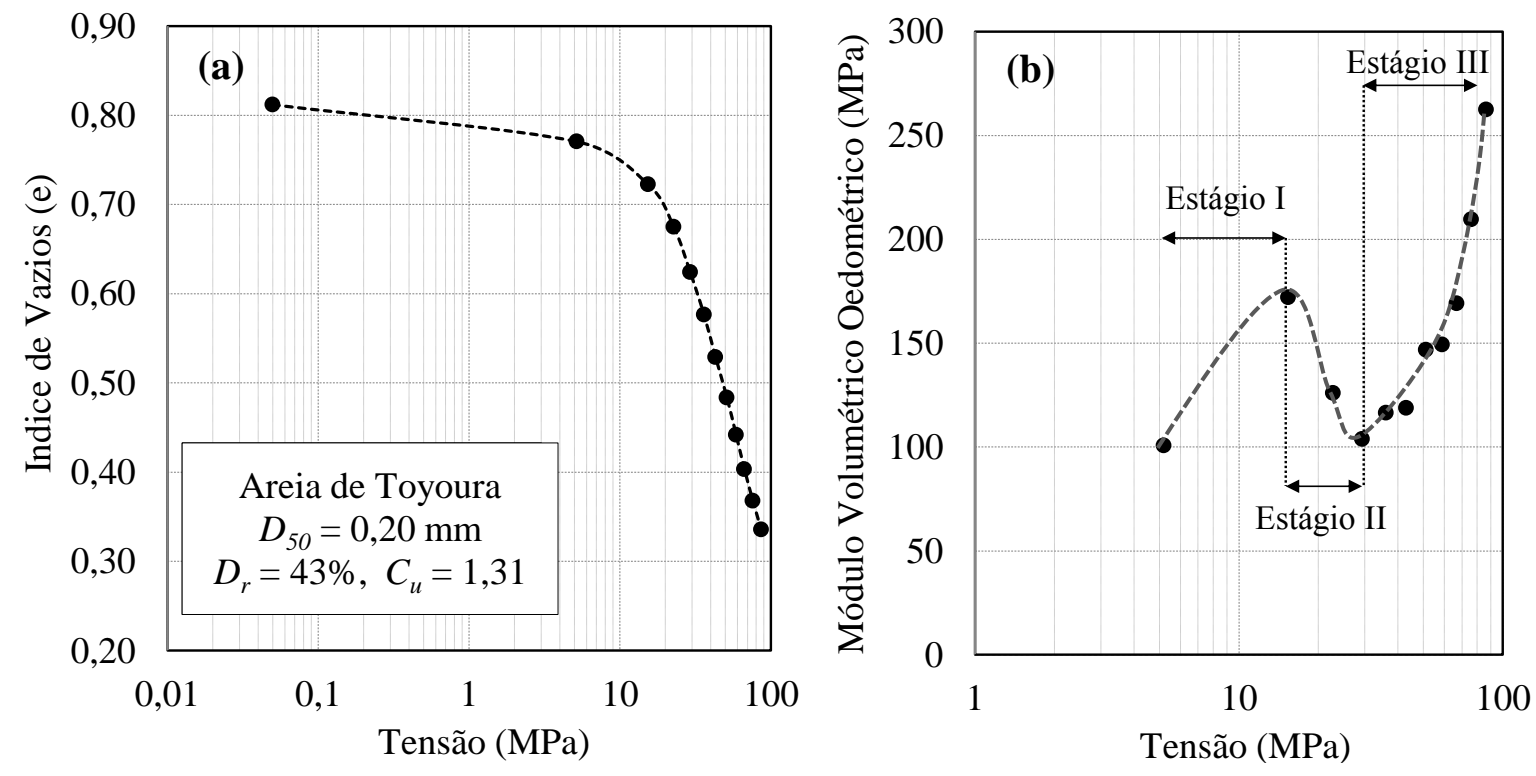

Figura 2.7. Curva de compressibilidade tipo A (Nakata et al., 2001b).

As curvas do tipo B (ver Figura 2.8) são similares às curvas tipo A nos estágios I e III. A diferença entre elas está no estágio II, no qual não existe nenhum mecanismo interno predominante, o que gera o equilíbrio entre os processos de bloqueio e desbloqueio. $\mathrm{O}$ módulo volumétrico neste tipo de curva permanece praticamente constante durante um intervalo de tensões (estágio II).
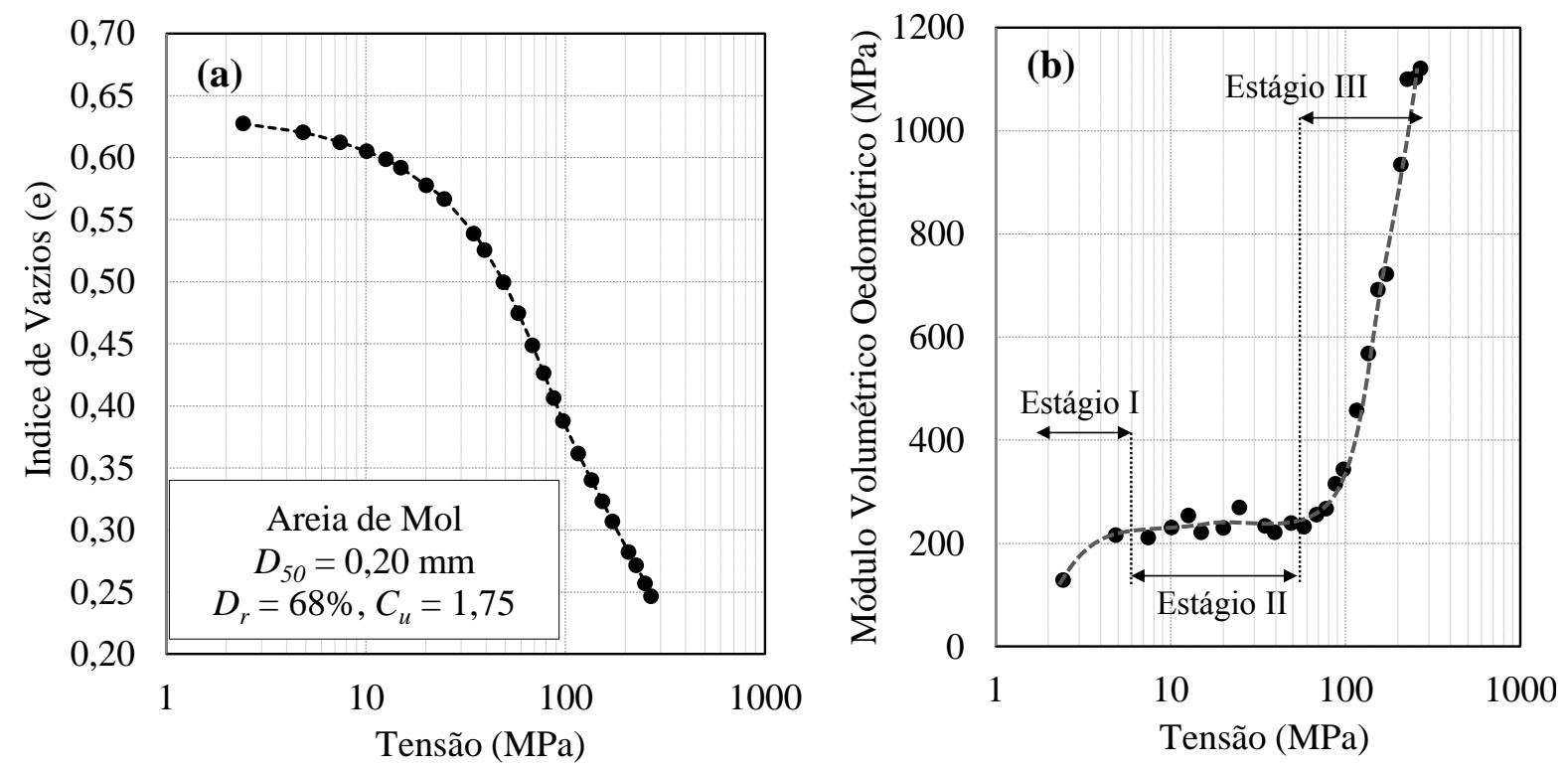

Figura 2.8. Curva de compressibilidade tipo B (De Beer, 1963).

As curvas tipo C (ver Figura 2.9) caracterizam-se por não possuírem o estágio II. O estágio I se dá de forma similar à curva tipo A, sendo que no final deste estágio inicia-se o dano tipo III e continua a aumentar gradualmente até atingir níveis de tensão altos. Os 
processos dominantes atuantes durante toda a compressão são os de bloqueio, onde o módulo volumétrico sempre aumenta (a uma taxa menor no início, a qual aumenta com o incremento de tensões). A Tabela 2.2 descreve cada um dos tipos de curvas de compressibilidade, de modo a mostrar as principais características durante cada um dos estágios.
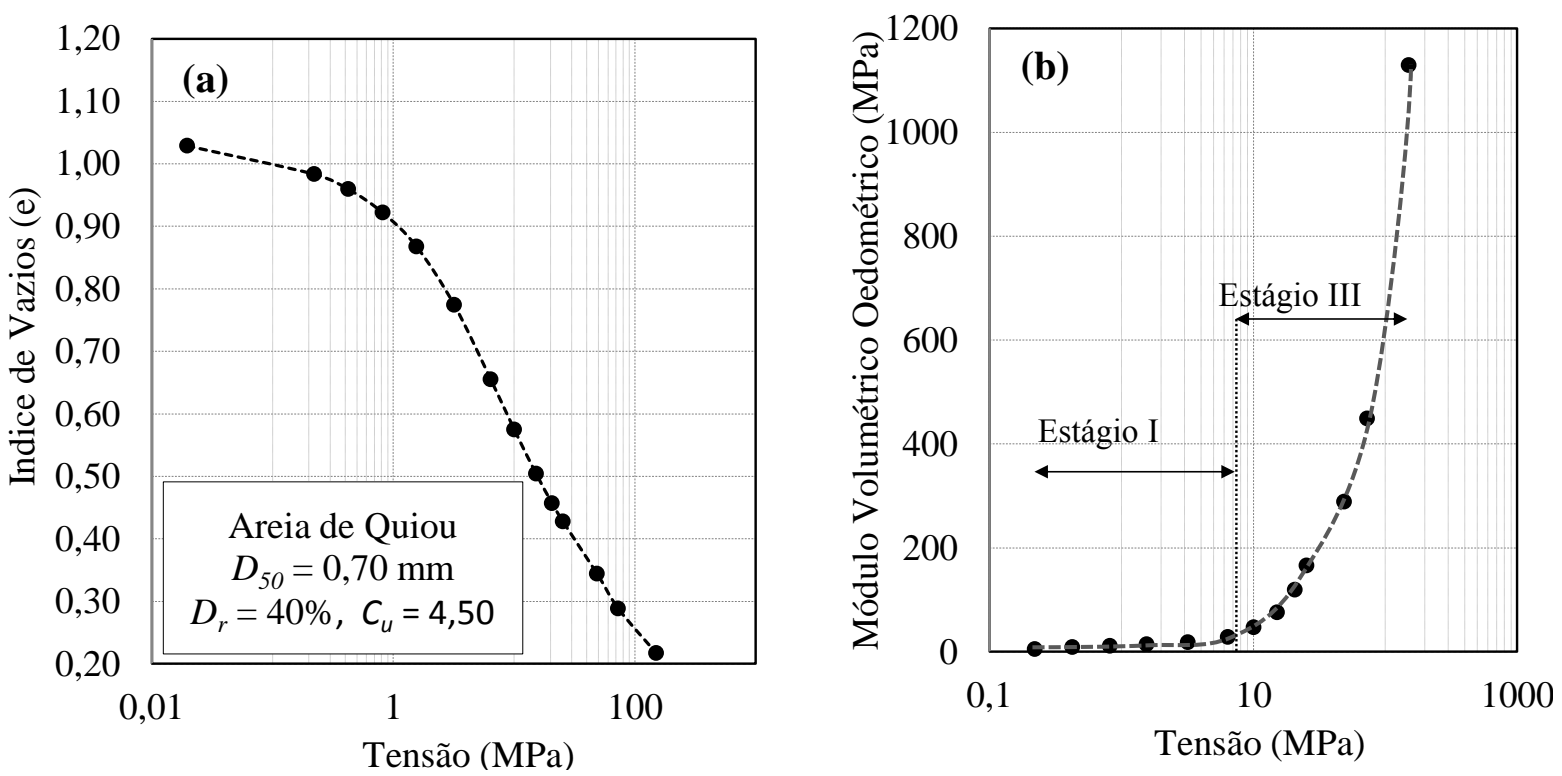

Figura 2.9. Curva de compressibilidade tipo C (Pestana \& Whittle, 1995).

Tabela 2.2. Descrição das características dos tipos de curvas de compressibilidade.

\begin{tabular}{|c|c|c|c|c|c|c|c|c|}
\hline \multirow{3}{*}{ है } & \multirow{3}{*}{ 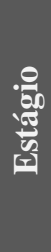 } & \multicolumn{4}{|c|}{ Mecanismos } & \multirow{3}{*}{$\begin{array}{c}\text { Bloqueio } \\
\text { vs. } \\
\text { Desbloqueio }\end{array}$} & \multirow{3}{*}{$\begin{array}{c}\text { Módulo } \\
\text { Volumétrico } \\
M=\frac{\Delta \sigma_{V}^{\prime}}{\Delta \varepsilon_{V}}\end{array}$} & \multirow{3}{*}{ Observações } \\
\hline & & \multicolumn{3}{|c|}{$\begin{array}{l}\text { Dano } \\
\text { Dominante }\end{array}$} & \multirow{2}{*}{$\begin{array}{c}\text { Intertravamento } \\
\text { de Grãos }\end{array}$} & & & \\
\hline & & I & II & III & & & & \\
\hline \multirow{3}{*}{ A } & 1 & $\mathrm{x}$ & $x$ & & & $\mathrm{~B}>\mathrm{D}$ & $\mathrm{M} \uparrow$ & Pequenos movimentos e danos \\
\hline & 2 & & & $\mathrm{x}$ & ג & $B>D$ & $\mathrm{M} \downarrow$ & $\begin{array}{l}\text { A quebra reorganiza a } \\
\text { estrutura }\end{array}$ \\
\hline & 3 & $\mathrm{x}$ & $x$ & $\mathrm{x}$ & & $B>D$ & $\mathrm{M} \uparrow$ & Não tem Dano dominante \\
\hline \multirow{3}{*}{ B } & 1 & $x$ & $x$ & & & $B>D$ & $\mathrm{M} \uparrow$ & \multirow{3}{*}{$\begin{array}{l}\text { Equilíbrio entre mecanismos } \\
\text { no estágio } 2 \text { durante um } \\
\text { intervalo de tensões, no qual } \\
\text { acontecem quebras } \\
\text { significativas. }\end{array}$} \\
\hline & 2 & & & $x$ & & $\mathrm{~B} \approx \mathrm{D}$ & $\mathrm{M}=$ Constante & \\
\hline & 3 & $x$ & $x$ & $x$ & & $\mathrm{~B}>\mathrm{D}$ & $\mathrm{M} \uparrow$ & \\
\hline \multirow{2}{*}{$\mathrm{C}$} & 1 & $\mathrm{x}$ & $x$ & $\mathrm{x}$ & & $\mathrm{B}>\mathrm{D}$ & $\mathrm{M} \uparrow$ & \multirow{2}{*}{$\begin{array}{l}\text { O dano } 3 \text { começa } \\
\text { gradualmente no estágio } 1 \mathrm{e} \\
\text { vai aumentando gradualmente } \\
\text { até chegar em tensões altas. }\end{array}$} \\
\hline & 3 & $x$ & $\mathrm{x}$ & $x$ & オ & $\mathrm{B}>\mathrm{D}$ & $\mathrm{M} \uparrow$ & \\
\hline
\end{tabular}


Devido à particularidade do comportamento desse tipo de material, nas últimas décadas, vários centros de pesquisas produziram trabalhos experimentais e numéricos sobre o assunto (Burland, 1990; Leroueil \& Vaughan, 1990; Coop \& Atkinson, 1993; Cuccovillo \& Coop, 1999; Liu \& Carter, 2002). A grande maioria destes trabalhos foi desenvolvida sob a perspectiva macroscópica, muitas vezes tendo observações na microescala, mas em poucas ocasiões foi analisado o comportamento micromecânico inerente. Na Figura 2.10 apresenta-se a curva de compressibilidade da areia cimentada de Cambria, com o efeito da estruturação gerado pela cimentação.

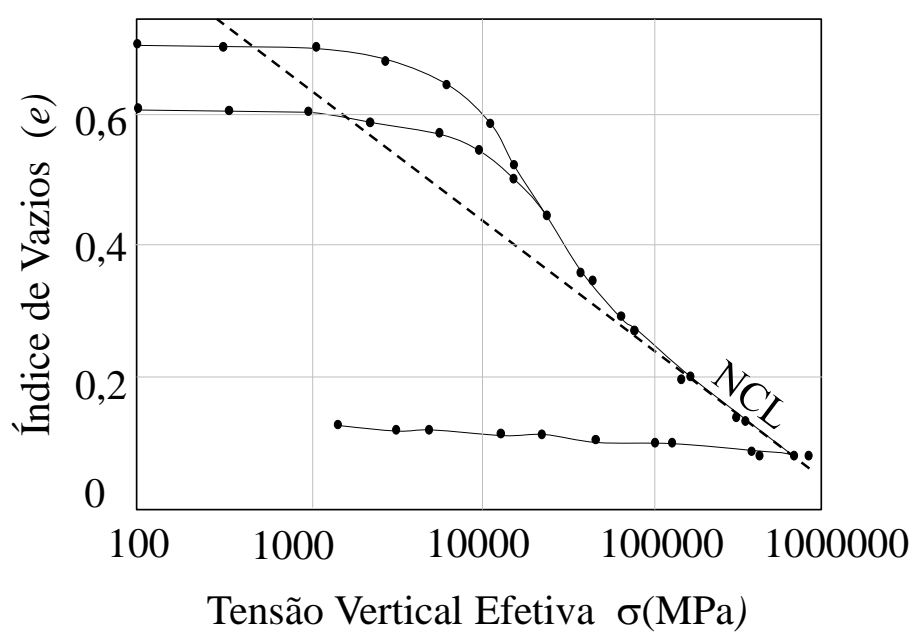

Figura 2.10. Curva de compressibilidade da areia cimentada estruturada de Cambria (Yamamuro et al., 1996).

\subsubsection{Comportamento Micromecânico}

O solo é um sistema de partículas independentes, como pode ser observado para o caso de areias, mas este conceito também se aplica para qualquer tipo de solo, ainda que para alguns tipos sejam necessárias técnicas microscópicas para a sua percepção (Lambe \& Whitman, 1969). O entendimento do comportamento dos solos é muito importante na engenharia geotécnica, sendo motivo de estudo ao longo do tempo. Para tal finalidade, o solo tem sido tratado classicamente como um meio contínuo em análises e projetos de engenharia, sem considerar aspectos microscópicos relevantes em seu comportamento.

As primeiras abordagens para o entendimento da micromecânica de materiais granulares foram feitas por meio do uso de elementos simples como discos, cilindros e esferas, com o uso de métodos teóricos e experimentais. Entre os trabalhos teóricos, destacase o estudo da relação entre a porosidade e a permeabilidade, com arranjos sistemáticos de 
esferas (Fraser, 1935), e o estudo da relação entre a forma da partícula e o empacotamento (packing) de partículas (White \& Walton, 1937). Do ponto de vista experimental, destaca-se o estudo fotoelástico de discos carregados, realizado por Jong e Verruijt (1969), no qual se observa, mediante imagens, a distribuição de tensões nos discos (ver Figura 2.11). Posteriormente, foram desenvolvidos estudos numéricos sobre a micromecânica de sistemas de particulados, entre os quais o trabalho de Cundall e Strack (1979) foi o mais popularizado devido à simplicidade do método e a capacidade de reproduzir padrões observados experimentalmente. Todas essas abordagens têm evoluído bastante até a atualidade, em virtude do desenvolvimento de tecnologias, tanto no campo experimental (tomógrafos, processamento de imagens, etc.), quanto no campo numérico (supercomputadores, melhores técnicas de programação, etc.).

A geomecânica de solos granulares está relacionada com as características microscópicas (tamanho dos grãos, forma das partículas, granulometria, arranjo das partículas, etc.) e com fenômenos micromecânicos (não saturação, cimentação, quebra, etc.), como é ilustrado na Figura 2.12. A seguir, uma breve revisão bibliográfica sobre as diferentes características microestruturais de solos granulares (micromecânica de geomateriais) é apresentada.

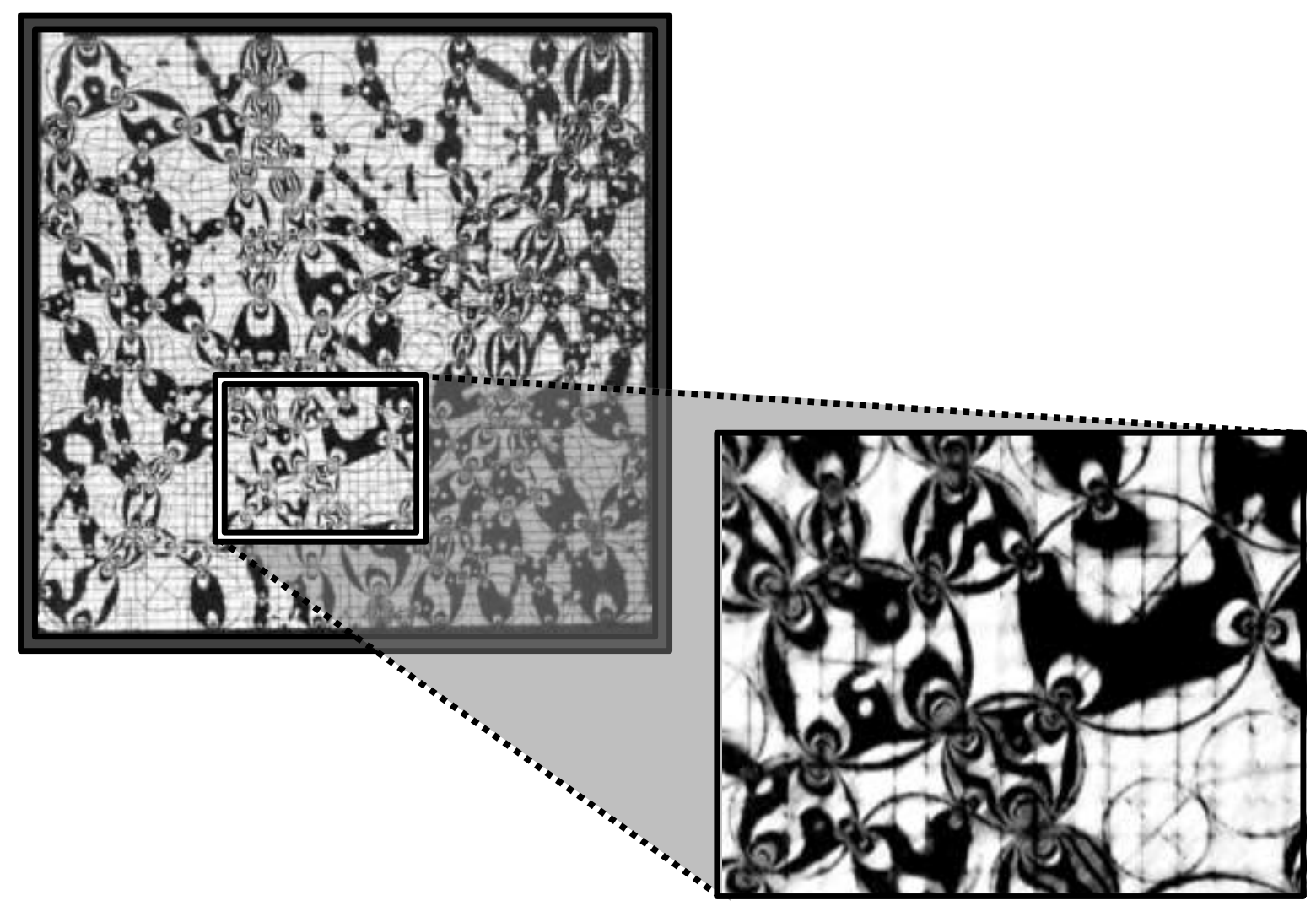

Figura 2.11. Resultados do estudo fotoelástico de discos carregados (Jong \& Verruijt, 1969). 


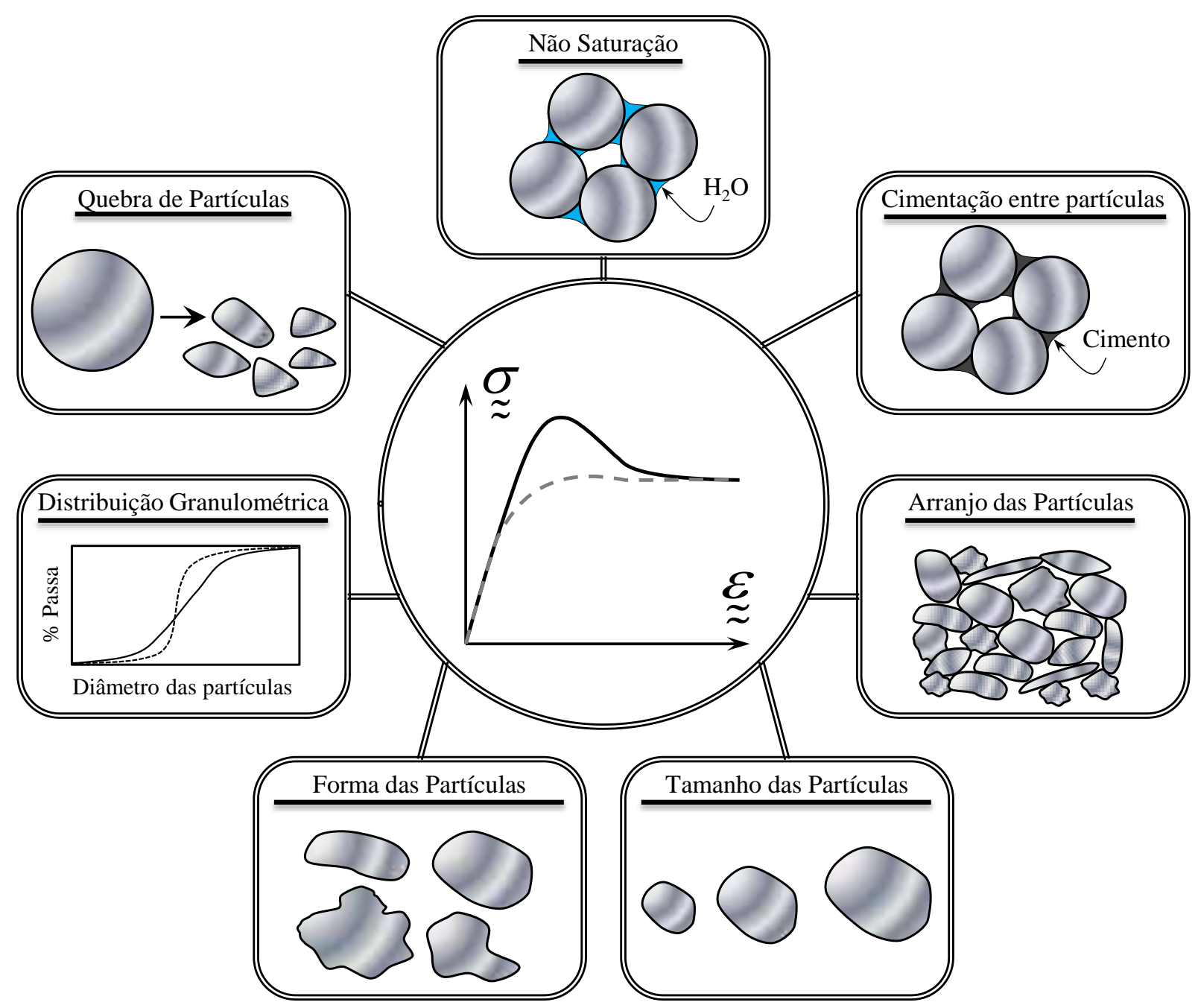

Figura 2.12. Elementos micromecânicos que influenciam o comportamento macroscópico.

\subsubsection{Arranjo de partículas}

A forma como as partículas estão arranjadas entre si está relacionada com a organização dos contatos e, consequentemente, com a transmissão das tensões distribuídas no material. Na Figura 2.13 mostram-se as partículas esféricas organizadas para o estado mais fofo (a, c) e mais denso (b, d), observadas no espaço 2D e 3D, respectivamente.

$\mathrm{O}$ arranjo das partículas é mais do que uma característica microestrutural, sendo o resultado de várias características microestruturais, além das condições externas às quais o material está submetido. $\mathrm{O}$ arranjo, do ponto de vista macroscópico, tem sido quantificado de forma indireta por meio da utilização do índice de vazios, da porosidade ou de alguma medida correlacionada com uma das anteriores. De acordo com a micromecânica, o tipo de arranjo está diretamente relacionado com o número de contatos, de modo a influenciarem na forma como as partículas interagem entre si. 

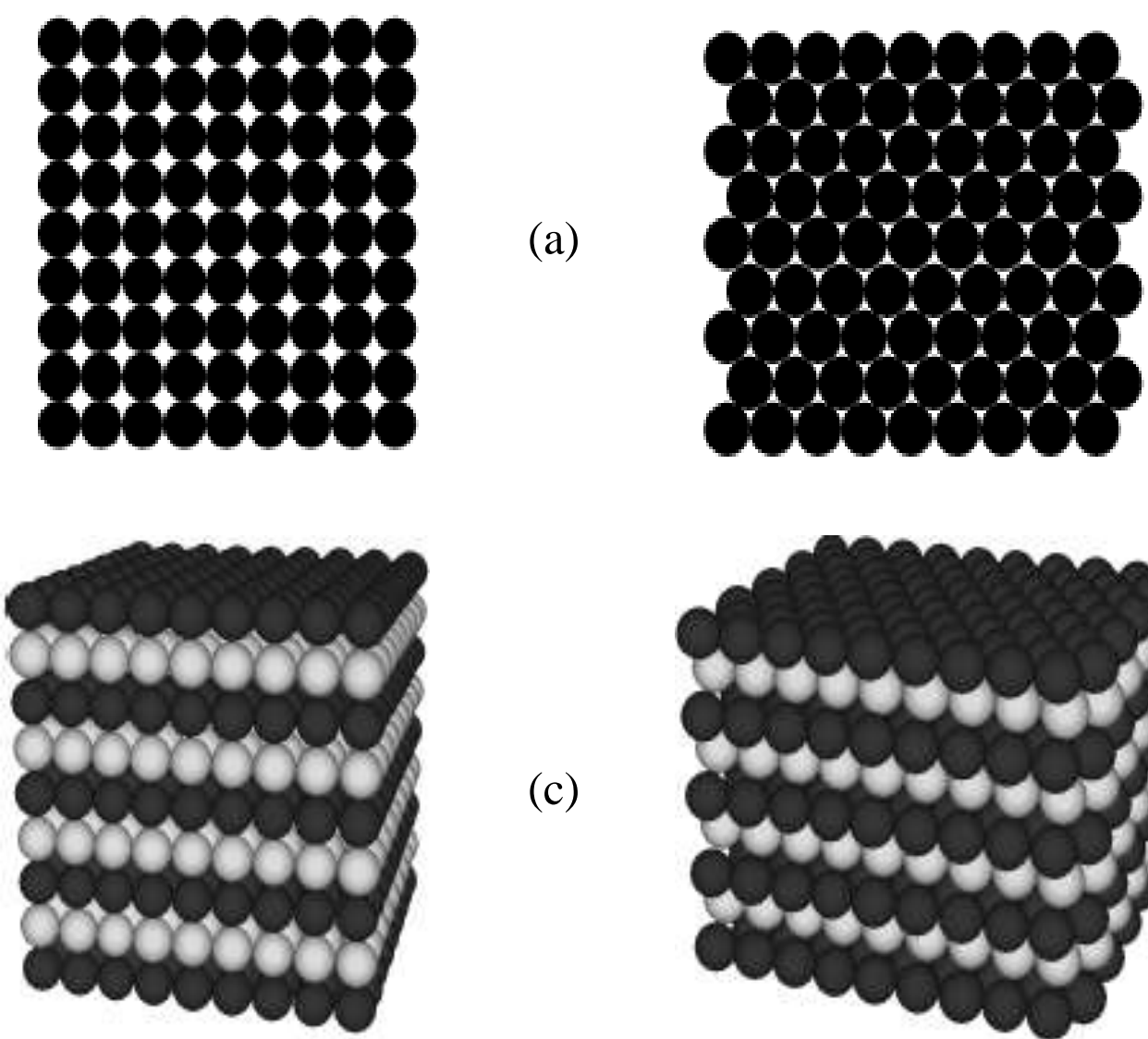

(c)

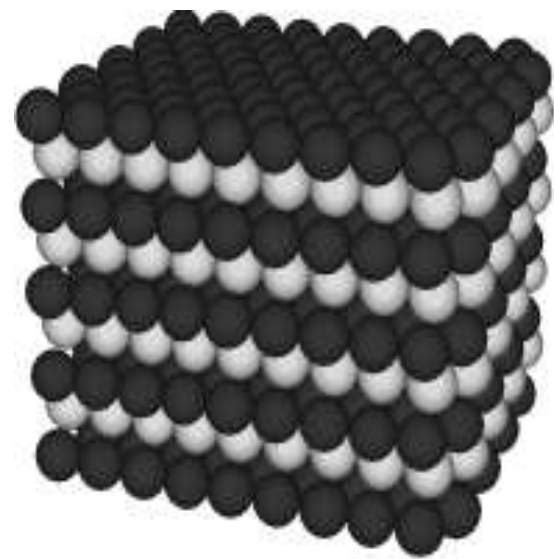

Figura 2.13. Influência do arranjo das partículas do solo na sua compacidade (Neves, 2009).

\subsubsection{Cimentacão das partículas}

O efeito da cimentação no comportamento mecânico de solos granulares cimentados se traduz em termos de aumento da rigidez e da resistência do material. Este ganho nas propriedades do material deve-se ao fato de a cimentação entre partículas proporcionar restrições ao movimento, os quais diminuem com o incremento de tensões. Na Figura 2.14 são mostradas imagens de diferentes cimentações, as quais fornecem uma ideia da capacidade de restrição, de acordo com o material cimentante.

A melhoria nas propriedades pelo efeito da cimentação e o processo de degradação, do mesmo, têm sido motivos de estudos por vários pesquisadores, na maioria dos casos com uma abordagem macroscópica. Com os avanços nas técnicas numéricas micromecânicas, surgiram pesquisas experimentais para o entendimento da interação entre as partículas cimentadas. Merecem destaque os trabalhos de Jiang et al. (2012a, 2012b), nos quais foram realizadas campanhas experimentais com barras de alumínio cimentadas submetidas a diferentes condições. Com base nos resultados estes autores sugerem melhorias no modelo de contato. 

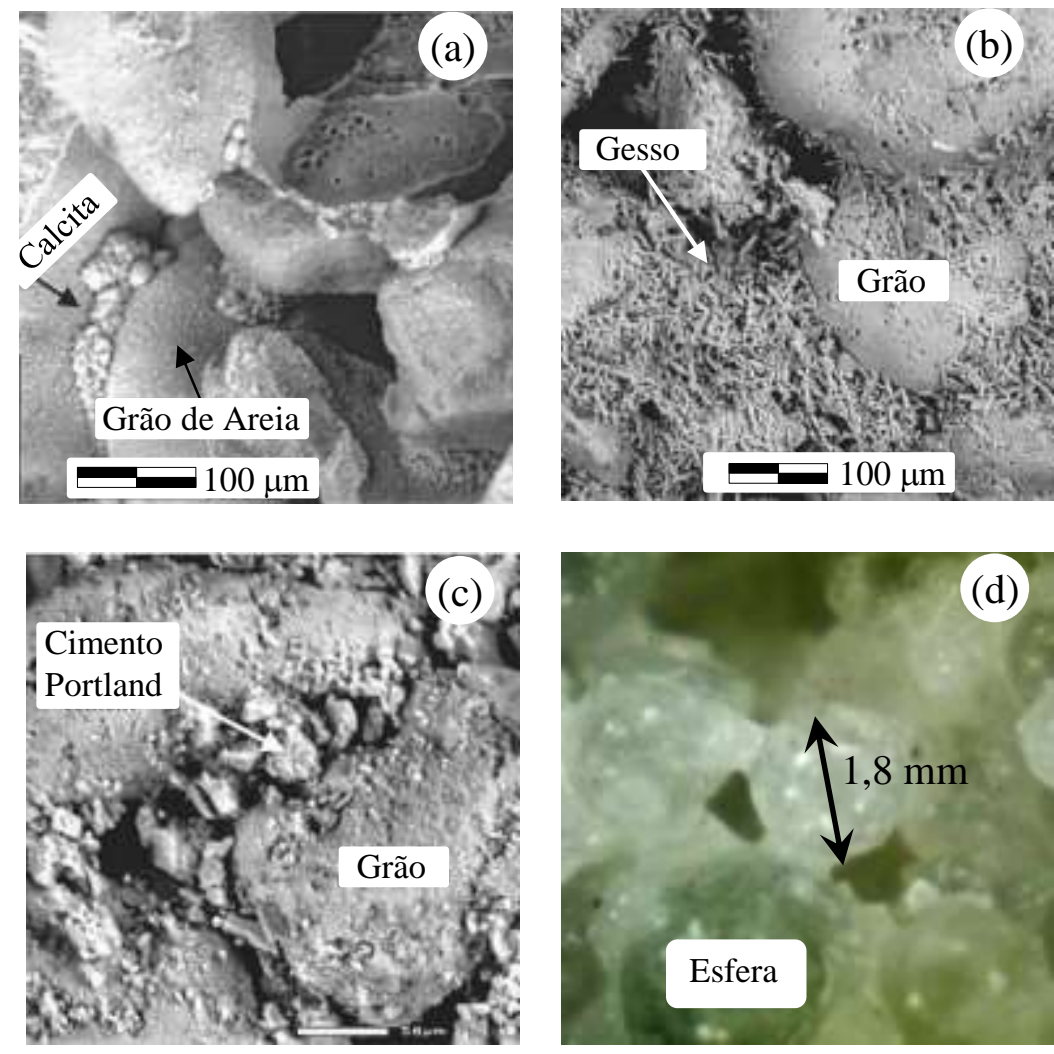

Figura 2.14. . Detalhe da cimentação entre as partículas calcárias, cimentadas com (a) Calcita, (b) Gesso, e (c) Cimento Portland (Ismail et al., 2002), e entre as esferas de vidro cimentadas com epóxi(Zuluaga, 2011).

\subsubsection{Quebra de partículas}

A quebra de partículas (crushing) é um processo que ocorre em escala microscópica, onde as partículas começam a sofrer fraturamento, após ser atingido um certo nível de tensões. Este fenômeno se deve à conjugação de vários fatores, entre os quais destacam-se: a gradação e o tamanho das partículas, a mineralogia e o nível de tensões. A Figura 2.15 mostra um detalhe da quebra de partículas. A imagem refere-se ao resultado obtido a partir de uma amostra moldada com esferas de vidro submetida a compressão confinada. Todas as características geométricas estão relacionadas com o aumento e com a diminuição de números de contatos entre partículas. Para um número de contatos maior, as cargas se distribuirão melhor e a quebra será menor. Assim, materiais bem graduados e/ou com partículas pequenas, possuem menos quebra do que materiais uniformes e/ou com partículas grandes. A mineralogia dos grãos está relacionada com a facilidade de quebra, de modo a permitir a determinação da velocidade com que ocorre o processo, além de definir o tipo de fragmentação. Na Figura 2.16 são apresentados os resultados de ensaios de compressibilidade 
confinada, onde mostra-se a influência do tipo de mineral predomina no comportamento das partículas.

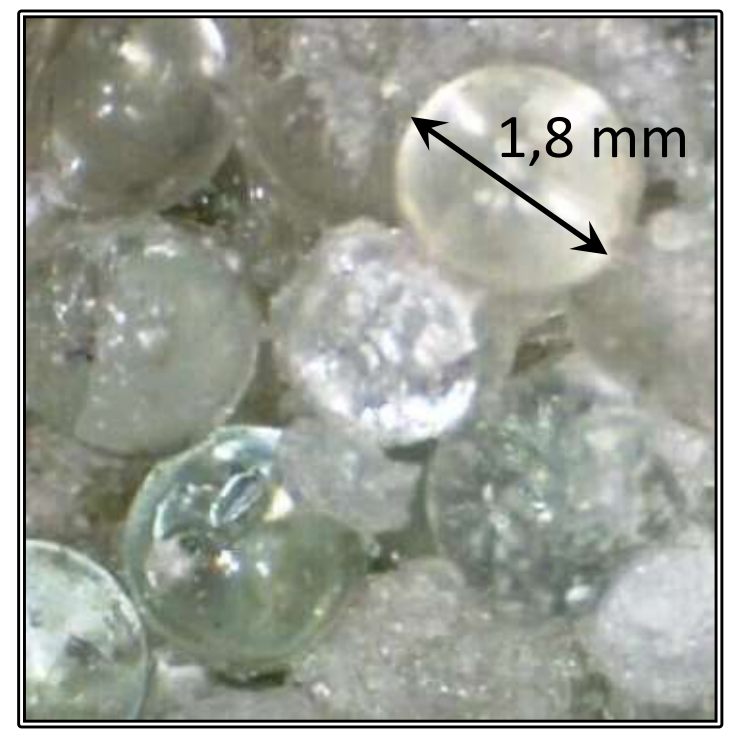

Figura 2.15. Detalhe da quebra de microesferas de vidro.
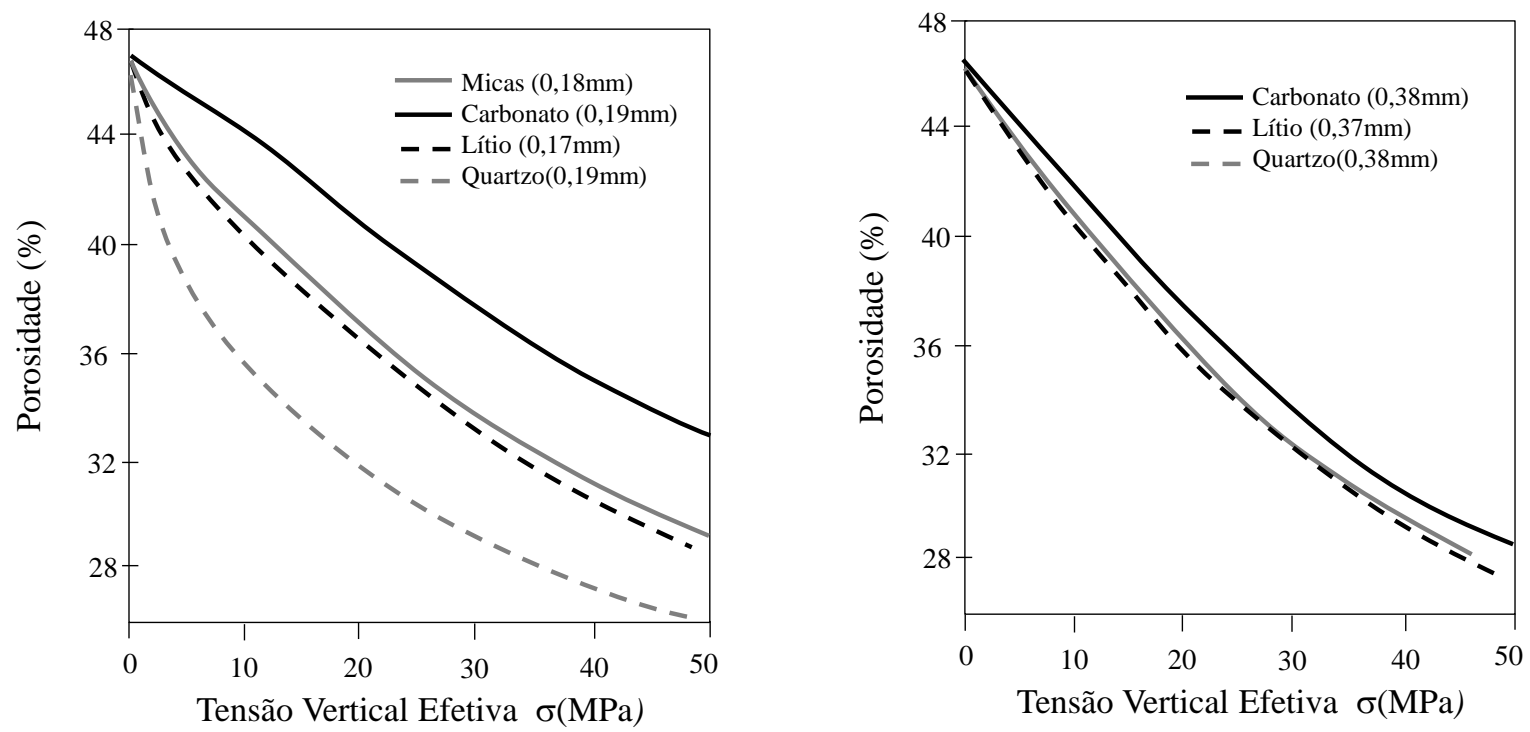

Figura 2.16. Comportamento de compressão unidimensional de areias com várias composições mineralógicas para dois tamanhos de grão (Chuhan et al., 2003).

A quebra de partículas pode ocorrer no campo, em solos granulares submetidos a cargas monotônicas, como, por exemplo, no material localizado sob a ponta de uma estaca ou sob a base de uma fundação. Adicionalmente, o fraturamento pode ocorrer também em solos submetidos a cargas cíclicas em bases granulares para pavimentos e/ou ferrovias (TorregrozaAldana, 2007). Estudos têm sido desenvolvidos a fim de melhorar o entendimento desses micromecanismos, tanto na área experimental (Nakata et al., 2001a), quanto na área numérica 
(Lobo-guerrero, 2006). A grande dificuldade está no procedimento de como juntar as duas escalas de trabalho para utilização nos projetos geotécnicos.

\subsubsection{Não saturaç̃̃o}

A não saturação tem incidência amplamente estudada no comportamento mecânico dos solos. A presença de meniscos nos contatos intergranulares das partículas submete o solo a um estado de tensão negativo (sucção), o que influencia a tensão efetiva, a resistência e a rigidez do mesmo. A interferência da sucção no comportamento tensão-deformaçãoresistência pode ser explicada a partir do estado de tensões nos contatos entre as partículas de solos não saturados. Na Figura 2.17, ilustra-se o efeito do menisco de água e observa-se que este atua como uma força de tração entre as partículas cuja resultante seria uma normal ao plano de contato $\left(\mathrm{N}_{\text {capilar }}\right)$. Os efeitos diretos da água capilar são o aumento da tensão efetiva e o ganho de rigidez contra as forças cisalhantes $(\mathrm{T})$, o que dificulta o movimento relativo entre as partículas (Ibañez, 2008).

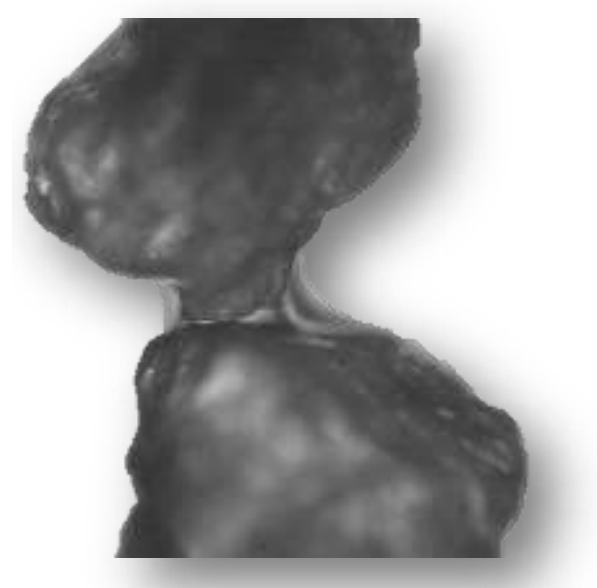

(a)

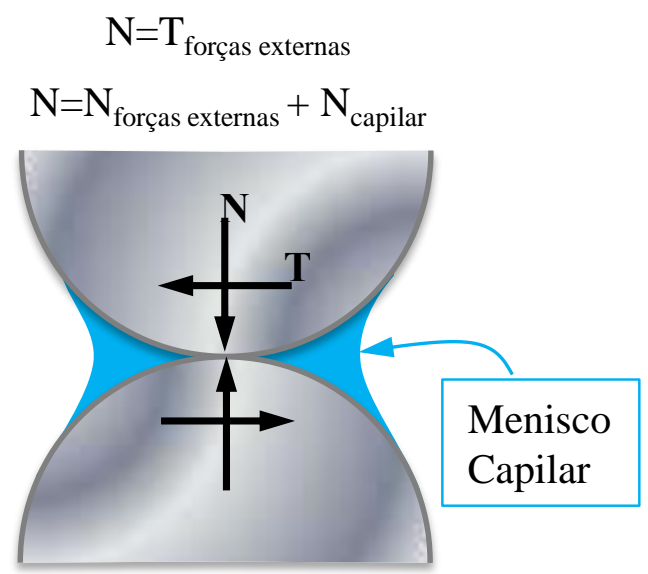

(b)

Figura 2.17. Influência da sucção no contato entre os grãos de solo: (a) detalhe do menisco entre duas partículas reais (Alonso \& Gens, 2010); (b) ilustração das forças atuantes no contato(Ibañez, 2008).

A formação e evolução do menisco em materiais granulares é tratada por Toll et al. (2012), os quais estudaram em detalhe as características geométricas que o menisco desenvolve. Algumas destas características são ilustradas na Figura 2.18. Uma das observações importantes feitas nesse trabalho é que a forma do menisco pode ser predominantemente côncava ou convexa, e inclusive, estas formas podem coexistir (ver detalhes na Figura 2.19). 

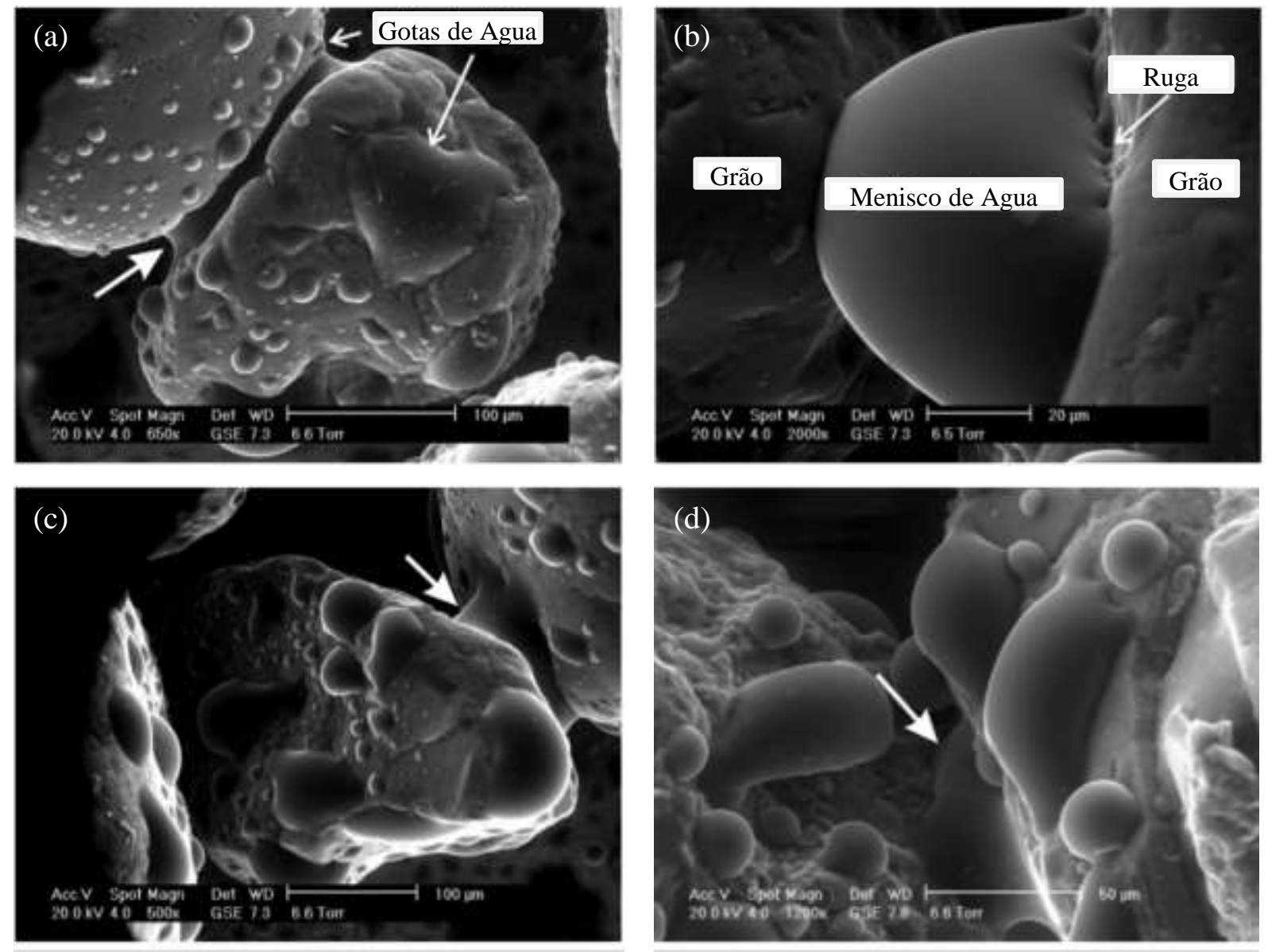

Figura 2.18. Forma dos meniscos de água sobre grãos de areia: (a), (c) e (d) mostram meniscos predominantemente côncavos; (B) mostra menisco convexo. As 'rugas' das interfaces ar / água são claros em (b) (Toll et al., 2012).

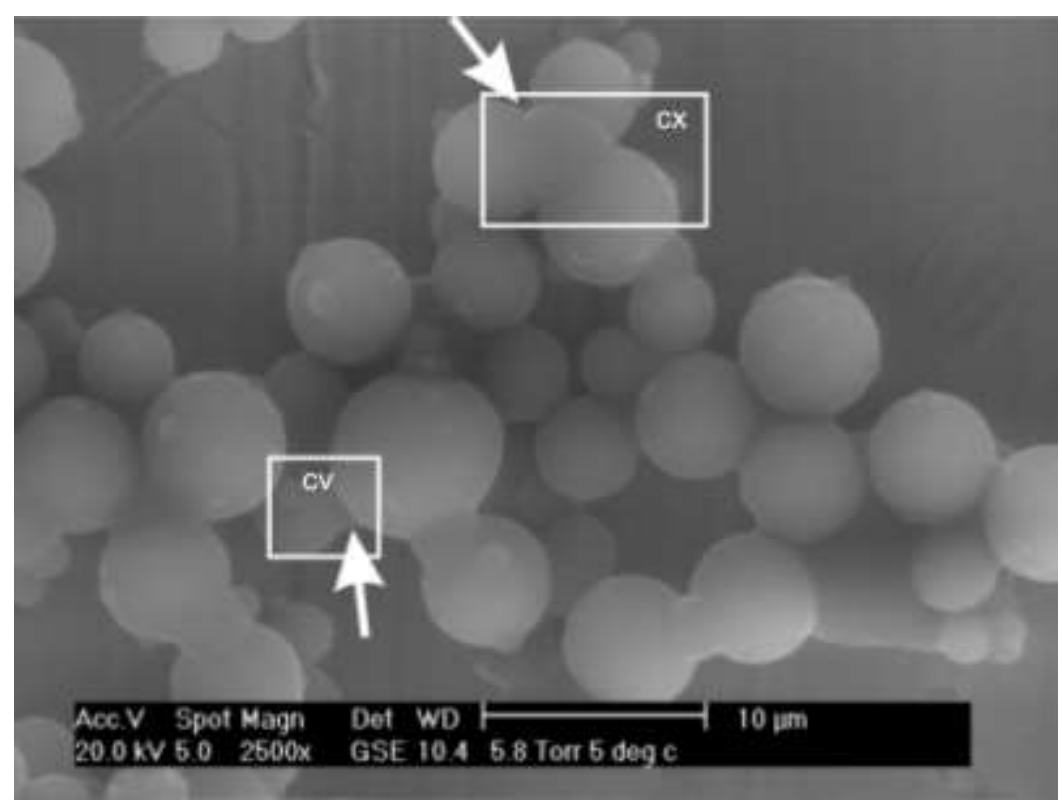

Figura 2.19. Forma do Menisco de água em microesferas. A imagem mostra que meniscos côncavos (cv) e convexos (cx) coexistem num material com a mesma umidade relativa (Toll et al., 2012). 
Os efeitos macroscópicos típicos de condições não saturadas têm sido motivo de estudo nas últimas décadas (Ibañez, 2003; Sheng, 2011), ajudando a explicar vários fenômenos. Na Figura 2.20, apresenta-se esquematicamente a influência da sucção na curva compressibilidade e na envoltória de resistência, mostrando que com o aumento da sucção resulta em um solo menos compressível e mais resistente.

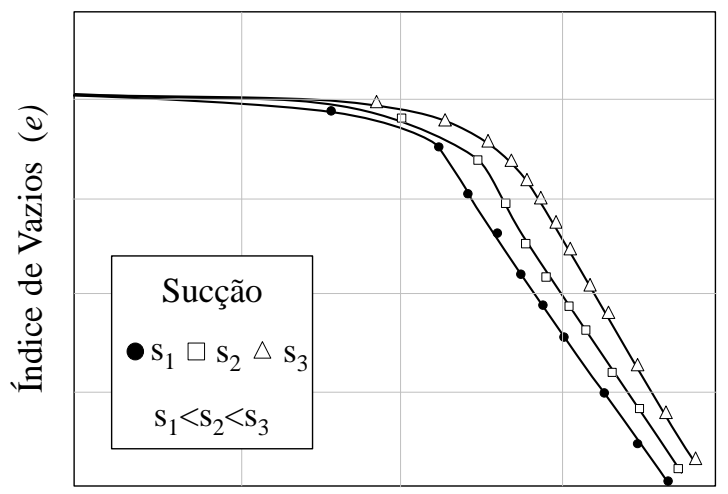

Tensão Vertical Efetiva $\sigma(\mathrm{MPa})$

(a)

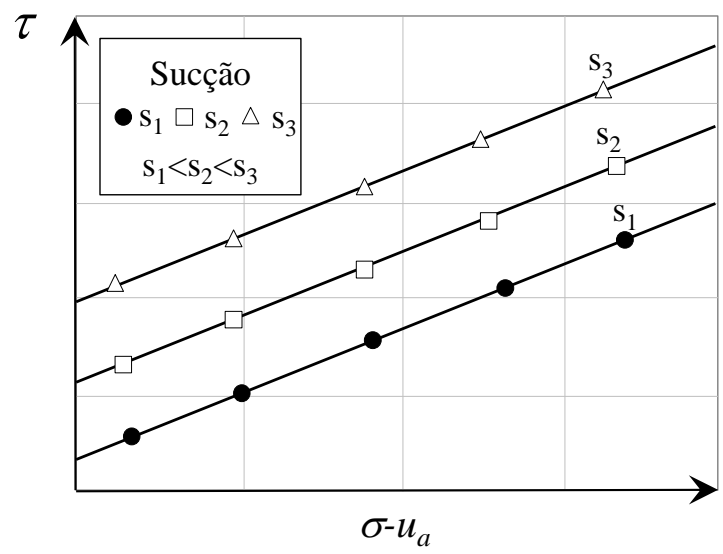

(b)

Figura 2.20. Representação esquemática dos efeitos da não saturação no comportamento.

\subsubsection{Tamanho}

O tamanho e a forma das partículas dos solos expressam as características do processo de formação desses materiais. Na geotecnia clássica, o tamanho dos grãos é considerado como um parâmetro determinante para o entendimento do comportamento do material e é utilizado nas suas classificações como um dos indicadores de possíveis fenômenos físicos. A relação desta característica com processos como o fraturamento de partículas é relevante e ajuda a esclarecer o início da quebra, a qual é mais rápida para partículas de tamanho maior (Nakata et al., 2001b). Evidências da influência do tamanho das partículas na compressibilidade de um solo específico são ilustradas na Figura 2.21, de modo a enfatizar que para partículas menores, o material tem maior rigidez. Os métodos tradicionais para a determinação dos tamanhos de partículas que constituem o solo são as análises granulométricas por peneiramento e por sedimentação. A primeira é adequada para análise de grãos com diâmetro maior do que $0,075 \mathrm{~mm}$, enquanto a segunda técnica é apropriada para analisar partículas menores, isto é, aquelas que passam na peneira \#200. Todavia, o tamanho de uma partícula, que não tenha forma esférica ou cúbica, não pode ser definido, exclusivamente, por uma dimensão linear (Lambe \& Whitman, 1969), já que o significado de tamanho depende da dimensão medida e do método de medição. 


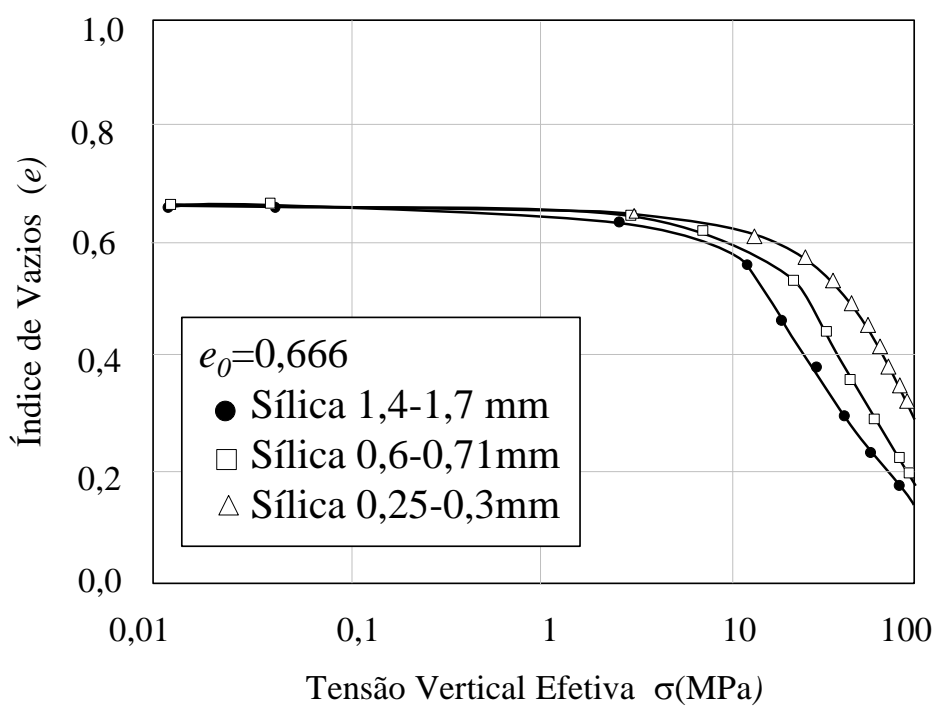

Figura 2.21. Influência do tamanho das partículas na compressibilidade de uma areia sílica

(Nakata et al., 2001b).

\subsubsection{Forma das partículas}

A forma das partículas tem função fundamental no entendimento de fenômenos comportamentais de solos. Os comportamentos macroscópicos de solos granulares são o resultado da interação entre as partículas, sendo esses mecanismos micromecânicos (rotações e deslizamentos) influenciados diretamente pela forma das partículas.

Existem três parâmetros adimensionais importantes para caracterizar a forma das partículas: a esfericidade, o arredondamento e a rugosidade. O primeiro refere-se à forma global das partículas e reflete a similaridade entre o comprimento, a altura e a largura das mesmas. A esfericidade pode ser quantificada como o diâmetro da maior esfera inscrita em relação ao diâmetro da menor esfera circunscrita. O segundo parâmetro (arredondamento) descreve a escala das características principais de superfície que têm, tipicamente, uma ordem de grandeza menor do que o tamanho das partículas e é quantificada como a relação entre o raio médio de curvatura de características de superfície e o raio da maior esfera inscrita na partícula. Por último, a rugosidade descreve a textura das superfícies das partículas em relação ao raio das partículas. Na Figura 2.22, ilustra-se como é determinada a forma das partículas e o significado de cada um dos parâmetros supracitados.

Várias pesquisas mostram a importância da forma das partículas, no entanto, poucas vezes esta variável é considerada nas avaliações geotécnicas. Na Figura 2.23, ilustra-se a influência da forma das partículas na compressibilidade de materiais granulares, com diâmetros aproximadamente similares. 


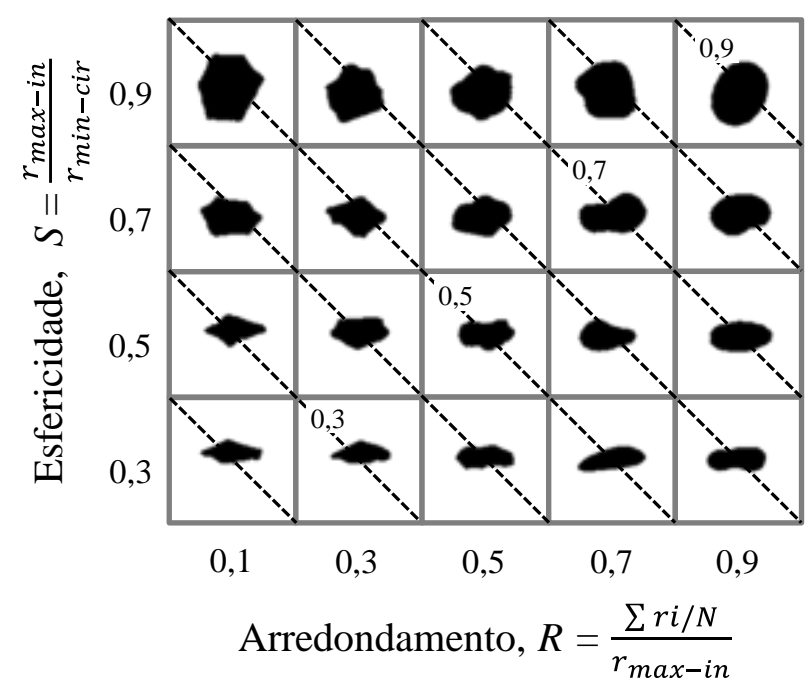

(a)

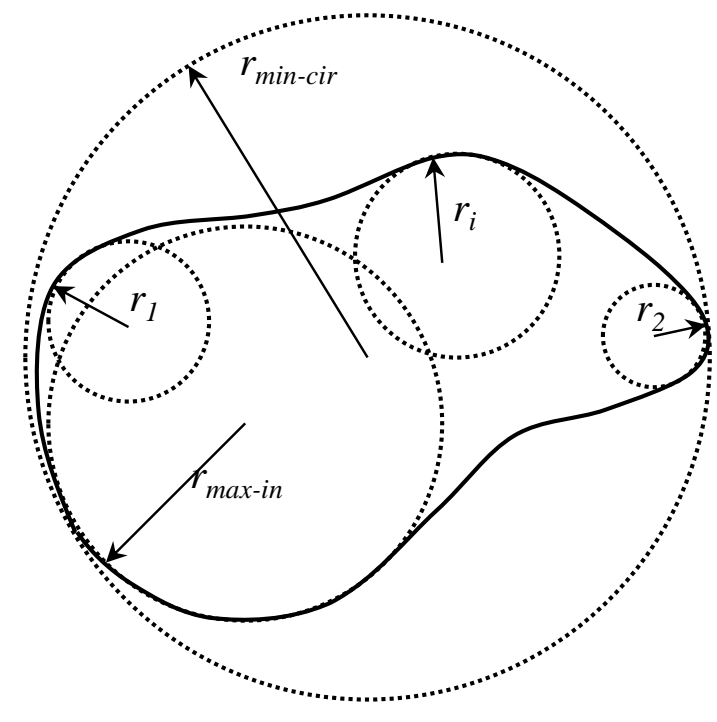

(b)

Figura 2.22. Determinação da forma das partículas: (a) Carta de esfericidade $S$ e arredondamento $R$. As linhas tracejadas correspondem à constante de regularidade das partículas $\rho=(\mathrm{S}+\mathrm{R}) / 2$. (b) ilustração das medidas necessárias para a obtenção das características da forma das partículas (Cho et al., 2006).

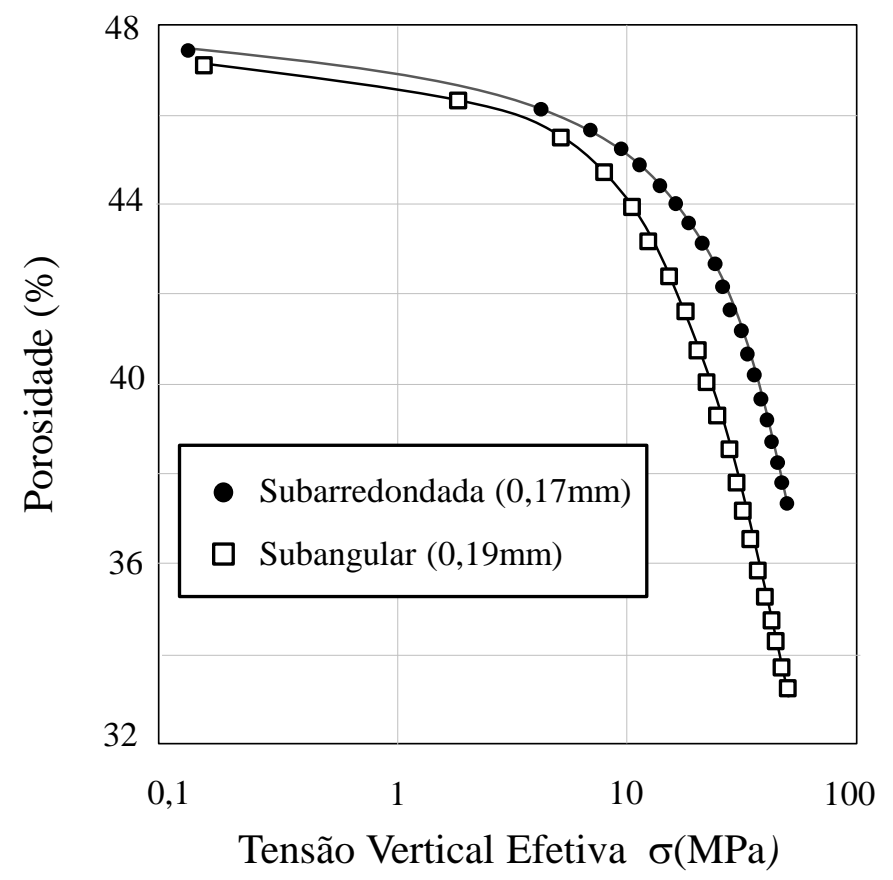

Figura 2.23. Efeitos da variação da forma dos grãos para areias bem graduadas ricas em quartzo (Chuhan et al., 2003).

Um estudo relevante foi feito por Cho et al. (2006), no qual foram avaliados os efeitos da forma das partículas na densidade e no comportamento de solos arenosos. Os autores concluíram que a forma das partículas deve ser avaliada explicitamente como parte de cada exercício de caracterização de solos, em particular, quando areia ou cascalho limpos estão 
envolvidos. A Figura 2.24 mostra algumas influências da forma das partículas no comportamento de materiais granulares e no arranjo das mesmas. Ilustra-se que com o aumento do arredondamento, o ângulo de atrito no estado crítico $\left(\phi_{\mathrm{sc}}\right)$ e os índices de vazios extremos $\left(e_{\max } \mathrm{e} e_{\min }\right)$ diminuem. Adicionalmente, são descritos os índices de compressibilidade em termos da regularidade ( $\rho$ : média aritmética entre o arredondamento e a esfericidade) e nota-se a diminuição destes com o aumento da regularidade.
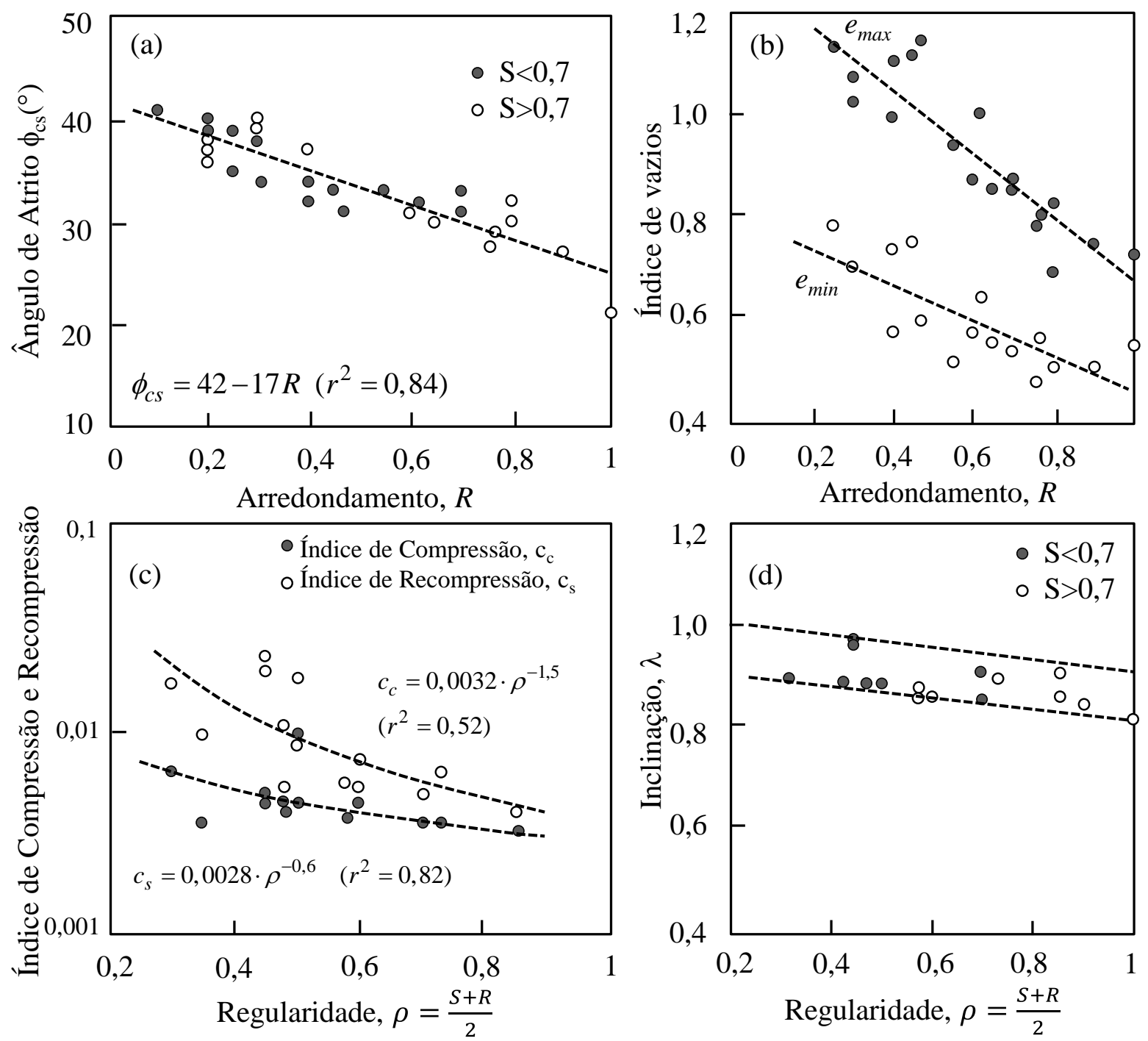

Figura 2.24. Algumas influências da forma das partículas no comportamento mecânico de materiais granulares (Cho et al., 2006).

\subsubsection{Distribuicão granulométrica}

A distribuição granulométrica tem influência direta na forma como os vazios do solo serão ocupados pelas partículas. Um material granular bem graduado apresenta um menor índice de vazios e mais entrosamento entre os grãos, portanto um maior ângulo de atrito macroscópico (Neves, 2009). Outra característica da distribuição granulométrica está 
relacionada com o fenômeno microscópico de quebra das partículas, uma vez que se observa mais quebra para materiais mal graduados.

Na Figura 2.25 mostra-se uma série de solos granulares, os quais foram submetidos a ensaios de compressão confinada. Nota-se o efeito da gradação e do tamanho das partículas na quebra das mesmas. Chuhan et al. (2003) estudaram a influência do coeficiente de uniformidade (cu) na compressibilidade, a partir da mistura de três tamanhos do mesmo material (ver Figura 2.26).

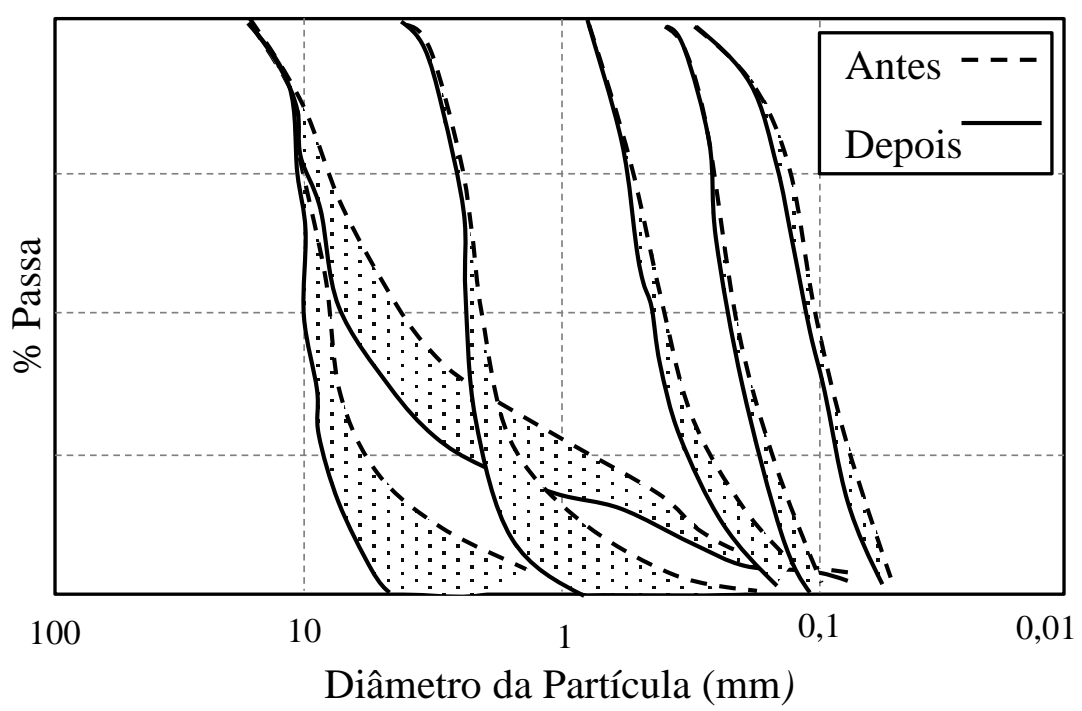

Figura 2.25. Efeito da graduação sobre a quebra das partículas de granito para ensaios de compressão isotrópica conduzido até 7,8 MPa (Lee \& Farhoomand, 1967 apud Hardin, 1985).

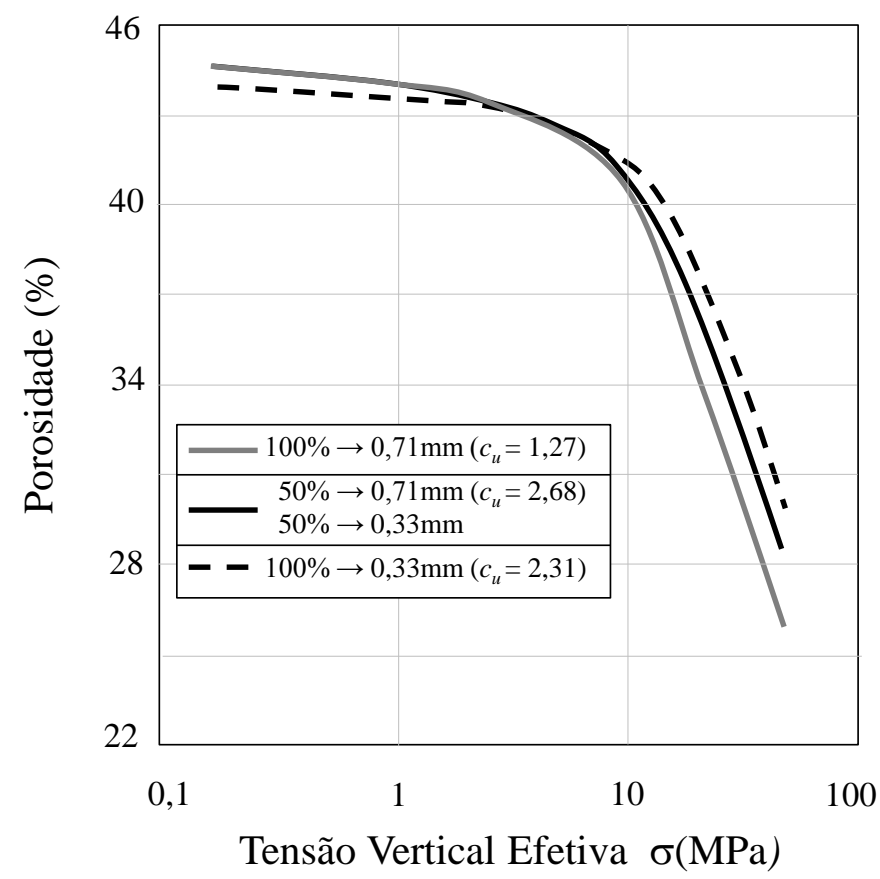

Figura 2.26. Efeitos da variação do coeficiente de uniformidade $\left(c_{u}\right)$ durante a compressão unidimensional de areias (Chuhan et al., 2003). 


\subsection{MÉTODO DOS ELEMENTOS DISCRETOS}

O Método dos Elementos Discretos (MED em português ou DEM em inglês) considera o meio analisado como um conjunto de partículas com propriedades mecânicas particulares e geometrias definidas. Este é o procedimento adequado para o estudo da dinâmica de meios particulados, já que considera explicitamente sua natureza discreta. O MED permite avaliar o comportamento físico e mecânico de materiais granulares, mediante o entendimento das propriedades mecânicas microscópicas das partículas e da interação entre as mesmas. Várias técnicas numéricas, usadas na modelagem de elementos discretos, foram desenvolvidas no transcorrer dos últimos anos. Estas são divididas em técnicas de contatos suaves e técnicas de contatos não-suaves (Zhu et al., 2007; O’Sullivan, 2011). A principal diferença entre as duas categorias é a forma de abordar o contato entre partículas. Os métodos de contatos suaves permitem a penetração entre partículas, enquanto, os de contato não suave inibe a interpenetração. A Figura 2.27 ilustra, esquematicamente, os mecanismos antes, durante e depois do contato.

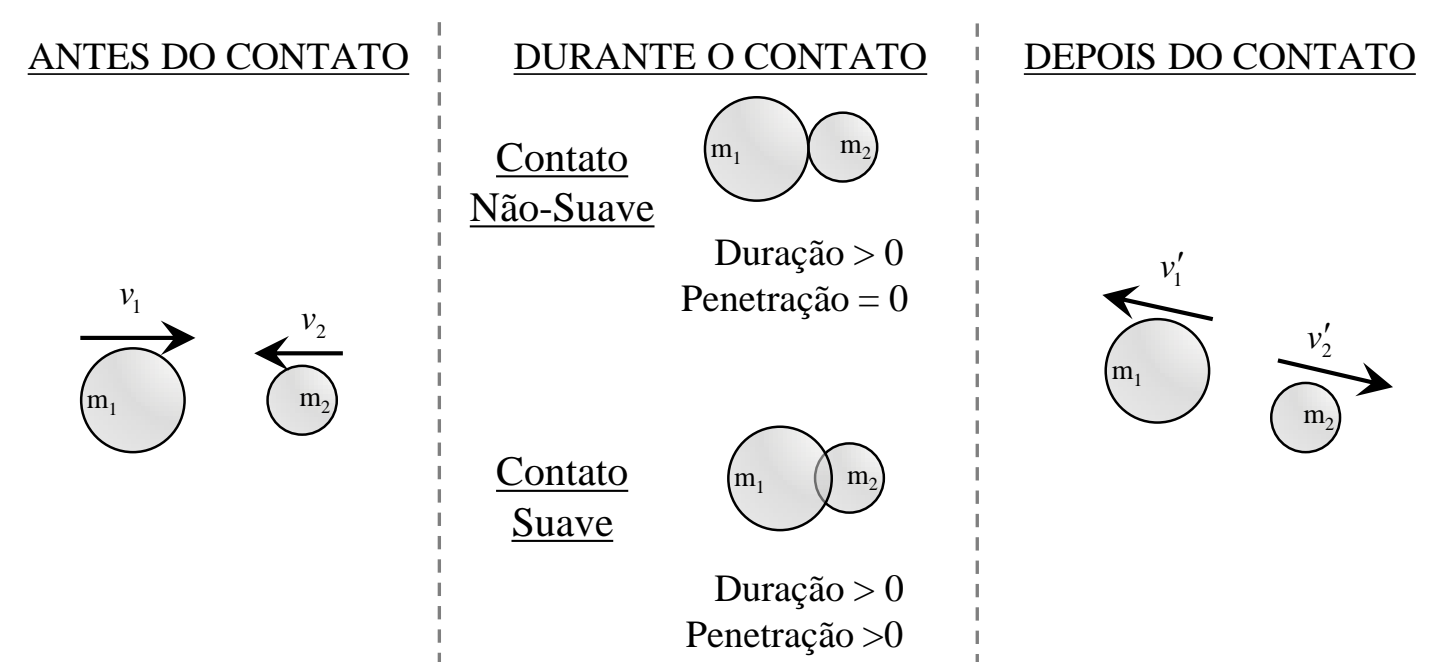

Figura 2.27. Ilustração das categorias de técnicas numéricas discretas, segundo a abordagem no contato (O’Sullivan, 2011).

O método mais tradicional da abordagem de contato suave é o proposto por Cundall e Strack (1979) para modelagem de solos granulares. Neste método as partículas são consideradas rígidas e interpenetráveis. A solução do sistema é feita mediante um esquema numérico explícito, onde cada partícula é tratada em separado. Devido à prevalência desta abordagem, comumente é chamada com os termos: "Método dos elementos discretos" e "Método dos elementos distintos". Na Figura 2.28, observa-se o resultado do trabalho de Cundall e Strack (1979), mostrando a coerência dos resultados numéricos com as evidências 
experimentais de Jong \& Verruijt (1969). Outra técnica, dentro da categoria de contato suave, é o método de análise de deformação descontínua (DDA), formulado por Shi e Goodman (1985, 1989) para rochas e posteriormente adaptado para materiais granulares (Ke \& Bray, 1995). A principal diferença, com o método anterior, é que a solução é alcançada mediante a minimização da energia potencial do sistema completo de elementos discretos. Existem várias técnicas discretas de contato suave, não obstante, as descritas anteriormente são as de principal uso na geotecnia.

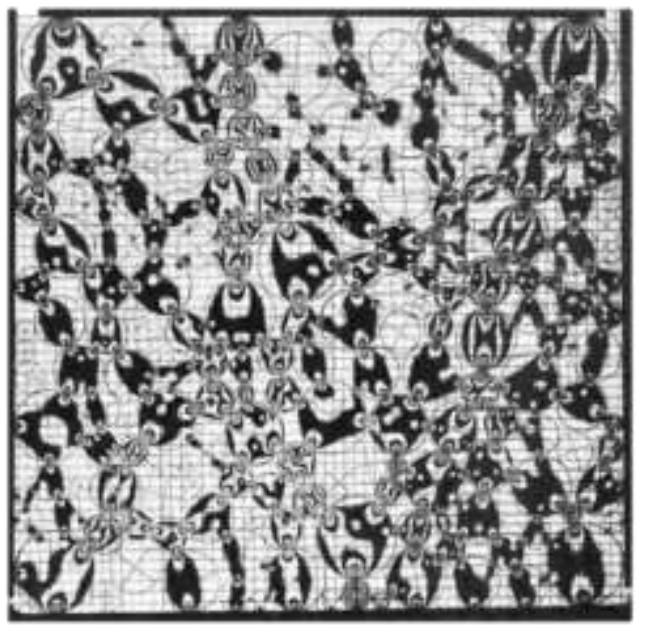

(a)

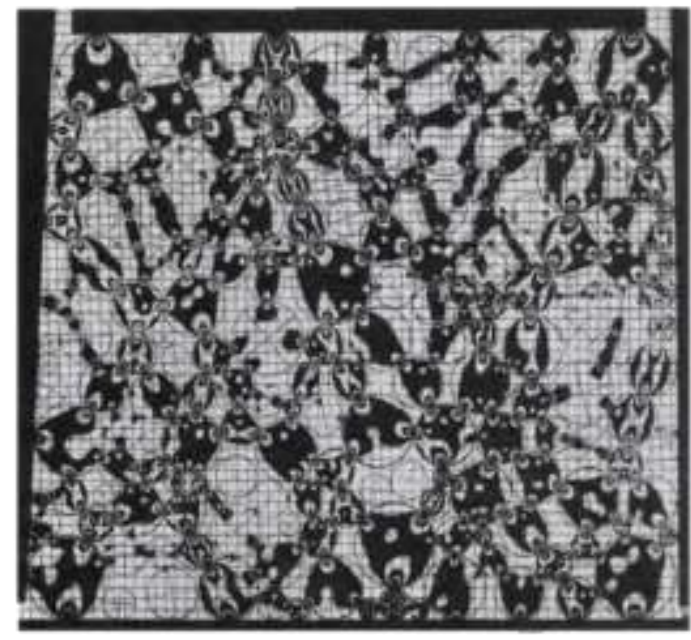

(c)

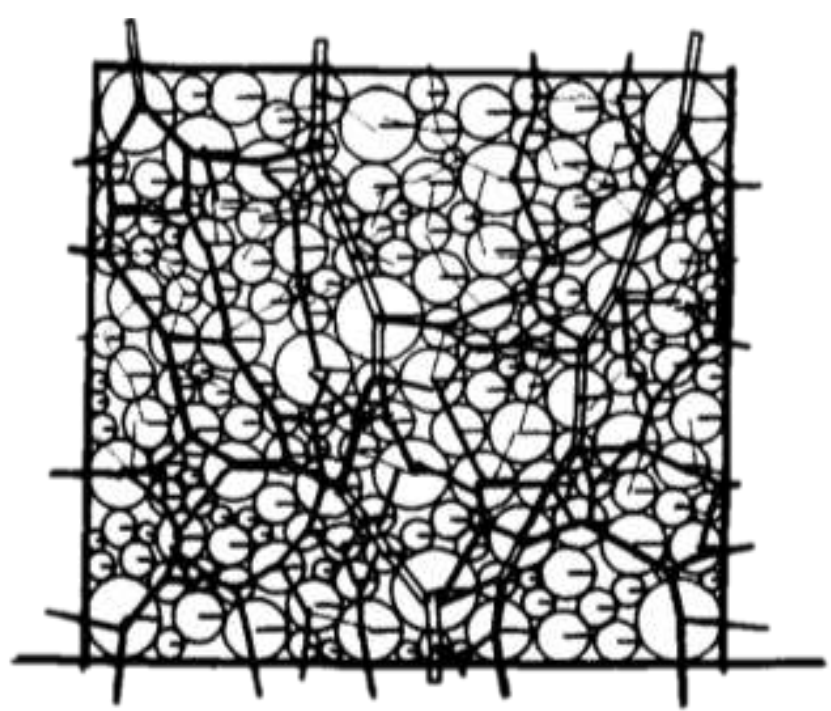

(b)

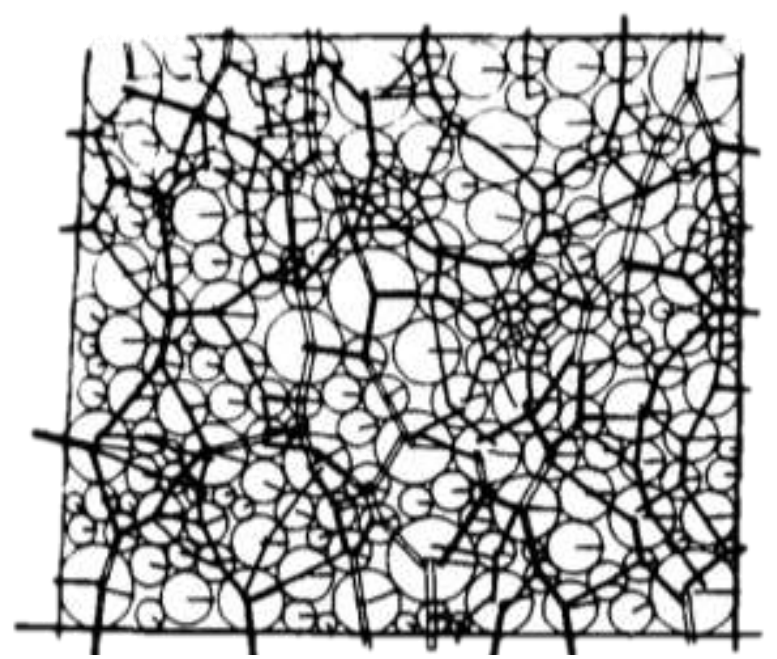

(d)

Figura 2.28. (a)-(c) Resultados experimentais do estudo fotoelástico de discos (Jong \& Verruijt, 1969); (b)-(d) Resultados das simulações numéricas com o método dos elementos discretos (Cundall \& Strack, 1979).

Os métodos da categoria de contato não suave podem ser classificados em dois tipos: (1) os que usam integradores orientados a eventos, e (2) os que usam integradores de passo de 
tempo (Donzé et al., 2009). Os primeiros são chamados de métodos Event-Driven. Nestes, a colisão ocorre quando dois elementos rígidos se tocam e as velocidades (linear e angular) póscolisionais são prescritas por um operador de colisão. As forças são tratadas uma de cada vez, e por este motivo o método não é adequado para sistemas com muitos contatos. O segundo é normalmente conhecido como o método da dinâmica dos contatos ("Contact Dynamics Method”). Este soluciona sistemas com muitos contatos, mediante o uso de esquemas numéricos, superando o anterior. Para isto, o método trabalha com a integral das forças e não com a própria força.

Nas seções subsequentes serão apresentados os princípios básicos de funcionamento do modelo de elementos discretos formulado por Cundall e Strack (1979). Posteriormente, serão definidas algumas quantidades importantes para a interpretação dos resultados discretos e, por último, serão mostrados alguns avanços nesta técnica para sua aplicação na engenharia geotécnica.

\subsubsection{Princípios Gerais}

Os princípios básicos de MED são descritos por O’Sullivan (2011) e ilustrados na Figura 2.29. Inicialmente o usuário especifica a geometria do sistema a analisar, incluindo as coordenadas das partículas e as condições de contorno. Além disso, deve-se especificar como vai ser a interação entre as partículas, mediante a escolha do modelo de contato e a definição dos valores dos parâmetros correspondentes, de acordo com o que se quer simular. Posteriormente, o usuário deve especificar a sequência de cargas ou deslocamentos que quer impor ao sistema. Assim, ficam definidas todas as condições geométricas e físicas do problema para a sua resolução.

O processo de cálculo é feito mediante uma análise transiente (ou dinâmica), tipicamente conhecida por especificar o número de incrementos de tempo. Desta forma, tendo definido o passo de tempo, os contatos das partículas são identificados. Assim, é possível determinar forças em cada um dos contatos entre as partículas, as quais estão relacionadas com a distância entre as partículas em contato. Com isto, a força e o momento resultante em cada partícula pode ser determinados. Conhecendo-se as propriedades geométricas da partícula, a inércia da partícula é determinada, e desta forma as acelerações translacionais e rotacionais da partícula podem ser calculadas. Consequentemente, o deslocamento e a rotação de cada partícula, para o incremento de tempo em questão, são encontrados mediante uma integração de diferenças finitas centrais simples. Usando esses incrementos de deslocamento e 
rotação, as localizações das partículas são atualizadas. No passo posterior de tempo as forças de contato são calculadas, usando a geometria atualizada e a sequência de passos, descritos anteriormente, é repetida.

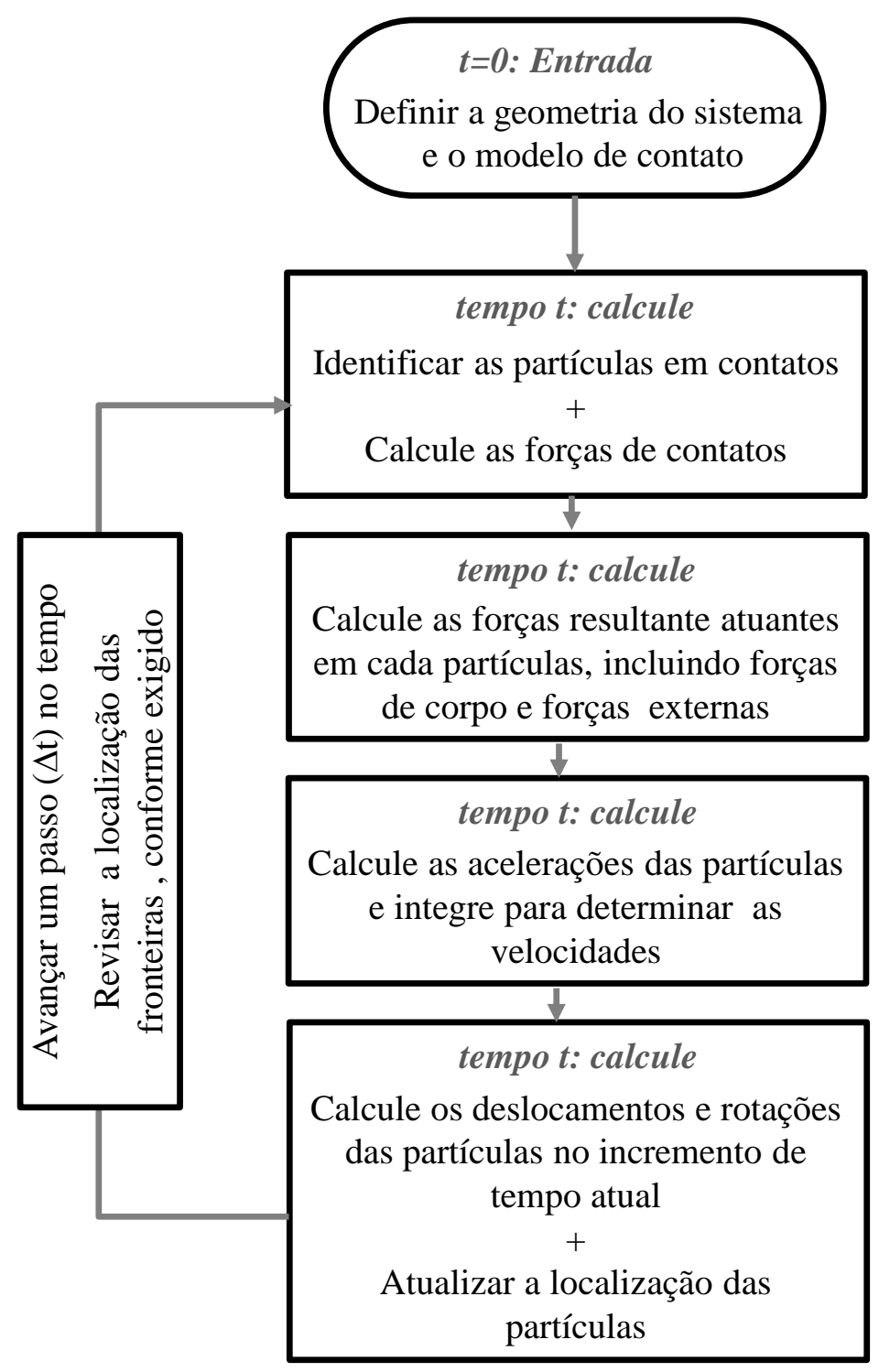

Figura 2.29. Princípios de modelagem MED (O’Sullivan, 2011).

As principais hipóteses usadas na formulação deste tipo de método são:

1. As partículas são elementos rígidos, que possuem inércia finita, descrita analiticamente.

2. As partículas podem se mover livremente uma da outra, podendo girar e deslocar.

3. O contato acontece unicamente entre duas partículas, sobre uma área infinitesimal.

4. As partículas podem se sobrepor levemente nos contatos, sendo esta interpenetração uma analogia com as deformações superficiais da partícula (esmagamento).

5. As forças de compressão entre partículas podem ser calculadas da interpenetração e as de tração (no caso cimentado) da separação das partículas. 
6. O passo de tempo utilizado no esquema de integração de diferenças finitas, necessário para o cálculo do movimento, deve ser suficientemente pequeno para garantir a estabilidade. Isto se associa à hipótese feita pelo MED com respeito ao incremento de tempo, na qual se assume que este é suficientemente pequeno para garantir que, durante um único intervalo de tempo, as perturbações só se propagam para a partícula vizinha.

Sadd (2000) mostra como o conceito geral do método pode ser explicado considerando um conjunto geral de partícula bidimensional como mostrado na Figura 2.30. Isolando a partícula i e aplicando as leis de Newton, tem-se que:

$$
\begin{aligned}
& \sum_{j=1}^{N} F^{i j}+F^{i}=m_{i} \ddot{x}_{i} \\
& \sum_{j=1}^{N} M^{i j}+M^{i}=I_{i} \ddot{\theta}_{i}
\end{aligned}
$$

onde $F^{i j}$ são as forças do contato $j$ com a partícula $i, F^{i}$ representa qualquer força de não contato que atua na partícula $i, M^{i j}$ são os momentos resultante (sobre o centro de massa da partícula) das forças de contato $F^{i j}, M^{i}$ é o momento resultante de qualquer força de não contato, $m_{i}$ é a massa da partícula e $I_{i}$ é momento de inercia da partícula.

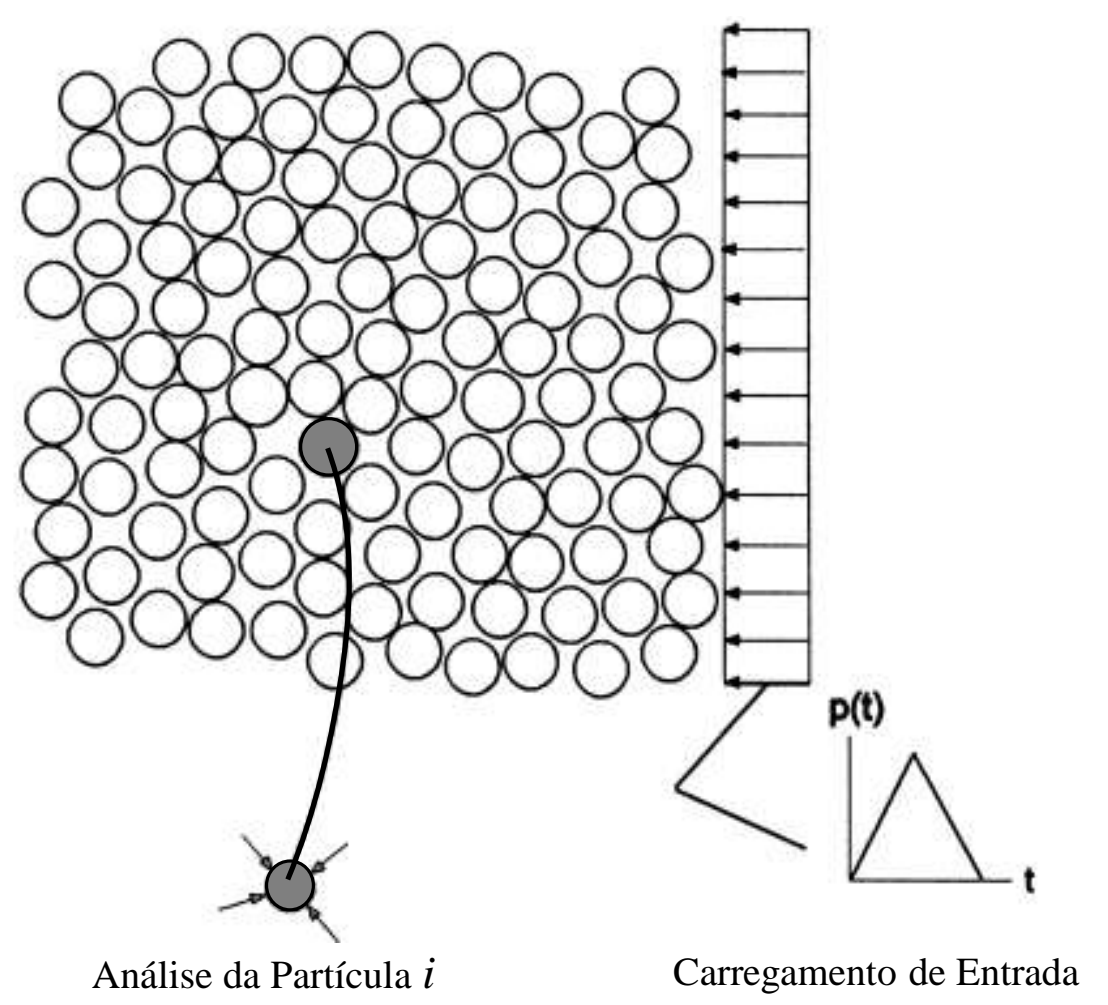

Figura 2.30. Procedimento do método de elementos discretos (Sadd et al., 2000) 
Assim, com o conhecimento das aceleração linear e a angular para cada partícula, as velocidades e os deslocamentos podem ser obtidos via integração numérica com o uso de diferenças finitas.

Assim, faltaria definir como é a resposta do contato entre duas partículas interagindo entre si. Para isto são estabelecidas leis constitutivas do contato, as quais dependem do fenômeno micromecânico que se deseja simular. Estas são construídas relacionando a força entre partículas com o deslocamento e a velocidade no contato (interpenetração). De forma geral, estas podem ser escritas como:

$$
\begin{aligned}
& F_{n}^{i j}=F_{n}^{i j}\left(\delta_{n}, V_{n}, \delta_{t}, V_{t}\right) \\
& F_{t}^{i j}=F_{n}^{i j}\left(\delta_{n}, V_{n}, \delta_{t}, V_{t}\right)
\end{aligned}
$$

onde $\delta_{n}$ e $\delta_{t}$ são os deslocamentos relativos normal e tangencial entre as partículas $i$ e $j, V_{n}$ e $V_{t}$ são as velocidades relativas normal e tangencial.

Na Figura 2.31 ilustra-se uma metodologia para a obtenção dos contatos, onde mostrase que cada partícula é mapeada dentro de células pertencentes a uma grade geral. A obtenção dos contatos é feita em duas fases. Numa primeira fase se buscam todas as possíveis partículas em contato, as quais correspondem a todas as partículas pertencentes às células vizinhas ( 8 ou 26 células, para o caso $2 \mathrm{D}$ ou $3 \mathrm{D}$, respetivamente) e à célula da partícula em questão. Na segunda fase, são determinados os contatos efetivos da partícula em análise com as partículas obtidas na primeira fase. Desta forma, a busca é concentrada na região de interesse, sendo mais eficiente que verificar o contato de cada partícula com todo o sistema. Existem várias metodologias para a obtenção de contatos, dependendo das caraterísticas do material estudado. Matuttis e Chen (2014) descrevem várias metodologias para a obtenção dos contatos, para 2D e 3D, mostrando suas vantagens e desvantagens. A principal finalidade no estudo deste processo é a otimização computacional, já que tem um peso muito importante na velocidade de execução do método.

A utilização de geometrias complexas para as partículas influenciará nos processos de determinação dos contatos de cálculo e nas forças de contato, tornando-se mais complicada e demandando maior esforço computacional (Neves, 2009). A grande maioria dos trabalhos tem se limitado à utilização de geometrias simples como cilindros (2D) ou esferas (3D), nos quais a geometria é definida pelo raio, facilitando os processos de cálculo. 


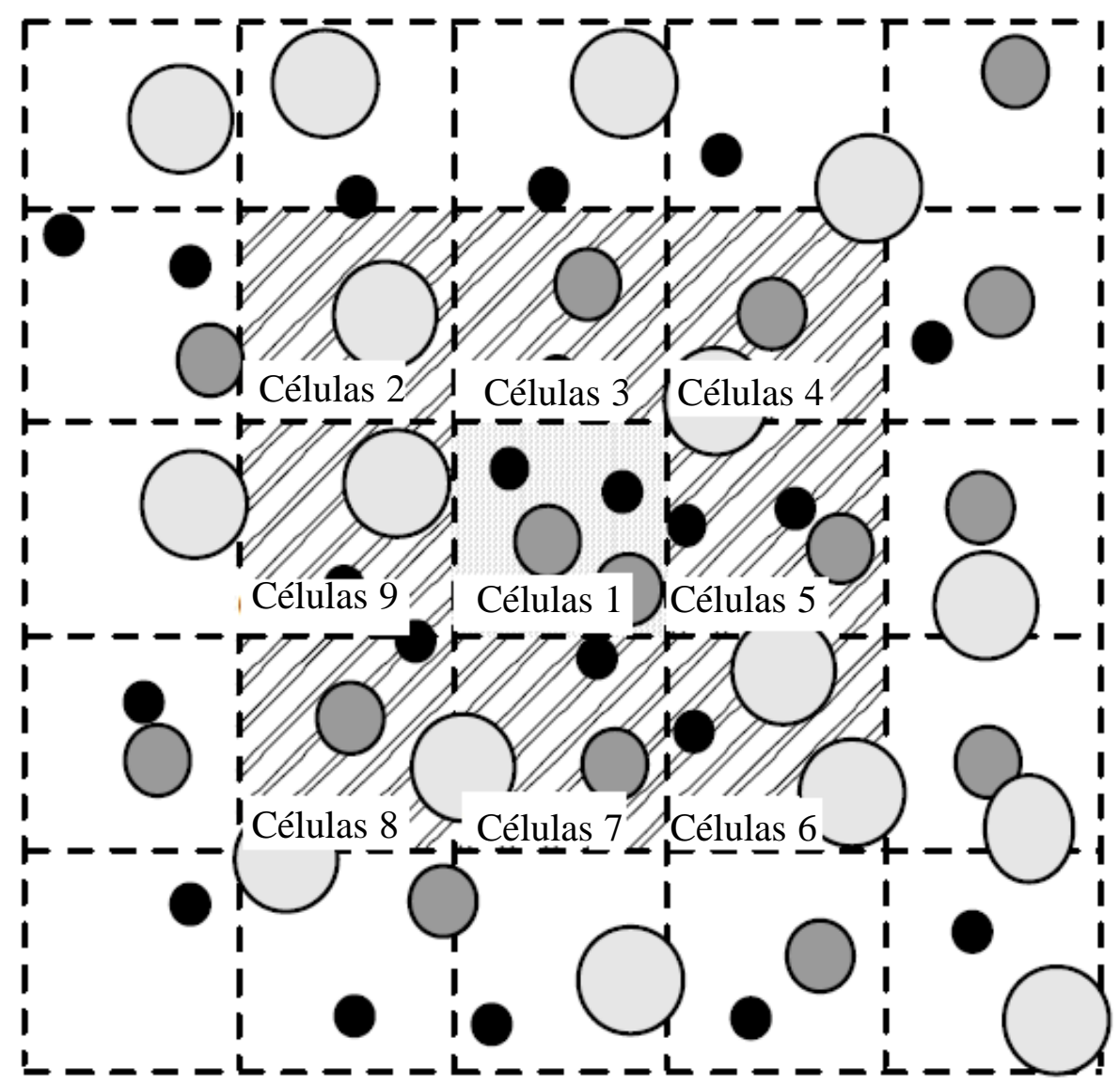

Figura 2.31. Mapeamento usado para a determinação dos contatos num problema 2D (O’Sullivan, 2011).

\subsubsection{Interpretação Micromecânica dos Resultados}

O método dos elementos discretos é uma ferramenta fundamental para o entendimento de comportamentos geomecânicos, uma vez que este permite observar processos entre as partículas, desenvolvendo uma melhor compreensão entre a resposta macroscópica e as interações internas entre partículas. Não obstante, para essas análises devem ser fornecidas ferramentas que ajudem a quantificar os fenômenos que acontecem na escala microscópica. A seguir serão descritos algumas quantidades escalares e tensoriais que provêm esta informação.

A primeira alternativa de uso comum é a utilização de linhas de forças resultantes da união dos centroides das partículas, nas quais a espessura da linha é proporcional à magnitude da força de contato transmitida. Esta metodologia demostrou que os resultados do método numérico eram semelhantes aos obtidos por fotoelasticidade, como se observou na Figura 2.28. Na Figura 2.32, mostra-se as linhas de forças de um ensaio de cisalhamento no início e no final do mesmo. Vale destacar que esta técnica é um pouco mais complexa de interpretar para casos tridimensionais. 

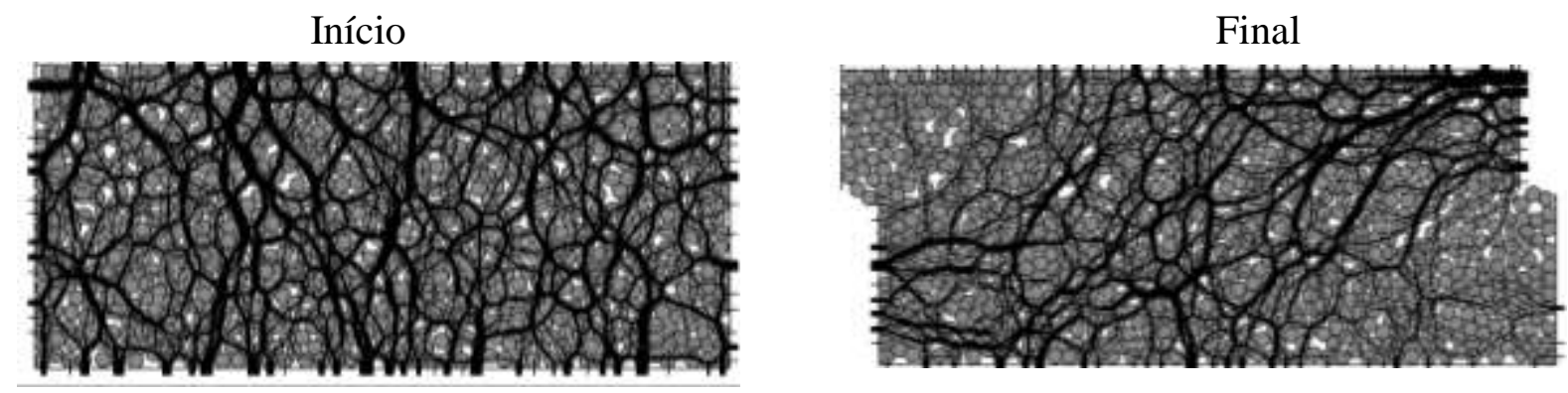

Figura 2.32. Linhas de força no ensaio de cisalhamento (Lobo-Guerrero \& Vallejo, 2006).

A utilização de linhas de forças fornece uma análise totalmente qualitativa da estrutura do material e da sua evolução com os processos de carregamento. Várias alternativas para quantificar os resultados obtidos da modelagem MED podem ser definidas. Um parâmetro simples é o número de coordenação, $\mathrm{Z}$, simplesmente dado como a razão entre o dobro do número de contatos no sistema $(\mathrm{Nc})$ pelo o número de partículas $(\mathrm{Np})$. O número de contatos é multiplicado por 2, porque cada contato é compartilhado por duas partículas. A função que define $\mathrm{Z}$ é dada por:

$$
Z=\frac{2 N c}{N p}
$$

Embora esse número possa ser útil, ele inclui todo tipo de linha de força, mesmo aquelas mais fracas que não participam efetivamente da transmissão de forças. Consequentemente, Thornton (2000) propõe um novo parâmetro, chamado de número de coordenação mecânico $(\mathrm{Nm})$. Este parâmetro só considera as partículas com dois ou mais contatos, uma vez que as partículas com um ou nenhum contato não podem transmitir carga em situações 2D ou 3D. Tal número é dado por:

$$
N m=\frac{2 N c-N p^{1}}{N p-N p^{0}-N p^{1}}
$$

onde $N p^{0}$ e $N p^{1}$ são o número de partículas com nenhum ou um contato, respectivamente. Thornton (2000) demonstrou que as amostras soltas e densas do mesmo material convergem para o mesmo número de coordenação mecânica após uma pequena quantidade de deformação.

Um fenômeno bastante conhecido é a anisotropia do solo tanto em termos de resistência quanto de rigidez. O MED consegue quantificar este fenômeno, observando sua evolução com o carregamento e proporcionando assim uma informação valiosa. $\mathrm{O}$ enfoque utilizado para essa finalidade foi proposto por pesquisadores experimentais (Oda et al., 1980), os quais 
definiram o conceito de fábrica e a metodologia para sua quantificação. A expressão mais usada para a quantificação da estrutura é o tensor de fábrica, dado por:

$$
\Phi_{i j}=\frac{1}{N c} \sum_{i}^{N c} n_{i} n_{j}
$$

sendo $N c$ o número total de contatos e $n_{i}$ e $n_{j}$ as componentes dos vetores unitários normais ao ponto de contato nas direções $i$ e $j$, respectivamente.

Todas estas quantidades são importantes para relacionar os fenômenos macroscópicos com as características microscópicas. Vale destacar que existem outros parâmetros, tais como: distribuição de forças de contato, histograma de orientações dos contatos, anisotropia dos vazios, entre outros (Bagi, 2003; O’Sullivan, 2011; Barreto et al., 2013). Alguns trabalhos na área experimental foram feitos nos últimos anos, analisando os comportamentos micromecânicos mediante as quantidades descritas anteriormente. Ressaltam-se os trabalhos feitos por Fonseca et al. (2013a, 2013b), que estudam a quantificação da evolução da fábrica durante o cisalhamento com parâmetros direcionais e escalares.

\subsubsection{Alguns Desenvolvimentos na Modelagem Micromecânica}

Nos últimos anos a comunidade científica interessou-se mais pela utilização do MED, mostrando grandes avanços nesta área. Na Figura 2.33 mostra-se a evolução do número de publicações relacionadas com MED ao longo do tempo, evidenciando um crescimento exponencial que está relacionado com os progressos tecnológicos na últimas duas décadas. A seguir, serão apresentados alguns desenvolvimentos feitos, enfatizando os resultados obtidos para forma da partícula, distribuição granulométrica, cimentação, não saturação e quebra de grãos.

Com respeito à forma da partícula, têm-se duas tendências: a primeira está relacionada com a geração de formas por meio de funções matemáticas; a segunda com construção da forma a partir de aglomerações de esferas (clusters). Na Figura 2.34-a-b, apresenta-se a partícula real e a gerada por meio de clusters, segundo a metodologia proposta por Ferellec e McDowell (2010). Por outro lado, amostras cuja forma da partícula foi gerada matematicamente, por meio da combinação de poliedros esféricos com a construção de Voronoi, são mostradas na Figura 2.34-c-d (Galindo-Torres \& Pedroso, 2010). Outro exemplo de geração de partículas mediante funções matemáticas é ilustrada na Figura 2.34-e-f, mostrando como a combinação de polígonos com esferas reproduz formas complexas (Alonso-Marroquín, 2008; Alonso-Marroquín \& Wang, 2009). 


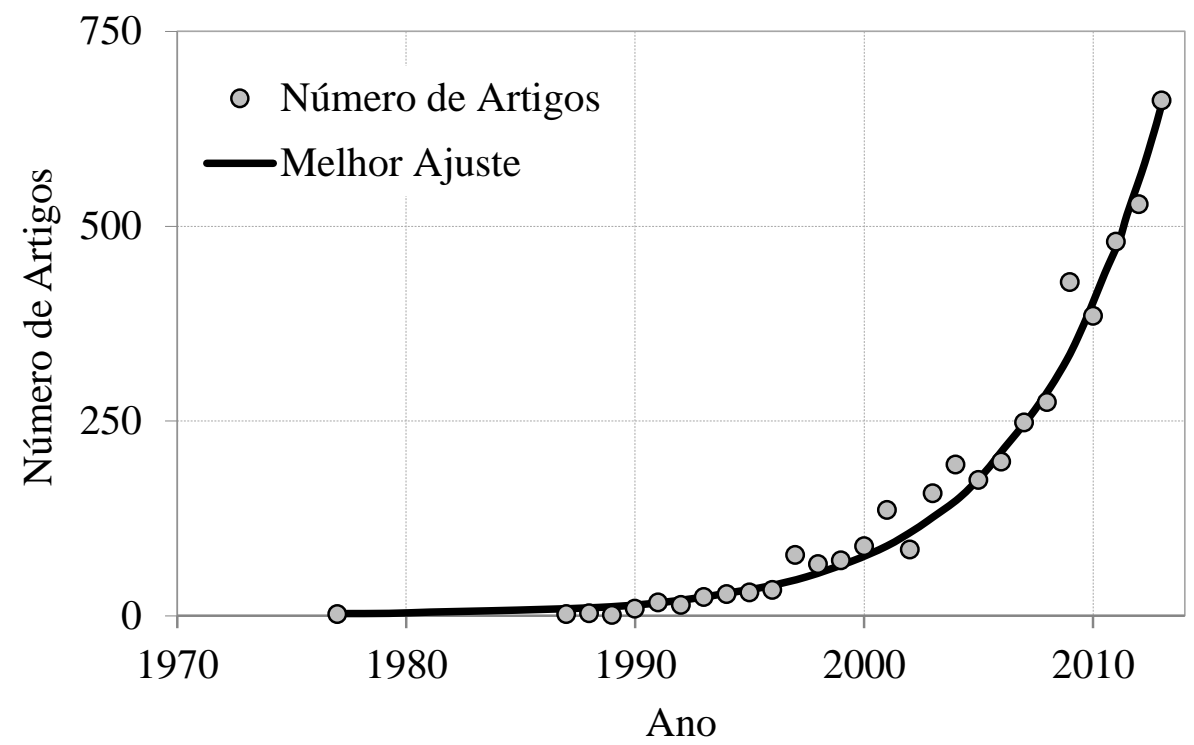

Figura 2.33. Número de publicações a longo do tempo (O’Sullivan, 2014).

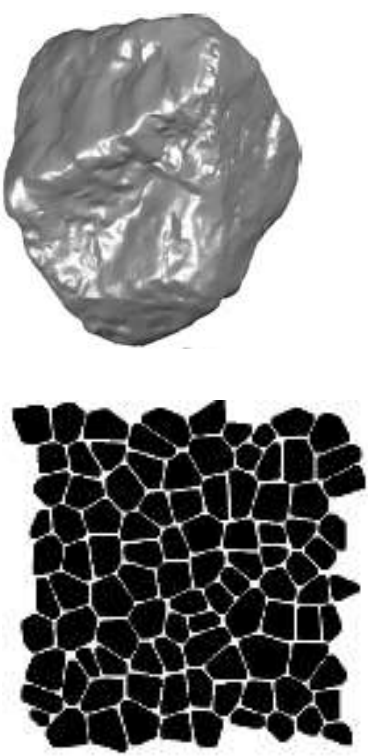

(a)

(c)

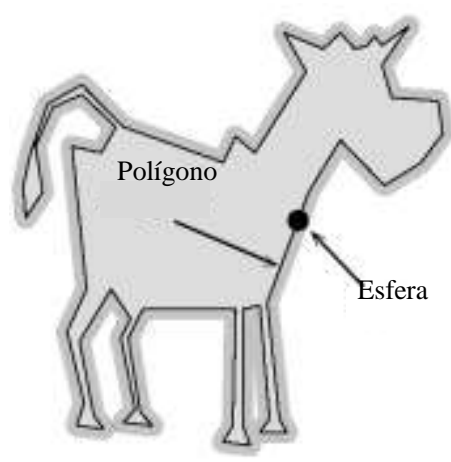

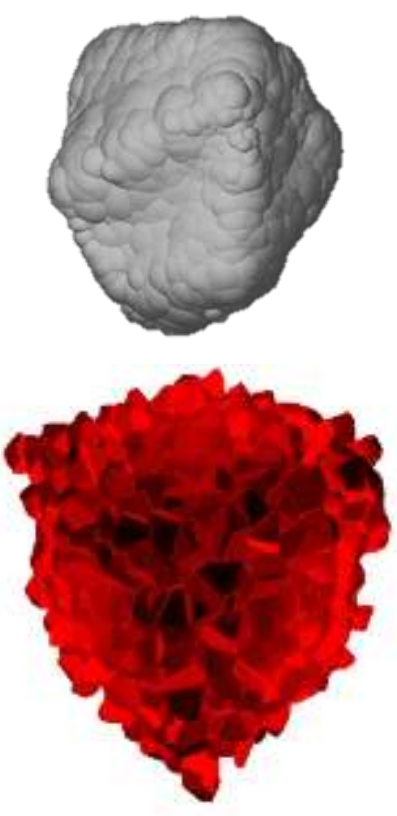

(e)

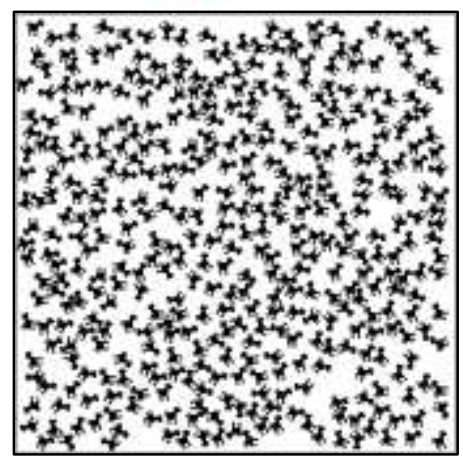

(b)

(d)

(f)

Figura 2.34. (a,b) Clusters (Mcdowell \& Ferellec, 2010). (c,d) Poliedros esféricos (GalindoTorres \& Pedroso, 2010). Esferopolígonos: (e) ilustração da geração de uma forma complexa, e (f) visualização da interação de 400 vacas numa caixa retangular confinada (AlonsoMarroquín, 2008). 
Com respeito à granulometria, há poucos trabalhos, porém merece destaque a pesquisa feita por Evans et al. (2009), na qual foram simulados ensaios de compressão bidimensional para diferentes granulometrias. Entre outras coisas, concluiu-se que amostras uniformes têm dilatância significativamente maior que solos bem graduados.

Considerar partículas 3D nas simulações numéricas é cada vez é mais frequente, tal como pode-se observar na Figura 2.35, na qual se mostra a evolução do tipo de partícula (2D ou 3D) ao longo do tempo.

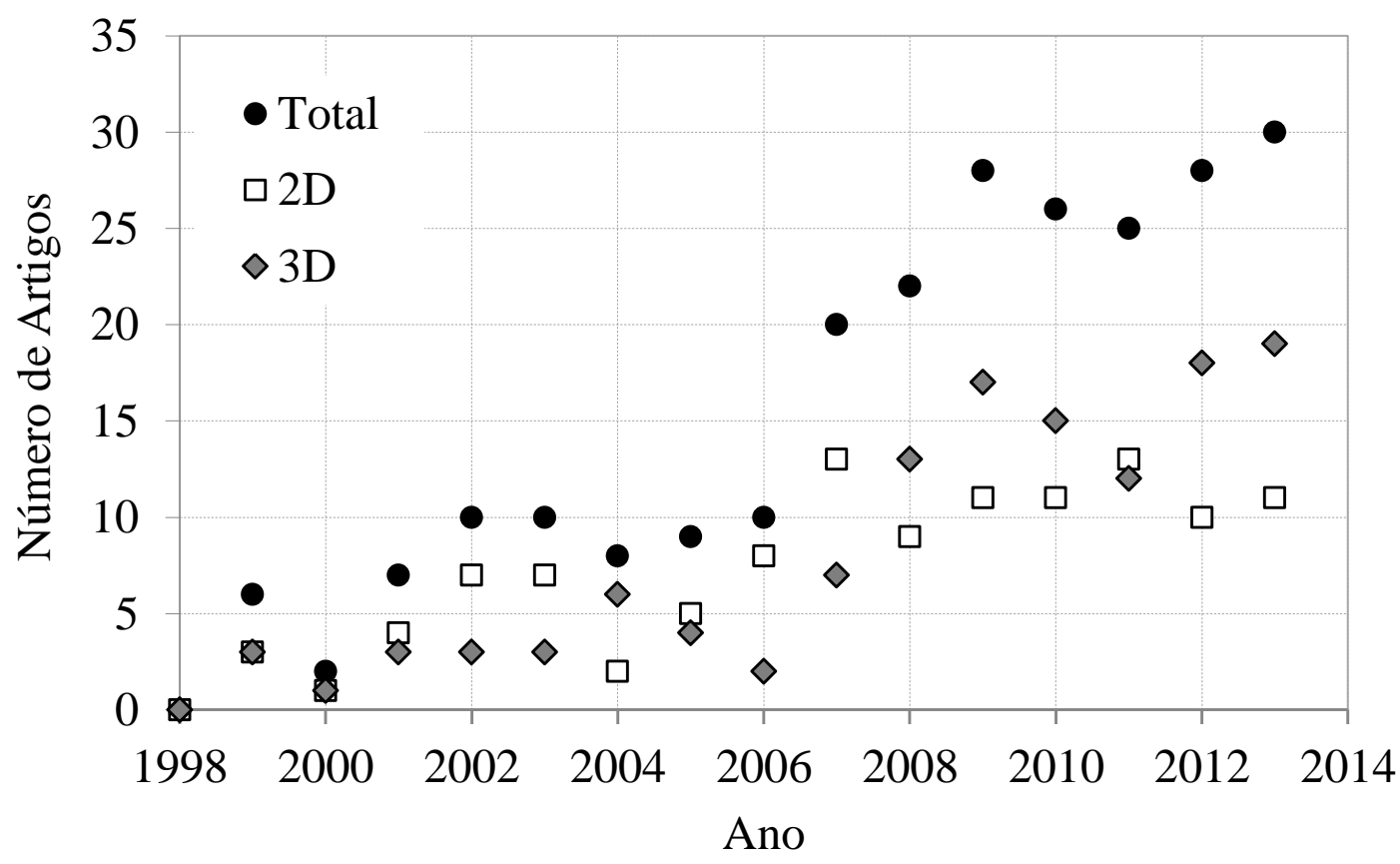

Figura 2.35. Número de publicações com uso de partículas 2D e 3D ao longo do tempo (O’Sullivan, 2014).

As pesquisas de elementos discretos relacionadas com o comportamento de solos não saturados têm sido limitadas aos solos no regime pendular e ao desenvolvimento de leis de contato para determinar as forças de tração pela ponte líquida interpartículas (O’Sullivan, 2011). Uma formulação simplista para o comportamento de solos não saturados, mediante a modificação do modelo de contato, é apresentada por Jiang et al. (2004). Este modelo é bastante simples, mas é capaz de representar suas principais características. O modelo de contato consiste de um modelo de contato normal e tangencial para resistir às forças de tração e cisalhantes, respectivamente. Comparado com o modelo de contato original para meios granulares, o modelo de contato normal adiciona um elemento de ligação para representar a ação da água capilar (CW), enquanto que o modelo de contato tangencial inclui um atrito $\mathrm{CW}$. A inclusão da nova parcela de atrito é devida ao aumento das forças normais interpartículas, devido à capilaridade, na Figura 2.36 ilustra-se o modelo este modelo. 


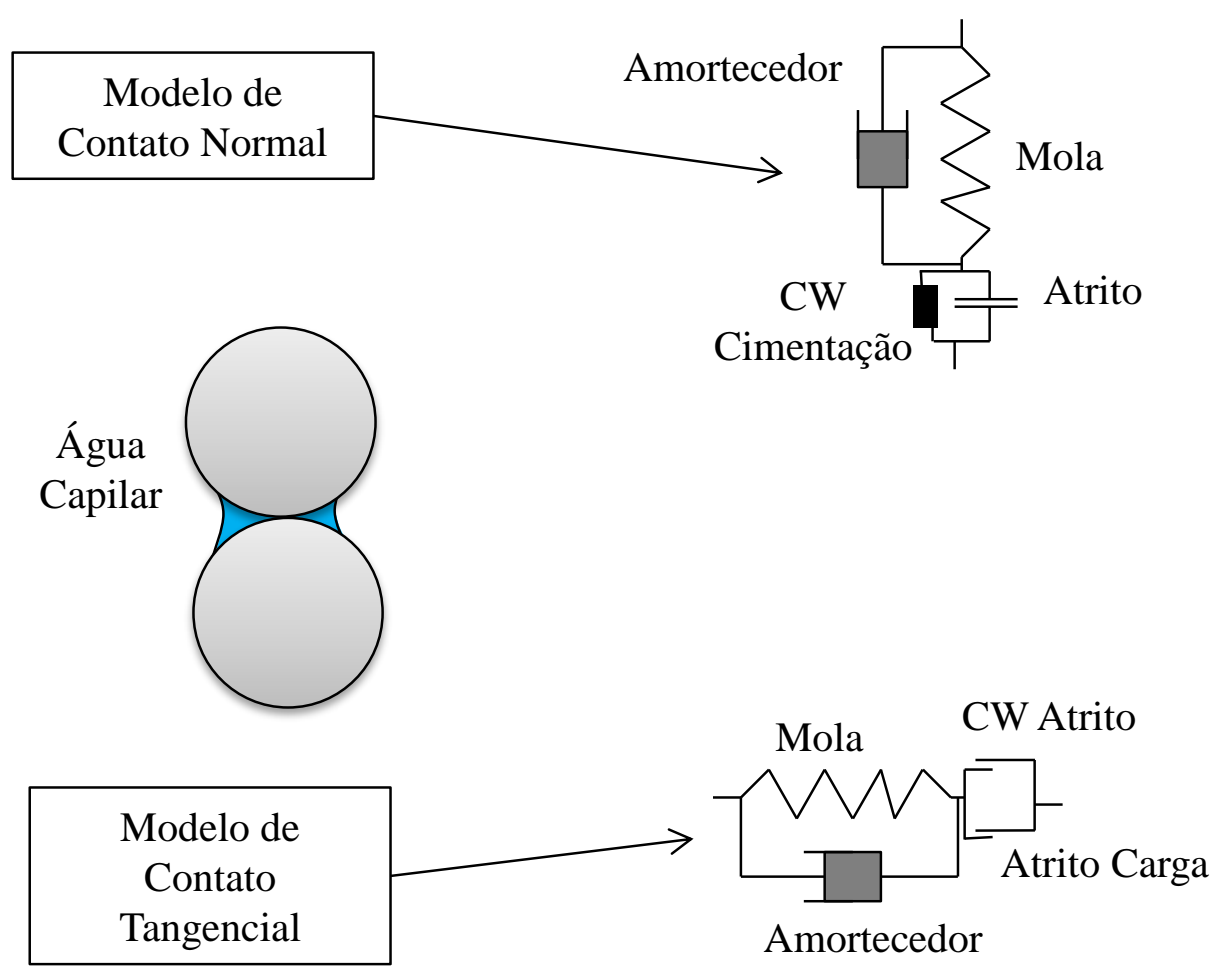

Figura 2.36. Modelo de contato simplista proposto para simular o efeito da agua capilar (CW) no MED (Jiang et al., 2004).

Outra abordagem é apresentada por Gili (1988) e Gili \& Alonso (2002) para o problema de fluxo não saturado em meios particulados. Este modelo define geometricamente as partículas, os poros e os meniscos. Os meniscos são idealizados, enquanto que os poros ficam definidos a partir dos vazios deixados pelo arranjo das partículas, como se observa na Figura 2.37-a. A força capilar no contato é o resultado da soma das forças devidas às tensões superficiais e a pressão da água dentro do menisco (ver Figura 2.37-b). Com respeito ao fluxo, Gili \& Alonso (2002) assumem que todos os processos de transferência de massa entre as diferentes fases ocorrem mediante leis lineares, os quais estão ilustrados na Figura 2.37-c.

Para a simulação de fenômenos de quebra de partículas, usando o método dos elementos discretos, são usadas duas alternativas. A primeira consiste em substituir a partícula quebrada por fragmentos menores (Åström \& Herrmann, 1998; Lobo-guerrero, 2006; Ben-Nun \& Einav, 2010). A segunda alternativa consiste no uso de um aglomerado (cluster) que possui propriedades micromecânicas (Harireche \& Mcdowell, 2002; McDowell \& Harireche, 2002; Cheng et al., 2003). Na Figura 2.38-a-b ilustram-se as formas de abordar o problema de quebra de partículas em simulações com o MED. A Figura 2.38-c ilustra como é o uso de clusters, para incluir o efeito da quebra, na simulação de ensaios de compressão (Lim \& McDowell, 2005). 


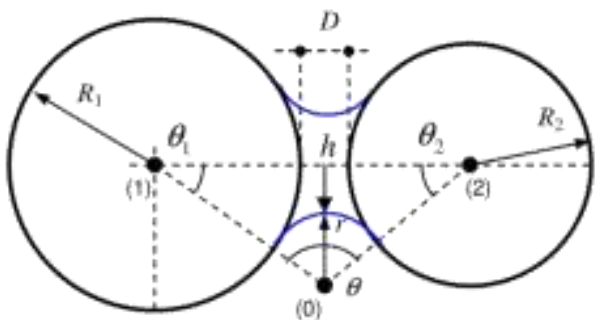

(a)

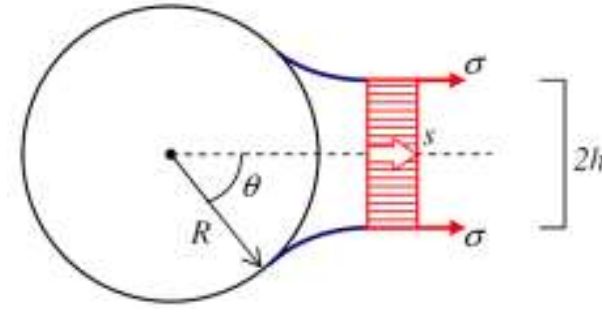

(b)

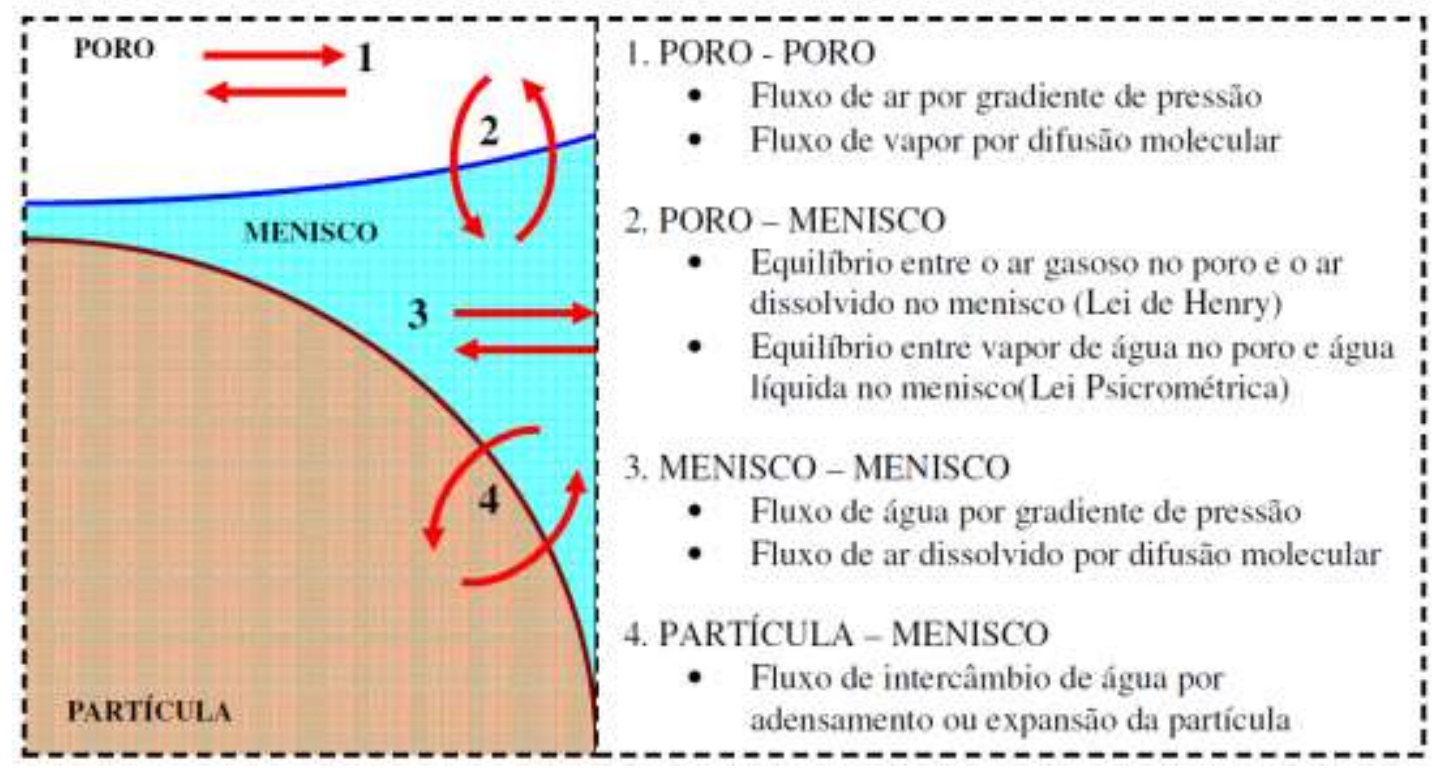

(c)

Figura 2.37. (a) Geometria idealizada do menisco; (b) força capilar no menisco; (c) processos de transferência de massa partícula-menisco-poro (Ibañez, 2008).

No que diz ao respeito à cimentação, tem-se desenvolvido vários modelos para a representação desta caraterística. A seguir serão apresentados os dois modelos que mais sobressaem nas publicações de DEM com aplicações na geotecnia. O primeiro é a abordagem feita por Jiang et al. (2005), que incluem este efeito mediante a modificação do modelo de contato. Na Figura 2.39, são apresentados os detalhes do modelo, mostrando que são adicionados dois elementos de cimentação (um normal e outro tangencial), os quais indicam a resistência máxima em cada uma das direções. No caso da direção normal, uma vez ultrapassado o valor máximo de força a tração (quebra da cimentação), a contribuição desta componente no sistema de forças da partícula é totalmente nula. No caso da direção tangencial, se o elemento ultrapassa a resistência, a cimentação desaparece, mas ainda vai ter a atuação do atrito entre as partículas. Esta proposta tem evoluído nos últimos anos, melhorando os critérios de resistência, com base nos resultados de campanhas experimentais de barras de alumínio cimentadas, submetidas a diferentes tipos de cargas (Jiang \& Yan, 2007; Jiang et al., 2007, 2012a, 2012b). Este modelo tem sido utilizado na simulação de 
ensaios de laboratório de geomateriais cimentados, ajudando a entender a influência da degradação do cimentante no comportamento macroscópico (Jiang et al., 2014a, 2014b).

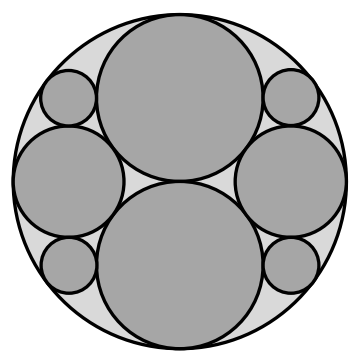

(a)
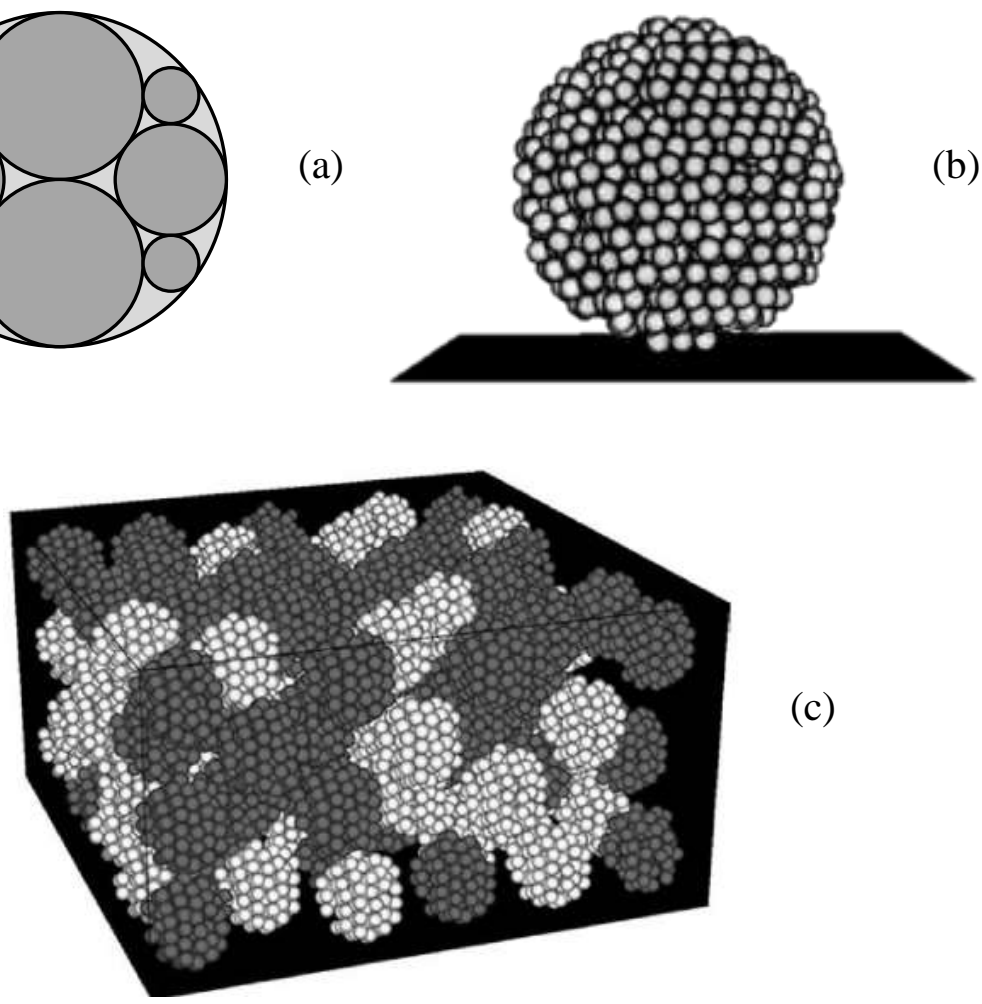

(c)

Figura 2.38. Abordagens para simular a quebra de partículas: (a) substituição por fragmentos menores (Lobo-guerrero, 2006) e (b) usando cluster de esferas (Harireche \& Mcdowell, 2002). (c) aplicação de clusters para a simulação de ensaios de compressão (Lim \& McDowell, 2005).

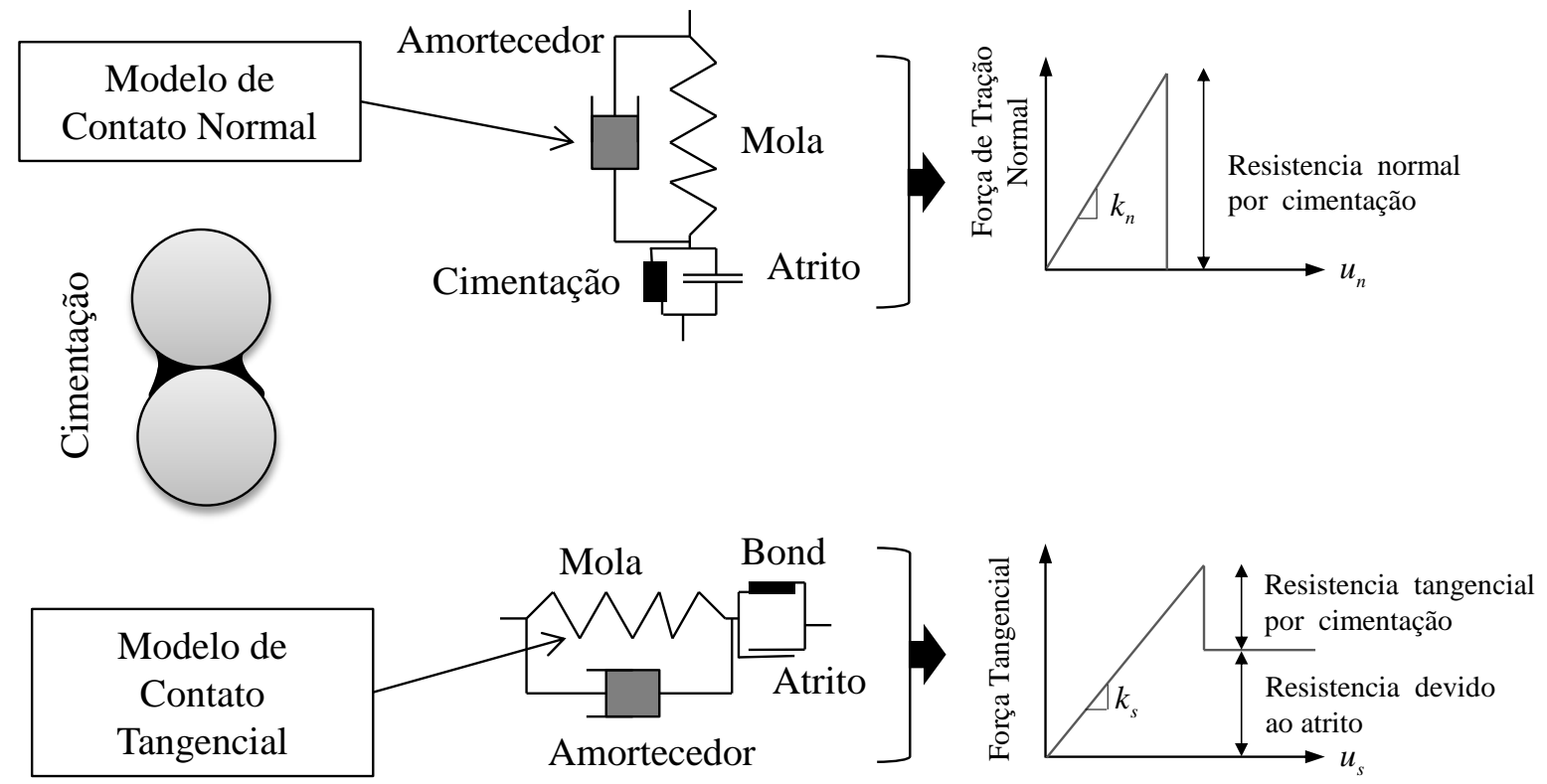

Figura 2.39. Modelo de cimentação de Jiang et al (2005). 
O outro modelo de contato para cimentação, de bastante popularidade na geotecnia, é o proposto por Potyondy e Cundall (2004) e que é chamado do modelo das conexões paralelas. Este consiste em adicionar molas com rigidez normal e cisalhante, que trabalham em paralelo com as molas do contato entre partícula, usado no caso sem cimentação. Desta forma, com os movimentos relativos no contato, forças normais e cisalhantes e momentos são transmitidos entre partículas. O efeito das molas paralelas desaparecerá no momento em que as forças transmitidas ultrapassem um critério de resistência (definido da teoria de vigas). Na Figura 2.40-a-b, mostram-se os detalhes de cada uma das componentes do modelo de conexões paralelas, mostrando de forma explícita os elementos das forças atuantes e os critérios de resistência. Uma aplicação deste modelo de contato para a simulação de solos cimentados é feita por Wang e Leung (2008). Neste trabalho é incluído o efeito do cimentante mediante o modelo de contato e mediante a inclusão de partículas menores de cimento (ver Figura 2.40c). Desta forma, o efeito geométrico do cimentante no comportamento macroscópico é incluído.

(a) Comportamento do Grão

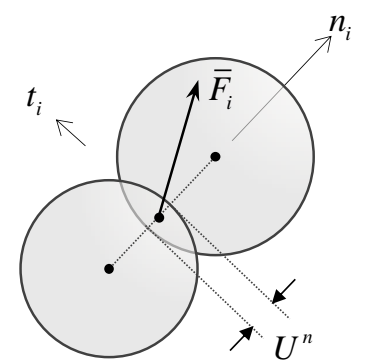

$$
\begin{aligned}
& F^{n}=K^{n} U^{n} \\
& \Delta F^{s}=-k^{s} U^{s}
\end{aligned}
$$

(b) Comportamento do Cimento

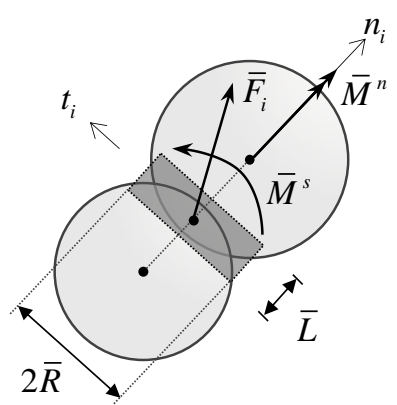

$$
\begin{array}{ll}
\Delta \bar{F}^{n}=\bar{k}^{n} A U^{n} & \Delta \bar{M}^{n}=\bar{k}^{s} J \Delta \theta^{n} \\
\Delta \bar{F}^{s}=-\bar{k}^{s} A U^{s} & \Delta \bar{M}^{s}=-\bar{k}^{n} I \Delta \theta^{s}
\end{array}
$$

$$
F^{s}<\mu F^{n}
$$

(c) Aplicação do modelo de $\underline{\text { cimentação }}$

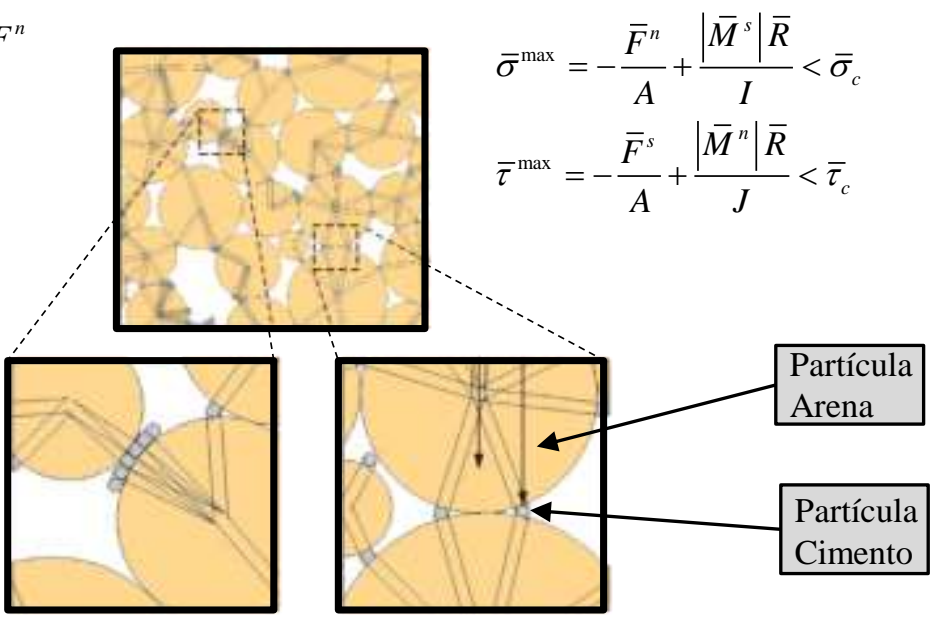

Figura 2.40. Modelo de conexões paralelas para material cimentado(Potyondy \& Cundall, 2004): (a,b) mostram os detalhes da concepção do modelo, e (c) mostra a aplicação feita por Wang e Leung (2008). 


\subsection{QUEBRA DE MATERIAIS GRANULARES}

A quebra de partículas ocorre em várias aplicações da engenharia geotécnica (barragens altas, cravação de estacas, ferrovias, etc.), e está normalmente associada a níveis de tensão altos. Este fenômeno tem um impacto significativo no comportamento mecânico de materiais granulares. No momento que acontece a quebra, é gerada uma mudança da distribuição granulométrica, causando um incremento na compressibilidade devido ao rearranjo do empacotamento. Além disso, efeitos na resistência, pressão de poros e permeabilidade estão também intimamente ligados com o processo de fragmentação do material.

Existem diversos fatores que favorecem a quebra das partículas, os quais podem ser agrupados em três categorias. A primeira está relacionada com as características do elemento básico do material, a partícula, onde suas condições físicas e geométricas condicionaram o surgimento do fenômeno. A segunda está relacionada com a geometria do conjunto de partículas, onde normalmente se avalia com alguma medida direta ou indireta do arranjo do dos elementos da amostra. Na última, encontram-se as condições externas às quais o material será submetido. A seguir é apresentada uma lista das componentes de cada uma das categorias e uma breve descrição do efeito na quebra com base na consulta bibliográfica deste tema (Hardin, 1985; Yamamuro et al., 1996; Matsuoka \& Liu, 1998; Nakata et al., 2001b; Tapias et al., 2012).

\section{- Características da partícula}

Tamanho: para materiais submetidos a condições similares de carregamento, a quebra acontecerá primeiro para partículas de maior tamanho.

Forma das Partículas: esta caraterística está associada com o modo como atuam as forças de contato na partícula. Assim, partículas angulares, com igual composição mineralógica, quebram primeiro que as arredondadas.

Composição mineralógica: a configuração de minerais do grão dá uma ideia da dureza da partícula. Assim, para duas partículas com as mesmas configurações geométricas e de carregamento, a de maior dureza precisará de maiores níveis de carga para a ruptura.

Resistência das partículas: esta medida é uma mescla entre a forma da partícula e a composição mineralógica. Quanto maior for a resistência, menor vai ser a quebra no material. A sua avaliação no laboratório tende a ser mais complicada 
para formatos de partículas complexas, além de presentar uma dificuldade de padronização.

\section{- Arranjo das partículas}

Número de coordenação Z: esta medida está relacionada com o número de contatos da partícula. Assim, para um sistema com o mesmo nível de carregamento, as partículas do conjunto com menor número de coordenação, individualmente, estão mais carregadas e terão maior possibilidade de ruptura. Realizar a leitura no laboratório desta medida é muito difícil para materiais reais, e normalmente $\mathrm{Z}$ é avaliado em simulações numéricas discretas.

Índice de vazios: quando se tem um índice de vazios menor, significa que a estrutura granular está mais fechada, possuindo um maior número de contatos. Desta forma, materiais com índices de vazios baixo, consequentemente têm números de coordenação altos e portanto as tensões nas partículas são menores.

Gradação do Solo: a gradação fornece uma ideia de como estão distribuídas os tamanhos das partículas, o qual indiretamente é uma medida das possibilidades de contatos do sistema. Quando a granulometria é bem distribuída (bem graduada) o sistema se configura com menos espaços livres, o que significa um número de contatos maior. No caso oposto, os contatos são menores. Assim, solos uniformes apresentam mais quebras de partículas do que os bem graduados.

\section{- Condições de contorno}

Intensidade do carregamento: para maiores níveis de carga, as possibilidades a quebra são maiores. Caso já esteja acontecendo o fenômeno, as quantidades de quebra aumentam com o aumento do carregamento.

Trajetória do carregamento: a forma como é carregado o conjunto de partículas vai repercutir diretamente na distribuição de forças nos contatos. Assim, para o mesmo material com as mesmas condições inicias do arranjo das partículas, para diferentes trajetórias será necessário chegar em diferentes níveis de deformação para alcançar a mesma quantidade de quebra.

Água no sistema: a quantidade de água presente no sistema altera a intensidade de quebra do material, tem-se mostra que se aumenta a fragmentação com o aumento do teor de água no sistema. 
Esta temática de quebra tem sido motivo de várias pesquisas nas últimas décadas. Abordagens experimentais, analíticas e numéricas foram desenvolvidas para entender a resposta de materiais granulares com a influência dos efeitos da quebra, que tipicamente acontecem para níveis altos de tensões.

\subsubsection{Quebra de Partícula Individual}

A ruptura da partícula ocorre quando o estado de tensões no material supera a sua resistência. É amplamente aceito na que a ruptura de uma partícula esférica carregada a compressão pura se dá por tração, sendo a ruptura iniciada pelas trincas existentes e a concentração de tensões associada (Bono, 2013). Jaeger (1967) propõe que a tensão de tração característica induzida, nestas condições, seja definida pela seguinte expressão:

$$
\sigma_{f}=\frac{F}{d^{2}}
$$

onde $F$ é a força diametral na ruptura e $d$ é o diâmetro do grão.

Este valor de resistência para materiais naturais como os solos não é constante, mesmo que tenha idênticas condições geométricas e de composição mineral. Existe uma variabilidade na resistência devido à presença de fissuras na estrutura interna da partícula.

No caso de partículas com comportamento frágil a variabilidade da resistência pode ser descrita mediante uma distribuição de Weibull (McDowell et al., 1996; McDowell \& Bolton, 1998; Nakata et al., 1999). Este modelo define que a probabilidade de sobrevivência $P_{s}\left(V_{0}\right)$ do bloco de material de volume $V_{0}$, submetido a uma tensão normalizada $\sigma / \sigma_{0}$, é dada por:

$$
P_{s}\left(V_{0}\right)=\exp \left[-\left(\frac{\sigma}{\sigma_{0}}\right)^{m}\right]
$$

onde $P_{s}\left(V_{0}\right)$ é a probabilidade de sobrevivência de uma partícula de volume $V_{0}$ para uma tensão característica $\sigma=F / d^{2}, \sigma_{0}$ é a tensão característica para a qual $37 \%$ do número total não se fraturam e $m$ é o módulo de Weibull.

A Figura 2.41 mostra a distribuição de probabilidade acumulada para módulos entre 0,6 (mais disperso) e 5 (menos disperso). Desta forma o módulo $m$ incrementa com a diminuição da variabilidade. 


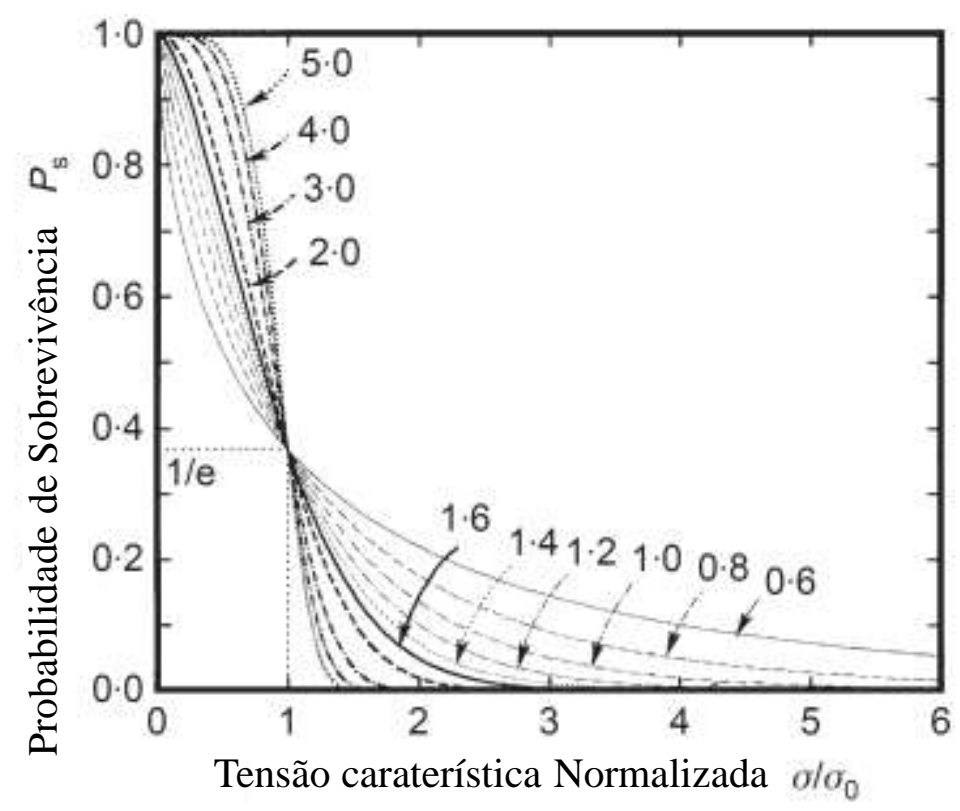

Figura 2.41. Curvas da distribuição de probabilidade acumulada de Weibull (Nakata et al., 1999).

A probabilidade sobrevivência para uma dada tensão de quebra $\sigma_{c}$ é dada por:

$$
p=1-\frac{\text { Número de partículas quebradas a } \sigma \geq \sigma_{c}}{\text { Número total de partículas ensaiadas }}
$$

Na Figura 2.42 é apresenta a distribuição acumulada real de resistência de um mesmo material para várias faixas de diâmetro, mostrando a similaridade para os diferentes tamanhos.

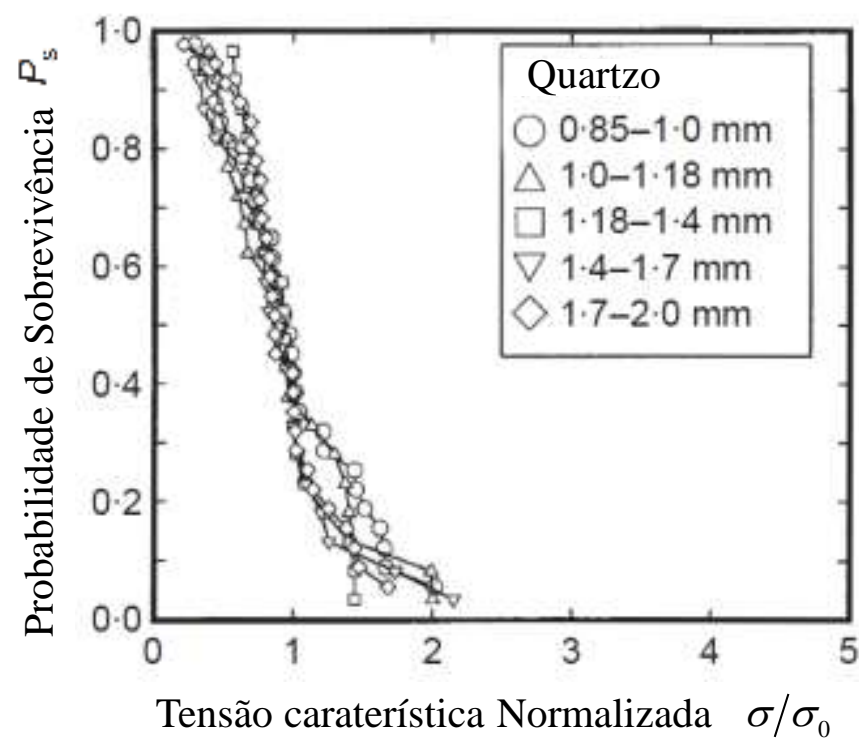

Figura 2.42. Probabilidade de sobrevivência normalizada (Nakata et al., 1999). 
Reescrevendo a equação 2.10 como:

$$
\ln \left[\ln \left(\frac{1}{P_{s}\left(V_{0}\right)}\right)\right]=m \cdot \ln \left(\frac{\sigma}{\sigma_{0}}\right)
$$

pode-se avaliar o modulo de Weibull para o material real. Na Figura 2.43 apresenta-se o resultado deste parâmetro para o material real estudado por Nakata et al (1999).

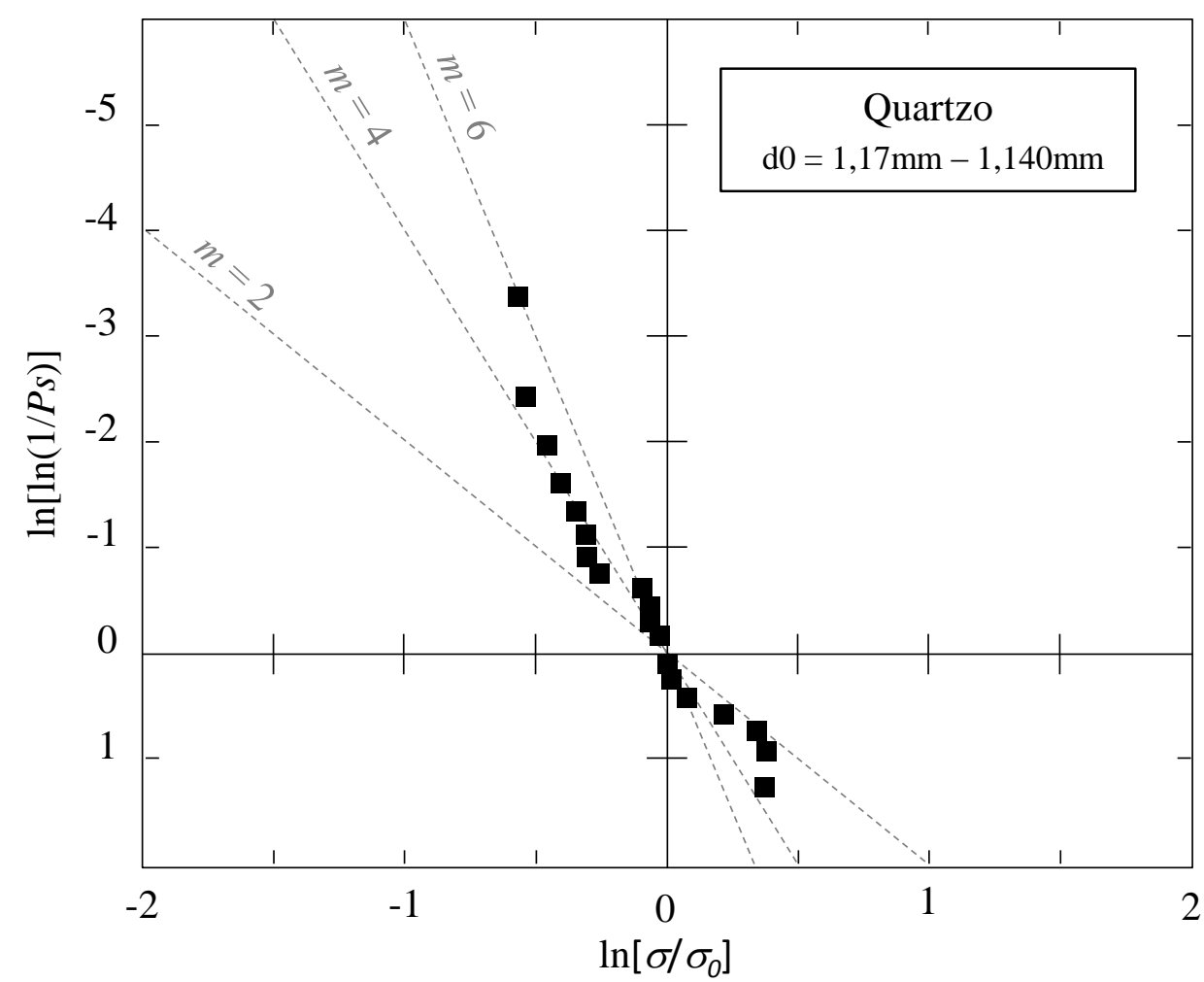

Figura 2.43. Comparação dos dados observado com a função de Weibull para uma areia de quartzo (Nakata et al., 1999).

Assumindo que as partículas são geometricamente similares, McDowell e Bolton (1998) modificaram a equação de Weibull para obter a probabilidade de sobrevivência de uma partícula de diâmetro $d$ sujeita a compressão diametral, obtendo a seguinte expressão:

$$
P_{s}(d)=\exp \left[-\left(\frac{d}{d_{0}}\right)^{3}\left(\frac{\sigma}{\sigma_{0}}\right)^{m}\right]
$$

onde $P_{s}(d)$ é a probabilidade de sobrevivência para qualquer partícula de diâmetro $d$ sujeita a uma tensão $\sigma$, e $\sigma_{0}$ é a tensão característica onde o $37 \%$ das partículas de tamanho $d_{0}$ sobrevivem. 
Observando a equação 2.13 , pode-se deduzir que o valor de tensão caraterística $\left(\sigma_{0, d}\right)$ para a partícula de diâmetro $d$ é dada por:

$$
\sigma_{0, d}=\left(\sigma_{0} d_{0}^{-3 / m}\right) d^{-3 / m}
$$

Assim,

$$
\sigma_{0, d} \propto d^{b}
$$

Esta equação descreve as características estatísticas da distribuição de Weibull para uma amostra de partículas de um solo com diferentes diâmetros. Na Figura 2.44 são apresentados alguns valores para materiais reais. Nesse caso foram obtidos os valores de $-0,357,-0,343$ e 0,420 para a areia de Leiht Buzzard, para um material calcário carbonífero e para um calcário oólitico, respectivamente.

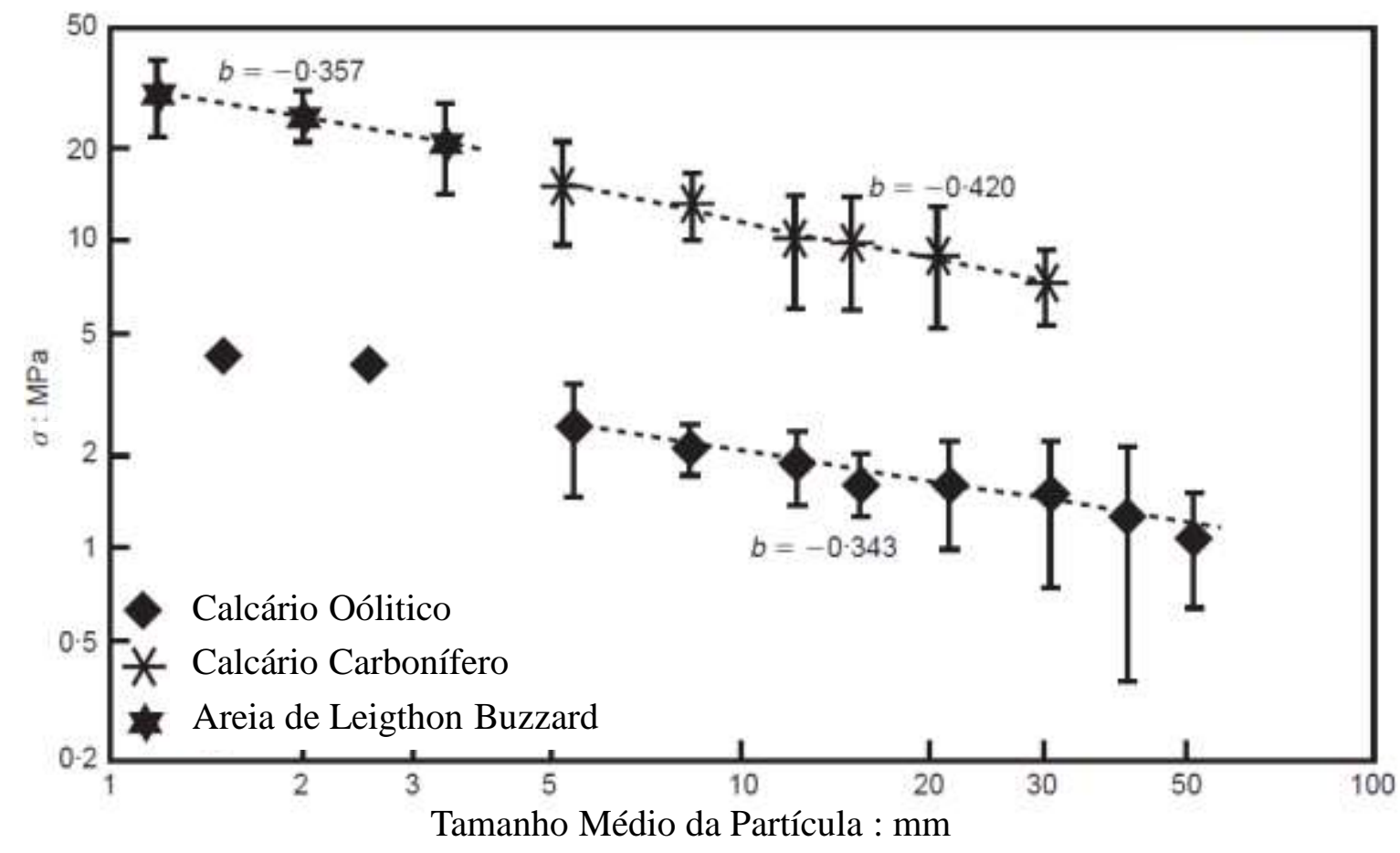

Figura 2.44. Tensão de tração média em função do diâmetro da partícula (McDowell \& Bolton, 1998).

\subsection{2 Índices de Quebra}

Várias propostas de índices de quebra têm surgido das pesquisas desenvolvidas desde de 1960, quando começaram os primeiros trabalhos. Todas as medidas de quebra têm uma relação direta ou indireta com as curvas granulométricas de antes e depois do ensaio. Existem desde propostas simples, onde a comparação é feita pela mudança de algum diâmetro 
característico da distribuição granulométrica, até metodologias mais elaboradas, onde se consegue quantificar a dimensão fractal da amostra. Alguns desses índices são apresentados a seguir.

Lee e Farhoomand (1967) executaram ensaios sobre condições de compressão anisotrópicas em areias, avaliando o efeito a quebra de partículas no comportamento de materiais empregado para barragens. $\mathrm{O}$ índice proposto consiste na comparação do $D_{15}$ para as condições do antes e depois do ensaio, mediante a seguinte fórmula:

$$
B=\frac{D_{15 \text { inicial }}}{D_{15 \text { final }}}
$$

Marsal (1980) realizou várias pesquisas para estudar o comportamento de materiais granulares, tendo como principal finalidade o entendimento para a aplicação em barragens. A proposta consiste na avaliação das mudanças individuais entre a distribuição inicial e final. Para o cálculo do índice $B_{g}$ são calculadas as diferenças da porcentagem retida para cada tamanho, mediante a seguinte equação:

$$
\Delta W_{k}=W_{k f}-W_{k i}
$$

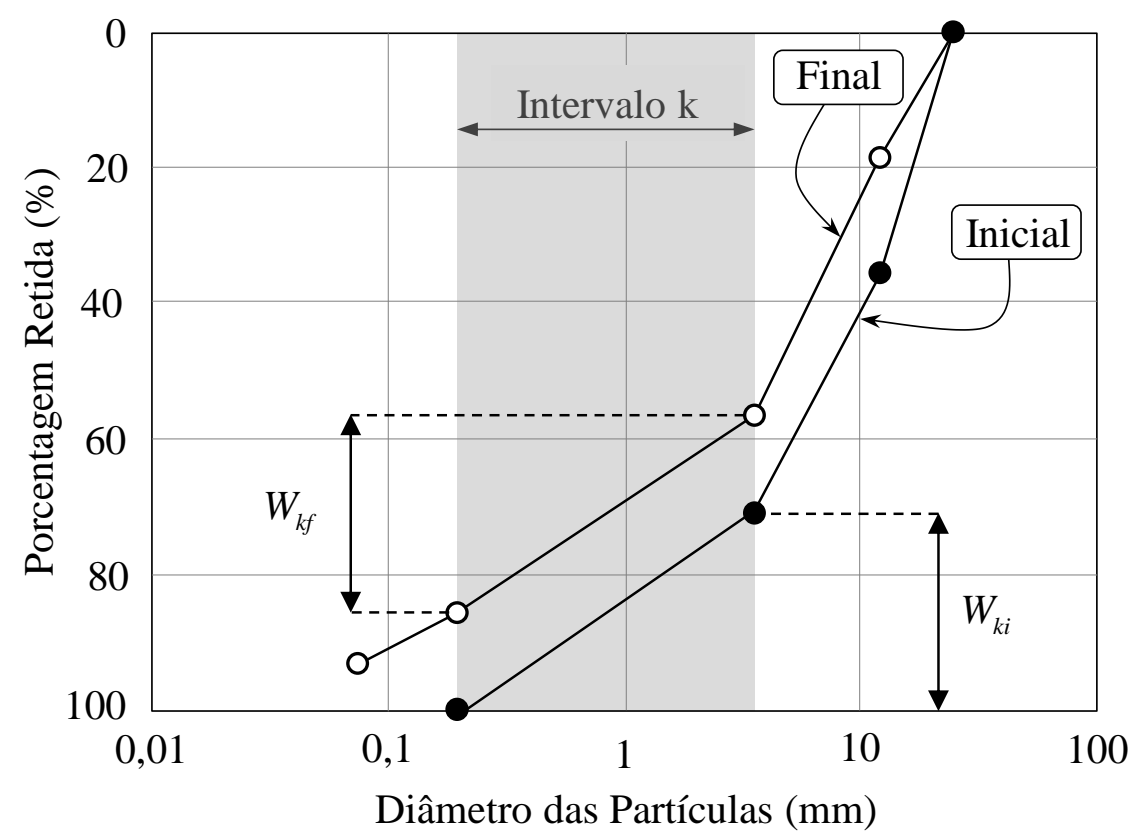

Figura 2.45. Avaliação do índice $B_{g}$

Assim, o cálculo do índice $B_{g}$ é dado por:

$$
B_{g}=\sum_{k=1}^{n}\left\langle\Delta W_{k}\right\rangle
$$


onde

$$
\Delta W_{k}=\left\{\begin{array}{l}
\Delta W_{k}<0 \rightarrow\left\langle\Delta W_{k}\right\rangle=0 \\
\Delta W_{k} \geq 0 \rightarrow\left\langle\Delta W_{k}\right\rangle=\Delta W_{k}
\end{array}\right.
$$

Este índice só soma os valores positivos de $\Delta W_{k}$. No caso de não acontecer quebra $B_{g}=0 \%$, e o limite superior seria $100 \%$, correspondente à quebra máxima que o material pode sofrer.

Hardin (1985) propõe uma medida levando em consideração a mudança de toda a curva granulométrica, definindo duas quantidades diferentes. A primeira é a quebra potencial, $B_{p}$, correspondente à área abaixo da curva granulométrica original. A segunda é a quebra total, $B_{t}$, definida como área entre as curvas granulométricas inicial e final. Uma restrição imposta na hora de fazer as contas é que as áreas só serão calculadas para diâmetros superiores a 0,074 (peneira \#200). A Figura 2.46 ilustra como são obtidos os diferentes parâmetros desta metodologia. O cálculo do índice de quebra é dado por:

$$
B_{r}=\frac{B_{t}}{B_{p}}
$$

onde $B_{r}$ foi chamado de índice de quebra relativa. $\mathrm{O}$ valor máximo corresponde à unidade (quebra máxima) e o mínimo é igual a zero (sem quebra).
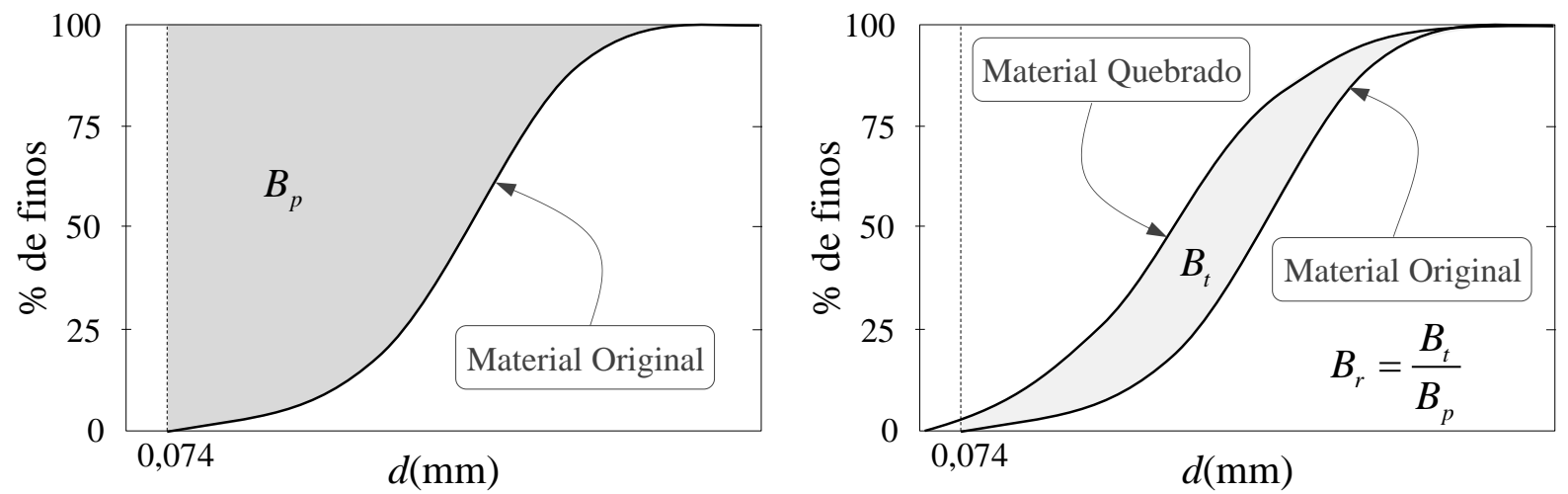

Figura 2.46. Metodologia para a obtenção do índice de quebra relativo $B_{r}$ (modificado Cantor et al., 2015)

Lade et al. (1996) propuseram um novo índice com o objetivo de estimar a permeabilidade do material resultante do processo de quebra. Como várias correlações da 
permeabilidade na literatura estão baseadas no diâmetro efetivo, equivalente a $10 \%$ dos finos ( $D_{10}$ ), a proposta de medida de quebra foi:

$$
B_{10}=1-\frac{D_{10 f}}{D_{10 i}}
$$

onde $D_{10 i}$ e $D_{10 f}$ são os diâmetros efetivos da gradação inicial e final, respectivamente. O limite inferior deste índice é zero, relacionado com a não existência da quebra. O limite superior é quando esta medida é a unidade, correspondendo a quebras de partículas infinita.

A geometria fractal se fundamenta no fato de que um objeto geométrico quando se divide em partes, cada uma destas guarda a semelhança com a original (Mandelbrot, 1982). Uma análise fractal pode ser feita com a finalidade de descrever as alterações na mudança da distribuição de tamanhos dos grãos. Turcotte (1986) faz um estudo da fragmentação com uma abordagem fractal, para uma ampla variedade de materiais, encontrando que existe uma relação entre o número de partículas e seu tamanho. A equação matemática para descrever esta relação é:

$$
N(L>d)=A \cdot d^{-D}
$$

onde $N(L>d)$ é o número de fragmentos que tem um diâmetro de tamanho $L$ maior que o tamanho $d, A$ é uma constante de proporcionalidade e $D$ é a dimensão fractal.

Posteriormente, Tyler \& Wheatcraft (1992) desenvolveram com teoria fractal uma equação normalizada relacionando a massa do material com os diâmetros das partículas, expressada como:

$$
\frac{M\left(<R_{i}\right)}{M_{T}}=\left(\frac{R_{i}}{R_{\text {máx }}}\right)^{3-D}
$$

onde $M(R<r)$ é a massa acumulada das partículas com um $R$ menor a $r, M_{T}$ é a massa total das partículas, $r$ é a abertura da peneira e $R_{\text {máx }}$ é o tamanho máximo. Deve-se destacar que está expressão é bastante útil para a aplicação a engenharia geotécnica, já que trabalhar com massa sempre é mais simples do que trabalhar com número de partículas.

A dimensão fractal para materiais granulares varia entre 1,5 e 2,5 (Torregroza-Aldana, 2007). Vários autores reportam que os valores máximo de dimensão fractal, no processo de fragmentação, estão em torno de 2,5-2,6 para materiais submetidos a quebra pura (Turcotte, 
1986; McDowell \& Bolton, 1998; Daniell \& McDowell, 2001). Para obter a dimensão fractal de um material bastaria reescrever a equação 2.23 da seguinte forma:

$$
\log \left(M\left(<R_{i}\right)\right)=(3-D) \cdot \log \left(R_{i}\right)-\left[(3-D) \cdot \log \left(R_{\text {máx }}\right)-\log \left(M_{T}\right)\right]
$$

e depois plotar os dados experimentais de $R_{i}$ contra $M$ da forma que se encontram na Figura 2.47 para a obtenção da dimensão fractal.

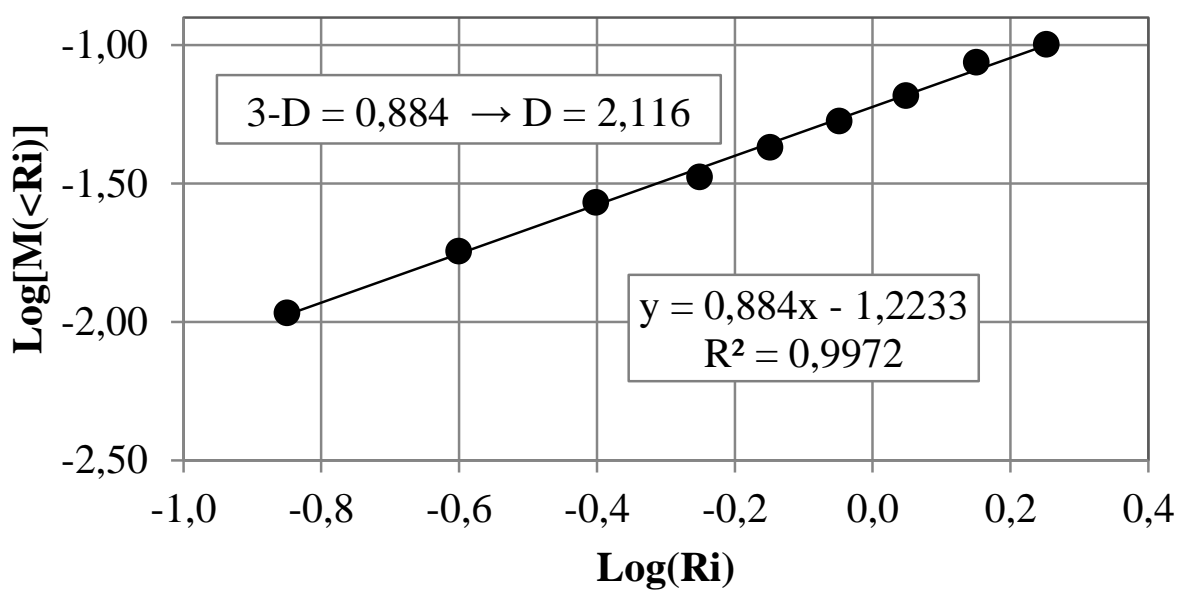

Figura 2.47. Determinação da dimensão fractal de um solo real (Ghanbarian \& Daigle, 2015).

\subsubsection{Quebra da Amostra de Solo}

Durante a década de 1960, programas experimentais pioneiros foram realizados em diversos materiais de barragens de enrocamento, e esses resultados ainda são uma referência para engenheiros e pesquisadores. A quebra dos grãos comumente ocorre quando um material granular sofre compressão e cisalhamento, especialmente para níveis de tensões confinantes altas. A longo do desenvolvimento das pesquisas das últimas décadas foram concebidas várias técnicas experimentais para o entendimento dos materiais granulares, tais como triaxiais de altas pressões e ensaios de compressão confinadas unidimensionais (com e sem leitura das tensões laterais). A seguir serão descritas brevemente os principais trabalhos realizados até hoje.

Lee \& Farhoomand (1967) estudaram a compressibilidade de solos granulares e os possíveis efeitos das quebras submetidas a altas pressões, que ajudassem à concepção de projeto de filtros em barragens de grande porte. Realizaram um programa de ensaios de compressão anisotrópica com a finalidade de avaliar a influência do seguintes fatores: $(a)$ tamanho da partícula, $(b)$ forma da partícula, $(c)$ distribuição granulométrica, $(d)$ intensidade do carregamento, e $(e)$ anisotropia do carregamento. Na Figura 2.48 são apresentados os 
resultados de avaliação da quebra para diferentes materiais, mostrando a influência do tamanho da partícula. O fenômeno de quebra fica mais acentuado para tamanhos maiores. $\mathrm{Na}$ Figura 2.49 são plotados os resultados de quebra para diferentes condições de carregamento, mostrando que o efeito da quebra é mais forte com o aumento da anisotropia do carregamento.

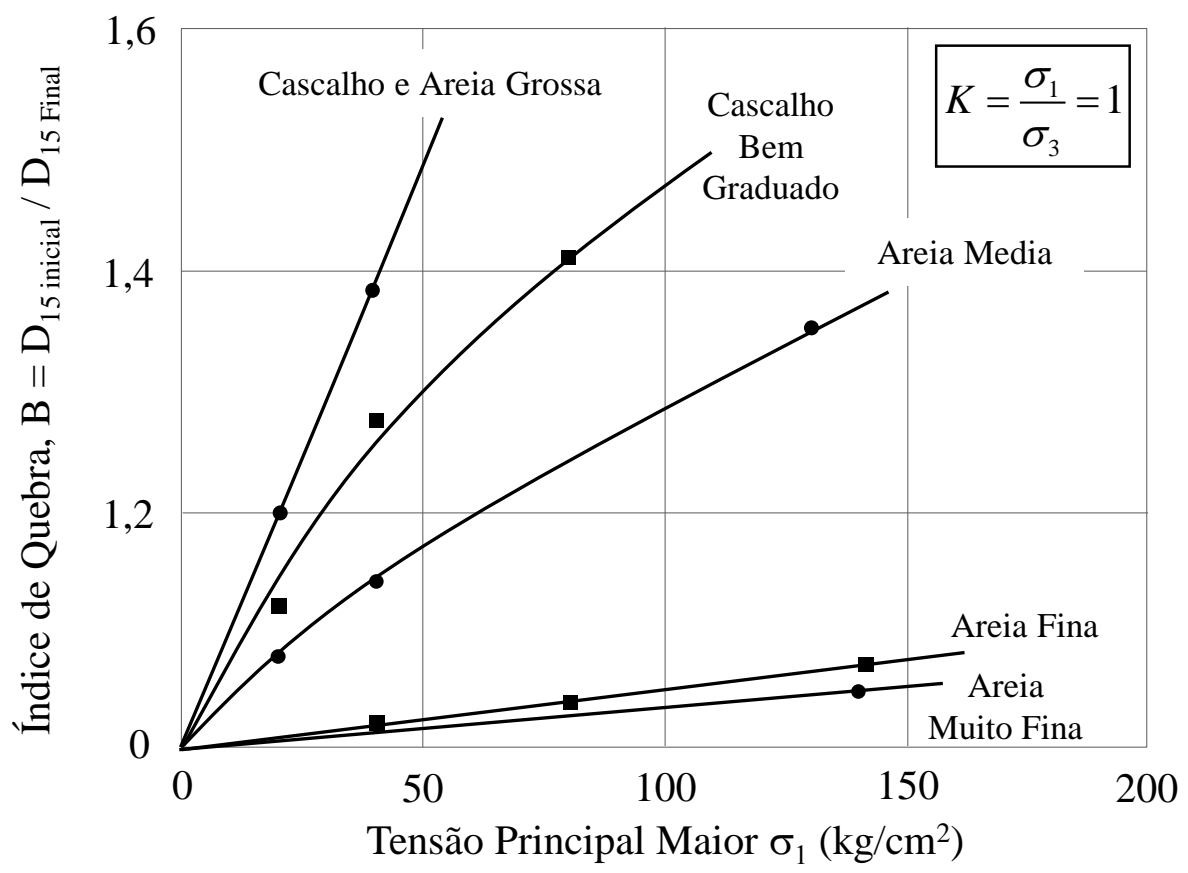

Figura 2.48. Efeito da quebra para diferentes tamanho de partículas iniciais (Lee \& Farhoomand, 1967).

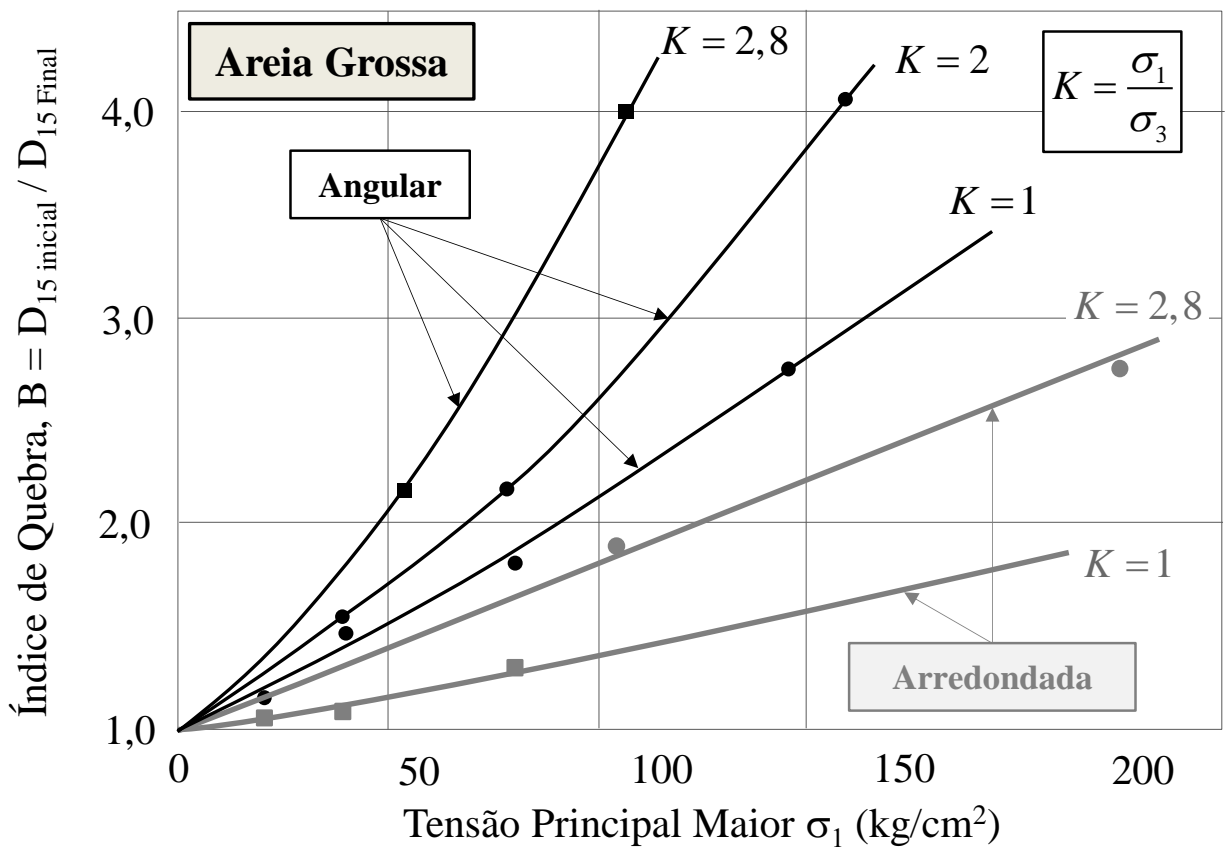

Figura 2.49. Efeito da quebra para diferentes condições de carregamento (Lee \& Farhoomand, 1967) 
Lo \& Roy (1973) estudaram o comportamento cisalhante de três areias angulares com as granulometrias inicias similares, mas com composições mineralógicas diferentes. Realizaram ensaios triaxiais convencionais levando o material a níveis de tensão confinantes altas. Este trabalho mostra como o comportamento tensão deformação está intimamente ligado com a resistência da partícula. Na Figura 2.50 é apresentada a variação volumétrica para os três materiais, mostrando que as intensidades de quebra alteram totalmente o comportamento.

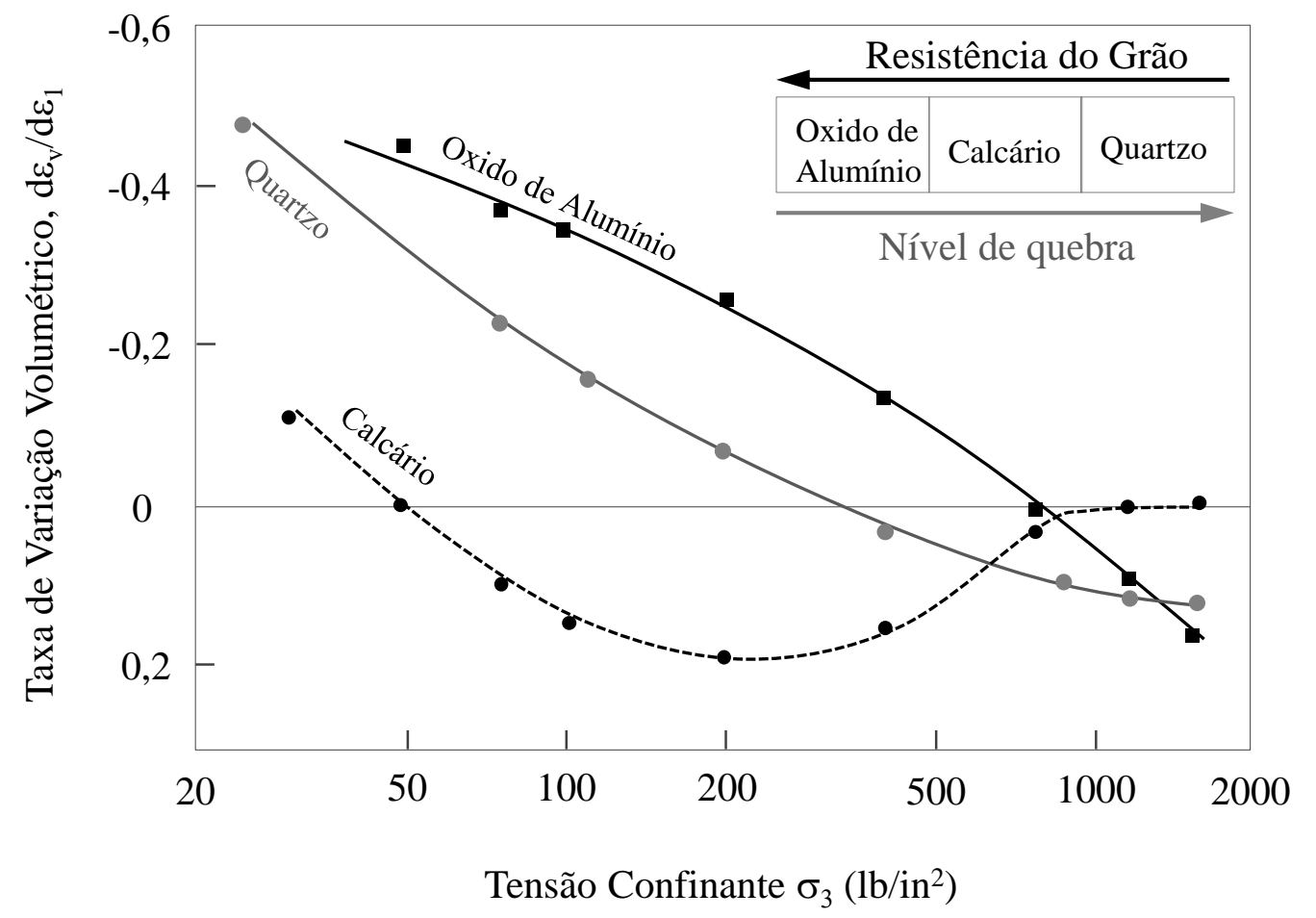

Figura 2.50. Variação volumétrica com o nível de confinamento (Lo \& Roy, 1973).

Miura \& O-hara (1979) estudaram a quebra de partículas mediante a execução de ensaios triaxiais para carregamentos estáticos e repetitivos. Além disso, realizaram uma análise em termos de energia, na qual se estabeleceu que o incremento da área superficial das partículas $(\Delta S)$, que é uma medida da quebra, está relacionado com o trabalho plástico $(W)$ induzido pelo carregamento. Na Figura 2.51 mostra-se como esta relação acontece, evidenciando que existe um excelente ajuste entre estas duas variáveis com base em resultados de vários ensaios do mesmo material com diferentes níveis de confinamento.

Lade et al. (1996) propõem trabalhar com a energia total para correlacionar com os valores de quebra. No caso de materiais em que a quantidade de quebra é significativa, a energia elástica é desprezível, assim, a diferença da energia total em relação à energia plástica 
é pequena. Esta hipótese simplifica bastante os cálculos. A correlação com esta medida é excelente, como pode ser observado na Figura 2.52, existindo uma única relação para todos os ensaios.

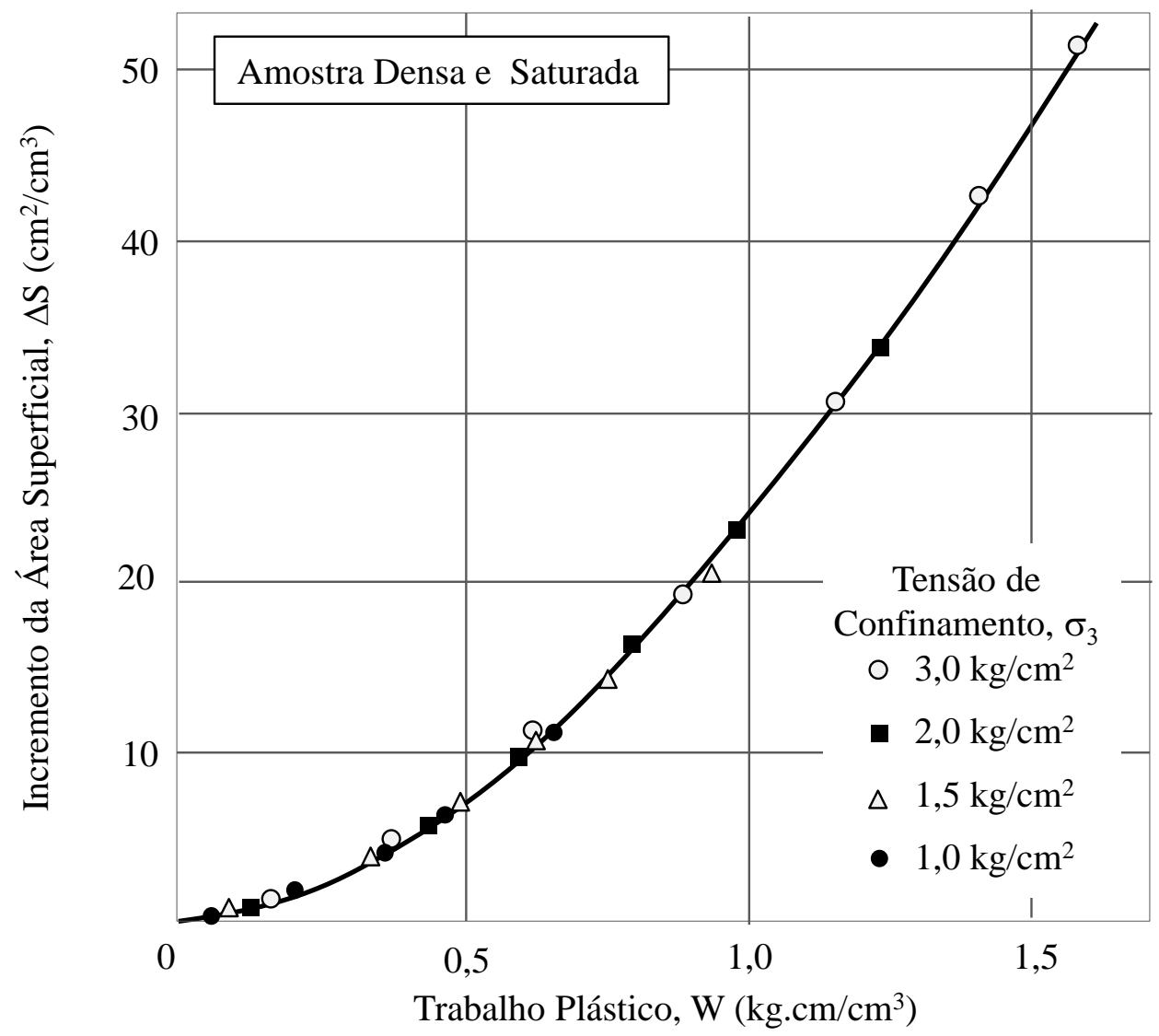

Figura 2.51. Relação entre o incremento da área superficial e o trabalho plástico para ensaios de compressão triaxial drenados (Miura \& O-hara, 1979).

Além dos trabalhos apresentados, na literatura são observados vários resultados experimentais do efeito. Normalmente estes mostram o processo de quebra utilizando alguma das avaliações de quebra citadas previamente e comparadas com o nível de tensões (quase a maioria dos trabalhos) ou com alguma medida da energia (poucos) (Hagerty et al., 1993; Yamamuro et al., 1996; Nakata et al., 1999; Cheng et al., 2001; Nakata, 2005; Engin et al., 2014).

Deve-se destacar que nos últimos anos a comunidade científica tem incorporado algumas ferramentas modernas para a avaliação dos processos de quebra. Um exemplo disto é apresentado na Figura 2.53, na qual se mostra como é o processo de fratura progressiva da partícula com o nível de tensão. Esta pesquisa desenvolveu um mini ensaio de compressão unidimensional com uma lente de vidro num dos extremos do molde, possibilitando a obtenção de imagens das partículas (Cheng et al., 2001). 


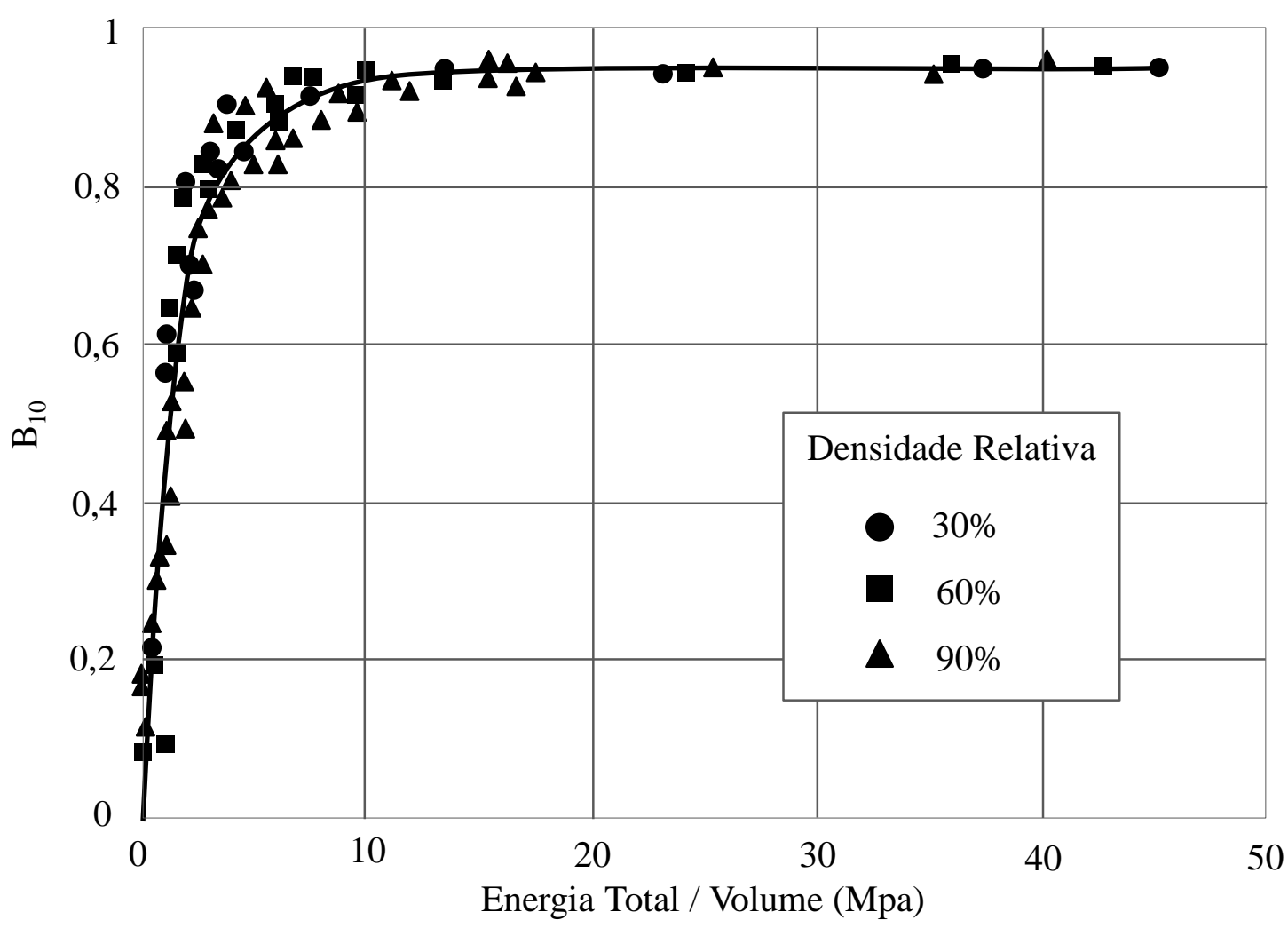

Figura 2.52. Quebra em função da energia total do sistema (Lade et al., 1996).

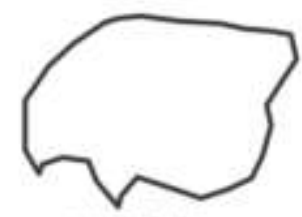

(A) $0 \mathrm{MPa}$

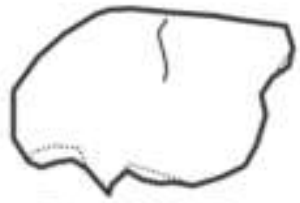

(B) $0,63 \mathrm{MPa}$
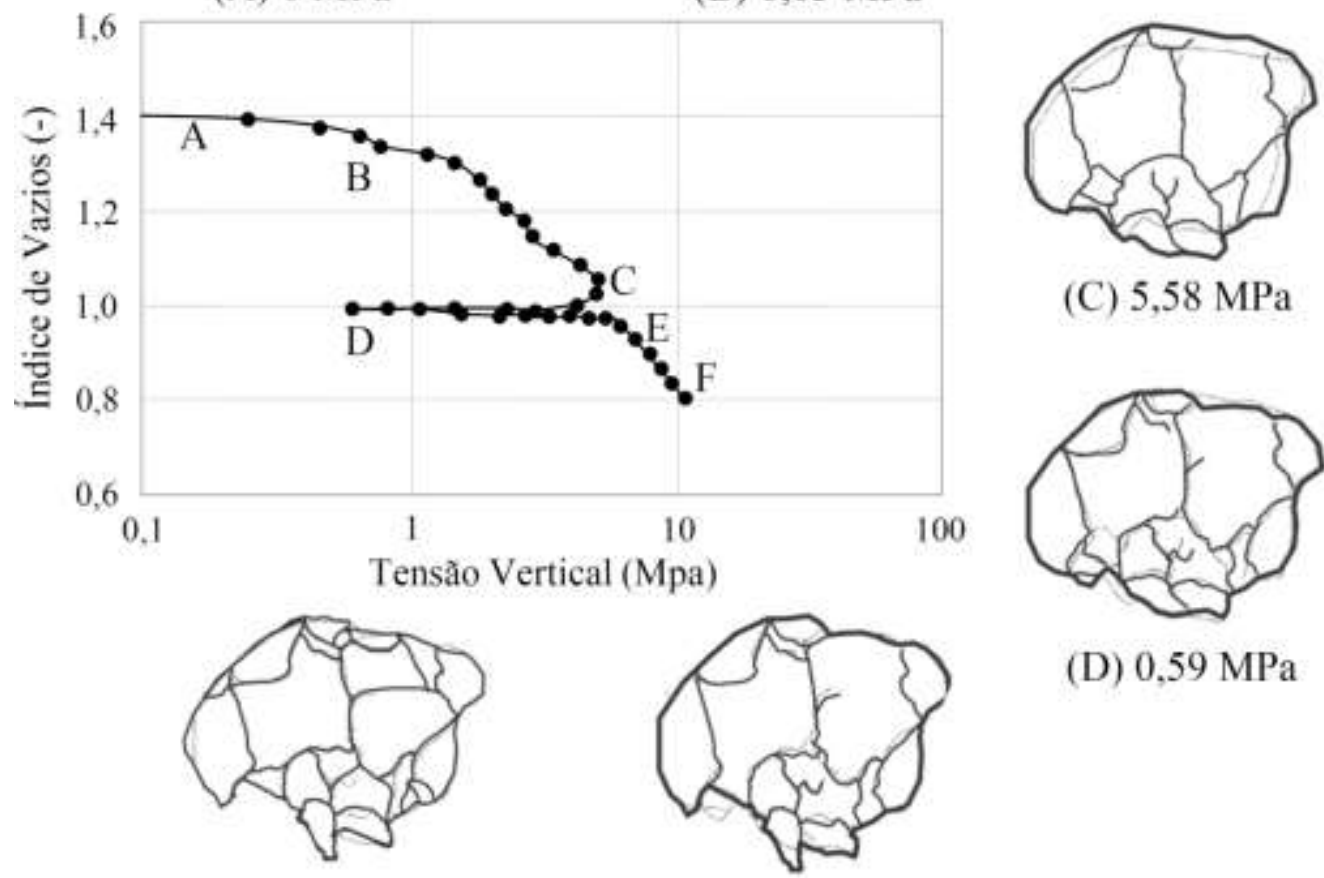

(C) $5,58 \mathrm{MPa}$

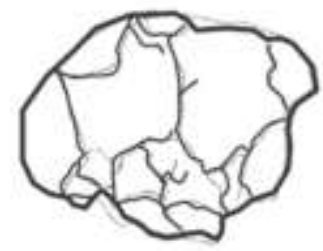

(D) $0,59 \mathrm{MPa}$

(F) $10,00 \mathrm{MPa}$

(E) $5,92 \mathrm{MPa}$

Figura 2.53. Processo de fratura do grão (modificado Cheng et al., 2001). 


\subsection{TÉCNICA DE EMISSÕES ACÚSTICAS (EA)}

As ondas elásticas geradas pela libertação súbita de energia de um material, são chamadas de emissões acústicas. A técnica de monitoramento de emissões acústicas (EA) é considerada uma ferramenta poderosa para entender o comportamento das deformações de materiais carregados. Um equipamento de emissões acústicas capta as ondas emitidas pelo fraturamento das partículas de solo ou de outros mecanismos de danos no interior do material (Michlmayr et al., 2012).

O funcionamento do equipamento é baseado no efeito piezométrico, mediante o qual os sensores capturam as ondas acústicas e as convertem em campos elétricos. Uma vez obtida a onda pelo receptor piezoelétrico, o sinal é levado para um pré-amplificador, que ajuda a melhorar a qualidade da informação, dependendo do tipo de aplicação. Posteriormente, a informação é transmitida a um sistema de aquisição dados, para a conversão do sinal em informação digital. Finalmente, é feito o processamento desses sinais para a interpretação física de cada aplicação. Na Figura 2.54, são ilustradas as componentes de um sistema de emissão acústicas.

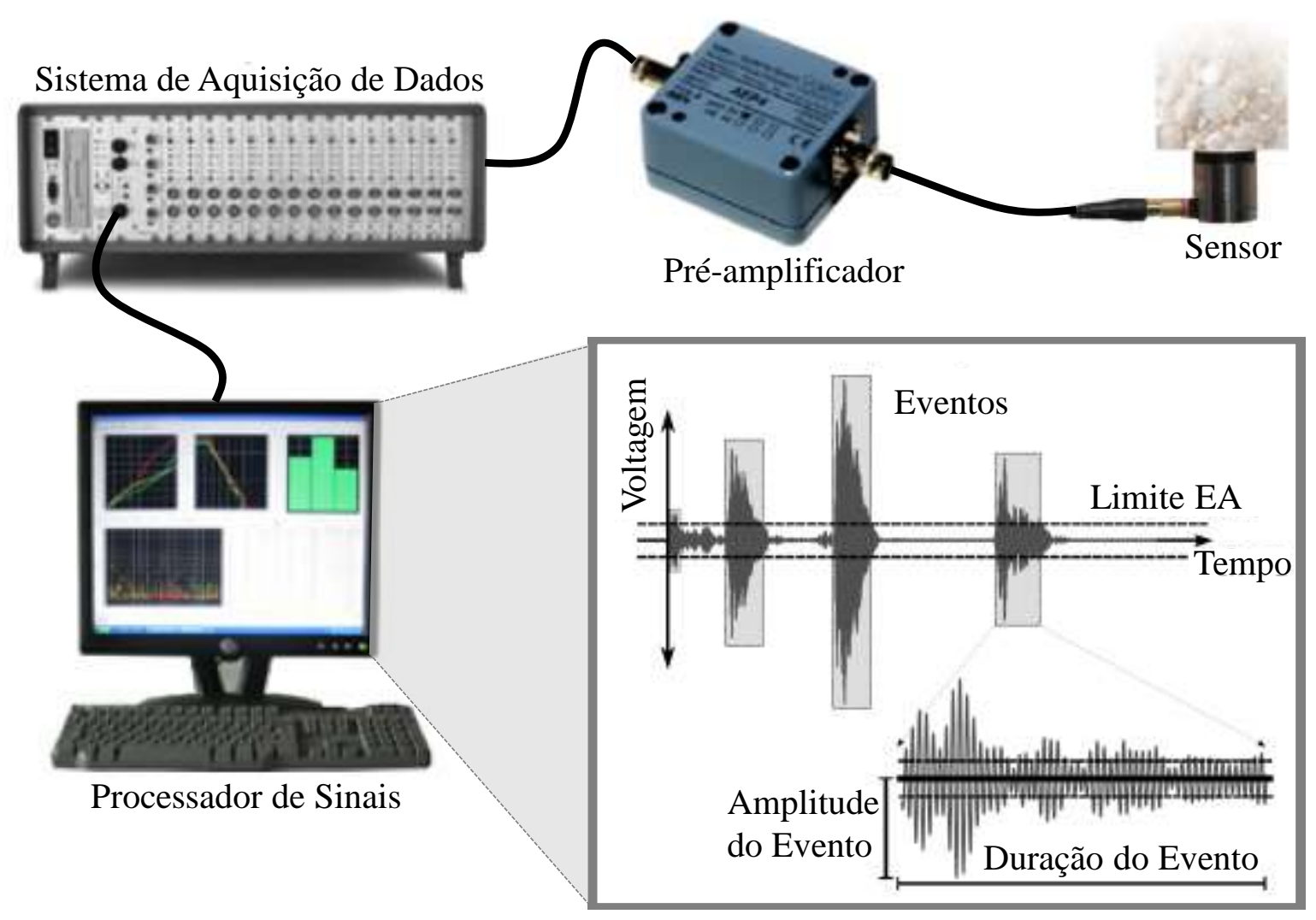

Figura 2.54. Componentes da técnica de emissões acústicas (Michlmayr et al., 2012). 
As principais caraterísticas das emissões acústicas estão ilustradas na Figura 2.55. Considera-se que um evento de emissão acústica (hit) acontece quando a amplitude do sinal ultrapassa um limite, definido pelo usuário. Este limite é imposto em relação ao material de trabalho e ao tipo de aplicação. O evento termina, quando a amplitude da onda for inferior ao limite. Assim, cada evento se caracteriza pela duração das flutuações da onda acima do limite, e pela amplitude máxima registrada. A contagem do número de vezes que a onda ultrapassa o limite, durante cada evento, é um parâmetro comumente usado para analisar os resultados de emissões acústicas.

Outro parâmetro de interesse para a compreensão dos registros acústicos é a energia PAC (Physical Acoustic Corporation). Esta energia é um parâmetro de dois bytes derivada da integral do sinal da voltagem retificada ao longo da duração do evento acústico (hit). A unidade da energia PAC é micro-volt-segundos por contagem e o intervalo de resposta é de 0 a 65535 em cada hit de EA.

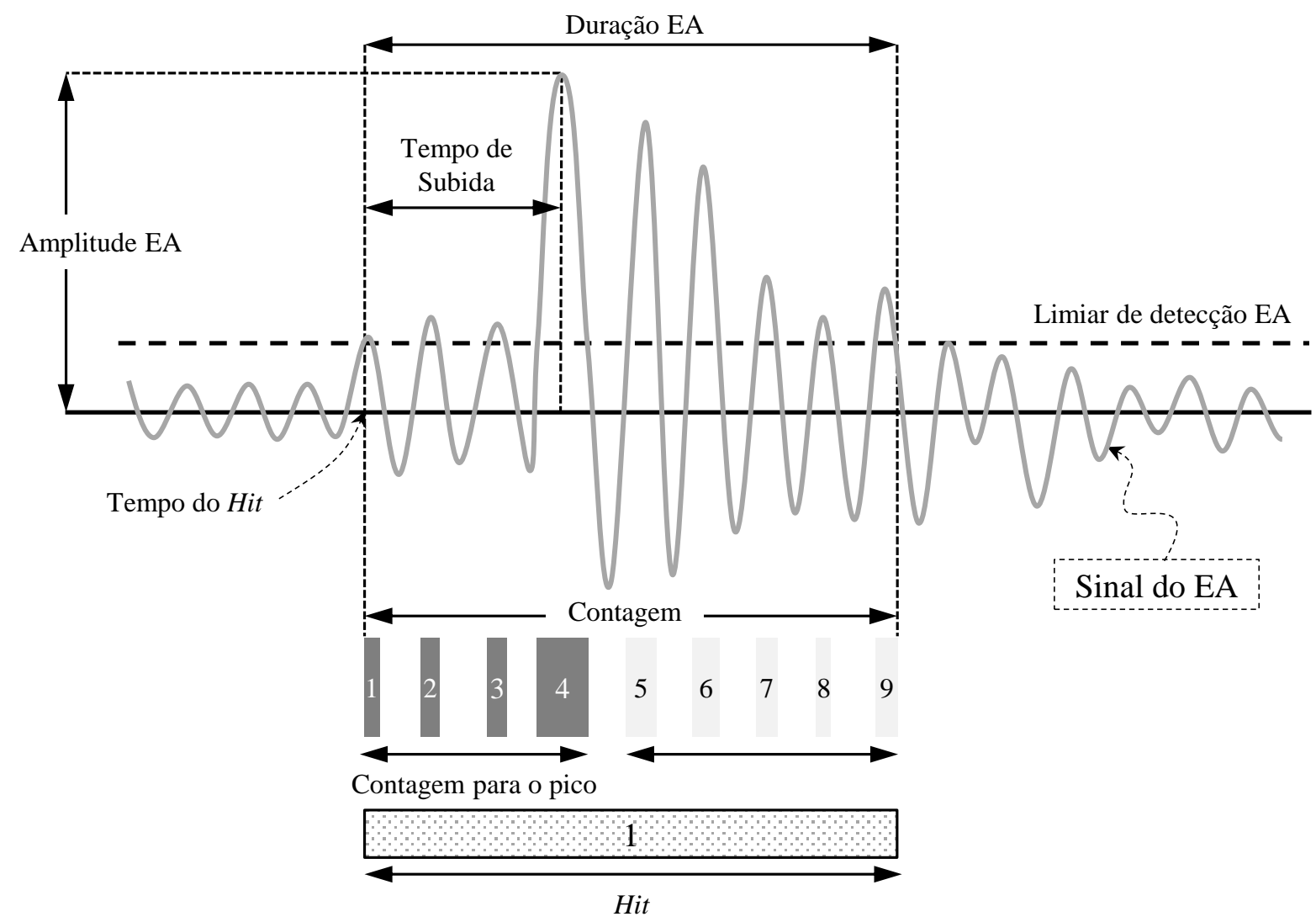

Figura 2.55. Algumas caraterísticas das emissões acústicas.

As primeiras aplicações da técnica de emissões acústicas na engenharia geotécnica foram na área da mecânica das rochas, começando na década de 1930, e estavam relacionadas com a determinação da instabilidade dos maciços e a previsão do colapso nos túneis de 
mineração (Hardy, 1981). No caso da mecânica de solos, os primeiros trabalhos com esta ferramenta são da década de 1960, aplicando de forma similar a técnica para o estudo de estabilidade de taludes. Posteriormente, foram iniciadas pesquisas para o entendimento da resposta de emissões acústicas em solos. Ressaltam-se os trabalhos desenvolvidos pelo professor Robert Koerner da universidade de Drexler (USA), que estudou as emissões acústicas nos ensaios triaxiais sob diferentes condições de carregamento (Koerner et al., 1981). Na Figura 2.56 são apresentados os resultados de um ensaio triaxial com monitoramento acústico, mostrando a correlação existente entre as leituras acústicas e o fenômeno de cisalhamento. Isto foi feito tanto para solos granulares como para solos coesivos, avaliando os efeitos da forma das partículas e da sua distribuição.
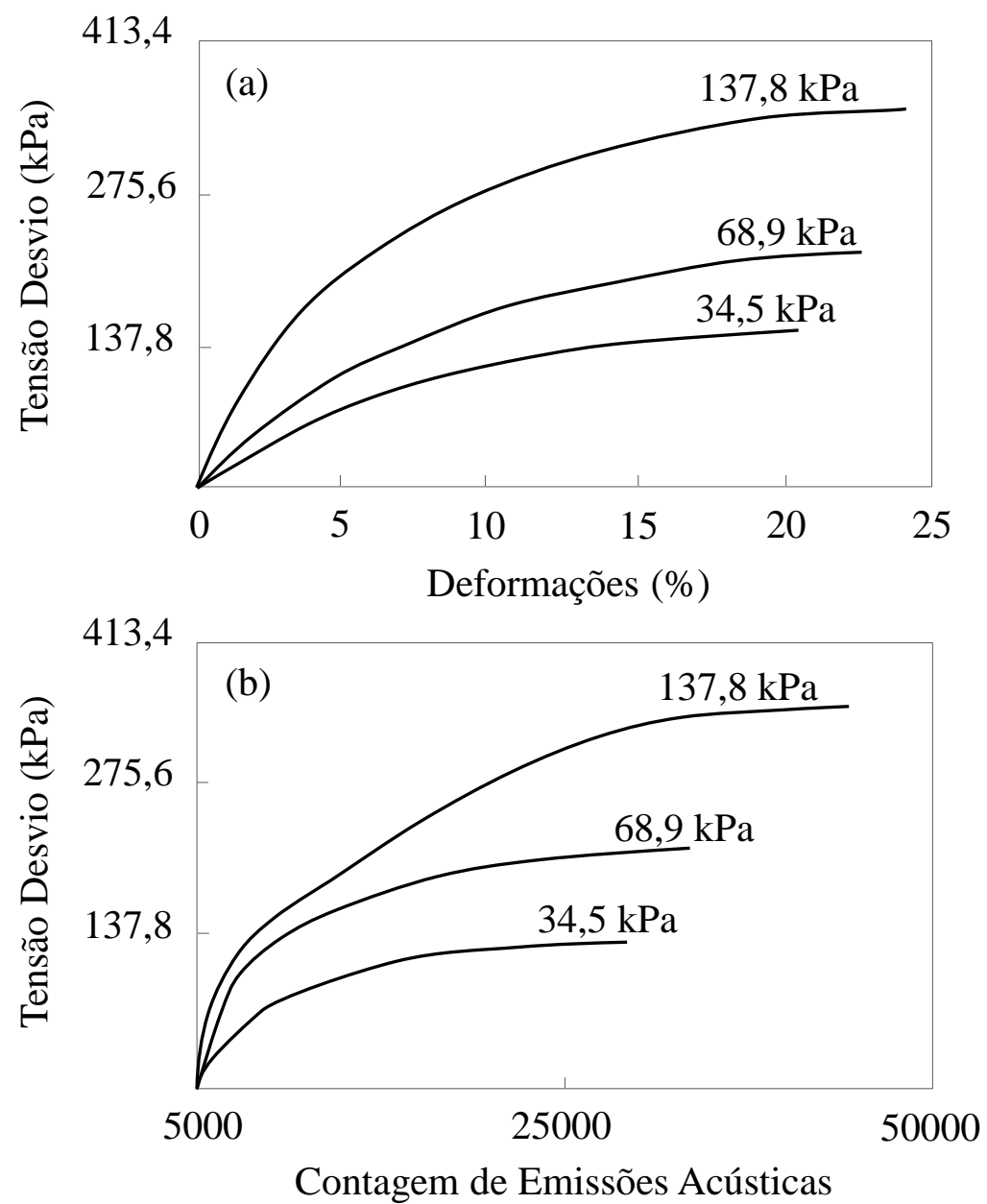

Figura 2.56. Ensaio triaxial como monitoramento acústico (Koerner et al., 1981).

Koerner et al. (1984) focaram seus trabalhos na obtenção da tensão de pré-adensamento com correlações de medidas acústicas. Na Figura 2.57 mostra-se o resultado de um ensaio de compressão unidimensional confinada em areia com monitoramento acústico e as previsões feitas de tensão de pré-adensamento. 


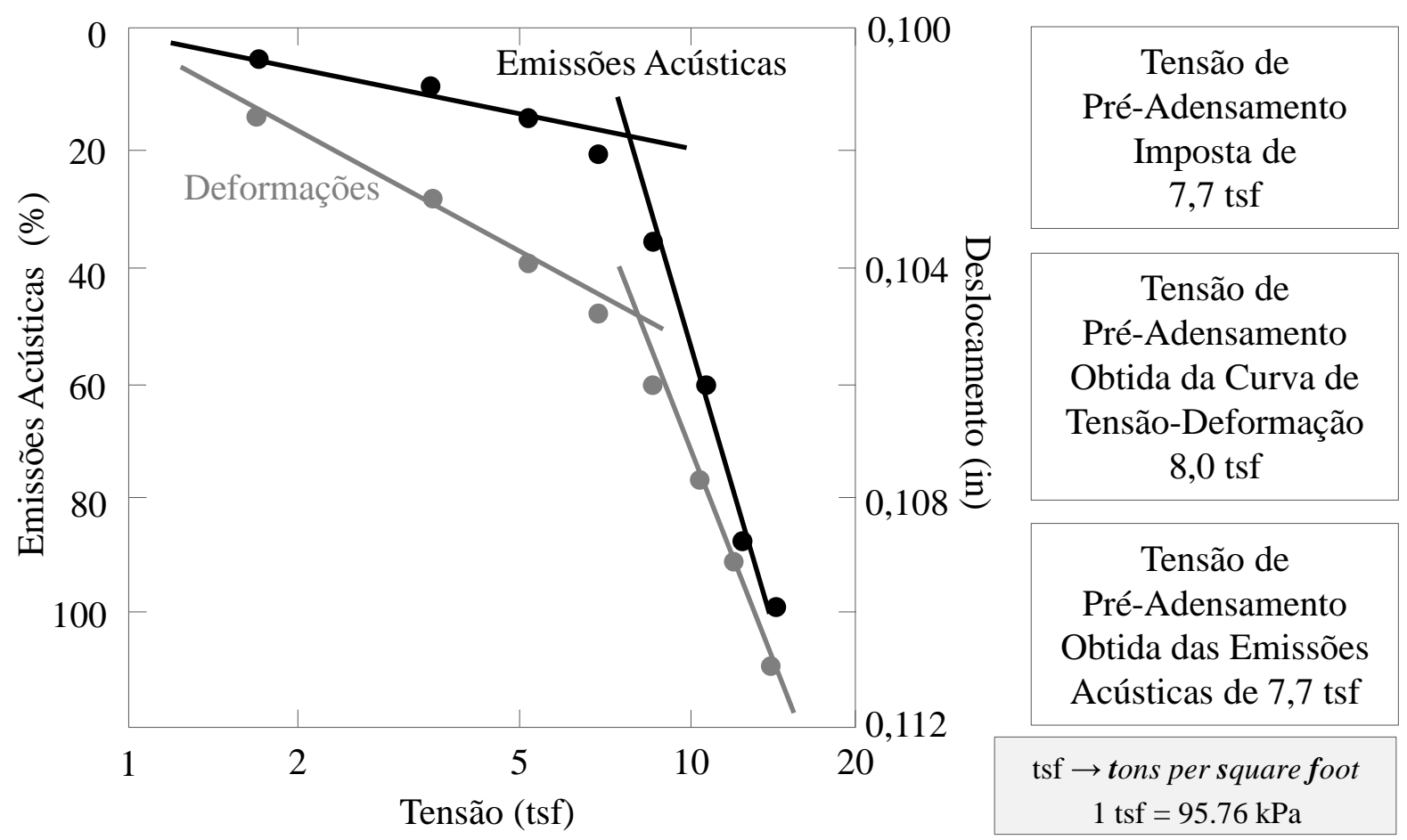

Figura 2.57. Resultados de um ensaio oedométrico em areia seca (Koerner et al., 1984).

Posteriormente a estes trabalhos, as pesquisas se concentraram na correlação de parâmetros do comportamento tensão-deformação e informações das emissões acústicas (EA). Entre os mais relevantes está o desenvolvido por Tanimoto \& Tanaka (1986), que pesquisaram as características dos solos sob condições triaxiais. Os resultados obtidos foram relevantes, conseguindo relacionar alguns estados volumétricos (contração e dilatância) do material com as medidas acústicas. Destaca-se o fato de usarem como critério unicamente os pulsos do sinal que passassem um limite definido (definido como evento acústico ou "hit"). Na Figura 2.58 é apresentado o resultado típico para uma trajetória de compressão isotrópica. Com ajuda desta ferramenta conseguiram construir a superfície de plastificação do material.

Ao longo desses últimos anos, os avanços tecnológicos foram grandes, não obstante, a ideia inicial de usar essa técnica como um subsídio ao entendimento de comportamentos não tem mudado. Michlmayr et al. (2012) fizeram uma compilação do uso das emissões acústicas em geomateriais, mostrando as mudanças tecnológicas nos equipamentos e o ganho de conhecimento.

Um trabalho relevante para esta pesquisa foi apresentado por Fernandes et al. (2010), no qual se ilustra detalhadamente o procedimento para a implementação desta técnica e a sua interpretação, para o caso de ensaio de compressão não confinada de materiais granulares. Nos resultados obtidos mostra-se claramente como se demarcam as fases do processo de compressão, explicadas em itens prévios, com o uso das emissões acústicas (ver Figura 2.59). 


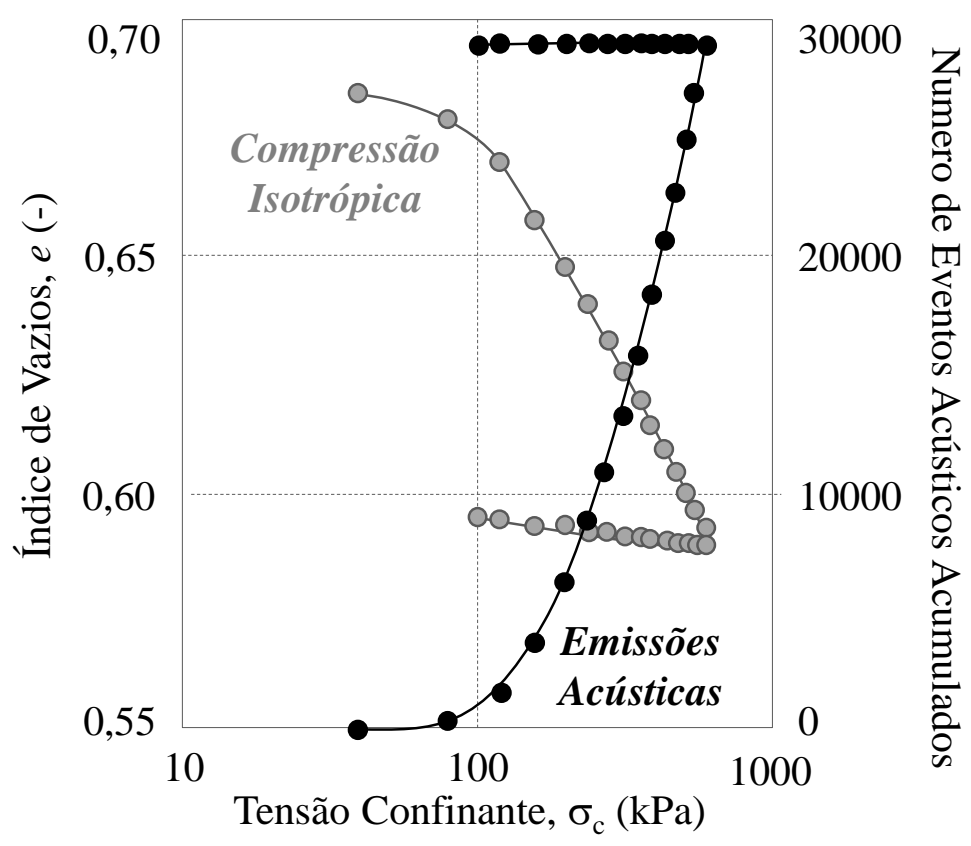

Figura 2.58. Evolução do índice de vazios e da contagem de emissões acústicas acumuladas para um ensaio de compressão isotrópica (Tanimoto \& Tanaka, 1986).

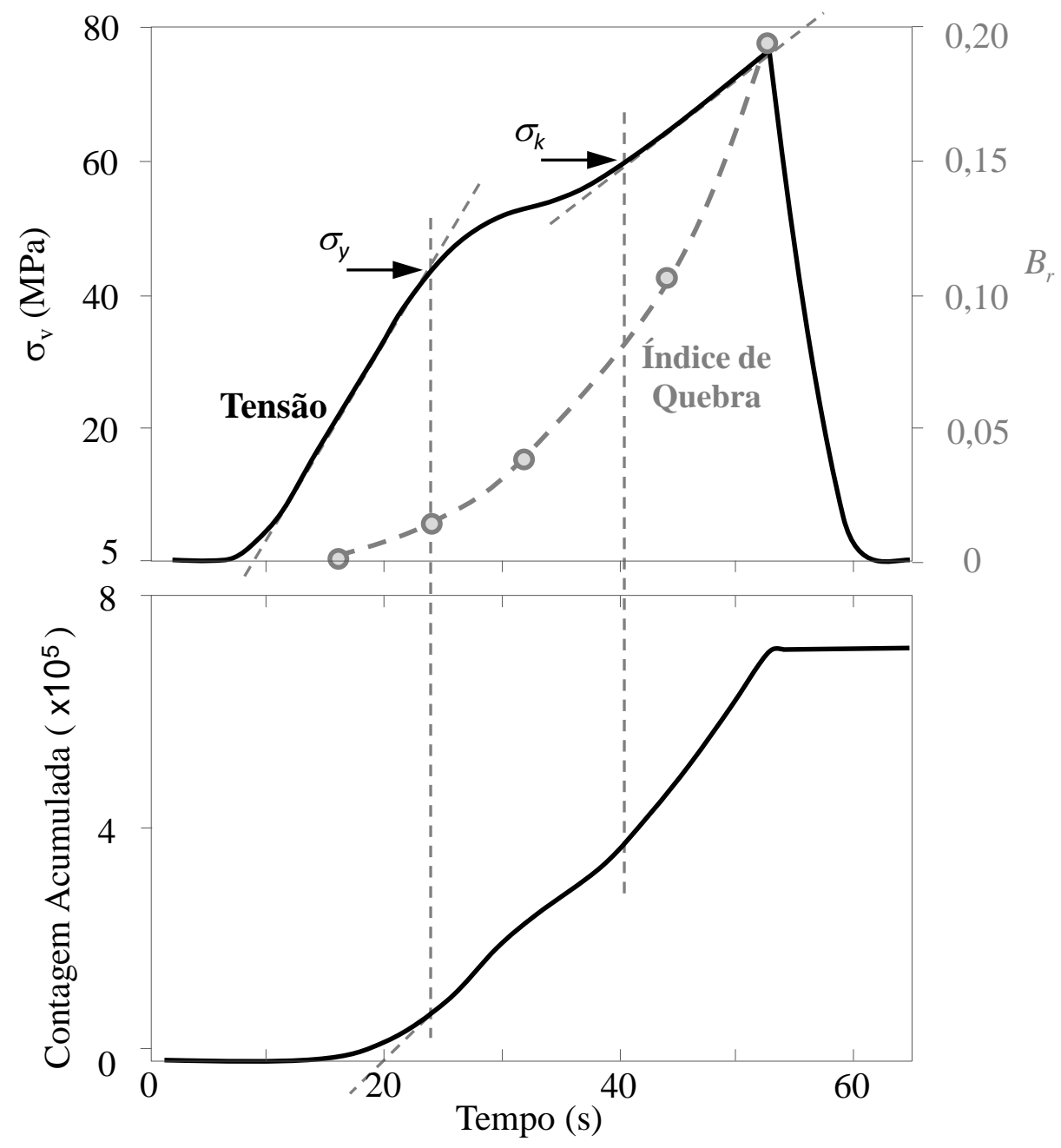

Figura 2.59. Evolução da tensão axial, do índice de quebra $\left(B_{r}\right)$ e a contagem de emissões acústicas acumuladas para um ensaio de compressão confinada (Fernandes et al., 2010). 


\section{METODOLOGIA}

Neste capítulo são descritas as componentes de cada uma das fases adotadas para o desenvolvimento desta pesquisa. Na primeira parte são apresentados os materiais e os métodos necessários para a execução da campanha experimental. Posteriormente, é exposta a abordagem proposta para realizar as simulações micromecânicas.

\subsection{CAMPANHA EXPERIMENTAL}

Esta fase compreende a realização de ensaios de compressão confinada, com esferas de vidro secas, com e sem cimentação, nos quais pode ser observado, claramente, o fenômeno de fragmentação de partículas e desestruturação do solo. A fim de compreender melhor o processo de quebra será realizado o monitoramento das emissões acústicas durante o processo. Além disso, serão realizadas análises granulométricas para avaliar o que ocorre com os grãos durante o processo de compressão. Como complemento, serão registradas imagens microscópicas das partículas, as quais serão úteis para as análises da evolução da forma do grão com o processo de quebra. A seguir são descritos os materiais e métodos usados para a execução desta fase.

\subsubsection{Materiais}

\subsubsection{Esferas de vidro}

Nos ensaios foram utilizadas microesferas de vidro para simular o solo, visando ter um material com geometria semelhante à usada nas simulações discretas. As microesferas utilizadas foram do tipo A170, A072 e AC, segundo classificação da empresa fornecedora (Potters Industrial Ltda.), compostas por vidro do tipo soda cal sem nenhuma sílica livre. Para caraterização do material foram feitos ensaios de granulometria, índice de vazios máximo e mínimo e massa específica aparente. Os resultados da caracterização das microesferas são mostrados na Tabela 3.1 e a curva granulométrica é mostrada na Figura 3.1.

\subsubsection{Agente cimentante}

Utilizou-se epóxi para simular o agente cimentante. Este material é um adesivo estrutural de elevada resistência mecânica que possui caraterísticas de endurecimento rápido, tendo diferentes aplicações dentro da indústria da construção. Nesta pesquisa, esse material foi utilizado para simular as condições de solos cimentados, mediante a mistura epóximicroesferas, sendo avaliado o efeito da cimentação no comportamento de compressão 
unidimensional, mantendo constante a velocidade de deformação aplicada. O tipo de resina epóxi empregada na confecção de corpos de prova cimentados é o Sikadur 32 fornecido pela empresa SIKA (Tabela 3.2). Destaca-se a relação de mistura das componentes A:B que por recomendação da empresa deve ser 2:1, a qual foi respeitada nessa pesquisa.

Tabela 3.1. Propriedades físicas das microesferas.

\begin{tabular}{lccc}
\hline Propriedade & & Valor \\
\hline Tipo de esferas Potters & $\mathrm{A} 170$ & $\mathrm{~A} 072$ & $\mathrm{AC}$ \\
Índice de Vazios Máximo $e_{\max }$ & 0,65 & 0,69 & 0,85 \\
Índice de Vazios Mínimo $e_{\min }$ & 0,59 & 0,60 & 0,61 \\
Massa Específica dos grãos $\mathrm{G}_{\mathrm{s}}$ & 2,53 & 2,52 & 2,51 \\
Esfericidade $(\%$ min) & 70 & 80 & 80 \\
Coeficiente de Uniformidade $(C u)$ & 1,30 & 1,31 & 1,56 \\
Coeficiente de Curvatura $(C c)$ & 1,14 & 0,91 & 1,04 \\
Diâmetro Médio $\left(D_{50}\right)$ em $\mathrm{mm}$ & 1,80 & 0,92 & 0,180 \\
\hline
\end{tabular}

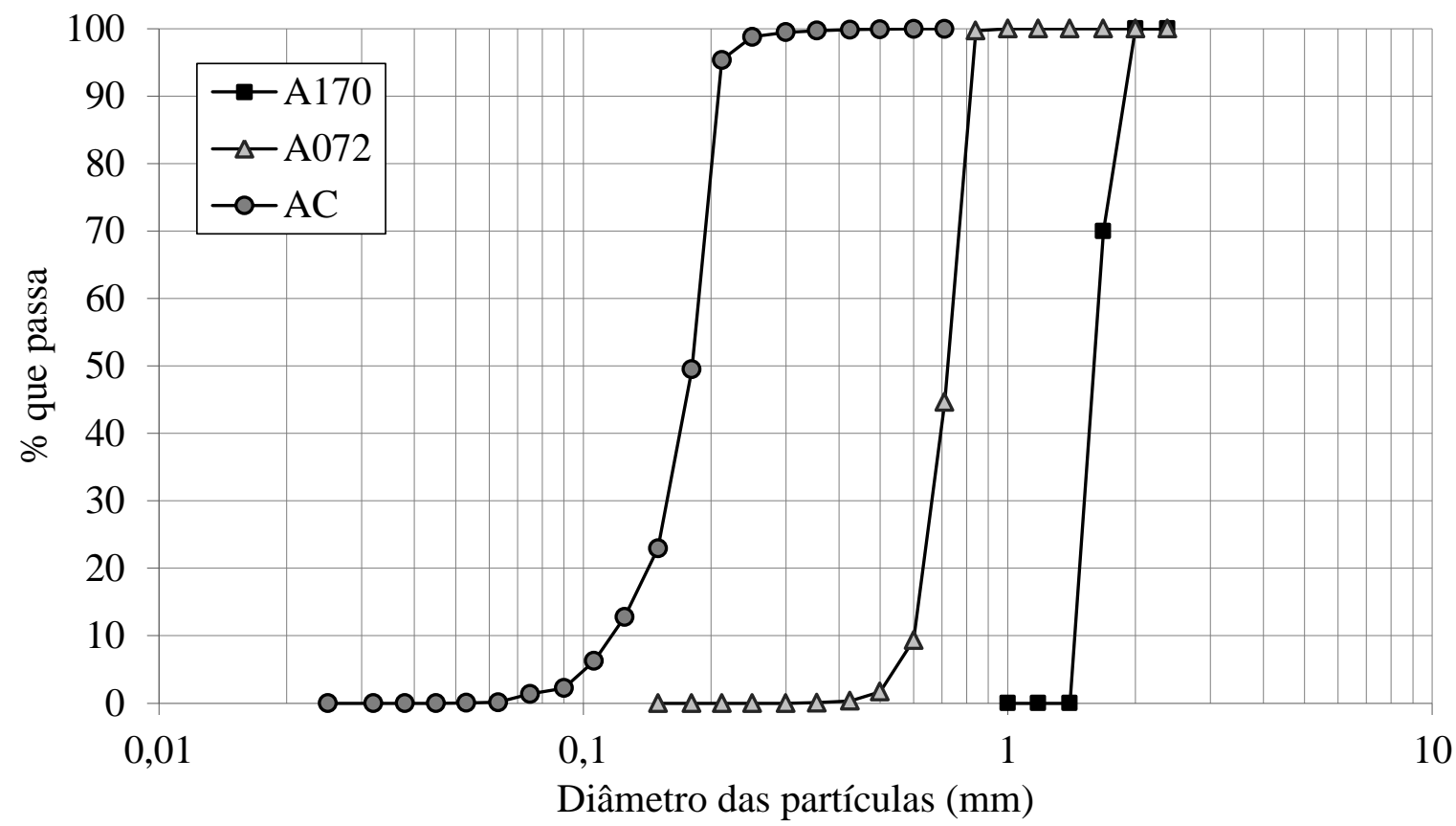

Figura 3.1. Curvas Granulométricas das microesferas.

Tabela 3.2. Dados técnicos da resina epóxi Sikadur 32.

\begin{tabular}{lc}
\hline Características & Especificação \\
\hline Relação de Mistura, em peso & $(\mathrm{A}: \mathrm{B})=2: 1$ \\
Vida útil da mistura (Pot-life) & $35 \mathrm{~min}\left(20^{\circ} \mathrm{C} / 50 \% \mathrm{UR}\right)$ \\
Massa específica & $1,43 \mathrm{~g} / \mathrm{cm}^{3}$ \\
Cura inicial & 5 horas \\
Cura final & 7 dias \\
Temperatura de aplicação & $+10^{\circ} \mathrm{C}$ a $30^{\circ} \mathrm{C}$ \\
Resistencia à compressão & $60 \mathrm{MPa}$ após $24 \mathrm{~h}\left(20^{\circ} \mathrm{C} / 50 \% \mathrm{UR}\right)$ \\
\hline
\end{tabular}




\subsubsection{Preparação de Amostras}

Os procedimentos para a obtenção dos corpos de prova dependeram das características dos elementos envolvidos na sua obtenção, os quais são explicados em itens posteriores. Durante a realização dos ensaios deve-se evitar ao máximo o atrito lateral gerado nas paredes do corpo de prova, para garantir a condição de deformação unidimensional. Este fenômeno é normalmente tratado no caso de solos coesivos mediante o uso de corpos de provas com relação de diâmetro/altura maiores que 2,5 (ASTM International, 2006). No trabalho foram usadas microesferas de vidro e foi estabelecida uma relação diâmetro/altura igual a 0,5 para garantir deformações compatíveis com a o sistema de medições. O problema de atrito foi minimizado utilizando lubrificante nas paredes do cilindro e filmes de plástico. O corpo de prova tem $5 \mathrm{~cm}$ de diâmetro e $10 \mathrm{~cm}$ de altura, para facilitar a percepção dos processos de quebra de partículas e desestruturação do material cimentado (Ver Figura 3.2). A seguir são descritos os procedimentos utilizados para cada um dos tipos de amostras.
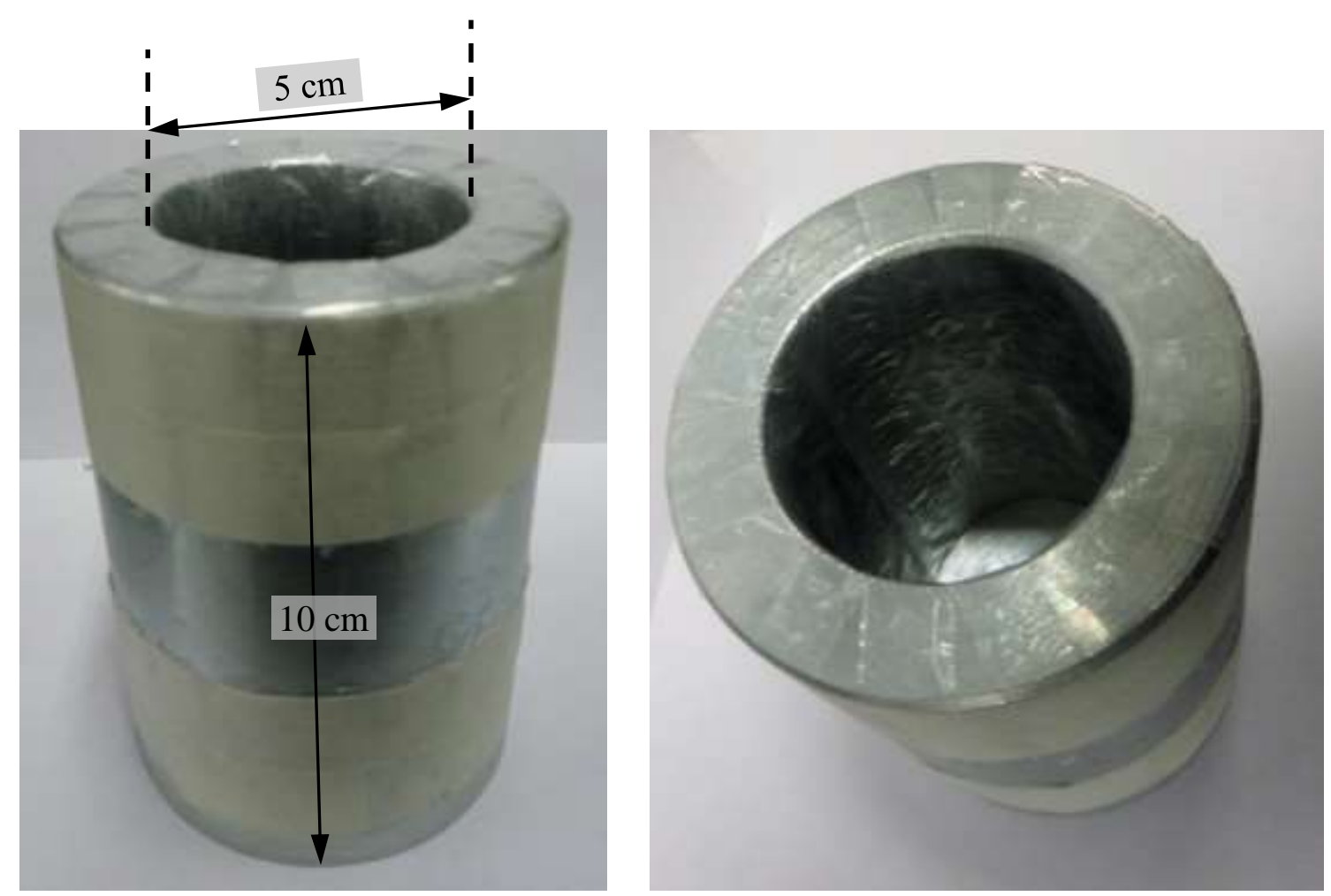

Figura 3.2. Detalhes do corpo de prova.

\subsubsection{Amostras não cimentadas}

Para evitar o atrito lateral das paredes das amostras foram colocadas duas camadas de vaselina e plástico intercaladas entre si, entre a parede do cilindro e as microesferas. O plástico utilizado foi o mais fino possível sem perder a trabalhabilidade, de modo que a quantidade de ar entre o plástico e parede fosse mínima. Deve ser destacado que, por se tratar de corpos de 
prova unicamente de microesferas, o cilindro que servia como molde era o mesmo utilizado na execução do ensaio. O processo para a preparação das amostras é descrito com detalhes a seguir:

1. Colocar duas camadas de vaselina e plástico intercaladas entre si, ver Figura 3.3-a;

2. Cortar os extremos dos plásticos longitudinalmente em várias secções, de modo que facilite a fixação das pontas resultantes no cilindro, como é mostrado na Figura 3.3-b;

3. Ao cilindro do passo anterior é superposto uma guia e depois é feita a deposição das microesferas mediante um funil até atingir a metade da altura da guia (Figura 3.3-c);

4. Colocar um sobrepeso maciço no interior da guia superior e em seguida o material mediante golpes laterais, com uso de um martelo. Os índices de vazios desejados são obtidos mediante tentativa e erro, ver Figura 3.3-d;

5. Tendo o nível de densificação desejado, é retirada a guia superior e o sobrepeso. A seguir, o material excedente é rasado com ajuda com uma régua de aço biselada (ver Figura 3.3-e). Assim o corpo de prova estaria pronto para a execução do ensaio. A seguir, medem-se os dados inicias do corpo de prova, tais como peso, dimensões etc. Na Figura 3.4 é apresentado uma imagem de um corpo de prova do material solto.

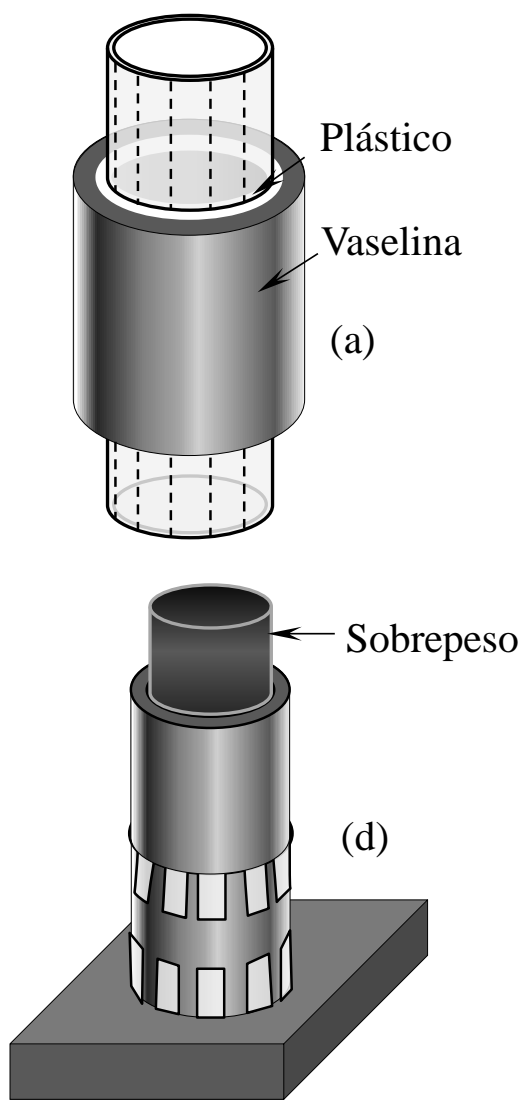

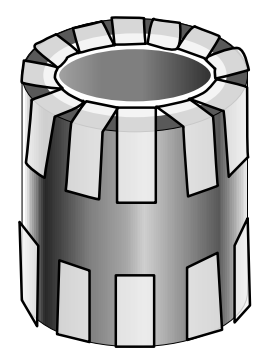

(b)
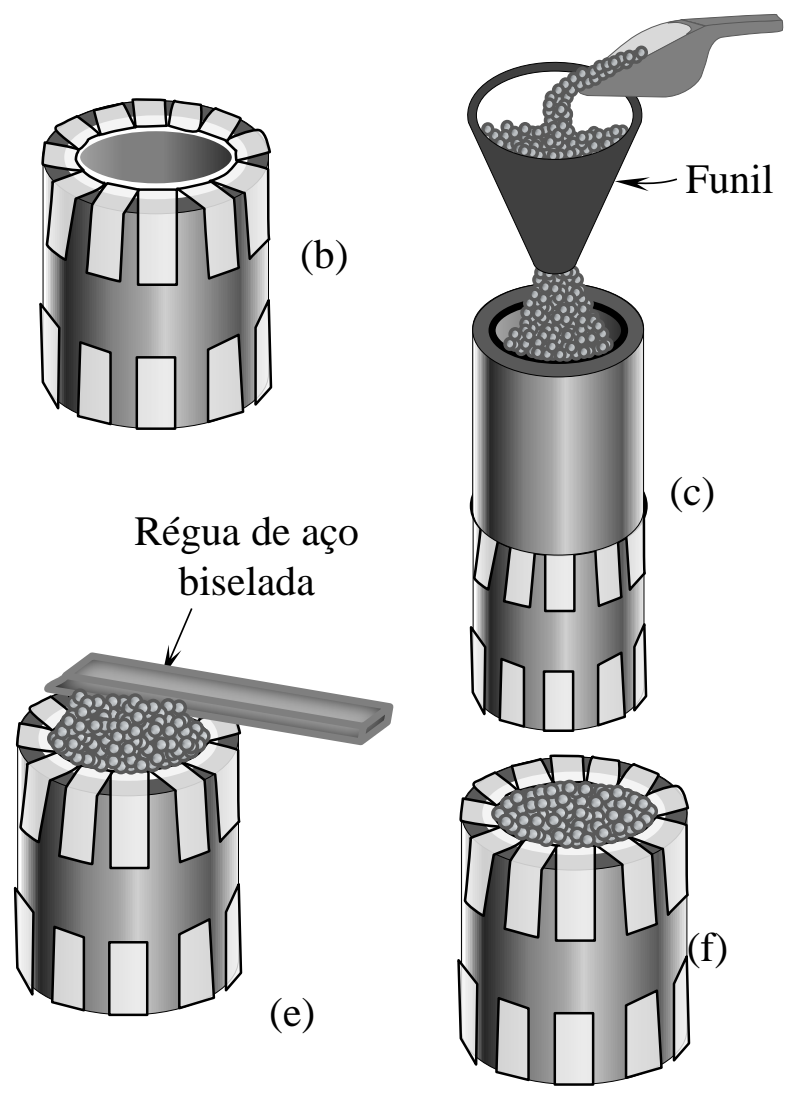

Figura 3.3. Processo de fabricação de amostras com material solto. 

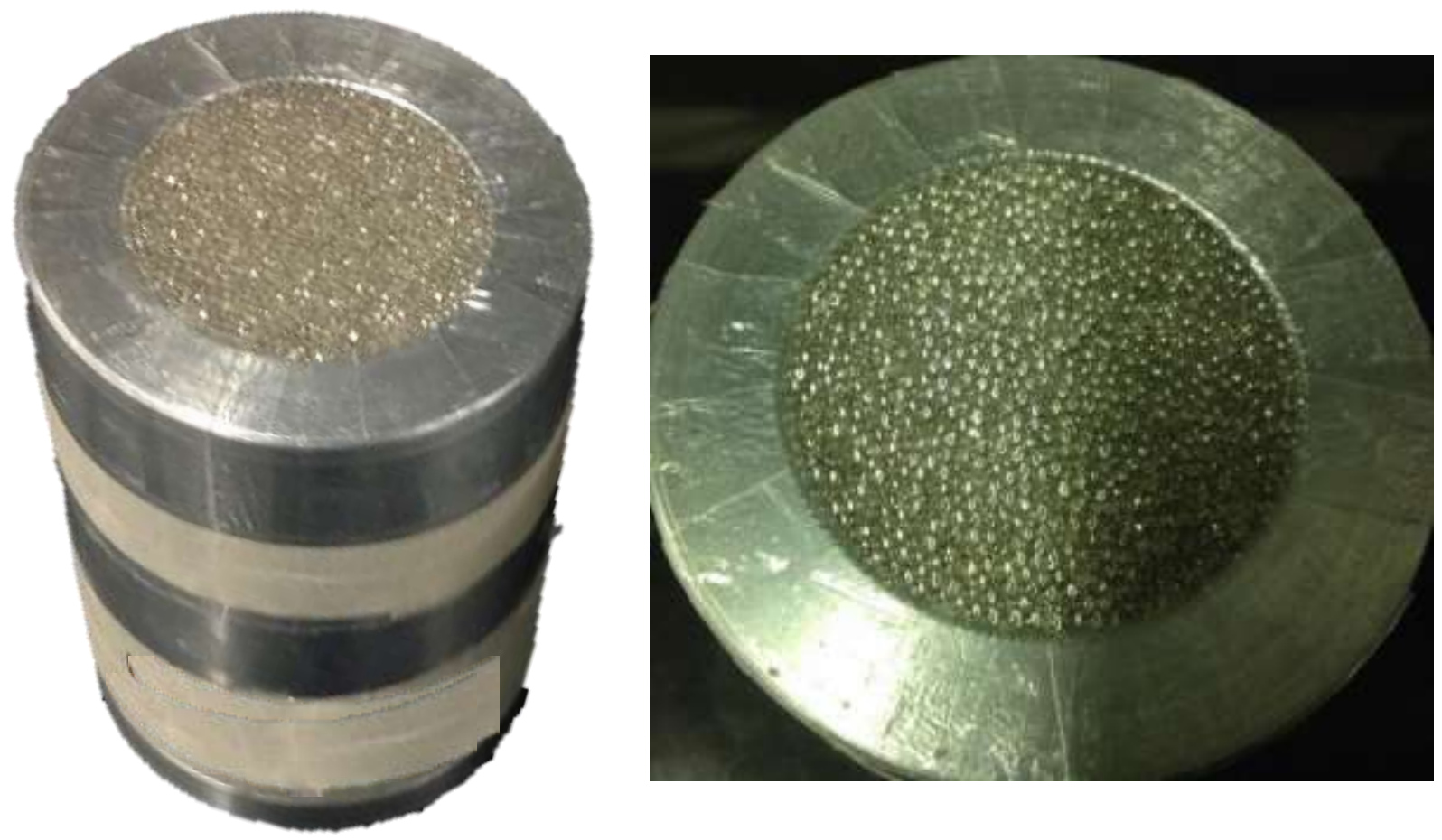

Figura 3.4. Detalhes do corpo de prova para material solto.

\subsubsection{Amostras cimentadas com epóxi}

$\mathrm{O}$ efeito da estrutura foi simulado mediante a mistura de microesferas com cimento epóxi. $\mathrm{O}$ procedimento de fabricação envolveu, de forma resumida, a preparação do aglomerante (epóxi), sua aplicação às microesferas e o repouso dos corpos de prova recém-moldados por um tempo de cura. Os passos do processo para a preparação das amostras são descritos seguir:

1. Preparar a resina e colocar a quantidade de microesferas pré-estabelecida na dosagem. Homogeneizar a mistura microesferas-epóxi mediante um processo de agitação (ver Figura 3.5-a);

2. A preparação do molde do corpo de prova, consistente em colocar duas camadas de vaselina e plástico intercaladas entre si, como no processo do material solto.

3. Para o enchimento do corpo de prova com a mistura e sua compactação, o processo é dividido em três fases: a) colocar material até a metade do cilindro, compactando-o mediante a imposição de uma sobrecarga (pistom de 400g); b) colocar material até a totalidade do cilindro, impondo posteriormente a sobrecarga; c) colocar 1,0 cm de material excedente no cilindro, impondo uma sobrecarga, culminando com o rasamento da superfície (ver Figura 3.5-b-c-d);

4. Cura do corpo de prova por 3 dias, para proceder com o ensaio de compressão. Ver detalhes do corpo de prova final na Figura 3.6. 

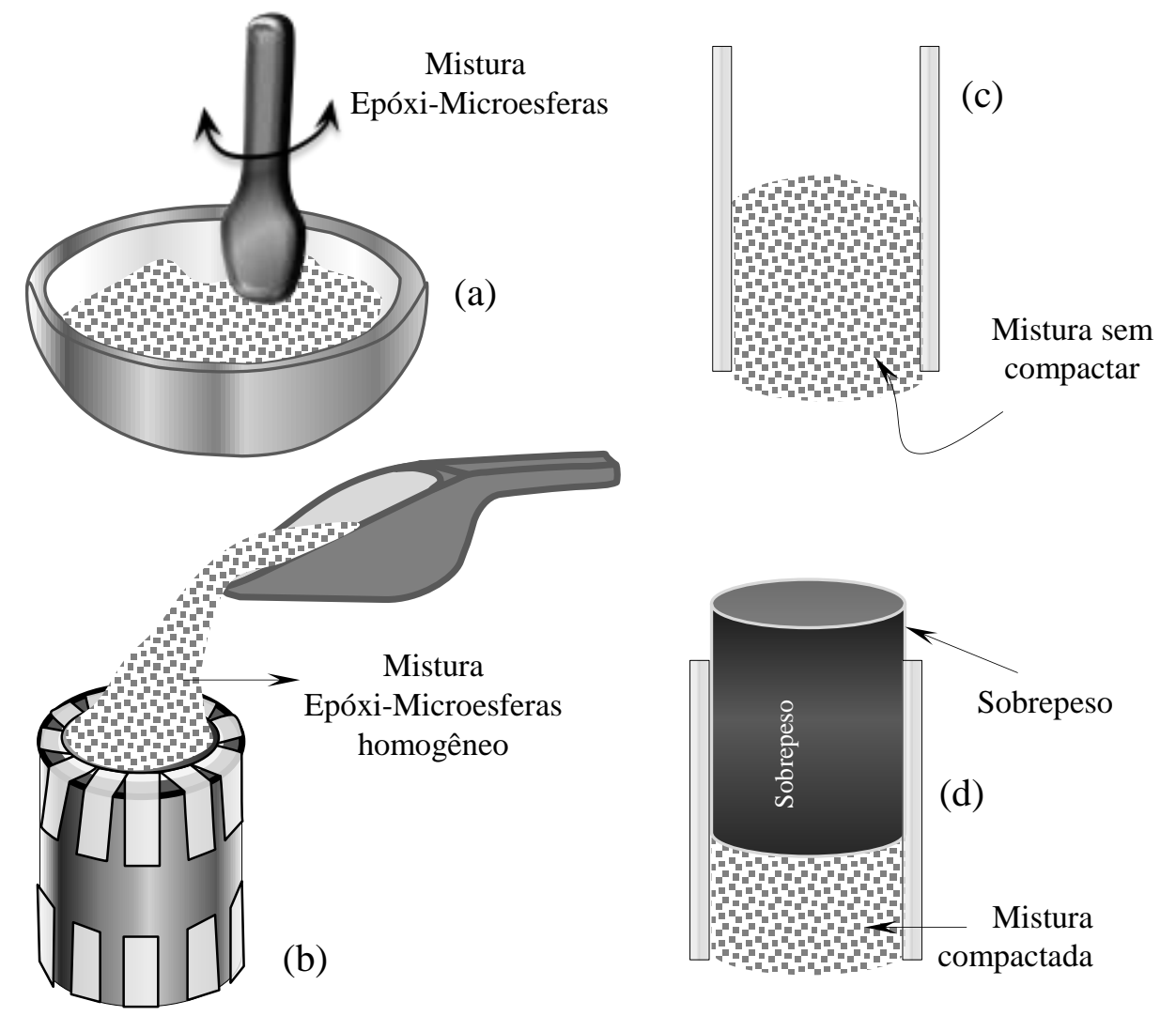

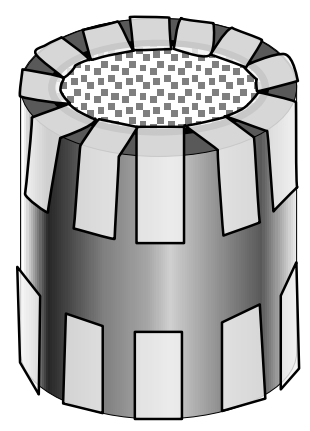

(e)

Figura 3.5. Processo de fabricação de amostras com material cimentado.
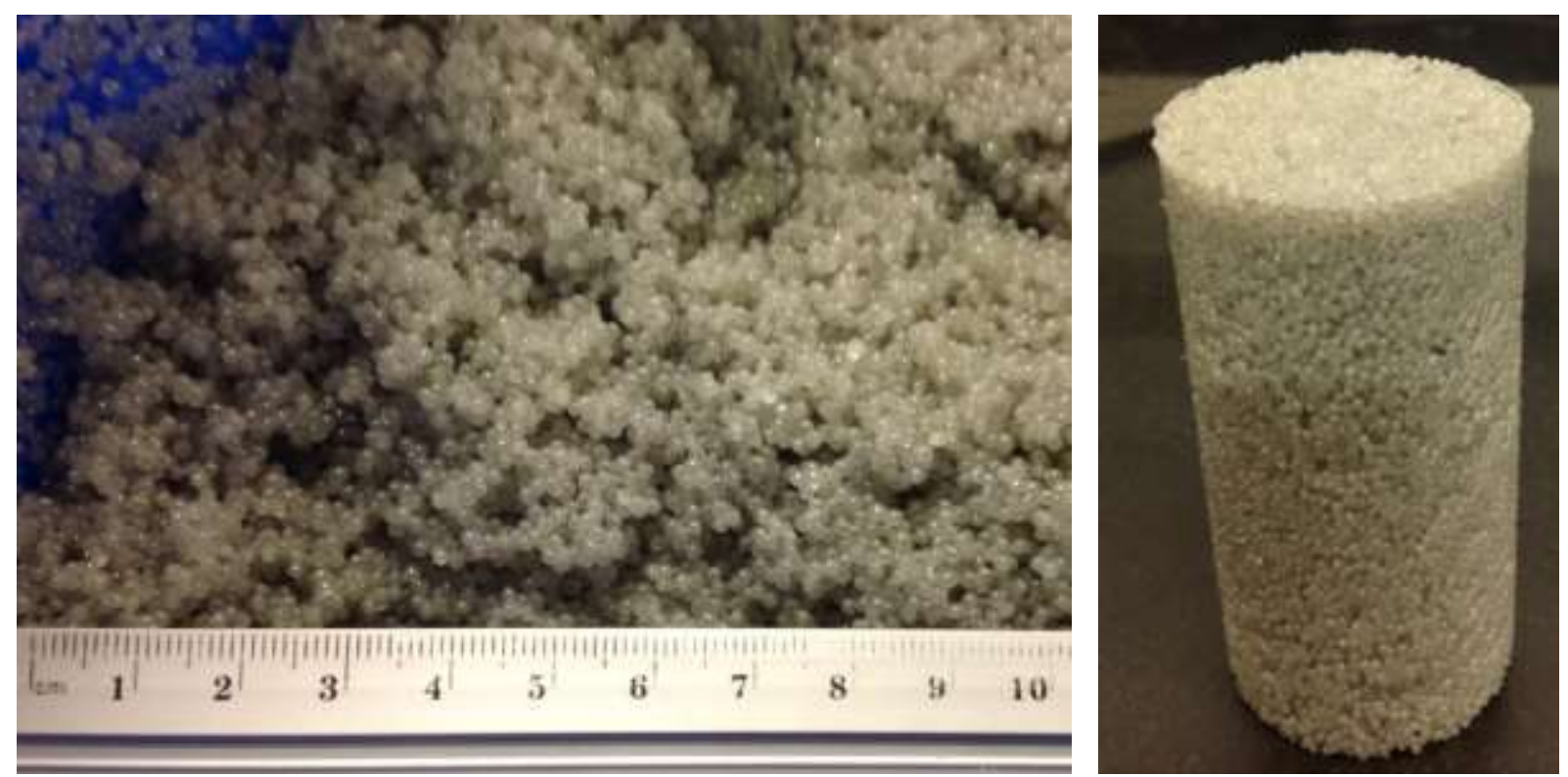

Figura 3.6. Detalhe da mistura epóxi-microesferas.

\subsubsection{Ensaio de Ruptura de Partículas}

O ensaio consiste na compressão diametral de uma partícula, colocada entre duas placas suficientemente rígidas para não apresentar deformações no momento em que é aplicada a carga (ver Figura 3.7). O ensaio é feito em condições de deformação controlada, impondo uma taxa de deslocamento de $0,1 \mathrm{~mm} / \mathrm{min}$. O diâmetro das placas que comprimem a partícula 
é de 50 mm (ver Figura 3.7-a). Foi usada uma célula de carga de 10 kN com uma resolução de 0,01 kN. O ensaio foi executado numa prensa HM-3000 de marca Humboldt. Este equipamento possui um sistema de aquisição de dados que registra as informações dos sensores de carga e deslocamento durante o ensaio. O resultado típico é apresentado na Figura 3.7-c, onde claramente se observa o ponto de ruptura da partícula.

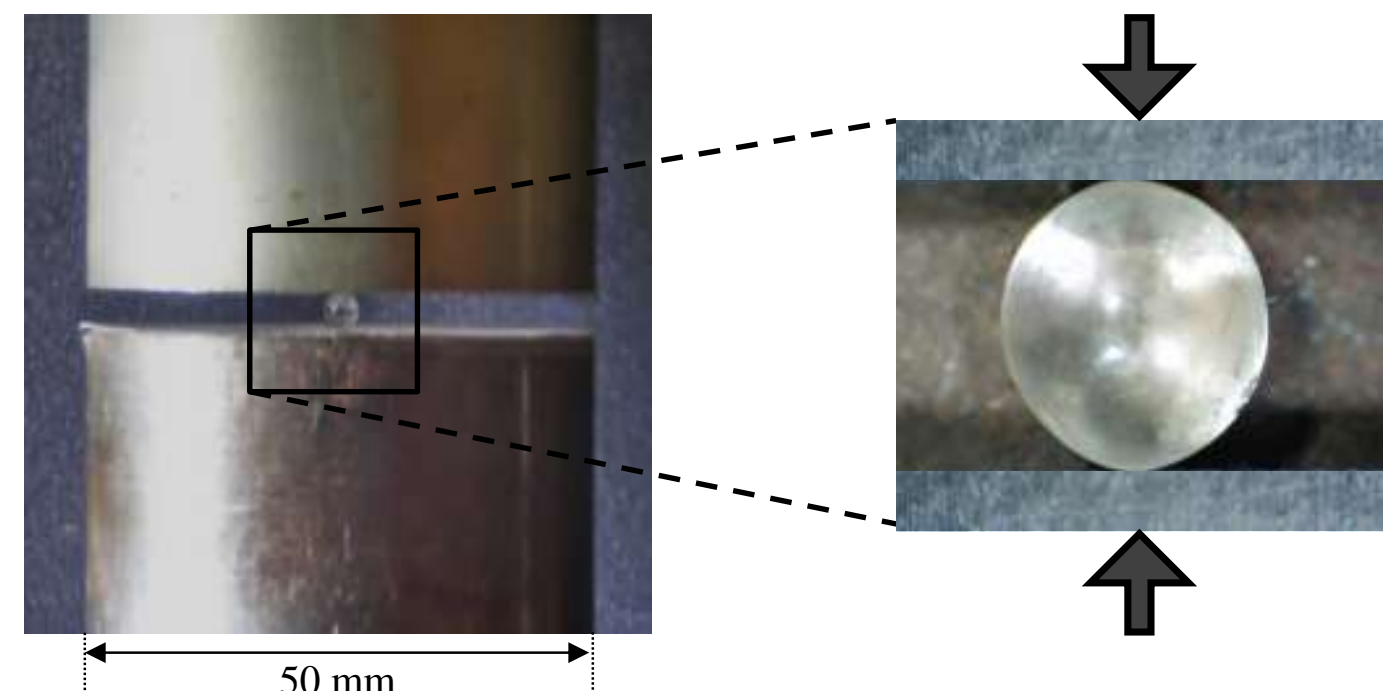

(a)

(b)

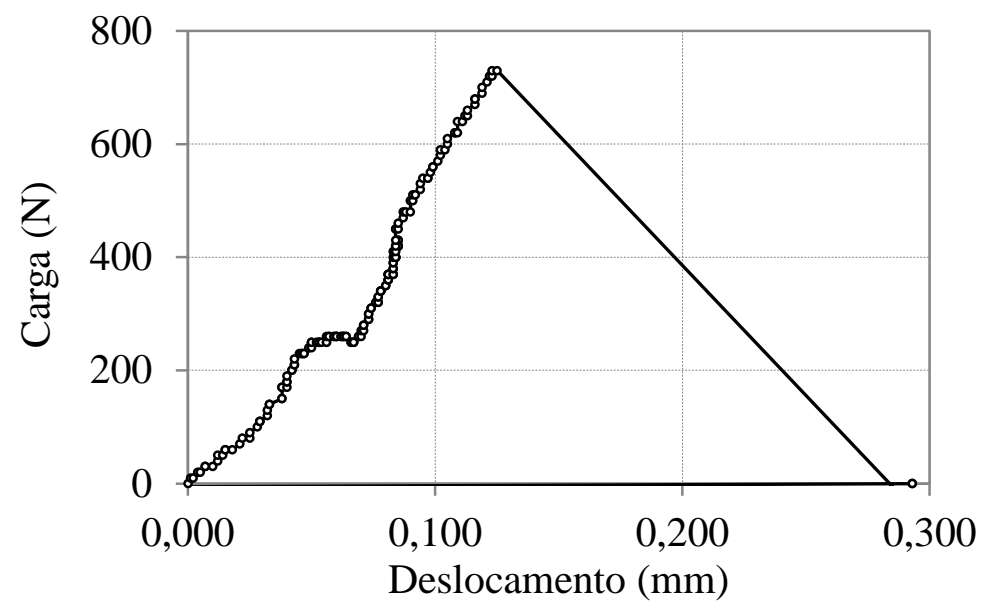

(c)

Figura 3.7. Ensaio de compressão diametral de uma partícula.

Para o estudo da quebra individual de partículas foram usadas unicamente as microesferas A170. A causa principal de concentrar o estudo neste tipo de material é que o equipamento tem limitações para a execução em partículas menores. Os dados vão ser analisados mediante a metodologia probabilística apresentada por Nakata et al. (1999). Desta forma, o material foi dividido, mediante o peneiramento, no maior número de faixas. $\mathrm{O}$ 
número de ensaios foi escolhido para ser estatisticamente válido e em função da quantidade disponível de partículas, como é apresentado na Tabela 3.3.

Tabela 3.3. Número de ensaios de ruptura de partícula.

\begin{tabular}{cccc}
\hline Faixa ASTM & $\mathbf{D}_{\text {máximo }}(\mathbf{m m})$ & $\mathbf{D}_{\text {mínimo }}(\mathbf{m m})$ & Número de Ensaios \\
\hline $8-10$ & 2,38 & 2,00 & 20 \\
$10-12$ & 2,00 & 1,68 & 20 \\
$12-14$ & 1,68 & 1,40 & 30 \\
$14-16$ & 1,40 & 1,18 & 30 \\
$16-18$ & 1,18 & 1,00 & 20 \\
\hline
\end{tabular}

\subsubsection{Ensaio de Compressão Unidimensional}

Foram feitos ensaios de compressão confinada unidimensional com deformação controlada (Constant Rate of Strain, CRS), tendo como objetivo a determinação da curva tensão-deformação no estado unidimensional. Os ensaios foram executados no Laboratório de Estruturas da universidade de Los Andes (Colômbia), mediante a utilização de uma prensa fabricada pela empresa MTS Systems Corporation, a qual tem uma capacidade de carga de 500 kN. O ensaio consiste na aplicação de carga na amostra, como resultado da imposição de uma velocidade de deformação constante pré-estabelecida $(1 \mathrm{~mm} / \mathrm{min})$, registrando a força e o deslocamento vertical. Além disso, são monitoradas as emissões acústicas dos processos micromecânicos do material. Na Figura 3.8 ilustra-se o equipamento utilizado para a execução do ensaio, mostrando um detalhe do corpo de prova e seus diferentes elementos.

Numa primeira fase da pesquisa foram feitos ensaios com diferentes configurações de parede (lixa, aço e dupla camada de plástico-vaselina) para verificar a influência do atrito lateral no comportamento macroscópico. Posteriormente, realizaram-se ensaios a diferentes velocidades para verificar o efeito na resposta do material.

No caso dos ensaios com material solto, foram aplicados dois critérios de parada do ensaio. O primeiro foi quando o material atingisse uma deformação vertical unitária do $20 \%$. O segundo foi o carregamento, selecionando três (3) ou quatro (4) níveis de carga progressivos dentro da curva de compressão e um último correspondente à carga máxima de trabalho da prensa $(450 \mathrm{kN})$. A relação destes ensaios é apresentada na Tabela 3.4.

No caso de materiais cimentados, o critério de parada foi sempre de deformação. As paredes foram para todos os ensaios cobertas com o sistema plástico-vaselina. Foram feitos ensaios para várias porcentagens de cimento. As condições são apresentadas na Tabela 3.5. 

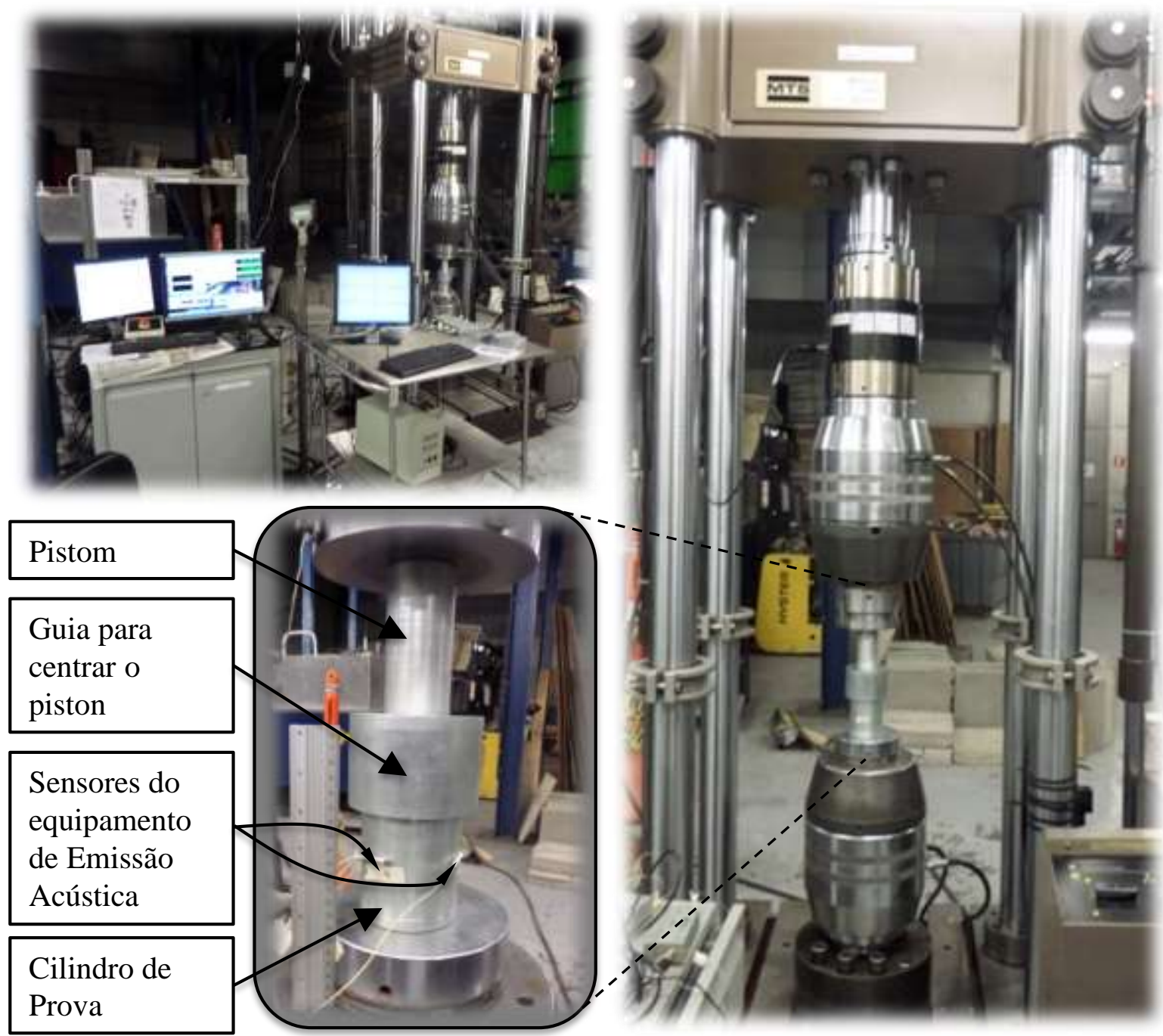

\begin{tabular}{|l|}
\hline Pistom \\
\hline $\begin{array}{l}\text { Guia para } \\
\text { centrar o } \\
\text { piston }\end{array}$ \\
\hline $\begin{array}{l}\text { Sensores do } \\
\text { equipamento } \\
\text { de Emissão } \\
\text { Acústica }\end{array}$ \\
\hline $\begin{array}{l}\text { Cilindro de } \\
\text { Prova }\end{array}$ \\
\hline
\end{tabular}

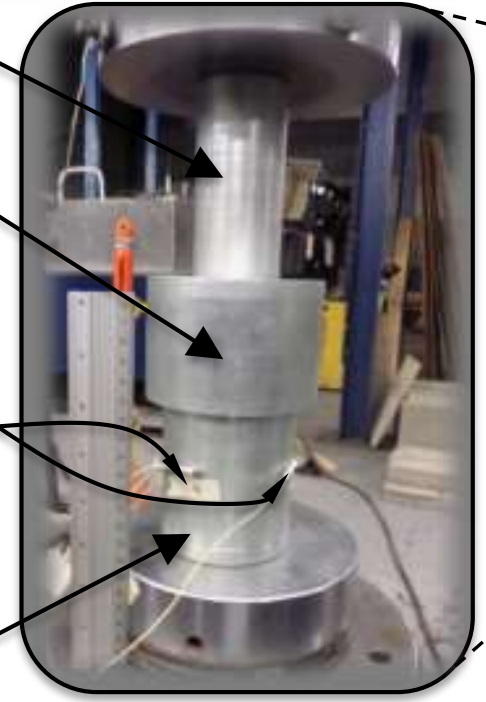

Figura 3.8. Equipamento de compressão unidimensional com deformação controlada.

Tabela 3.4. Relação de Ensaio para material solto.

\begin{tabular}{|c|c|c|c|c|}
\hline Material & Condições & $\begin{array}{l}\text { Número } \\
\text { Ensaios }\end{array}$ & Velocidade & Critério de Parada \\
\hline \multirow{6}{*}{ A170 } & Parede com lixa & 1 & $1 \mathrm{~mm} / \mathrm{min}$ & \multirow{5}{*}{$20 \%$ de deformação } \\
\hline & Parede sem plástico & 4 & $1 \mathrm{~mm} / \mathrm{min}$ & \\
\hline & Parede com plástico & 1 & $0,1 \mathrm{~mm} / \mathrm{min}$ & \\
\hline & Parede com plástico & 1 & $0,5 \mathrm{~mm} / \mathrm{min}$ & \\
\hline & Parede com plástico & 3 & $1 \mathrm{~mm} / \mathrm{min}$ & \\
\hline & Parede com plástico & 5 & $1 \mathrm{~mm} / \mathrm{min}$ & Carga \\
\hline \multirow{5}{*}{ A072 } & Parede com lixa & 3 & $1 \mathrm{~mm} / \mathrm{min}$ & \multirow{4}{*}{$20 \%$ de deformação } \\
\hline & Parede sem plástico & 4 & $1 \mathrm{~mm} / \mathrm{min}$ & \\
\hline & Parede com plástico & 1 & $0,1 \mathrm{~mm} / \mathrm{min}$ & \\
\hline & Parede com plástico & 3 & $1 \mathrm{~mm} / \mathrm{min}$ & \\
\hline & Parede com plástico & 4 & $1 \mathrm{~mm} / \mathrm{min}$ & Carga \\
\hline \multirow{2}{*}{$\mathrm{AC}$} & \multirow{2}{*}{ Parede com plástico } & 4 & \multirow{2}{*}{$1 \mathrm{~mm} / \mathrm{min}$} & $20 \%$ de deformação \\
\hline & & 4 & & Carga \\
\hline
\end{tabular}


Tabela 3.5. Relação de Ensaio para material cimentado.

\begin{tabular}{|c|c|c|c|c|}
\hline Material & Condições & $\begin{array}{l}\text { Número } \\
\text { Ensaios }\end{array}$ & Velocidade & Critério de Parada \\
\hline \multirow{3}{*}{ A170 } & $5 \%$ de cimento & 4 & \multirow{3}{*}{$1 \mathrm{~mm} / \mathrm{min}$} & \multirow{3}{*}{$20 \%$ de deformação } \\
\hline & $8 \%$ de cimento & 2 & & \\
\hline & $10 \%$ de cimento & 2 & & \\
\hline \multirow{3}{*}{ A072 } & $5 \%$ de cimento & 2 & \multirow{3}{*}{$1 \mathrm{~mm} / \mathrm{min}$} & \multirow{3}{*}{$20 \%$ de deformação } \\
\hline & $8 \%$ de cimento & 1 & & \\
\hline & $10 \%$ de cimento & 1 & & \\
\hline \multirow{3}{*}{$\mathrm{AC}$} & $5 \%$ de cimento & 2 & \multirow{3}{*}{$1 \mathrm{~mm} / \mathrm{min}$} & \multirow{3}{*}{$20 \%$ de deformação } \\
\hline & $8 \%$ de cimento & 1 & & \\
\hline & $10 \%$ de cimento & 2 & & \\
\hline
\end{tabular}

\subsubsection{Emissão acústica}

Durante os ensaios de compressão confinada foram colocados quatro (4) sensores acústicos nas paredes do molde prova para o monitoramento dos ruídos provocados pela quebra das partículas ao interior do recipiente. Na Figura 3.9 ilustra-se a localização dos sensores acústicos.
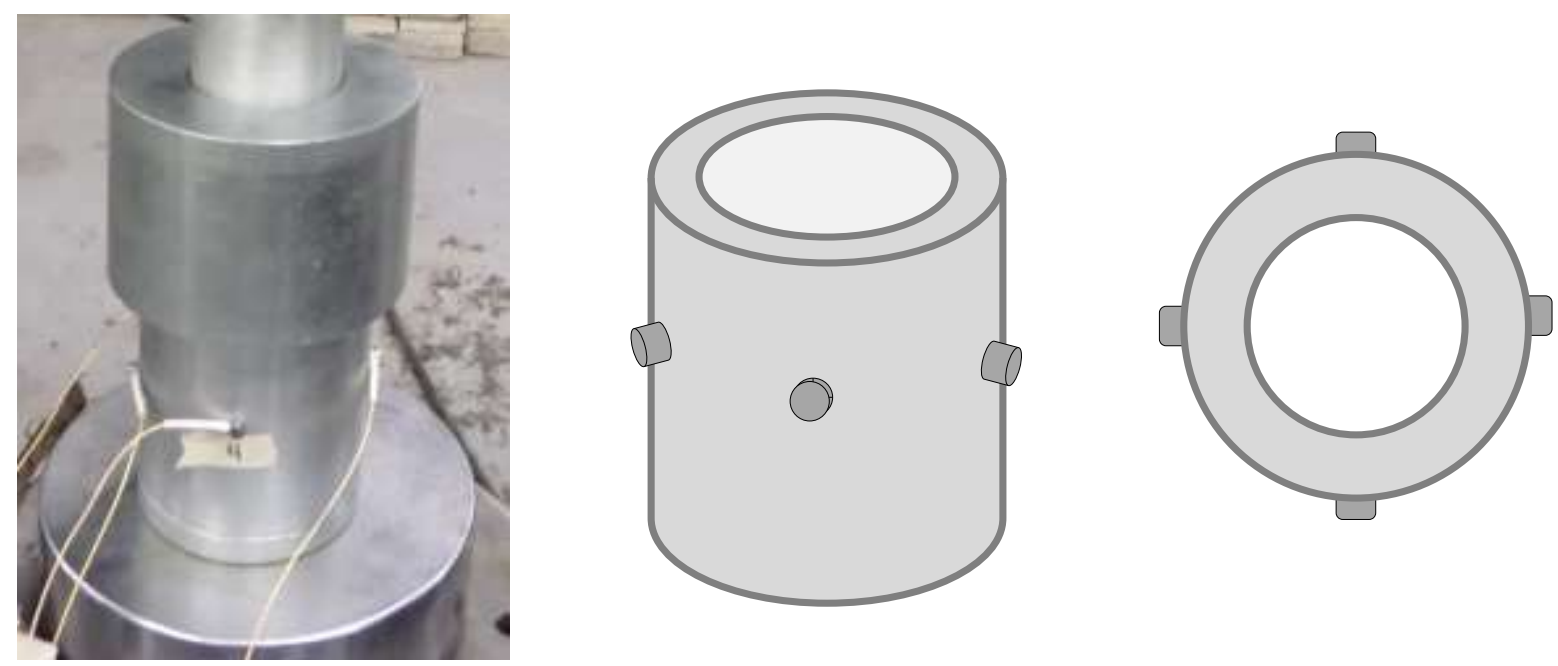

Figura 3.9. Detalhe da localização dos sensores acústicos.

Foi usado um sistema de captação de emissões acústicas da marca PA (Physical Acoustics) pertencente ao grupo MISTRAS, da universidade de Los Andes. O sistema é composto por: (1) sensores, (2) pré-amplificadores e (3) placa de aquisição de dados.

O tipo de sensor depende do fenômeno que se quer avaliar. Para este trabalho foram usados sensores tipo PICO-Ultra-MINI WB, empregados com êxito na avaliação da quebra de 
materiais granulares em pesquisas prévias da universidade de Los Andes (Mejía, 2009; Contreras, 2010). Na Figura 3.10 mostram-se detalhes dos sensores.
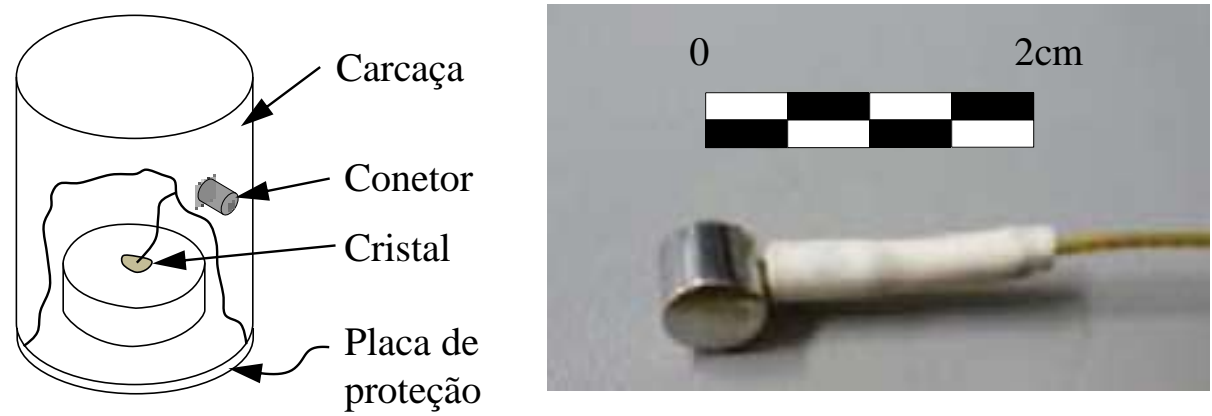

Figura 3.10. Detalhe do sensor acústico.

O pré-amplificador de sinais usado foi do tipo 2/4/6, capaz de aumentar o sinal num intervalo de $20 \mathrm{~dB}, 40 \mathrm{~dB}$ e $60 \mathrm{~dB}$, sendo ajustado facilmente mediante um interruptor (ver Figura 3.12). Para esta pesquisa foi selecionado uma amplificação de $40 \mathrm{~dB}$.

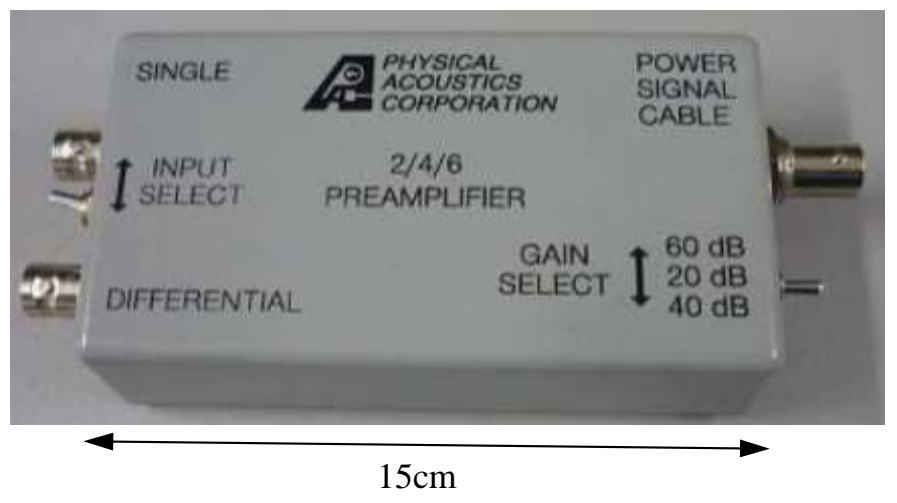

Figura 3.11. Detalhe do pré-amplificador de sinais acústicas.

Como sistema de aquisição de dados foi usado uma placa do tipo MICRO II PCI-2, instalada num computador, para o processamento dos sinais (ver Figura 3.12).

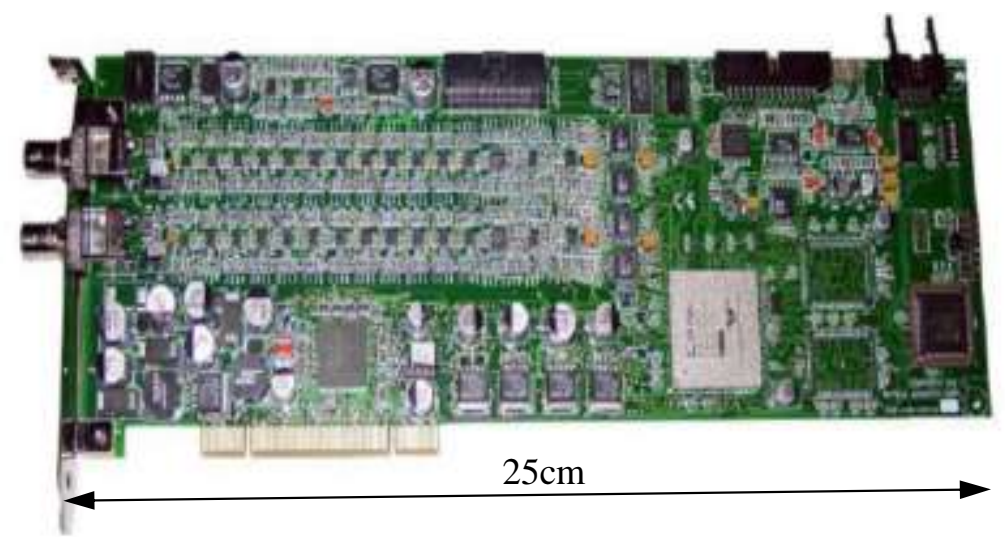

Figura 3.12. Placa de aquisição de dados. 
$\mathrm{Na}$ Figura 3.13 é apresentada o programa AEwin, o qual foi usado para o processamento das informações obtidas do monitoramento das emissões acústicas. Este programa plota vários gráficos ao mesmo tempo, permitindo assim a supervisão de várias variáveis.

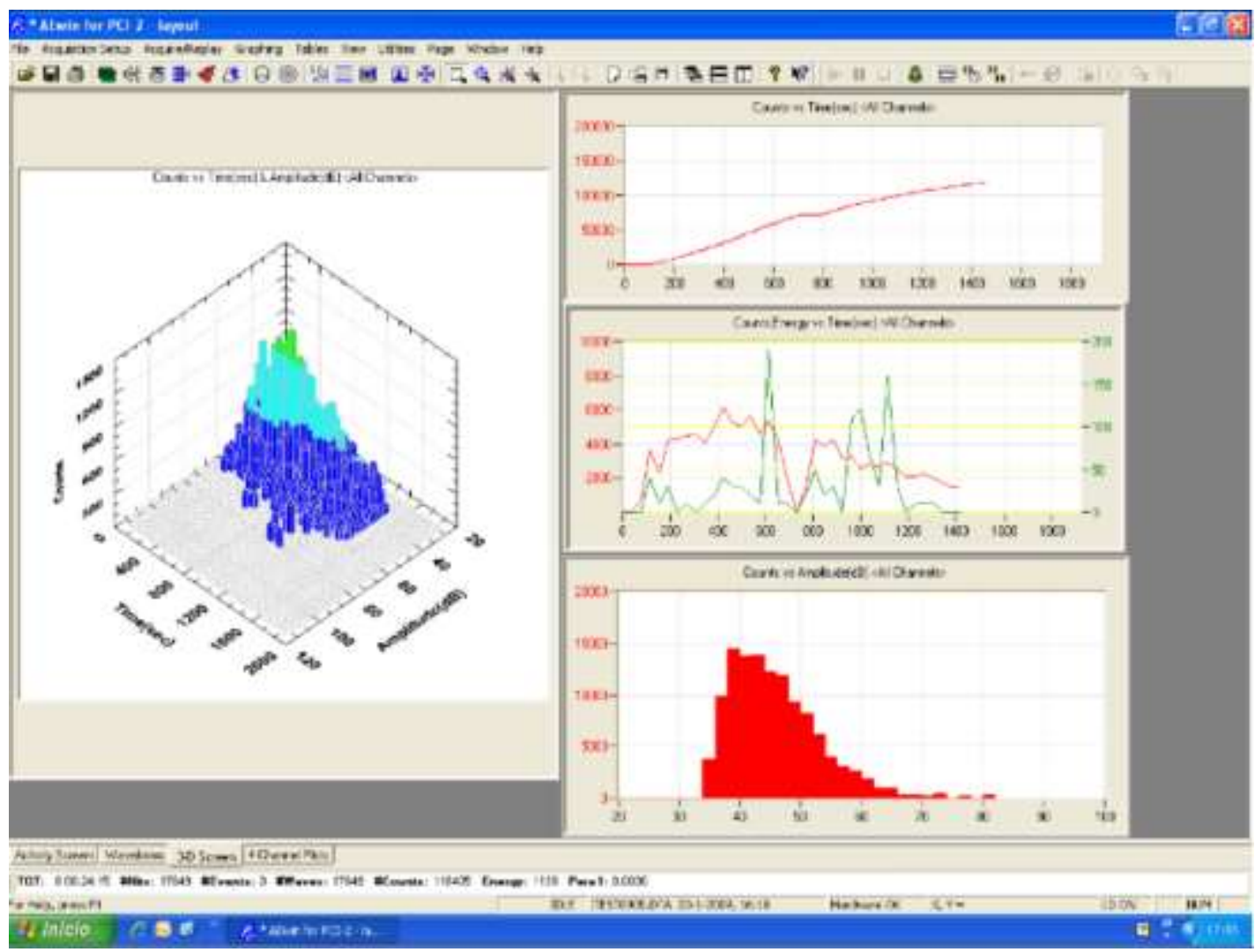

Figura 3.13. Interface do software AEwin.

\subsubsection{Avaliação da Quebra}

Posteriormente à realização dos ensaios de compressão foram feitas avaliações da intensidade de quebra do material mediante duas técnicas de laboratório. A primeira é uma simples análise granulométrica por peneiramento do material resultante. A segunda técnica é mediante o processamento de imagens do material quebrado, obtendo a distribuição de tamanhos das partículas e a estatística da forma das partículas.

\subsubsection{Granulometria}

A análise granulométrica por peneiramento foi feita seguindo os padrões típicos da geotecnia, não obstante, foi empregado o maior número de peneiras para a obtenção de uma curva bem definida. As peneiras usadas, segundo o número ASTM, são: 8, 10, 12, 14, 16, 18, $20,25,30,35,40,45,50,60,70,80,100,120,140,170,200,230,270,325,400,450$ e 500. 


\subsubsection{Processamento de Imagens}

Foi usado um sistema de análise de imagens dinâmica, o qual possibilita a determinação dos parâmetros geométricos através do processamento das imagens obtidas durante o fluxo de partículas. Esta técnica possibilita a caracterização de dezenas de milhares de partículas em poucos minutos. Esta tecnologia consiste em passar o material uma área onde existe uma fonte de luz LED e câmeras que capturam simultaneamente imagens que são processadas por um programa de análise de imagens. Uma condição essencial para usar esta técnica é que o material deve estar totalmente disperso para obter resultados válidos.

O equipamento usado nesta pesquisa foi o QICPIC, desenvolvido pela empresa Sympatec GmBH. Está companhia gentilmente realizou os ensaios no seu laboratório nos Estados Unidos com a ajuda do Engenheiro Kay Mootz. Este aparelho é um analisador de imagens de alta velocidade, que opera na escala dos nano segundos, e desta forma pode obter imagens quase estáticas das partículas em movimento. Além disso, possui facilidade de adaptação com diferentes tipos de dispersores.

Nesta pesquisa foram usados dispersores tipo Gradis para os materiais de maior diâmetro e Rodos para os mais finos, os quais são apresentados na Figura 3.14. A diferença entre os dois dispersores está nos mecanismos com os quais eles trabalham. O primeiro desagrega o material mediante a colisão entre as partículas e com o impacto das partículas contra as paredes. O segundo além destes mecanismos, possui um sistema que imprime forças centrífugas para a intensificação da dispersão. Na Figura 3.15 são ilustrados os diferentes mecanismos de dispersão.
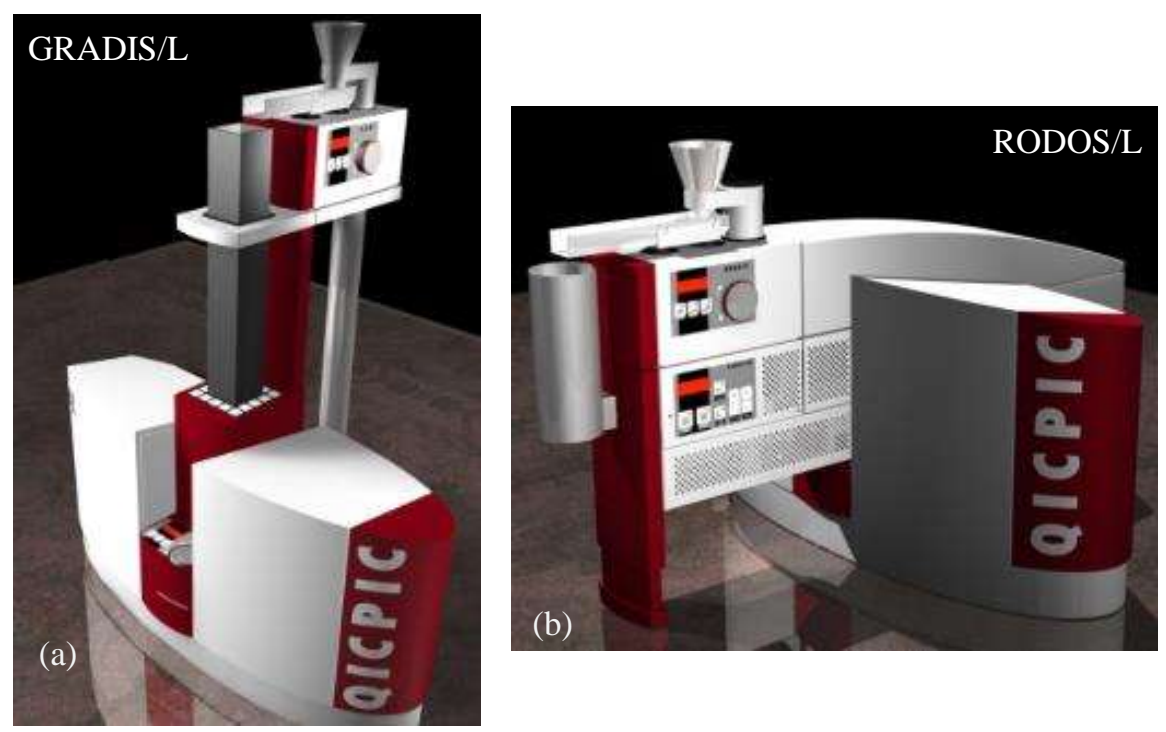

Figura 3.14. Sistema QICPIC com o dispersor: (a) tipo Gradis e (b) tipo Rodos (www.sympatec.com). 


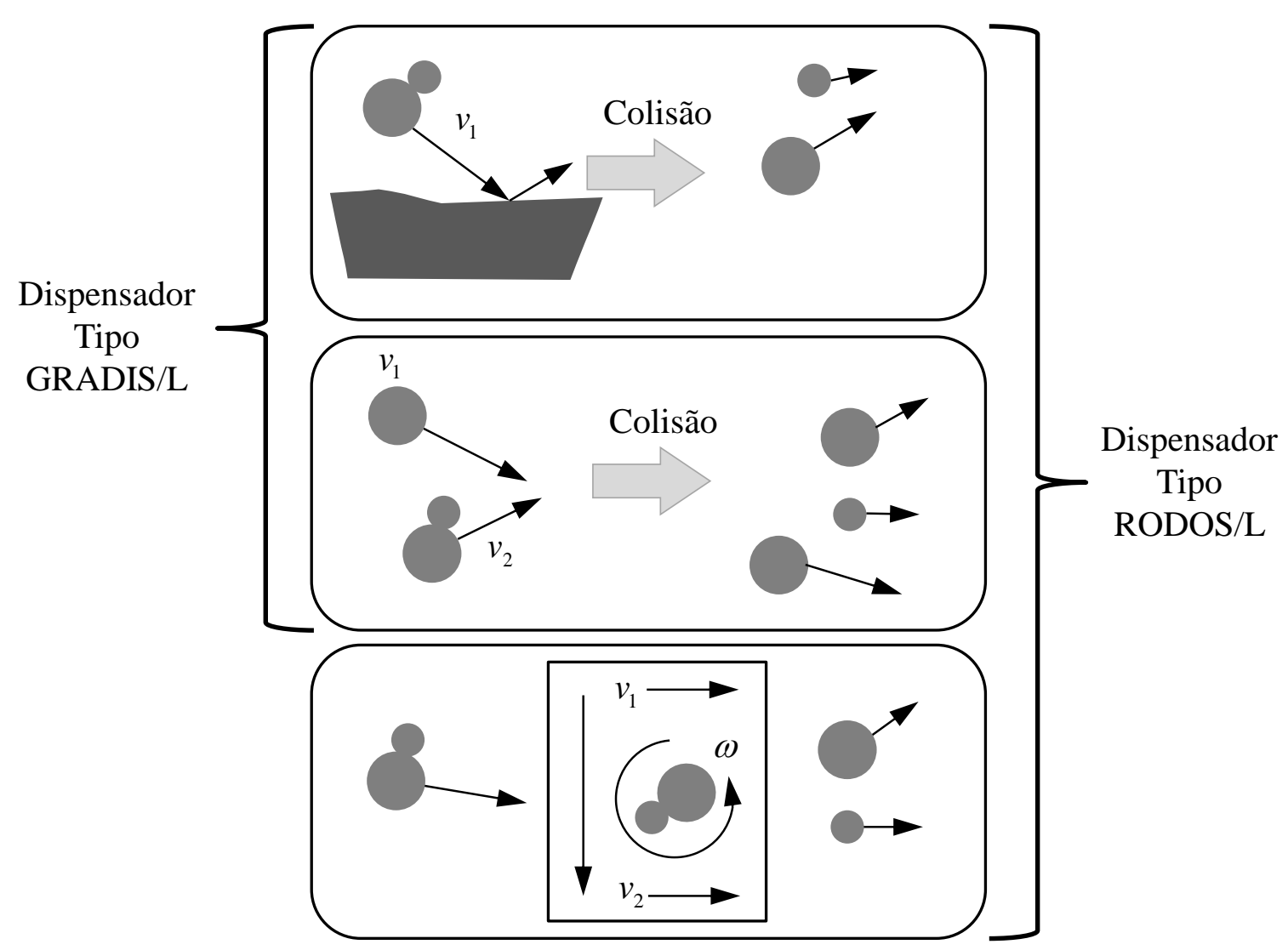

Figura 3.15. Princípios físicos dos dispersores (www.sympatec.com).

A avaliação das medições foi realizada com o programa Sympatec QX, que foi concebido para a avaliação analítica, estatística e gráfica das imagens das partículas. Para este trabalho foi usado a relação de aspecto (AR) para avaliar a forma das partículas. Está medida é a relação entre o tamanho máximo e mínimo da partícula, como está ilustrado na Figura 3.16. Foi usado o tamanho mínimo $\left(D_{\text {min }}\right)$ para a obtenção da distribuição da curva granulométrica, com o objetivo de comparar os resultados obtidos desta técnica com os dados do peneiramento.

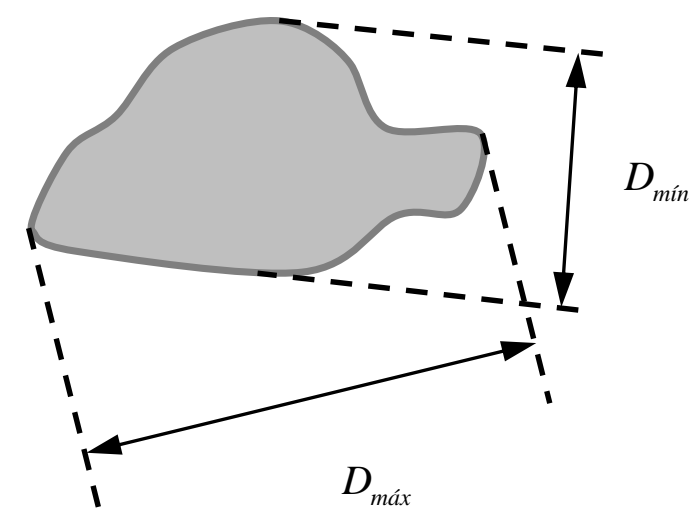

Relação de Aspecto

$$
A R=\frac{D_{\min }}{D_{\max }}
$$

Figura 3.16. Medidas obtidas do QICPIC. 


\subsection{SIMULAÇÕES MICROMECÂNICAS}

Esta fase compreende a simulação numérica dos ensaios de laboratório com o objetivo de reproduzir os fenômenos observados experimentalmente. Esta parte do trabalho foi limitada à avaliação do fenômeno de quebra de partículas exclusivamente. Com os resultados destas análises, busca-se avaliar a capacidade da ferramenta de MED para reproduzir aspectos do comportamento macroscópico, tais como:

- A transição existente entre o trecho de recompressão e a linha de compressão normal (NCL) da curva de compressibilidade, para solos soltos;

- A inclinação da linha de compressão normal (NCL);

- Evolução da distribuição granulométrica;

- Avaliação numérica dos índices de quebra.

A ferramenta numérica selecionada para a realização das simulações é a plataforma Yade (Šmilauer \& Chareyre, 2011; Šmilauer et al., 2011a, 2011b, 2014), a qual é uma alternativa de software livre (de filosofia open source), onde a mesma comunidade de usuários colabora e melhora o software. Esta plataforma é usada para a modelagem micromecânica, focando principalmente no método dos elementos discretos. O Yade foi programado em $\mathrm{C}++$, usando um modelo de objetos flexíveis, de modo a permitir a implementação de novos algoritmos e interfaces de forma independente. Esta ferramenta usa a linguagem Python para a construção de cenários concisos e rápidos, controle da simulação, pós-processamento e depuração de erros. Os modelos de contato necessários para a simulação dos fenômenos micromecânicos, abordados neste estudo, estão implementados na plataforma.

Em relação à quebra de partículas, clusters de partículas para a reprodução da quebra já estão implementados no Yade, não obstante esta é uma abordagem com um custo computacional alto. Para este trabalho optou-se pela implementação do processo de substituição da partícula que rompe por partículas menores. A abordagem escolhida neste trabalho para a simulação do fenômeno de quebra está fundamenta na pesquisa desenvolvida por Ciantia (2015).

A forma como é dividida a partícula original (esfera mãe), no momento que ela atinge a ruptura, é bastante relevante para a avaliação do comportamento macroscópico do material. A configuração escolhida nesta pesquisa para a fragmentação é apresentada na Figura 3.17, na qual a partícula mãe é dividida em quatorze (14) partículas filhas. Esta escolha se justifica 
pelo fato de que a resposta macroscópica para um número maior de esferas não tem uma mudança significativa no resultado (Ciantia et al., 2015), como pode ser observado na Figura 3.18 .
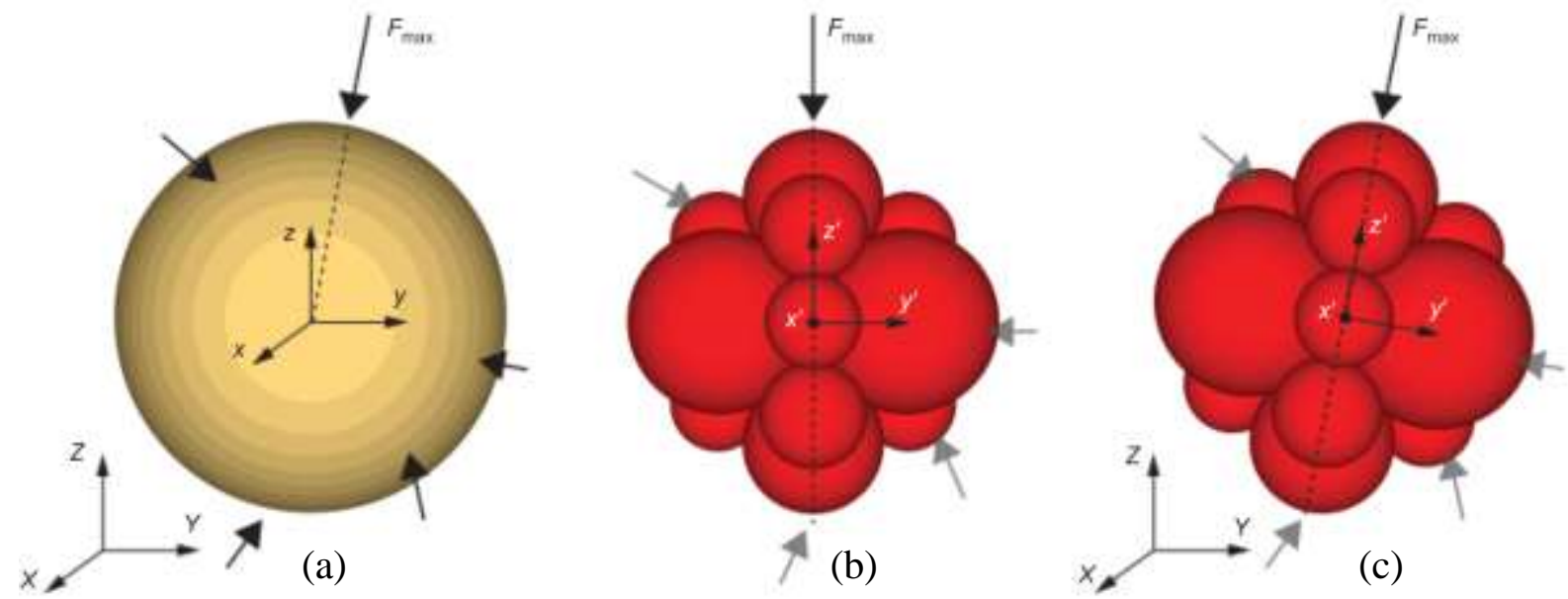

Figura 3.17. Configurações da quebra da partícula (Ciantia et al., 2014).

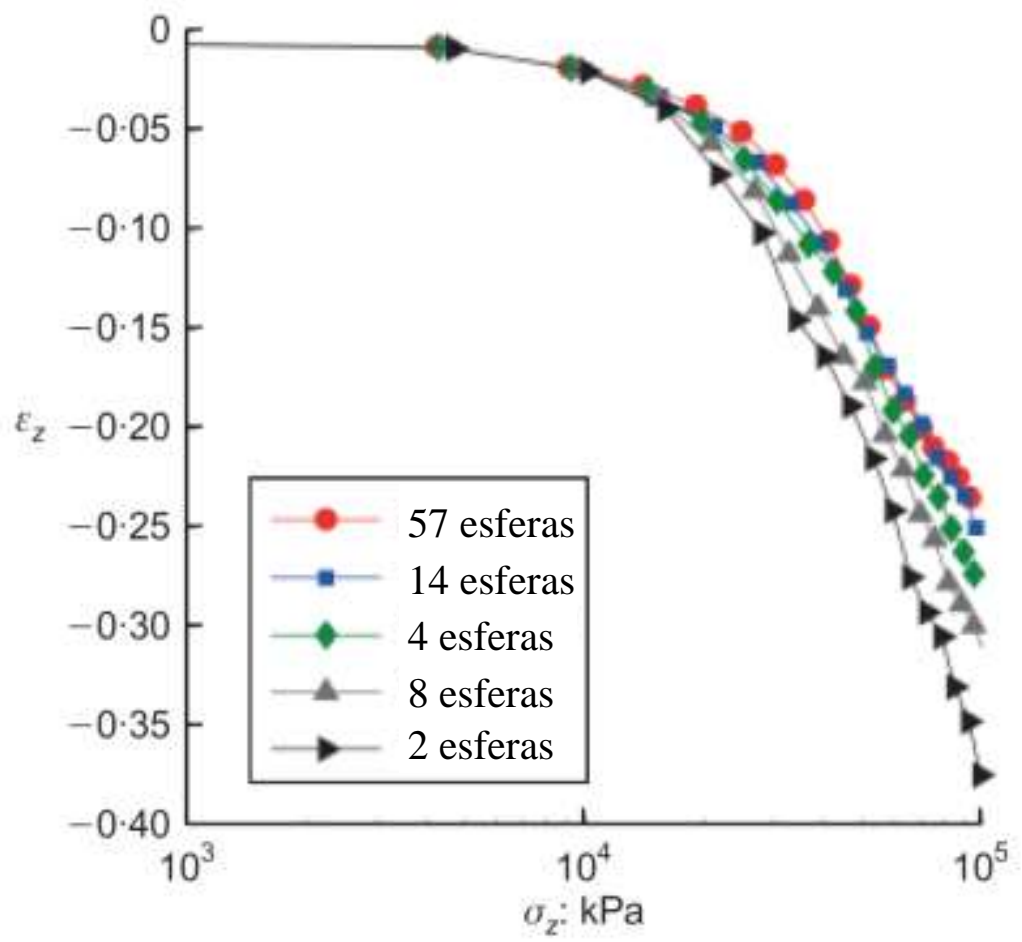

Figura 3.18. Resposta macroscópica num ensaio de compressão confinada para diferentes configurações de substituição da partícula mãe (Ciantia et al., 2015).

Outro aspecto a considerar na hora da substituição é alinhamento das partículas, já que existem partículas filhas com diferentes diâmetros, e que dependendo do arranjo final podem alterar o resultado macroscópico. Para isso, o que se faz é alinhar as esferas de maior diâmetro 
com a direção perpendicular à força máxima (ver Figura 3.17). Esta configuração é inspirada na fragmentação típica observada em materiais frágeis quando estão sujeitos a forças concentradas. Para a implementação basta ter as coordenadas dos centros das partículas filhas e seus respetivos diâmetros, e aplicar as rotações necessárias para cada partícula no momento do evento. Na Tabela 2.1 são apresentadas todas as informações geométricas do arranjo de quatorze esferas filhas.

Tabela 3.6. Configuração da substituição por 14 esferas, em que $R$ representa o raio da "esfera mãe", enquanto $r$ representa o raio das "esferas filhas" (Ciantia et al., 2015).

\begin{tabular}{|c|c|c|c|c|}
\hline ID & $r / R$ & $x^{\prime} / R$ & $y^{\prime} / R$ & $z^{\prime} / R$ \\
\hline 1 & 0,4641 & 0 & 0,5359 & 0 \\
\hline 2 & 0,4641 & 0,4641 & 0,2679 & 0 \\
\hline 3 & 0,4641 & 0,4641 & 0,2679 & 0 \\
\hline 4 & 0,224 & 0,672 & 0,388 & 0 \\
\hline 5 & 0,224 & 0,672 & 0,388 & 0 \\
\hline 6 & 0,224 & 0 & 0,776 & 0 \\
\hline 7 & 0,3659 & 0 & 0 & 0,6339 \\
\hline 8 & 0,3659 & 0 & 0 & 0,6339 \\
\hline 9 & 0,2573 & 0 & 0,5942 & 0,4456 \\
\hline 10 & 0,2573 & 0,5146 & 0,2971 & 0,4456 \\
\hline 11 & 0,2573 & 0,5146 & 0,2971 & 0,4456 \\
\hline 12 & 0,2573 & 0 & 0,5942 & 0,4456 \\
\hline 13 & 0,2573 & 0,5146 & 0,2971 & 0,4456 \\
\hline 14 & 0,2573 & 0,5146 & 0,2971 & 0,4456 \\
\hline
\end{tabular}

Como critério de ruptura da partícula adoptado para este trabalho é :

$$
F_{\lim } \leq \sigma_{\lim } \cdot A_{F}
$$

onde $\sigma_{\text {lim }}$ é a tensão limite que leva a quebra e $A_{F}$ é a área de contato da placa com a esfera num ensaio de compressão diametral da partícula (ver Figura 3.19). A primeira componente é calculada da seguinte maneira:

$$
\sigma_{\lim }=\sigma_{\lim , 0} \cdot\left(\frac{d}{d_{0}}\right)^{-3 / m}
$$

no qual $\sigma_{\lim , 0}$ é a tensão limite média para um diâmetro de referência $d_{0}$. Esta formulação é fundamentada na distribuição estatística de Weibull para resistência de partículas, descrita no item 2.3.1. Destaca-se que esta proposta tem um fator de correção pelo tamanho da partícula, 
o qual depende do parâmetro $m$, chamado de módulo de Weibull e que é função do tipo de material.

A área de contato, AF, é dada por:

$$
A_{F}=\frac{\pi}{4} \cdot d^{2} \cdot \sin ^{2} \theta
$$

onde $\theta$ é o ângulo sólido do contato. Para facilitar os procedimentos considera-se que esse valor é uma constante do material e independente da tensão limite, $\sigma_{\lim }$.

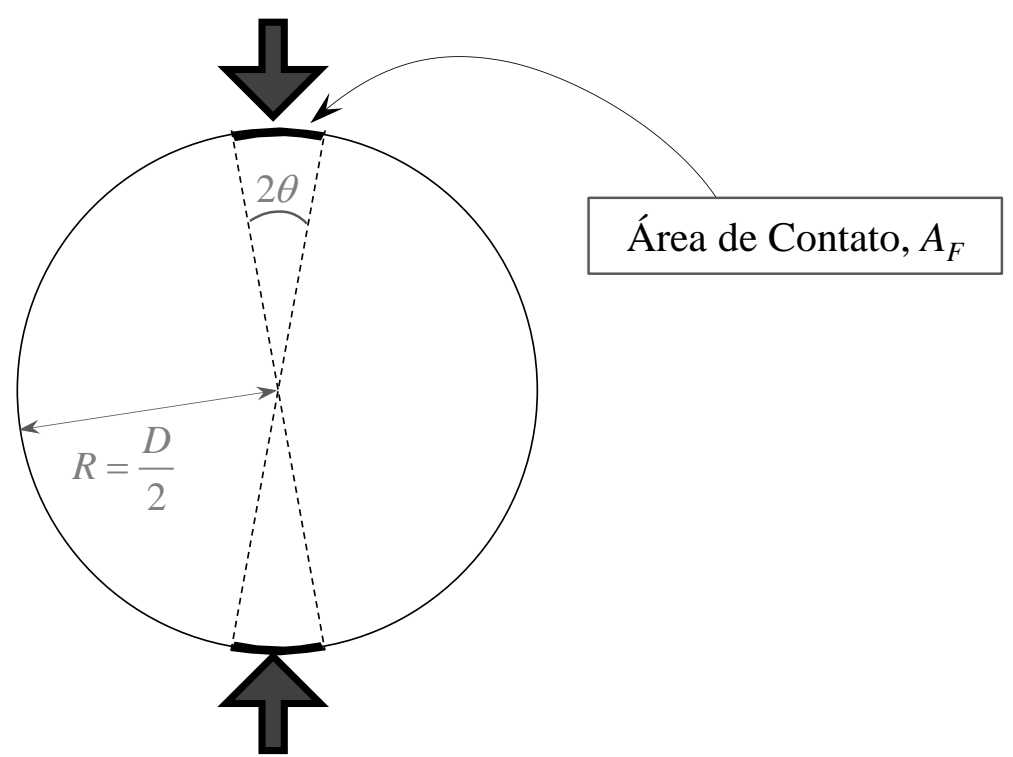

Figura 3.19. Hipóteses de critério de ruptura de uma partícula.

Desta forma o critério de ruptura adotado depende de três parâmetros: (a) tensão limite média $\left(\sigma_{\lim , 0}\right)$ para um diâmetro de referencia $d_{0}$, (b) módulo de Weibull $(m)$, e (c) o ângulo sólido do contato $(\theta)$. Os dois primeiros podem ser obtidos de ensaios de laboratório, enquanto que o último normalmente é arbitrado. Para este trabalho o valor de $\theta$ adotado foi de $\pi / 24$, com base em estudos anteriores para material quartzoso (tipo de material de interesse desta pesquisa).

As condições de contorno para as simulações são similares às impostas nos ensaios do laboratório, sem chegar a ser idênticas por questões de custo computacional. Como o objeto principal desta parte do trabalho é avaliar a capacidade desta ferramenta para a análise do fenômeno de quebra, não existe a necessidade de ajustar perfeitamente a simulação discreta aos ensaios de laboratório. 
As condições para a simulação discreta foram:

- Distribuição granulométrica uniforme, colocando todas as partículas com o mesmo diâmetro inicial $(0,1 \mathrm{~m})$.

- Cilindro de 2,14m de altura por 2,00m de diâmetro, como pode ser observado na Figura 3.20.

- Foi usado como modelo de Hertz para os contatos.

- A geração do arranjo inicial de partículas foi feita mediante a geração aleatória das partículas num cilindro de 2,4m de altura com 2,00 m de diâmetro. Posteriormente, foi executada uma compactação gravitacional até chegar no valor desejado de vazios (similar ao obtido no experimento).

- As paredes do cilindro e o fundo do cilindro permanecem sem nenhum movimento durante a simulação. Um plano rígido pressiona verticalmente o material a uma velocidade de $0,3 \mathrm{~m} / \mathrm{min}$. Assim, consegue-se simular a condição de laboratório (compressão confinada).

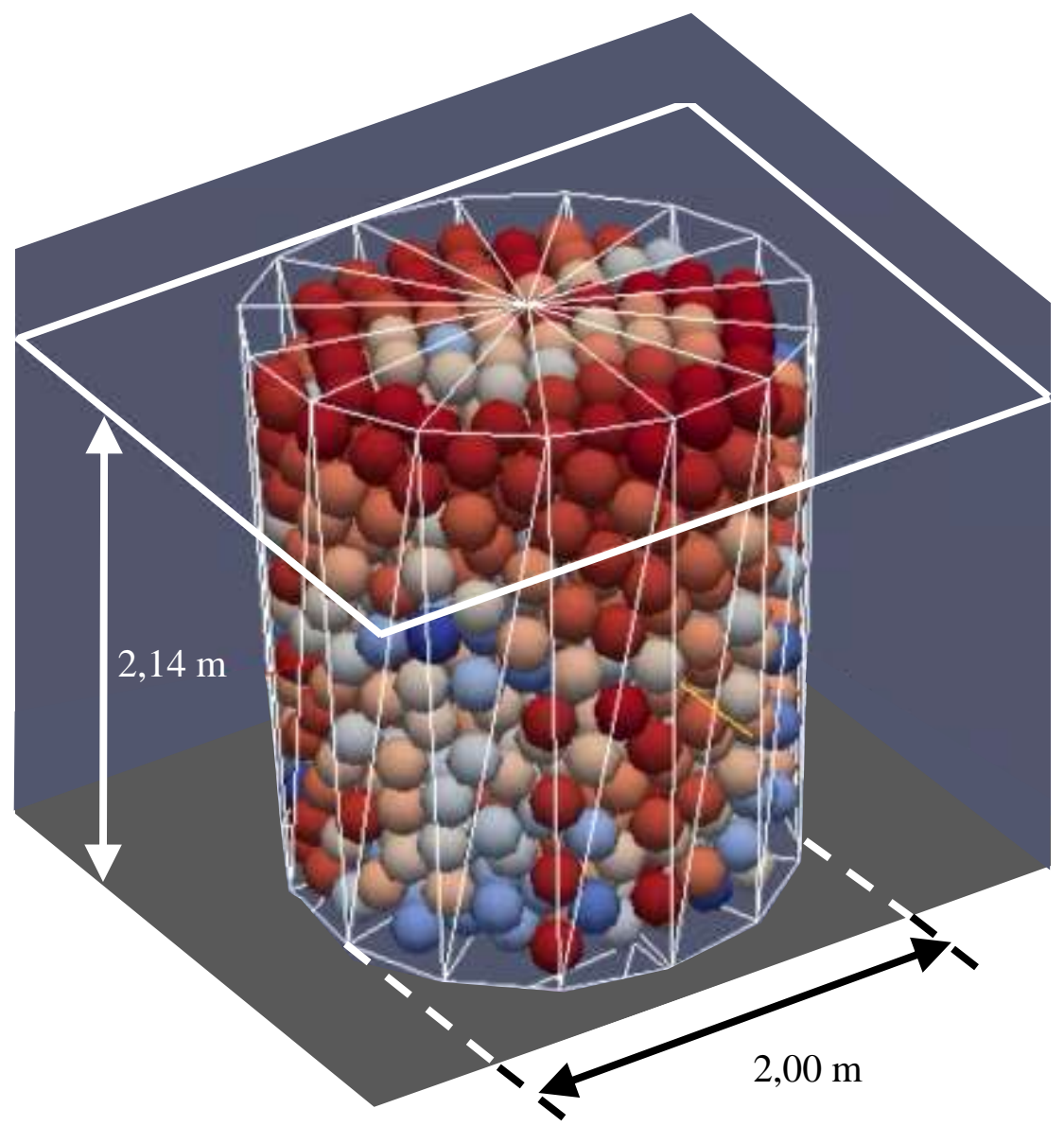

Figura 3.20. Condições de contorno iniciais da simulação. 


\section{APRESENTAÇÃO E ANÁLISE DE RESULTADOS}

Nesta seção são apresentados e analisados os resultados obtidos ao longo desta pesquisa. Inicialmente são mostradas todas as componentes das avaliações experimentais realizadas. Posteriormente, os resultados da simulação micromecânica do fenômeno de quebra são expostos, sendo feita sua respectiva discussão.

\subsection{RESULTADOS EXPERIMENTAIS}

Os resultados experimentais deste estudo, que são a fase inicial da metodologia proposta, podem ser agrupados em três categorias. A primeira corresponde ao estudo em essência do comportamento da partícula, o qual é obtido mediante a avaliação da ruptura individual do grão. $\mathrm{Na}$ segunda estão os resultados relacionados com o estudo da compressibilidade do conjunto de partículas, as quais podem ter contatos com ou sem cimentante. Na última categoria encontram-se as ferramentas experimentais usadas para a avaliação dos processos internos do material (processamento de imagens e emissões acústicas).

Inicialmente são apresentados os resultados do estudo da quebra do grão e o processamento estatístico necessário para uma melhor interpretação. Posteriormente, são expostos os resultados dos ensaios de compressão confinada unidimensional para os diferentes tipos de amostras, confeccionadas a partir dos procedimentos descritos no capítulo anterior. Inicialmente são mostrados os resultados dos corpos de prova feitos unicamente com microesferas. Posteriormente, aqueles moldados com uma mistura de epóxi e microesferas. De forma simultânea são apresentados os resultados dos monitoramentos das emissões acústicas, durante as compressões, as quais são analisadas para obter uma melhor interpretação dos resultados.

Por último, são mostrados os efeitos da quebra de partículas na curva granulométrica, em função do nível de tensão aplicado. A mudança granulométrica é avaliada principalmente pelo peneiramento (só alguns casos têm analises granulométrica a partir de imagens). Além disso, mostra-se a evolução da forma das partículas com esta degradação.

Foram executados cento e vinte (120) ensaios de compressão diametral de partículas individuais, cinquenta e três (53) ensaios de compressão confinada em amostras com diferentes densidades, todos monitorados com o equipamento de emissões acústicas, dos quais trinta e seis (36) ensaios concentram no estudo da quebra de partículas e dezessete (17) 
na avaliação dos materiais cimentados. As granulometrias por peneiramento foram feitas para todos os materiais no estado original e para os materiais resultantes dos ensaios (após ser carregado e quebrado). Além disso, foram feitos seis (6) ensaios de processamento de imagens, dois por material. O primeiro foi na condição sem dano (material original). $\mathrm{O}$ segundo foi realizado no material resultante de um ensaio de compressão confinada, submetido a um nível de tensão que permitisse a delimitação perfeita da NCL. A seguir são mostrados os resultados dos comportamentos encontrados durante esta fase experimental.

\subsubsection{RUPTURA DE PARTÍCULAS}

Os resultados dos ensaios de compressão diametral de partículas apresentados nesta seção são exclusivamente para o material A170. A realização com os outros materiais é complicada pelas dimensões dos grãos e pelas limitações do equipamento usado nesta pesquisa.

Na Figura 4.1 é ilustrada a montagem feita para a realização do ensaio de compressão diametral e o resultado típico do processo de quebra de uma partícula de vidro. Observam-se alguns fragmentos resultantes, os quais não recuperam a massa total da partícula, pois as partículas menores se dispersam durante a explosão da partícula original, mas são os mais representativos. Em termos gerais, observam-se divisões similares na maioria das partículas, a partir das evidências obtidas do material de maior tamanho.

Destaca-se que existe certa coincidência com algumas evidências obtidas de simulações numéricas, nas quais demostra-se que um certo número de partículas maiores controla o comportamento macroscópico do conjunto. No caso específico do critério de quebra implementado neste trabalho, descrito por Ciantia et al (2015), observam-se muitas semelhanças. Mesmo que o número de partes obtidas da quebra de uma partícula no laboratório (mais ou menos 8) não seja igual ao adotado no critério numérico (14), em ambos há evidências de quatro tipo de tamanhos caraterísticos, como pode ser visto na Figura 4.1.

Na Tabela 4.1 é apresentado um resumo das caraterísticas básicas dos resultados obtidos, ficando evidente a necessidade de realizar um processamento estatístico. Em essência todo material tem variabilidade, mesmo que seja um material industrial como o empregado nesta pesquisa. Impurezas na sua composição mineral, bolhas de ar geradas na fabricação, microfissuras, entre outras causas, afetam o resultado da resistência das partículas. Um fator relevante é a forma das partículas, que pode influenciar tanto o processo de realização do 
ensaio no laboratório como a interpretação do resultado. No caso do material de trabalho, observa-se na Figura 4.2 como varia a forma das partículas.
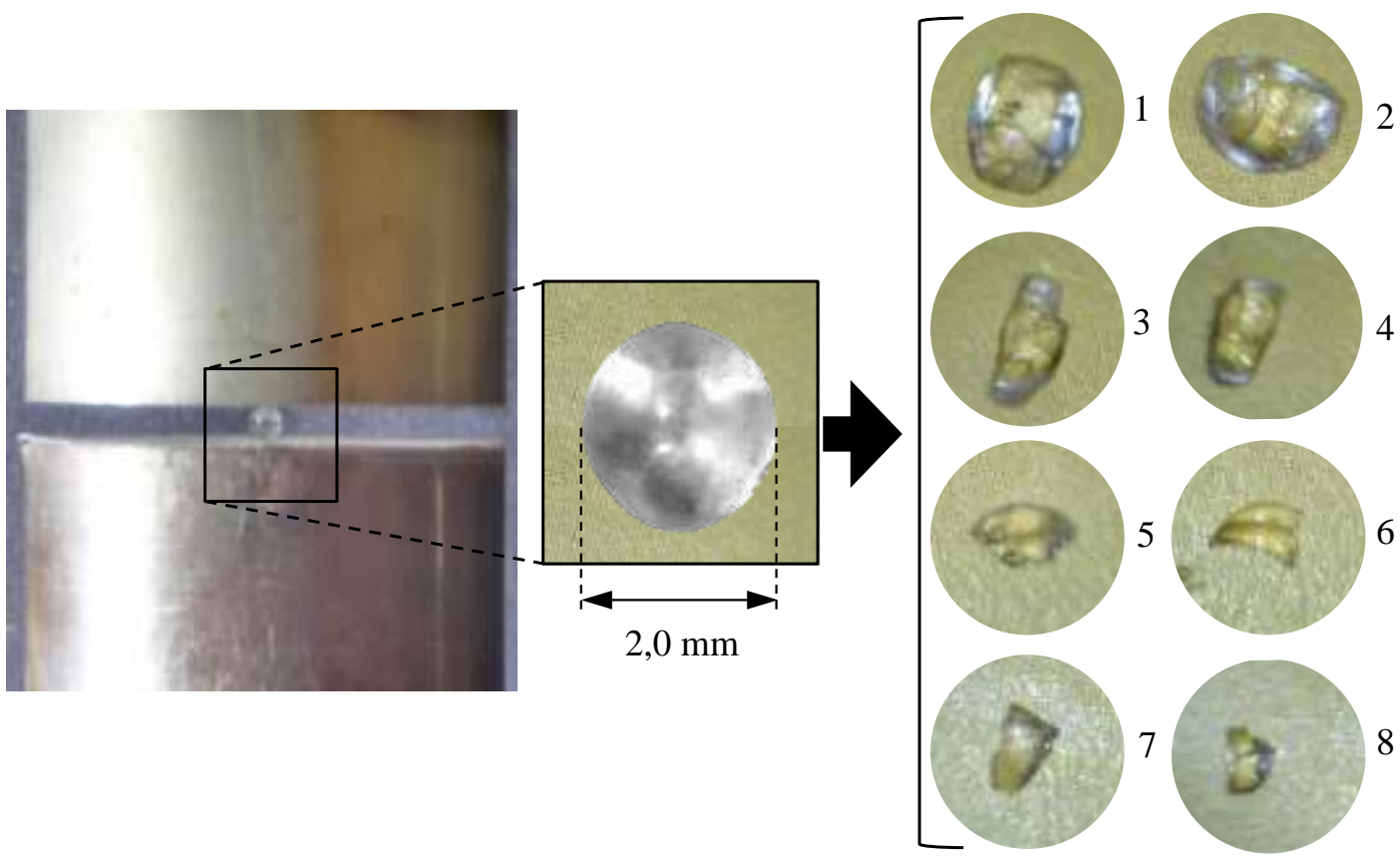

Figura 4.1. Detalhes do ensaio de compressão diametral e da quebra do grão.

Tabela 4.1. Estatística dos resultados primários do ensaio de compressão diametral dos grãos.

\begin{tabular}{|c|c|c|c|c|c|}
\hline \multirow{2}{*}{ Faixa ASTM } & \multirow{2}{*}{$\begin{array}{c}\text { Faixa } \\
\text { nanyyy}\end{array}$} & \multicolumn{2}{|c|}{ Diâmetros } & \multicolumn{2}{|c|}{ Força } \\
\cline { 3 - 5 } & $\mathrm{D}_{\text {mín }}(\mathrm{mm})-\mathrm{D}_{\text {máx }}(\mathrm{mm})$ & $\mu(\mathrm{mm})$ & $\sigma(\mathrm{mm})$ & $\mu(\mathrm{N})$ & $\sigma(\mathrm{N})$ \\
\hline $8-10$ & $2,00-2,38 \mathrm{~mm}$ & 2,15 & 0,07 & 883,50 & 317,58 \\
\hline $10-12$ & $1,68-2,00 \mathrm{~mm}$ & 1,81 & 0,06 & 878,00 & 314,57 \\
\hline $12-14$ & $1,40-1,68 \mathrm{~mm}$ & 1,38 & 0,04 & 419,00 & 86,61 \\
\hline $14-16$ & $1,18-1,40 \mathrm{~mm}$ & 1,11 & 0,04 & 293,80 & 71,19 \\
\hline $16-18$ & $1,00-1,18 \mathrm{~mm}$ & 0,95 & 0,04 & 238,50 & 61,33 \\
\hline
\end{tabular}

As curvas carga-deslocamento obtidas dos ensaios são apresentadas nas Figura 4.3 a Figura 4.7, ilustrando a variabilidade intrínseca do material nas variáveis primárias (força e deslocamento). A força máxima resistente aumenta com o aumento do diâmetro da partícula. Para a interpretação destes resultados foi usado o conceito de tensão caraterística $\left(\sigma=F / d^{2}\right)$, onde o diâmetro usado foi o valor da distância entre planos no momento do início da compressão, o que normalmente coincide com a menor dimensão da partícula.

O tratamento estatístico rotineiro para a interpretação deste tipo de dados é feito mediante o uso de uma distribuição de Weibull, como foi apresentado em detalhe no capítulo de revisão bibliográfica. A seguir serão apresentados os resultados desta abordagem e as interpretações necessárias. 

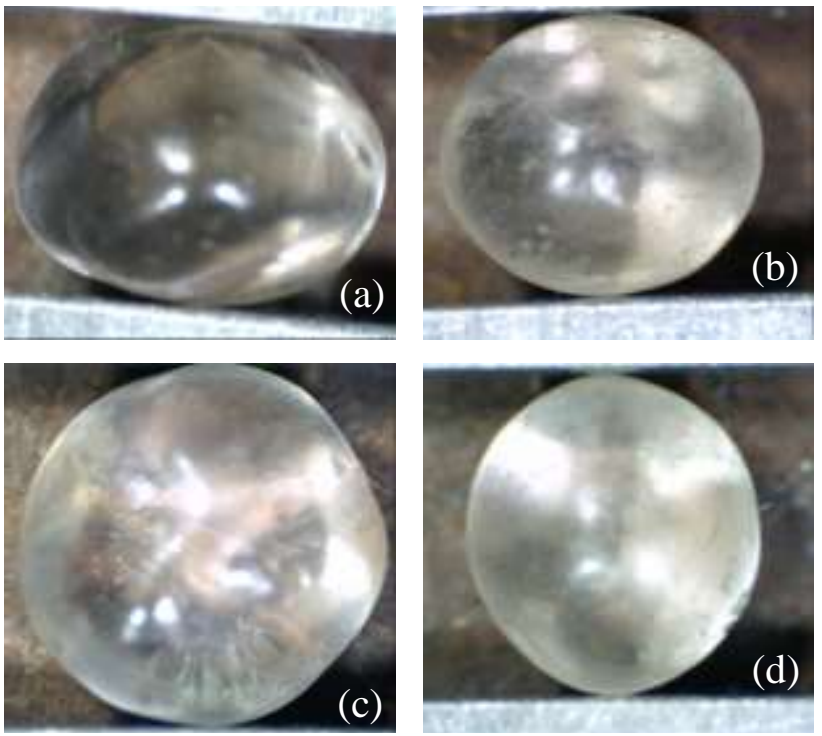

Figura 4.2. Detalhes da forma das partículas.

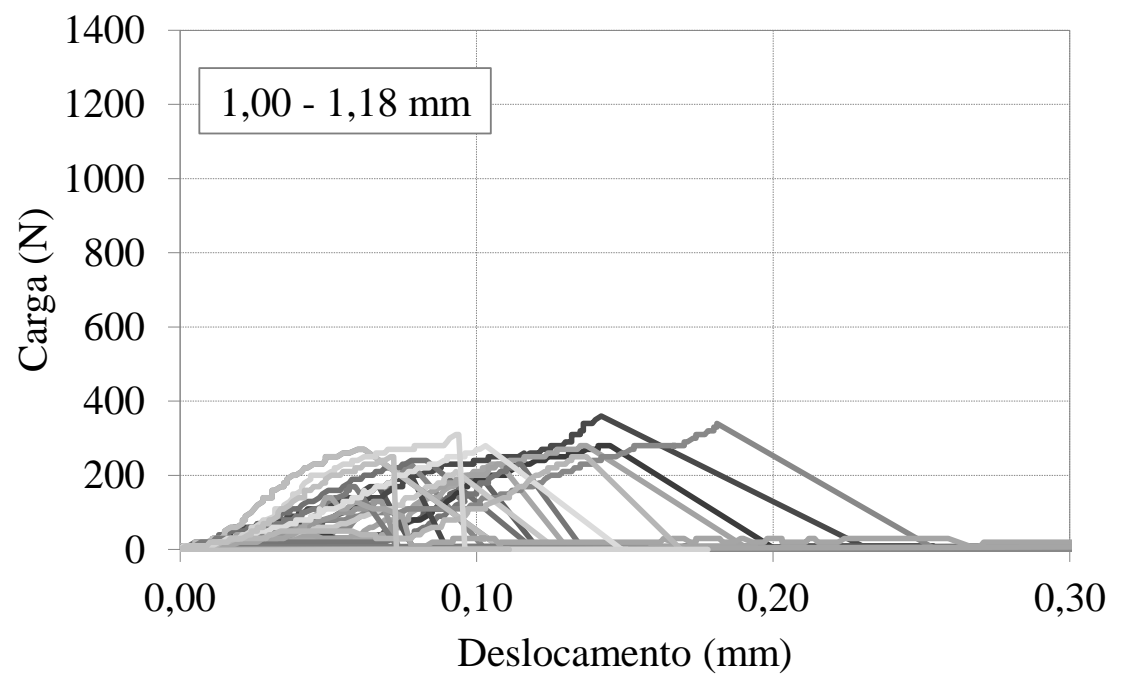

Figura 4.3. Ensaios de compressão diametral para esferas com diâmetros entre 1,00-1,18 mm.

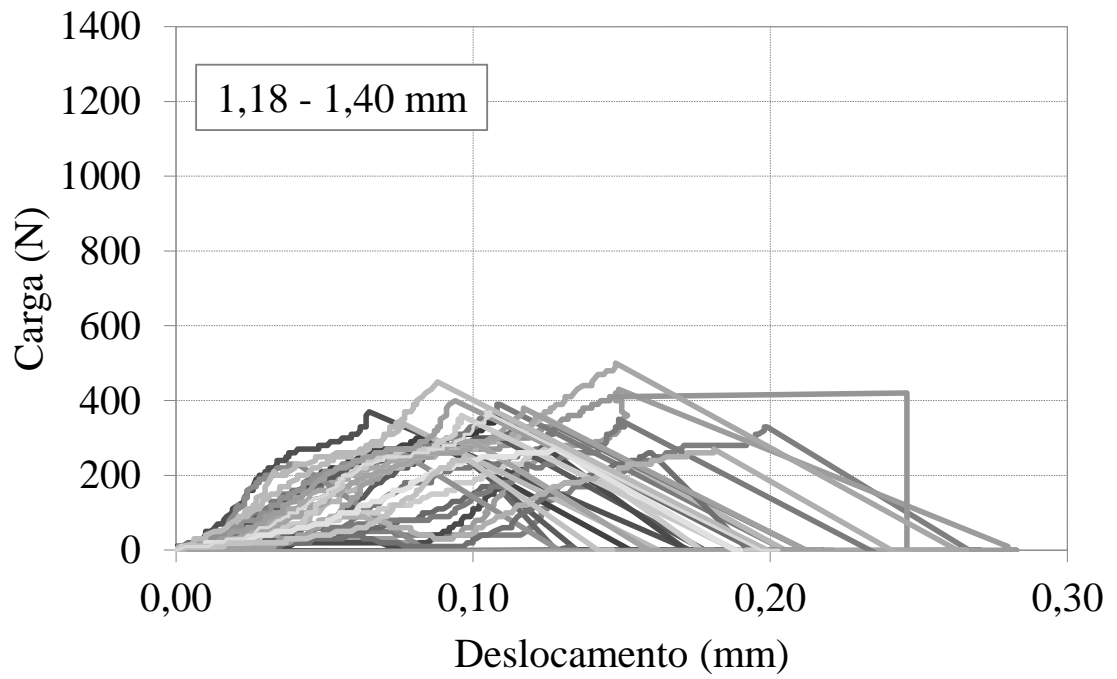

Figura 4.4. Ensaios de compressão diametral para esferas com diâmetros entre 1,18-1,40 mm. 


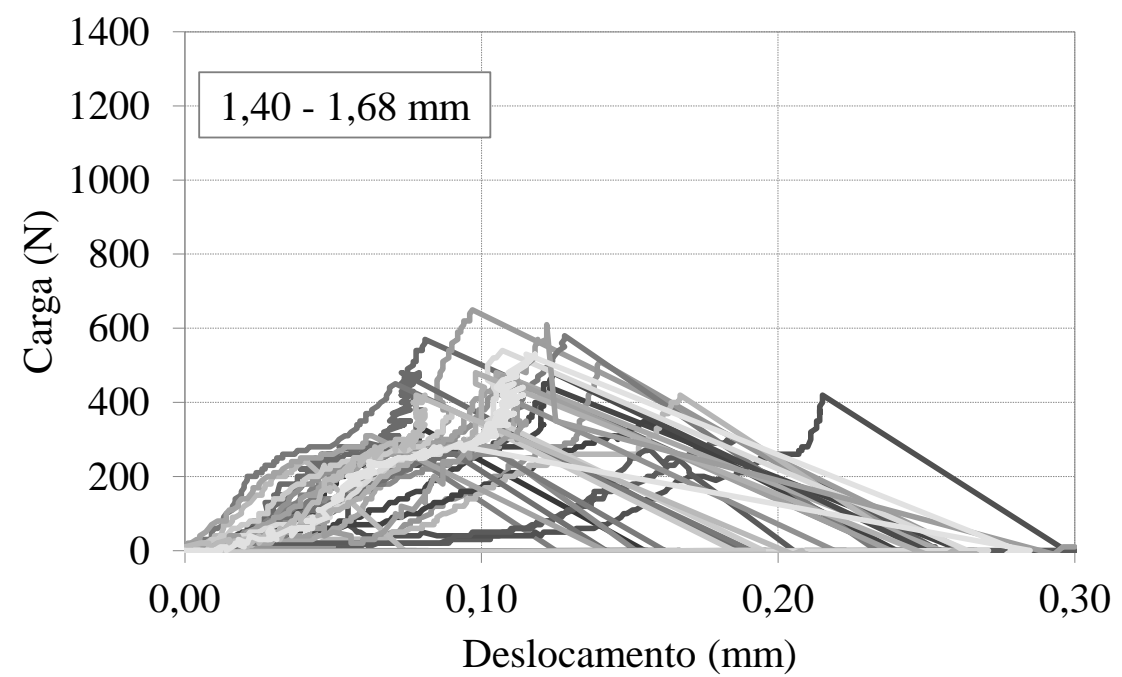

Figura 4.5. Ensaios de compressão diametral para esferas com diâmetros entre 1,40-1,68 mm.

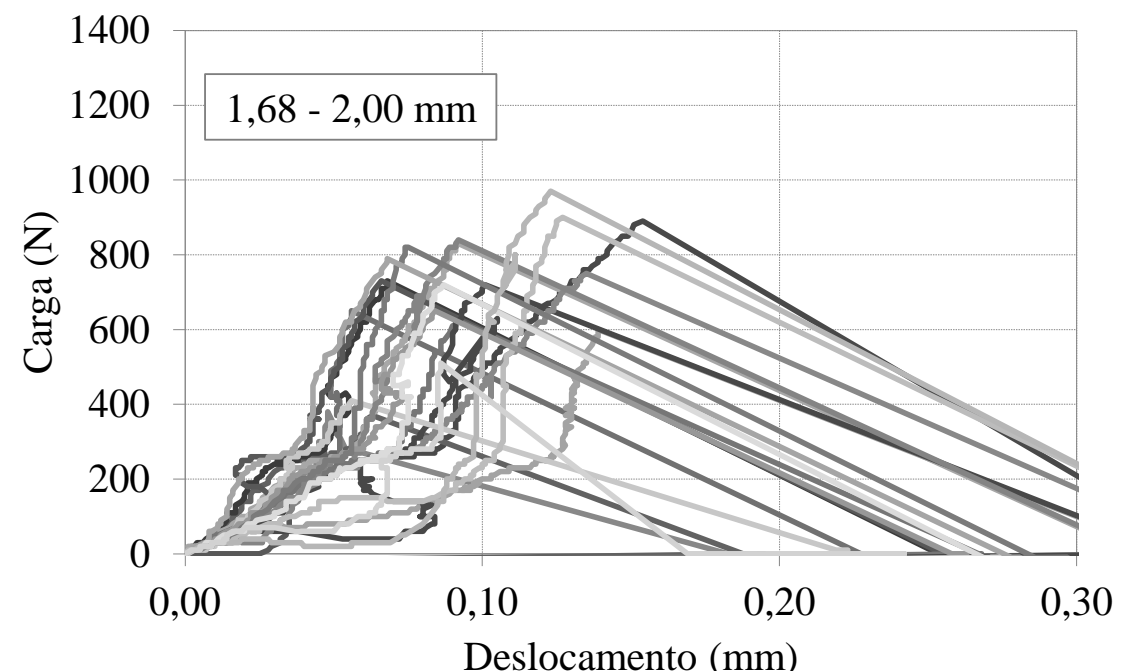

Figura 4.6. Ensaios de compressão diametral para esferas com diâmetros entre 1,68-2,00 mm.

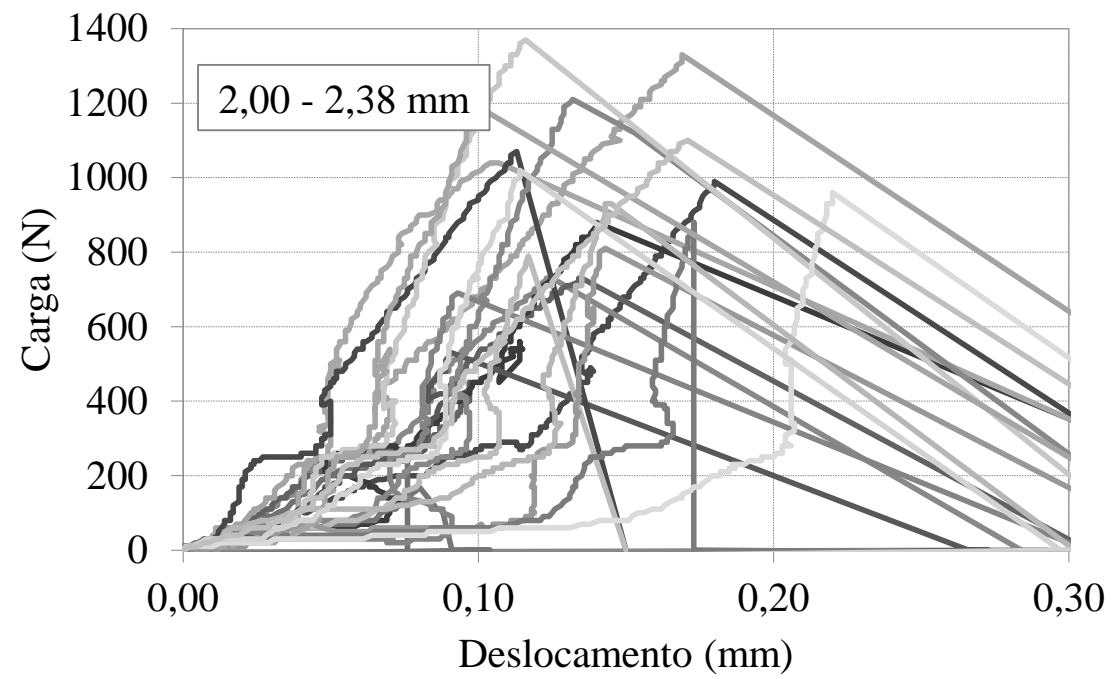

Figura 4.7. Ensaios de compressão diametral para esferas com diâmetros entre 2,00 -2,38 mm 
O primeiro passo é a construção das curvas de probabilidade de sobrevivência de uma partícula. Os resultados obtidos deste processo são apresentados na Figura 4.8, mostrando que o material apresenta o comportamento típico de um material quartzoso. Assim, entre as características está a tendência de partículas de diâmetro maior terem uma baixa probabilidade de sobrevivência para qualquer nível de tensões. A razão para isto é que nos eventos de fragmentação deste tipo de material, as quebras sempre acontecem em toda a partícula, o que vai depender do tamanho do grão (Nakata et al., 1999).

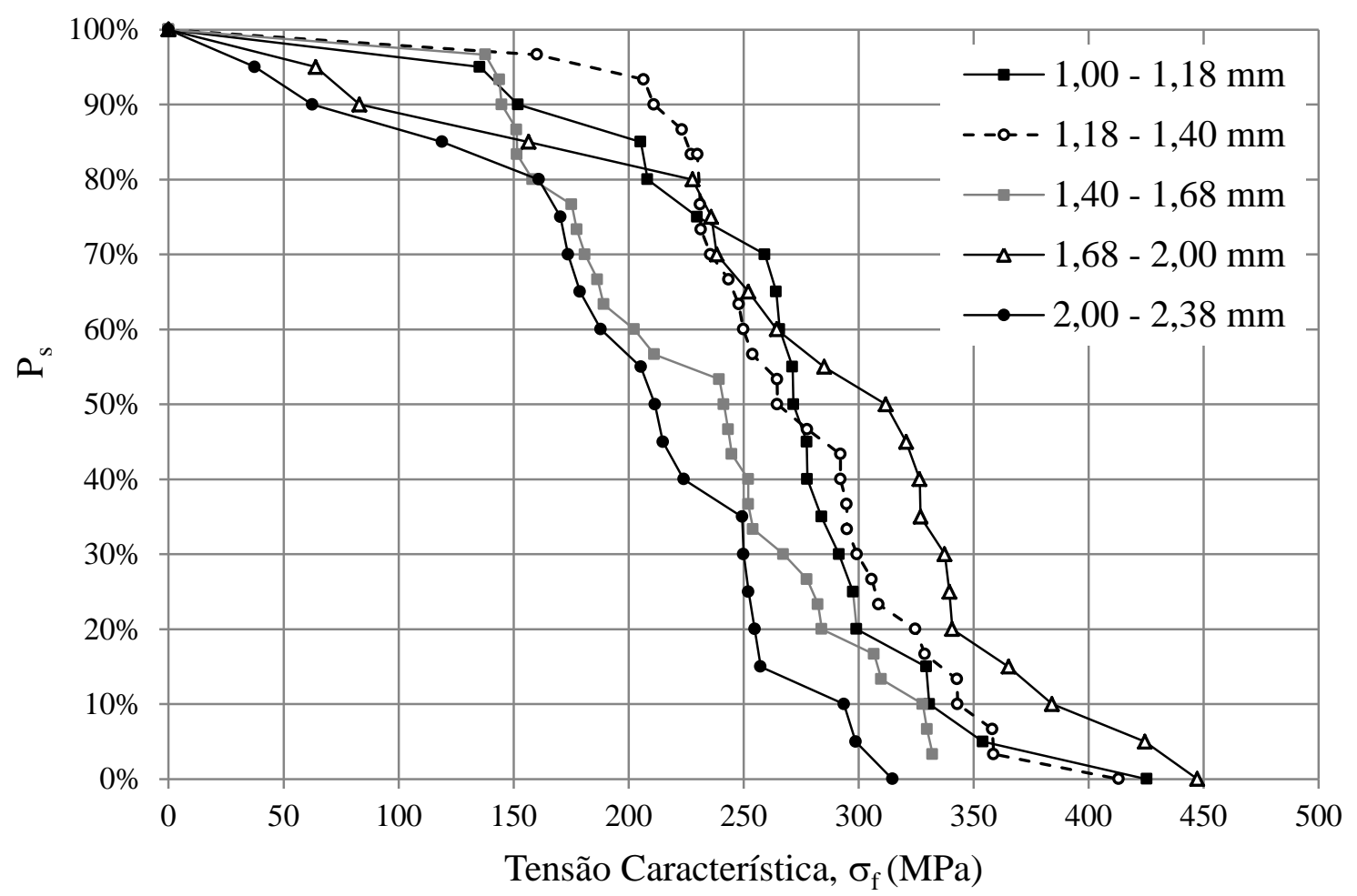

Figura 4.8. Curvas de probabilidade de sobrevivência.

Para uma melhor visualização dos resultados é feita a normalização das curvas em relação à tensão caraterística do $37 \%$ de probabilidade de sobrevivência $\left(\sigma_{0}\right)$, como é apresentado na Figura 4.9. Assim, elimina-se o efeito do tamanho para a realização da análise.

As curvas normalizadas mostram, que em termos gerais, a forma da curva para cada uma das faixas de tamanhos é similar. Isto em termos dos parâmetros da distribuição de Weibull está representada pelo módulo $(m)$, que mede a dispersão dos dados (diminuição da dispersão com o aumento do módulo). 


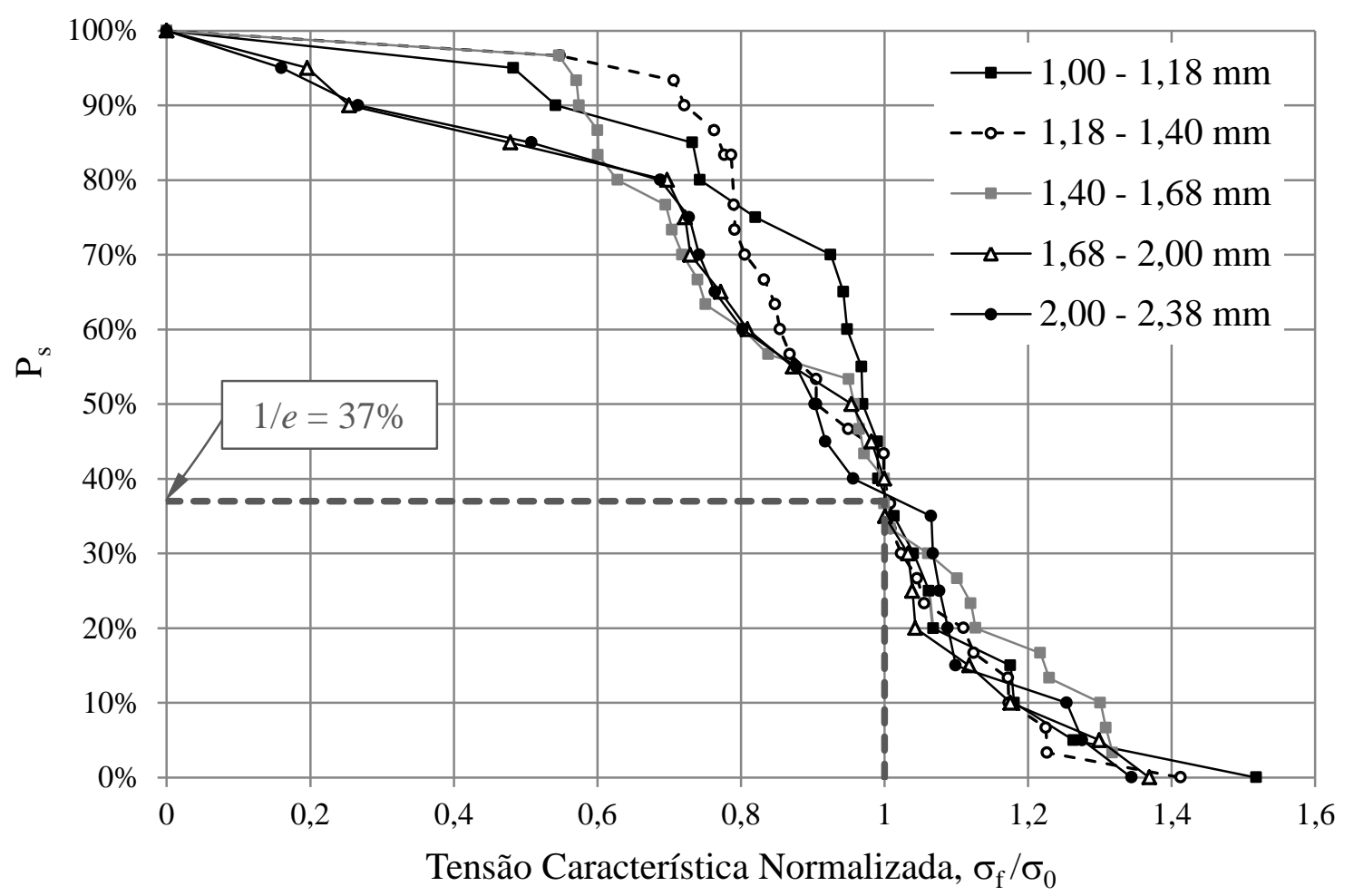

Figura 4.9. Curvas de probabilidade de sobrevivência normalizada pela tensão caraterística.

Um resumo dos parâmetros estatísticos de Weibull é apresentado na Tabela 4.2. Observa-se que os módulos são maiores para diâmetros menores, o que pode estar relacionado ao controle de qualidade das partículas. Materiais de maior diâmetro apresentam maiores impurezas e formatos menos controlados.

Tabela 4.2. Parâmetros da distribuição de Weibull para cada faixa de tamanhos.

\begin{tabular}{|c|c|c|c|c|}
\hline Faixa ASTM & $D_{\text {máx }}(\mathrm{mm})$ & $\mathrm{D}_{\text {mín }}(\mathrm{mm})$ & $\sigma_{0}(\mathrm{MPa})$ & $\mathrm{m}$ \\
\hline $8-10$ & 2,38 & 2,00 & 234,2 & 3,76 \\
\hline $10-12$ & 2,00 & 1,68 & 326,8 & 3,89 \\
\hline $12-14$ & 1,68 & 1,40 & 252,0 & 3,37 \\
\hline $14-16$ & 1,40 & 1,18 & 292,5 & 5,93 \\
\hline $16-18$ & 1,18 & 1,00 & 280,2 & 5,64 \\
\hline
\end{tabular}

Na Figura 4.10 são apresentadas as curvas usadas para a obtenção dos módulos de Weibull para os diferentes tamanhos. Ressalta-se que em alguns tamanhos foram descartados alguns dados (pontos de cor cinza) para a obtenção de um melhor ajuste. 

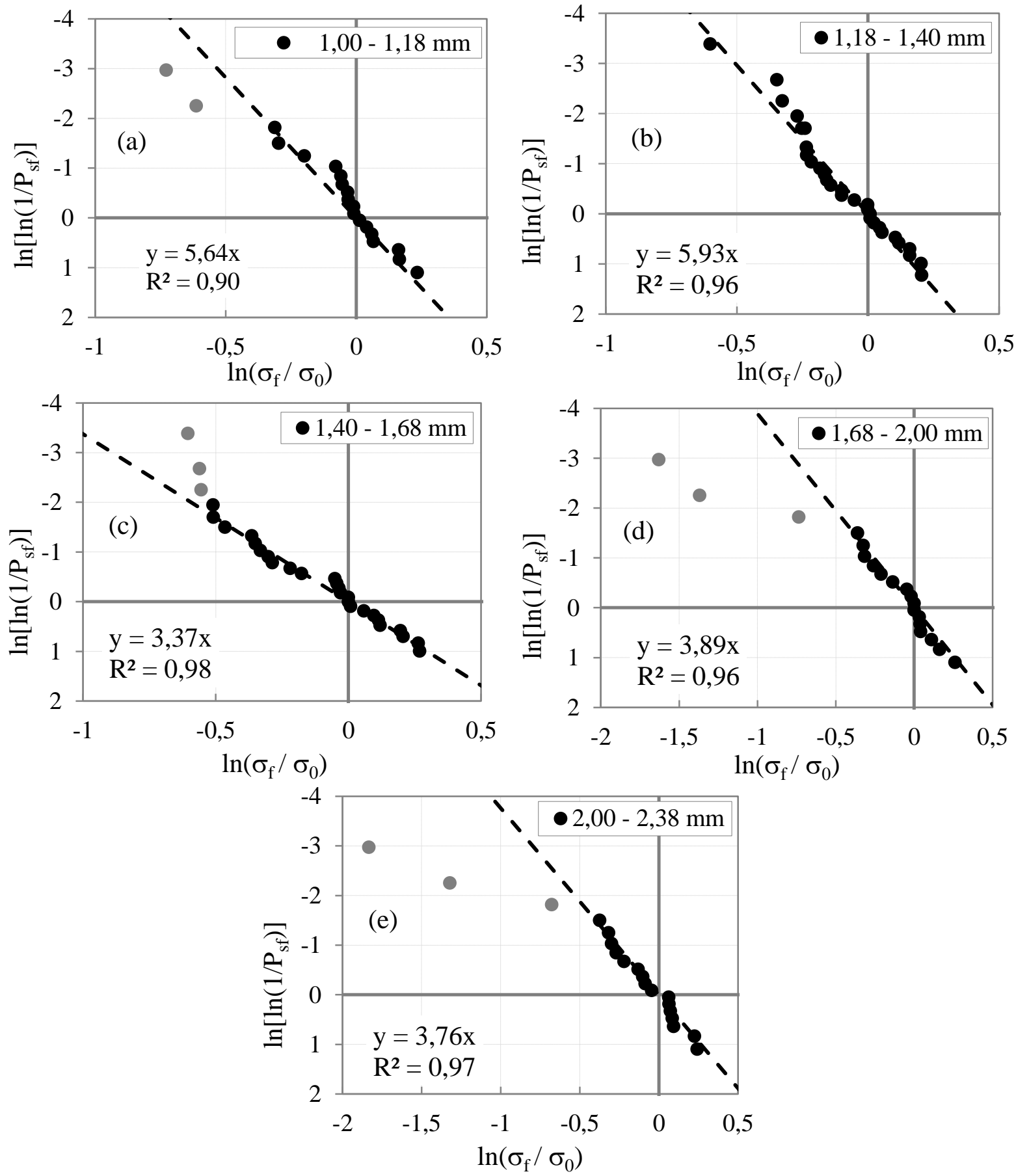

Figura 4.10. Curvas para a obtenção do modulo de Weibull dos materiais.

A metodologia de análise apresentada até este ponto é a normalmente encontrada na literatura para a caracterização das faixas granulométricas do material individualmente. Não obstante, o interessante seria a caracterização geral de todo o material com um grupo único de parâmetros. Para isto, na literatura normalmente é usada a seguinte expressão:

$$
P_{s}(d)=\exp \left[-\left(\frac{d}{d_{0}}\right)^{3}\left(\frac{\sigma}{\sigma_{0}}\right)^{m}\right]
$$


onde normalmente não fica claro qual é o valor do módulo $(m)$ e os valores de referência $\left(d_{0}, \sigma_{0}\right)$ para o conjunto de partículas de todos os tamanhos. Em muitos casos é usado o módulo $(m)$ correspondente ao diâmetro de referência, o qual é difícil de definir nos casos onde se tem valores muito diferentes (como o apresentado na Tabela 4.2). A seguir é apresentada a forma como foram obtidos os parâmetros que representam o grupo de partículas de todos os diâmetros.

O módulo de Weibull que representa todos os tamanhos de partículas é um valor médio dos valores individuais de cada tamanho. Para a obtenção deste parâmetro são plotadas todos as curvas de probabilidade de sobrevivência no gráfico de calibração (ver Figura 4.11). Assim, o valor de módulo é a inclinação da linha que passa pela origem do melhor ajuste por todos os pontos. Deve ser destacado que a probabilidade de sobrevivência é calculada para cada faixa de diâmetros e não para o conjunto completo. Na Figura 4.11 é apresentado o gráfico usado para a obtenção do módulo de Weibull para todo o conjunto de partículas (independente do tamanho). Observa-se que o módulo por faixa pode variar entre 3 e 8 , dependendo o tamanho escolhido, enquanto que o valor do conjunto é de 4,39. Este valor representa a dispersão do conjunto e não a de cada intervalo de diâmetros.

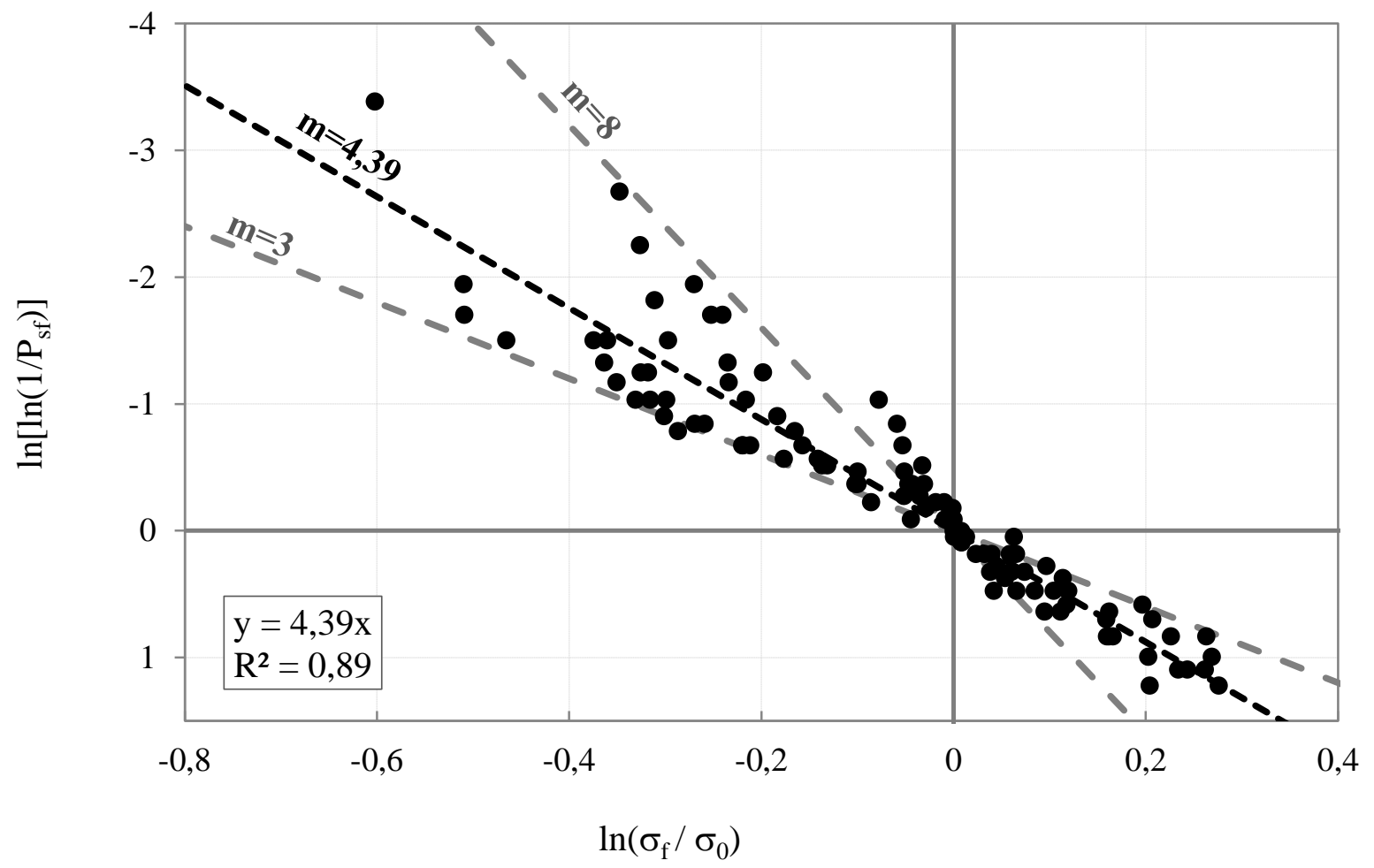

Figura 4.11. Obtenção do modulo de Weibull do conjunto de partículas. 
Por outro lado, é possível obter da equação 4.1 a lei de evolução da tensão característica para $37 \%$ de probabilidade de sobrevivência, como:

$$
\sigma_{0, d}=\sigma_{0} \cdot\left(\frac{d}{d_{0}}\right)^{-3 / m}
$$

Na Figura 4.12 são plotados os dados experimentais da relação de diâmetros $\left(d / d_{0}\right)$ contra tensão de quebra $\left(\sigma_{0}\right)$, assumindo como diâmetro de referência o valor médio da faixa de maior tamanho (Faixa ASTM 8-10, diâmetro médio de 2,19mm). Observa-se que foi descartado um ponto (cor cinza) para a obtenção do melhor ajuste.

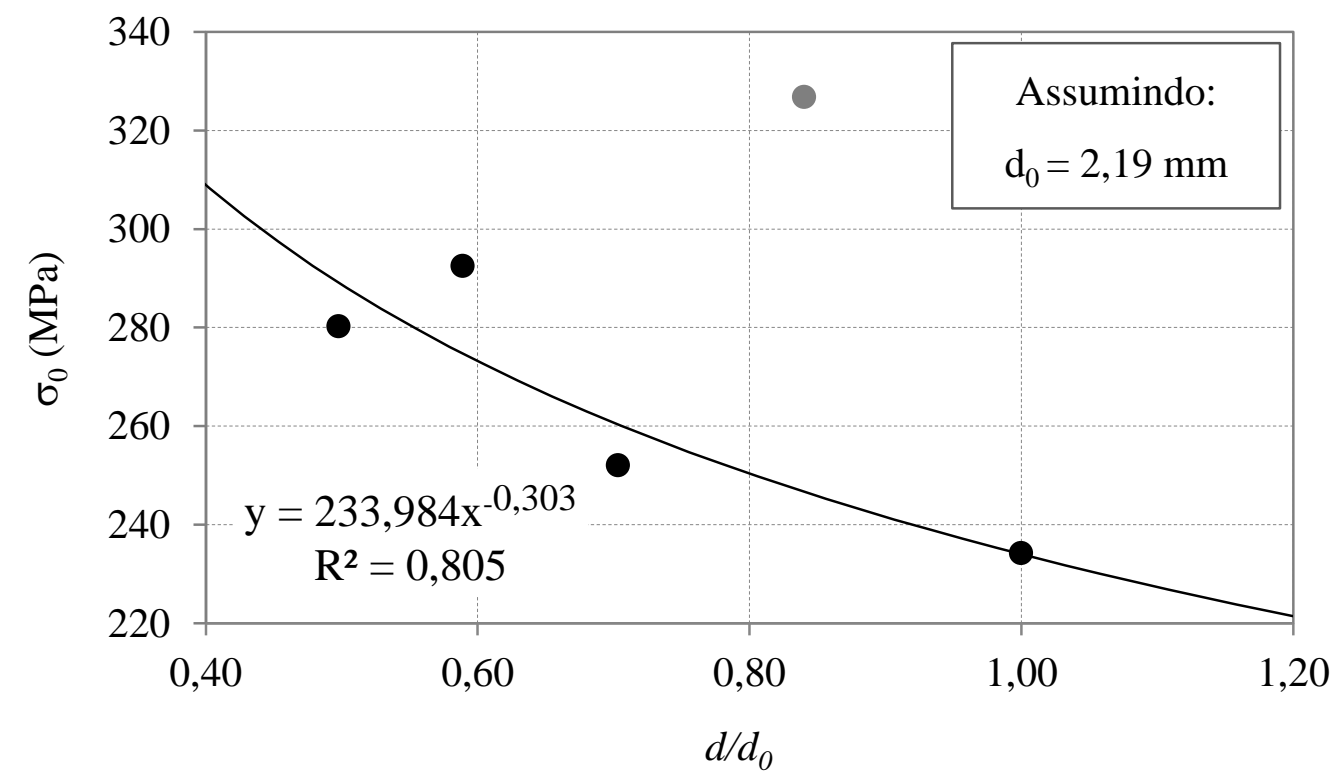

Figura 4.12. Efeito do tamanho da partícula na tensão de quebra do material A170.

Verifica-se que coeficiente da curva de potência coincide com o valor de tensão caraterístico da faixa de referência escolhida (234,2MPa). Quanto ao exponente, tem-se:

$$
\frac{-3}{m}=-0,303 \rightarrow m \approx 10
$$

Como pode-se observar, o valor de módulo não coincide com o valor calculado anteriormente. $\mathrm{O}$ autor desta tese verificou que o exponente da equação podia ser modificado, para levar em consideração o efeito do tamanho, da seguinte maneira:

$$
P_{s}(d)=\exp \left[-\left(\frac{d}{d_{0}}\right)^{\frac{4}{3}}\left(\frac{\sigma}{\sigma_{0}}\right)^{m}\right]
$$


assim,

$$
\sigma_{0, d}=\sigma_{0} \cdot\left(\frac{d}{d_{0}}\right)^{-\frac{4}{3 \cdot m}}
$$

Usando esta proposta e o expoente $m=-0,303$, obtido na Figura 4.12:

$$
\frac{-4}{3 \cdot m}=-0,303 \rightarrow m=4,40
$$

O valor de $m=4,40$ obtido com a fórmula proposta é muito próximo do valor de $m=4,39$ obtido com o melhor ajuste aos dados com todos os diâmetros mostrado na Figura 4.11. Para tentar validar está modificação foi feito o mesmo procedimento com a areia de quartzo estudada por Nakata et al (1999). Na Figura 4.13 e Figura 4.14 são apresentados os resultados da obtenção do módulo de Weibull e dos parâmetros da lei de evolução da tensão caraterística com o diâmetro da partícula. Desta forma pode-se verificar que:

$$
\frac{-4}{3 \cdot m}=-0,501 \rightarrow m=2,66
$$

O valor obtido de 2,66 é muito próximo ao valor de 2,52 quanto se aplica o ajuste médio a todos os diâmetros estudados por Nakata et al (1999), como mostrado na Figura 4.13. Não obstante, esta proposta deve ser validada com uma quantidade maior de dados, verificando a sua aplicabilidade a uma base de dados mais ampla.

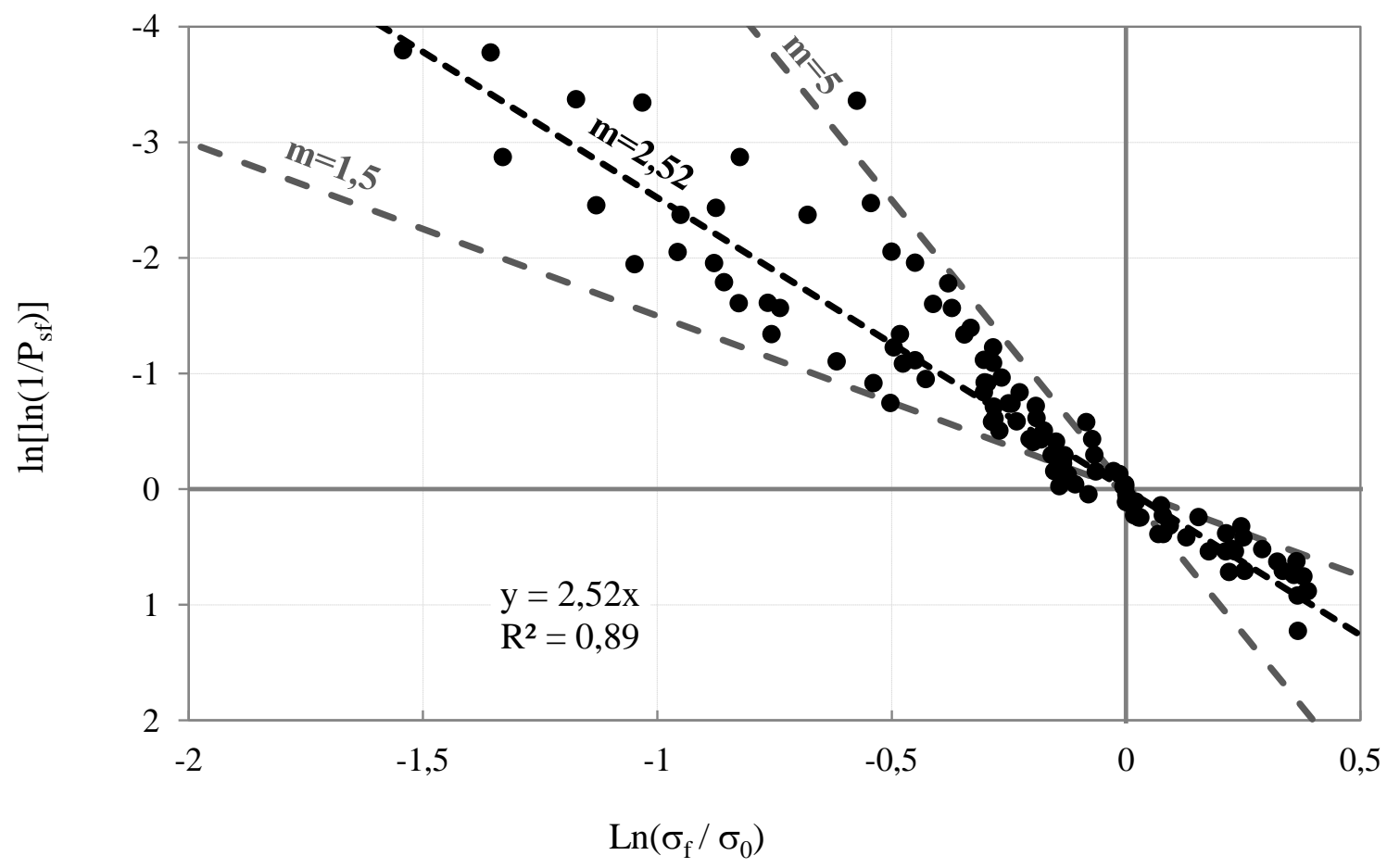


Figura 4.13. Modulo de Weibull da areia de quartzo da pesquisa feita por Nakata et al (1999).

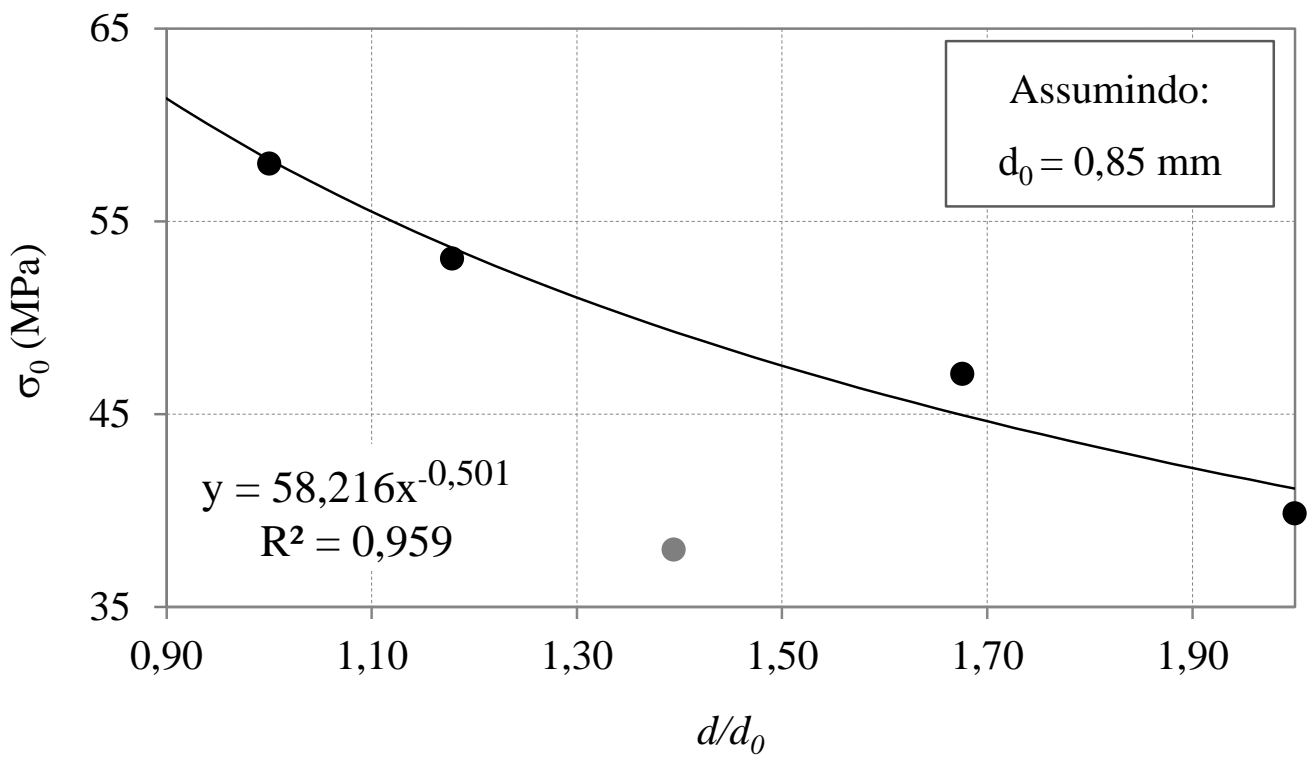

Figura 4.14. Efeito do tamanho da partícula na tensão de quebra para a areia de quartzo da pesquisa feita por Nakata et al (1999).

Em relação aos valores de referência $\left(d_{0}, \sigma_{0}\right)$, o autor verificou que a obtenção da evolução da tensão de quebra é indiferente aos valores escolhidos. Não obstante, deve-se ter cuidado na hora da calibração, procurando a configuração dos dados que permita o melhor ajuste.

Na Tabela 4.3 apresentam-se os resultados da tensão característica com probabilidade de sobrevivência de $37 \%$, obtidos mediante o modelo da equação 4.3, para cada uma das faixas de tamanhos. Observa-se que as partículas entre 1,68-2,00 mm apresentam o maior erro, não obstante, dentro das limitações do modelo e das dificuldades de simular este fenômeno, o ajuste é considerado bastante satisfatório.

Tabela 4.3. Resultados do modelo geral de distribuição de resistência da partícula.

\begin{tabular}{|c|c|c|c|c|c|c|c|c|c|}
\hline \multirow{2}{*}{$\begin{array}{c}\text { Faixa } \\
\text { ASTM }\end{array}$} & \multirow{2}{*}{$\begin{array}{c}\mathrm{D}_{\text {máximo }} \\
(\mathrm{mm})\end{array}$} & \multirow{2}{*}{$\begin{array}{c}\mathrm{D}_{\text {mínimo }} \\
(\mathrm{mm})\end{array}$} & \multirow{2}{*}{$\begin{array}{c}\mathrm{D}_{\text {médio }} \\
(\mathrm{mm})\end{array}$} & \multirow{2}{*}{$\mathrm{m}$} & \multirow{2}{*}{$\sigma_{0}(\mathrm{MPa})$} & \multirow{2}{*}{$\mathrm{D} / \mathrm{D}_{0}$} & \multicolumn{2}{|c|}{ Tensão para $\mathrm{Ps}=37 \%, \sigma(\mathrm{MPa})$} & \multirow{2}{*}{ Erro } \\
\hline & & & & & & & Modelo & Experimental & \\
\hline $8-10$ & 2,38 & 2,00 & 2,19 & 4,39 & 234,20 & 1,00 & 234,2 & 234,2 & $0,0 \%$ \\
\hline $10-12$ & 2,00 & 1,68 & 1,84 & 4,39 & 234,20 & 0,84 & 246,9 & 326,8 & $24,4 \%$ \\
\hline $12-14$ & 1,68 & 1,40 & 1,54 & 4,39 & 234,20 & 0,70 & 260,6 & 252,0 & $3,4 \%$ \\
\hline $14-16$ & 1,40 & 1,18 & 1,29 & 4,39 & 234,20 & 0,59 & 275,0 & 292,5 & $6,0 \%$ \\
\hline $16-18$ & 1,18 & 1,00 & 1,09 & 4,39 & 234,20 & 0,50 & 289,5 & 280,2 & $3,3 \%$ \\
\hline
\end{tabular}


Na Figura 4.15 são apresentadas as curvas de probabilidade de sobrevivência para cada uma das faixas de diâmetros de partículas. Na figura estão plotados os dados experimentais junto com a curva do modelo de distribuição de Weibull que usa os parâmetros calibrados com o mesmo grupo de parâmetros para todas as faixas (linha descontínua de cor preta), o qual mostra um ajuste razoável para sua aplicação, exceto para partículas na faixa de 1,682,00, Figura 4.15(d), como já comentado.
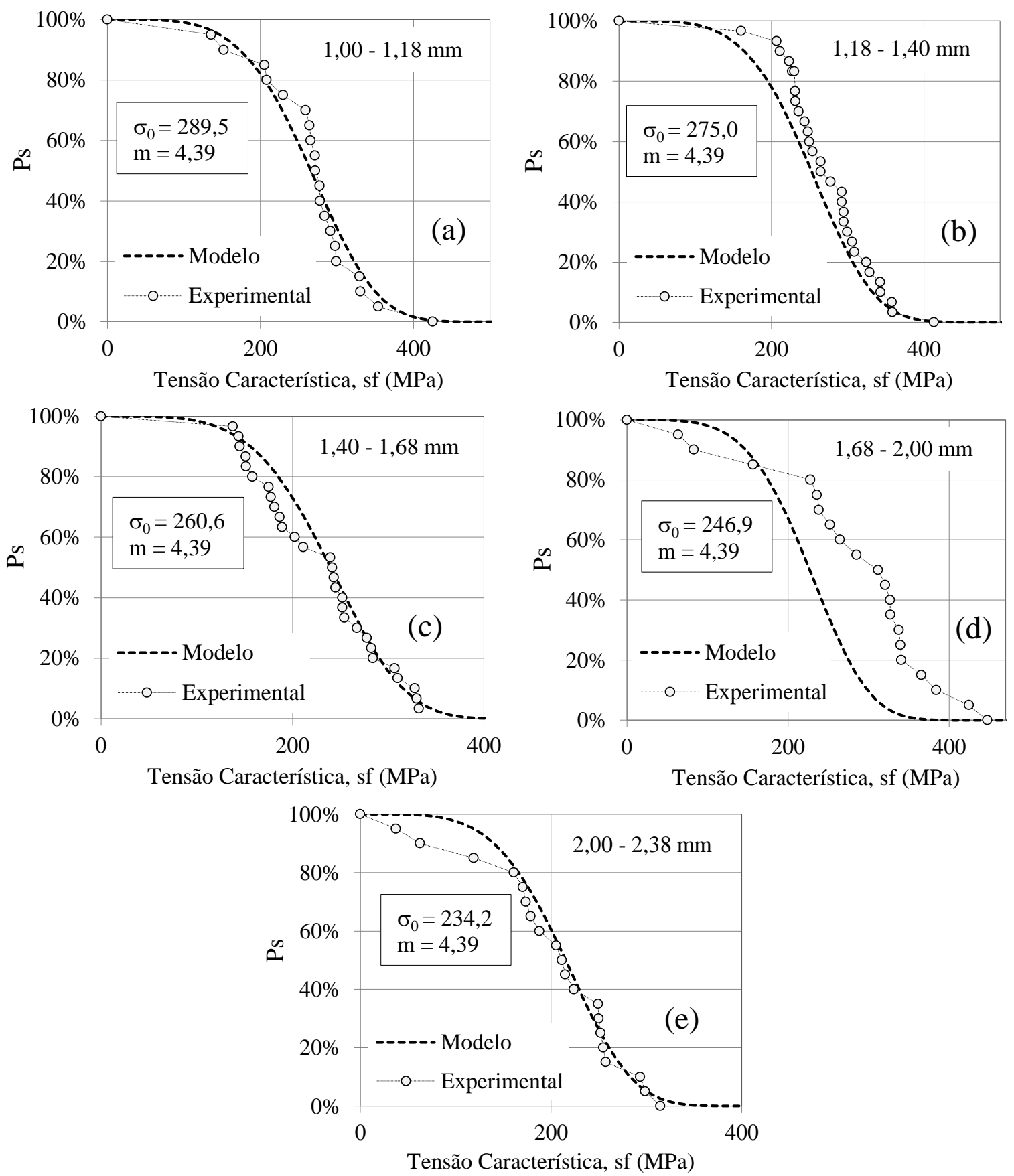

Figura 4.15. Curvas de probabilidade de sobrevivência: dados experimentais vs. Modelos calibrados. 
Na Figura 4.16 é apresentado o modelo teórico geral ajustado com um mesmo grupo de parâmetros. Está figura ilustra claramente as hipóteses descritas anteriormente. O fato de todas as curvas usarem o mesmo módulo, significa que todas as faixas têm a mesma dispersão, e que a inclinação central das curvas é a mesma. Em relação à lei de evolução da tensão de quebra $\left(\sigma_{0}\right)$, sua função é deslocar a curva horizontalmente para simular a mudança da resistência com o tamanho da partículas.

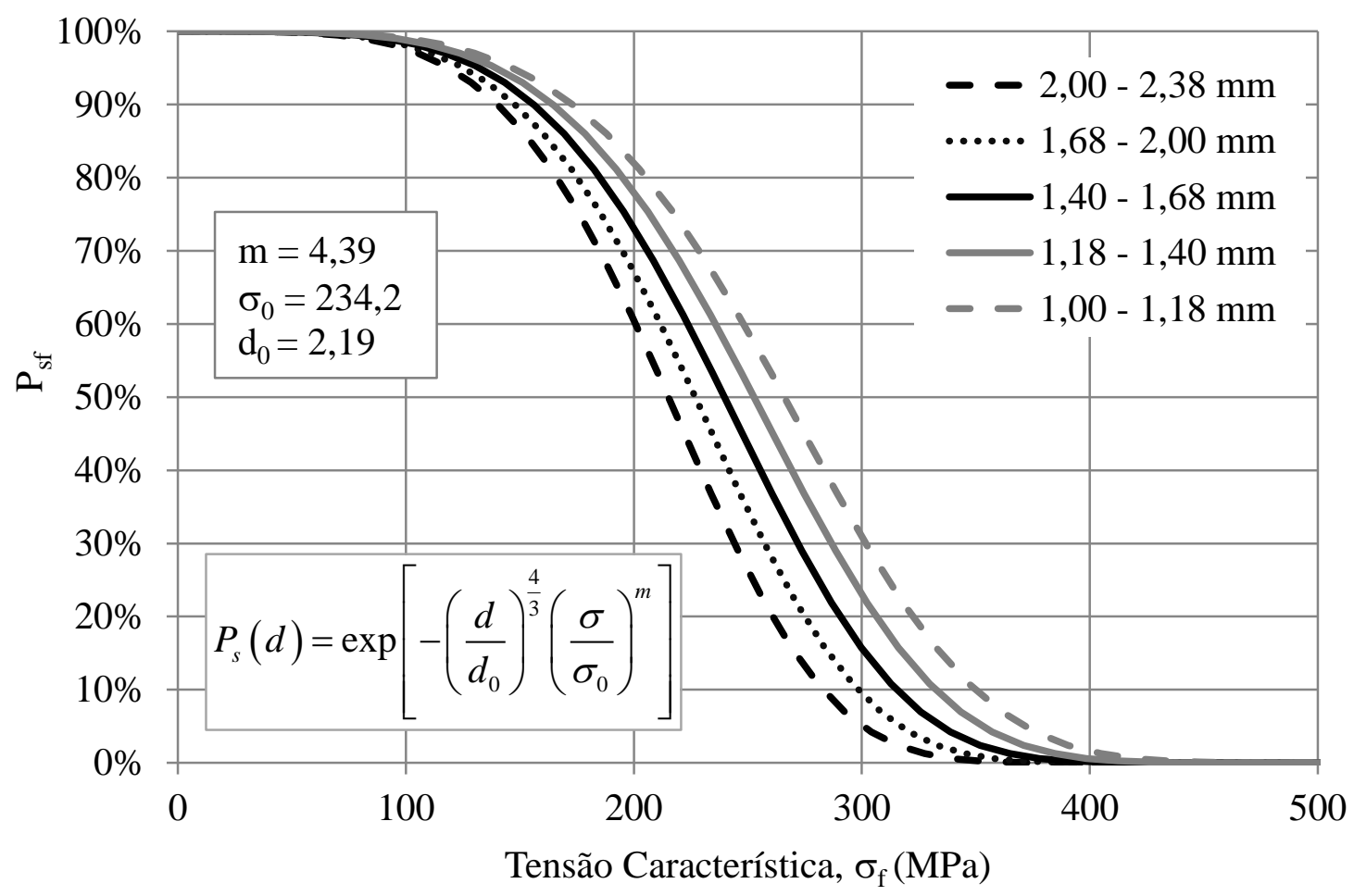

Figura 4.16. Modelo geral de probabilidade de sobrevivência.

\subsubsection{COMPRESSÃO CONFINADA - MATERIAL SOLTO}

\subsubsection{Condicões dos ensaios}

A primeira atividade executada durante esta campanha de ensaios foi a verificação de algumas condições, que poderiam distorcer a interpretação dos resultados. Uma destas condições, e possivelmente a mais crítica, é o atrito lateral das paredes do molde. Como foi descrito no capítulo anterior, para mitigar este problema foi usado um sistema plásticovaselina nas paredes, o qual diminui o atrito. Na Figura 4.17 são apresentados os resultados de vários ensaios de compressão confinada, com e sem o uso do plástico nas paredes, para dois tipos de materiais. Observa-se, que para condições sem plástico nas paredes (linhas cor cinza), a variação da inclinação, no trecho final da curva de compressibilidade, é bastante 
significativa. Com o sistema de plástico-vaselina, a variação na resposta das curvas de compressibilidade é minimizada, de uma forma bastante satisfatória, como pode ser observado na Figura 4.18. Assim, com o uso do sistema de plástico-vaselina na parede do molde, garante-se que qualquer possível mudança no comportamento, não é devida aos efeitos do atrito lateral.
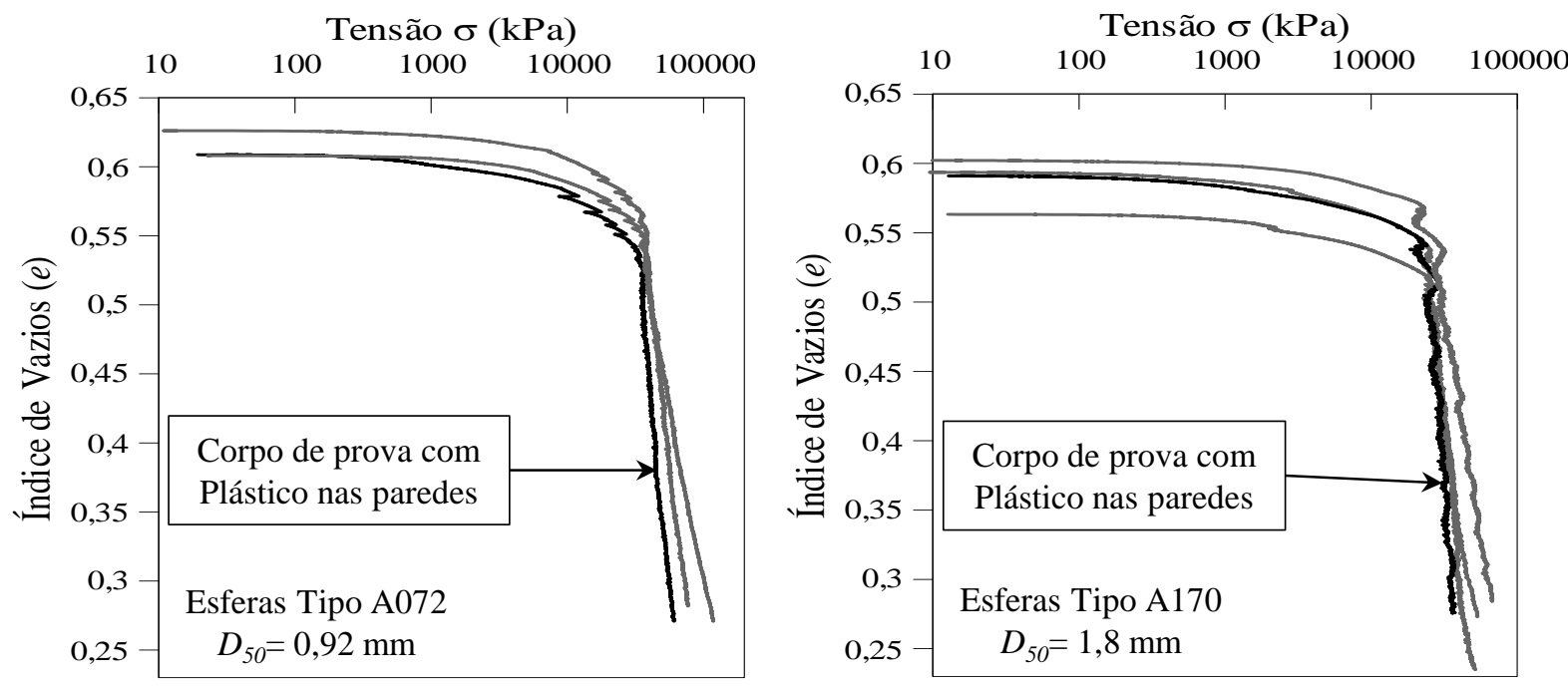

Figura 4.17. Influência do atrito lateral na compressão confinada.
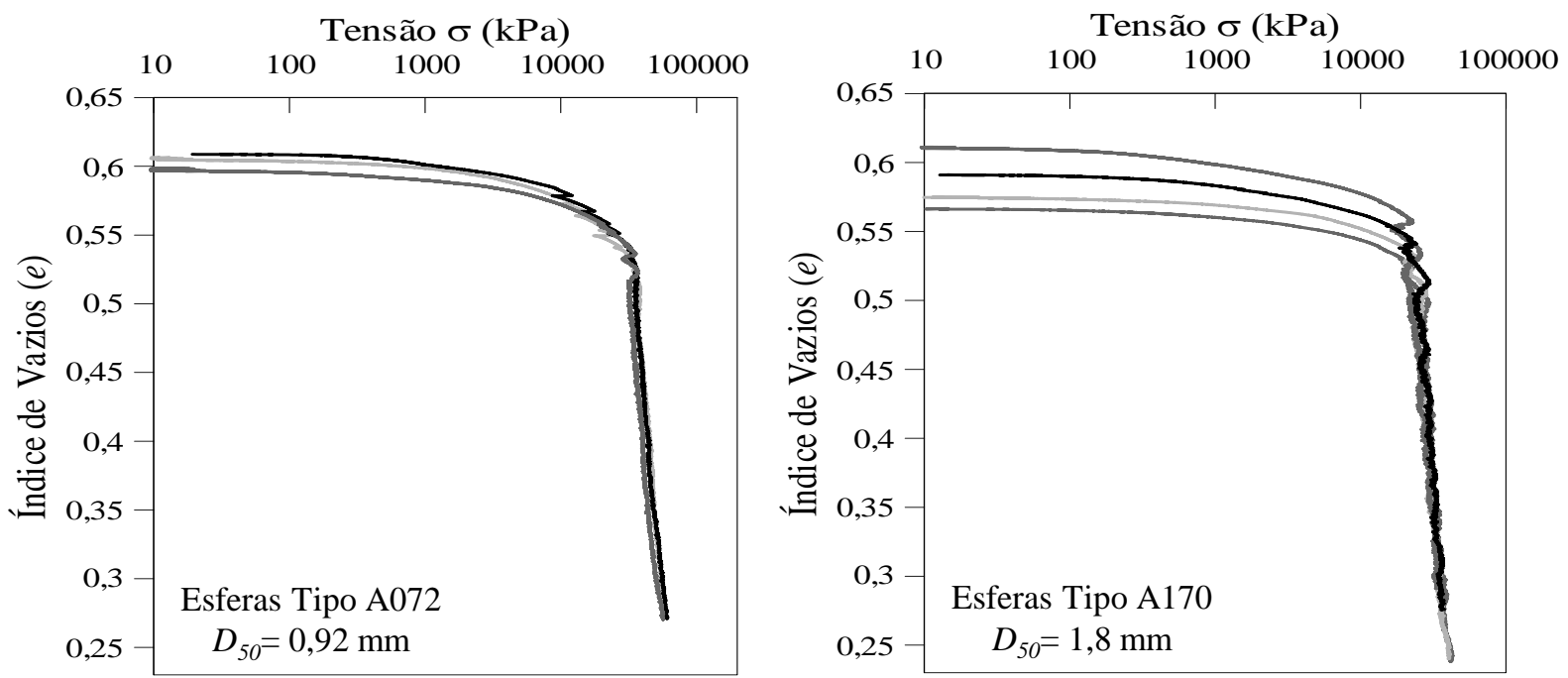

Figura 4.18. Curvas com compressibilidade com sistema plástico-vaselina nas paredes.

A Figura 4.19 mostra detalhes do plástico após o ensaio de compressão. Nestas imagens, evidencia-se que o nível de desgaste, sofrido na interface plástico-parede, é maior na parte superior do molde, em relação ao fundo do mesmo. Isto se deve aos maiores gradientes de deslocamento no contato direto com o pistom do sistema de carga, devido ao atrito nas paredes. Outra condição verificada foi a velocidade de deslocamento usada para a realização dos ensaios. Na maioria dos casos, o efeito da velocidade é pouco significativo na avaliação 
do comportamento de materiais granulares. Não obstante, se queria verificar se a resposta da compressibilidade unidimensional, com efeitos de quebra das partículas, realmente não era influenciada pela velocidade de deslocamento. A Figura 4.20 ilustra que a influência da velocidade é pouco significativa no comportamento, já que os padrões de compressibilidade são bastante similares, para as diferentes condições de velocidade.

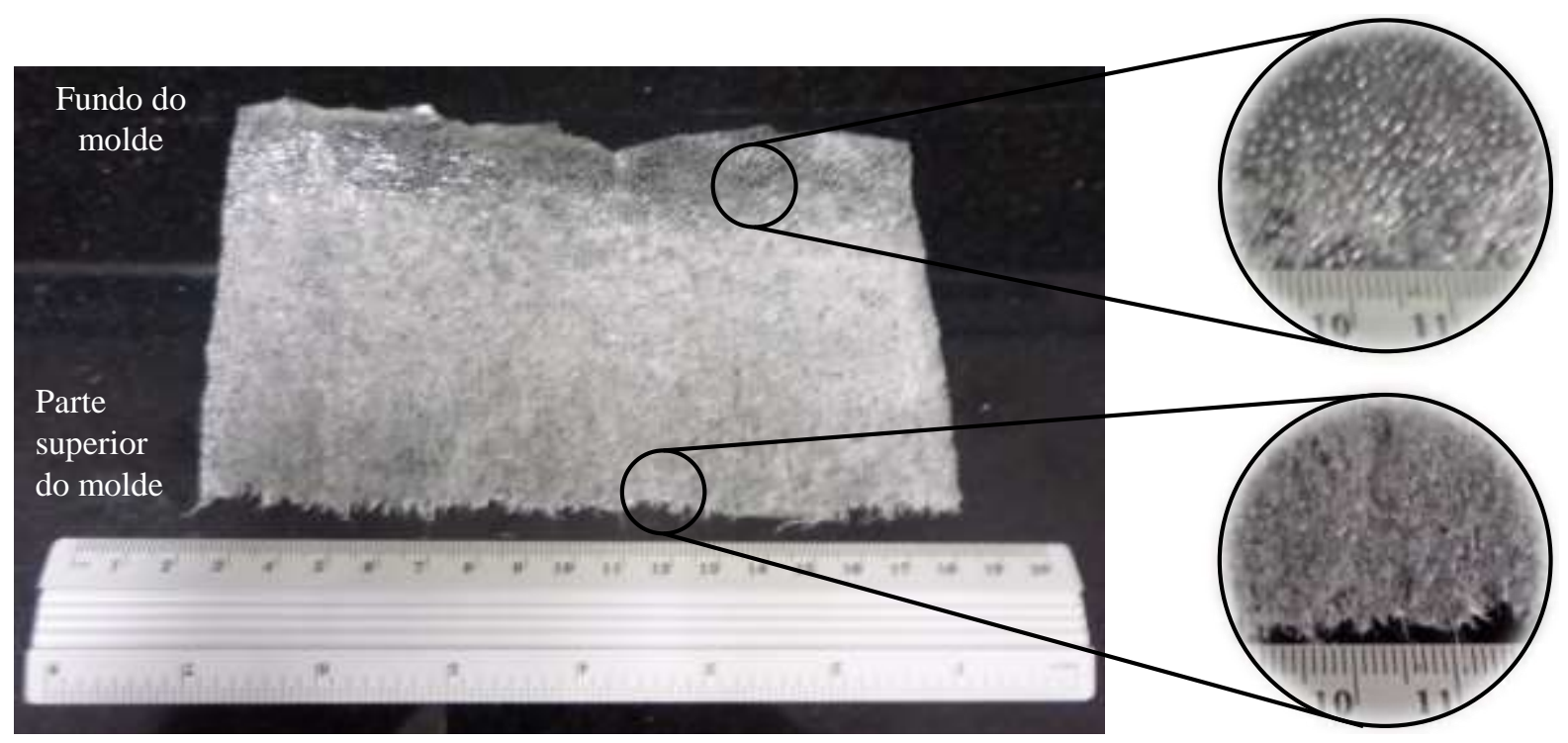

Figura 4.19. Imagem do plástico após o ensaio de compressão.

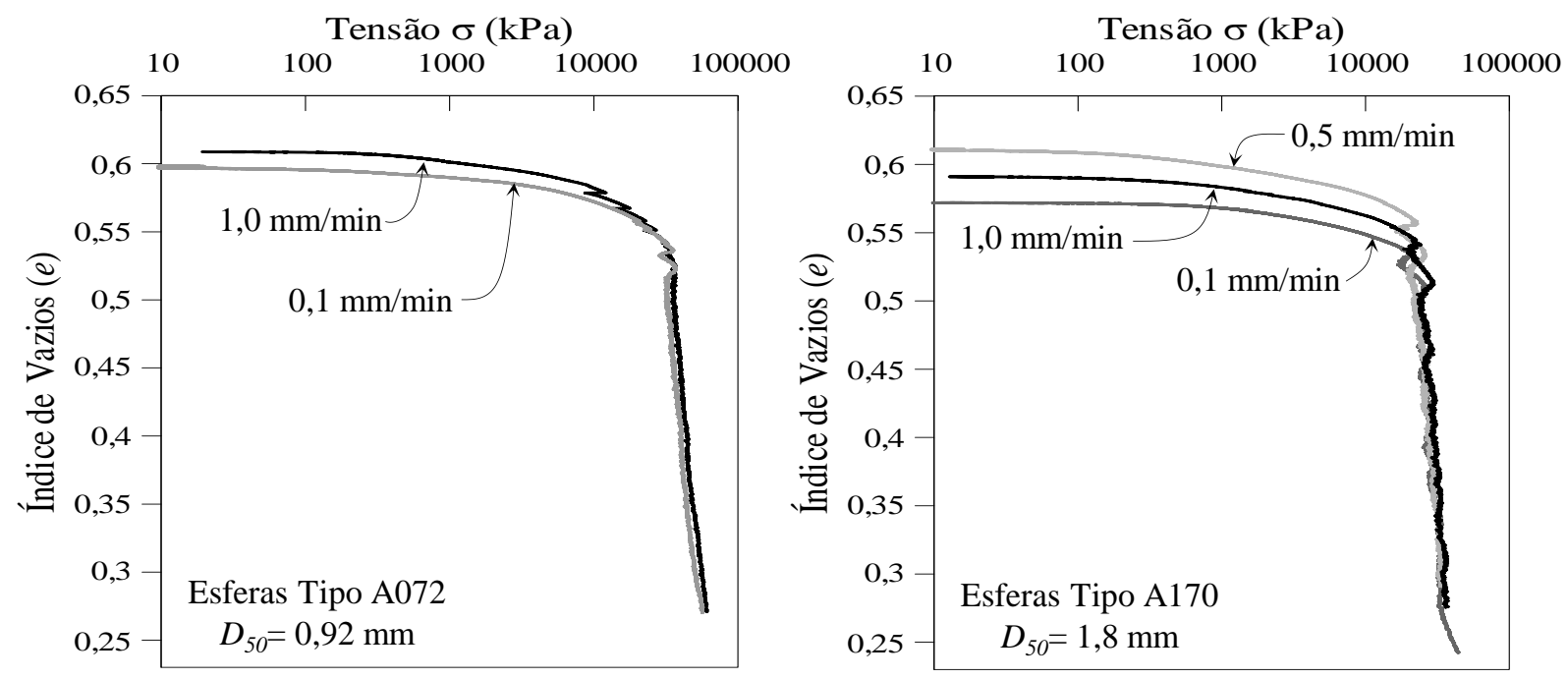

Figura 4.20. Influencia da velocidade de deslocamento no comportamento.

\subsubsection{Compressibilidade}

Com as amostras compostas unicamente por microesferas foram obtidas diferentes curvas de compressibilidade, avaliando a influência do tamanho da partícula. Na Figura 4.21, mostra-se o efeito do tamanho da partícula na curva de compressão do material. A primeira feição que se pode evidenciar é o deslocamento da linha de compressão normal (NCL) com a diminuição do tamanho da partícula. Isto está relacionado com a distribuição das cargas, já 
que para materiais de diâmetro menor, a quantidade de contatos aumenta significativamente, resultando em menores forças nas partículas. Assim, materiais com partículas de diâmetro menor têm uma maior capacidade de suporte (a nível macroscópico) que as partículas de diâmetro maior. Outra forma entender o fenômeno é associando o tamanho da partícula com o nível de tensão, para o qual a curva de compressibilidade tangencia a NCL. Sistemas granulares com partículas maiores se aproximam da NCL em níveis de tensão mais baixos. Cabe ressaltar que para se obter uma NCL bem definida num material granular, os níveis de tensão sempre são bastante elevados, assim, o fenômeno de quebra sempre será um mecanismo importante para o entendimento do comportamento.

Outra caraterística a ressaltar, é a intensidade na relaxação de tensões no momento que ocorre a quebra. Quando uma partícula se quebra dentro de um sistema, gera uma dissipação da energia acumulada por deformação. Assim, sistemas com partículas de diâmetros maiores, têm maior capacidade de dissipação de energia de deformação, que sistemas com grãos de menor diâmetro. Esta dissipação deve-se, exclusivamente, à quebra das partículas, e, portanto, pode dizer que a capacidade de dissipação de energia é uma medida do potencial de quebra. Na Figura 4.21, mostra-se uma ampliação de um setor da curva de compressibilidade, no início da quebra, que ilustra a intensidade da deformação, em função do tamanho da partícula.

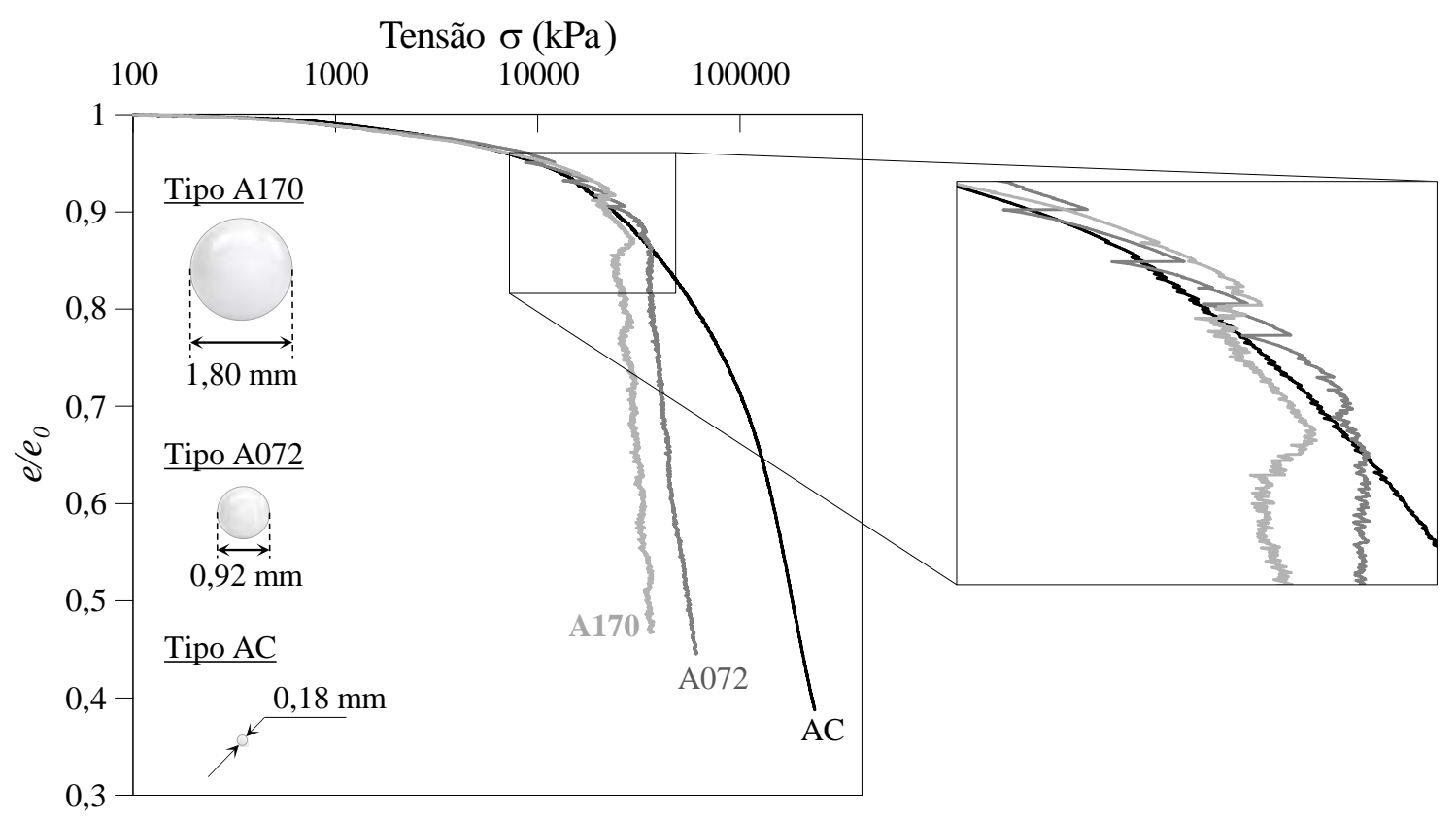

Figura 4.21. Influência do tamanho da partícula na compressão confinada.

Nas Figura 4.22, Figura 4.23 e Figura 4.24 são mostradas as curvas de compressibilidade normalizando o índice de vazios em relação o valor deste para $10 \mathrm{kPa}$. Percebe-se a uniformidade dos resultados obtidos para cada um dos materiais. Observa-se que 
o processo de quebra começa com tensões superiores a $10 \mathrm{MPa}$. Este nível de carga é bastante elevado, mas de grande importância em algumas obras (como é no caso de barragens altas).

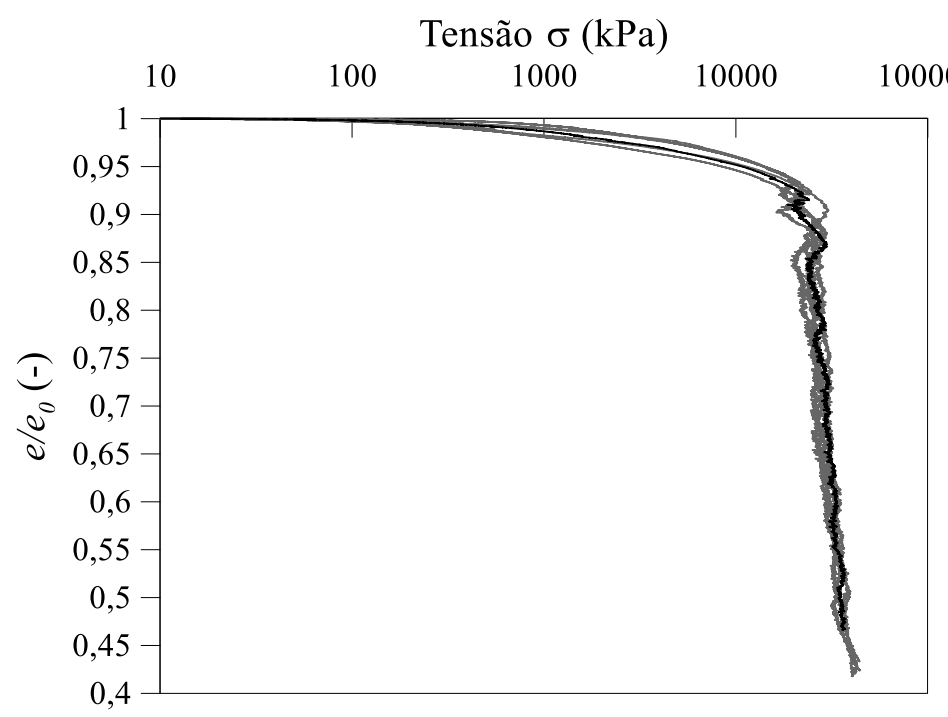

Figura 4.22. Curva de compressibilidade normalizada das microesferas tipo A170.

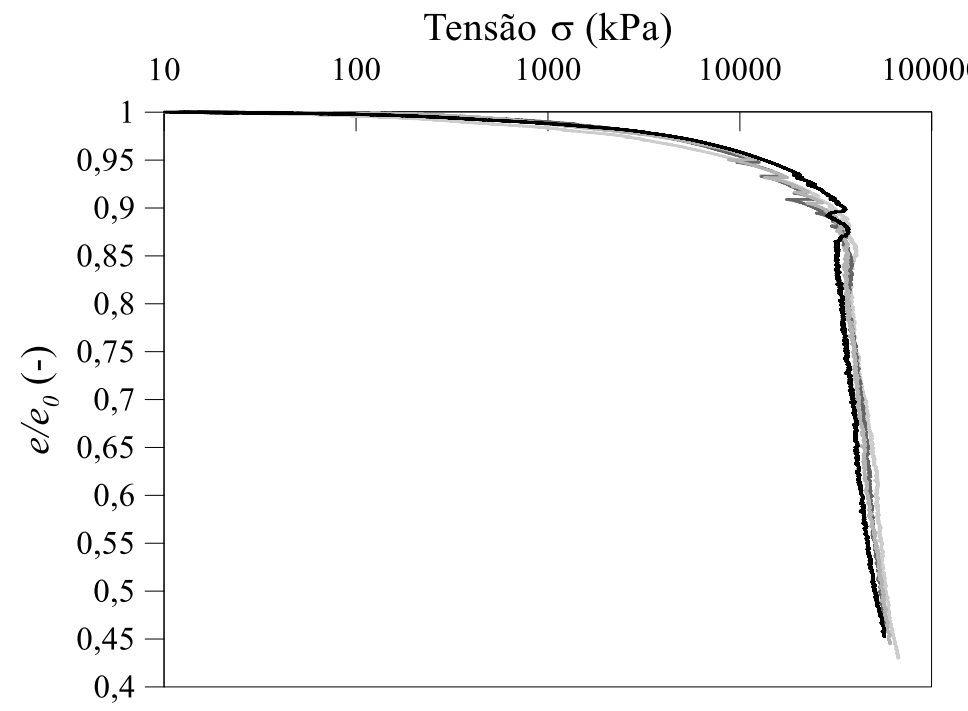

Figura 4.23. Curva de compressibilidade normalizada das microesferas tipo A072. 


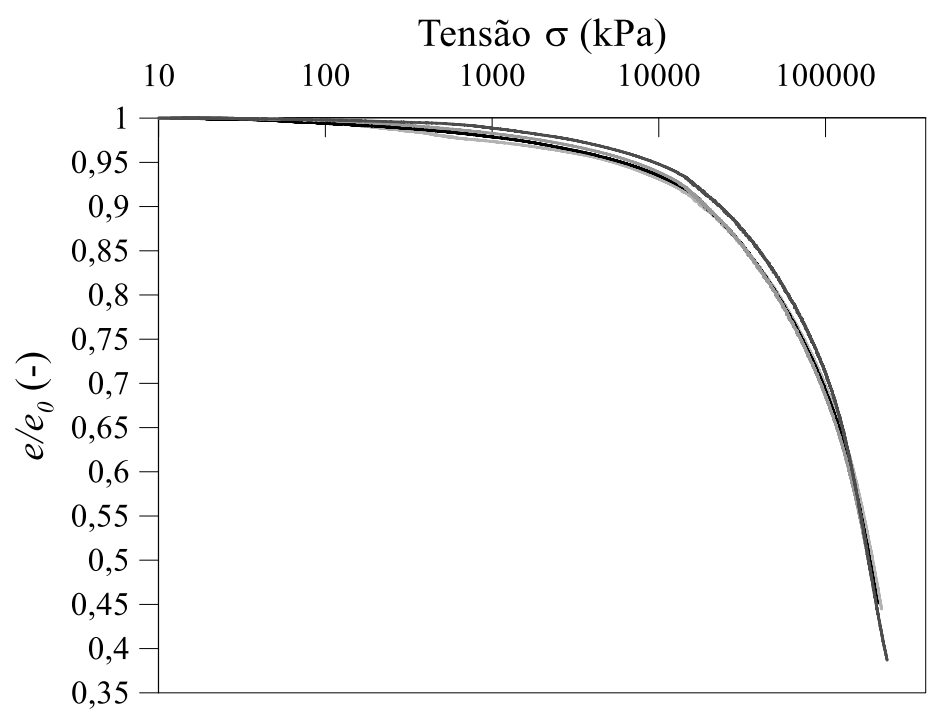

Figura 4.24. Curva de compressibilidade normalizada das microesferas tipo AC.

Para um mesmo material, pode-se observar que o processo de quebra inicia mais ou menos no mesmo nível de tensões, independente das condições iniciais do material (ver Figura 4.25, Figura 4.26 e Figura 4.27). A intensidade da relaxação de tensões, devido à quebra de partículas, é mais ou menos similar para as curvas de compressibilidade do mesmo material, sendo maior nas primeiras fragmentações e se estabilizando com a formação clara da NCL.

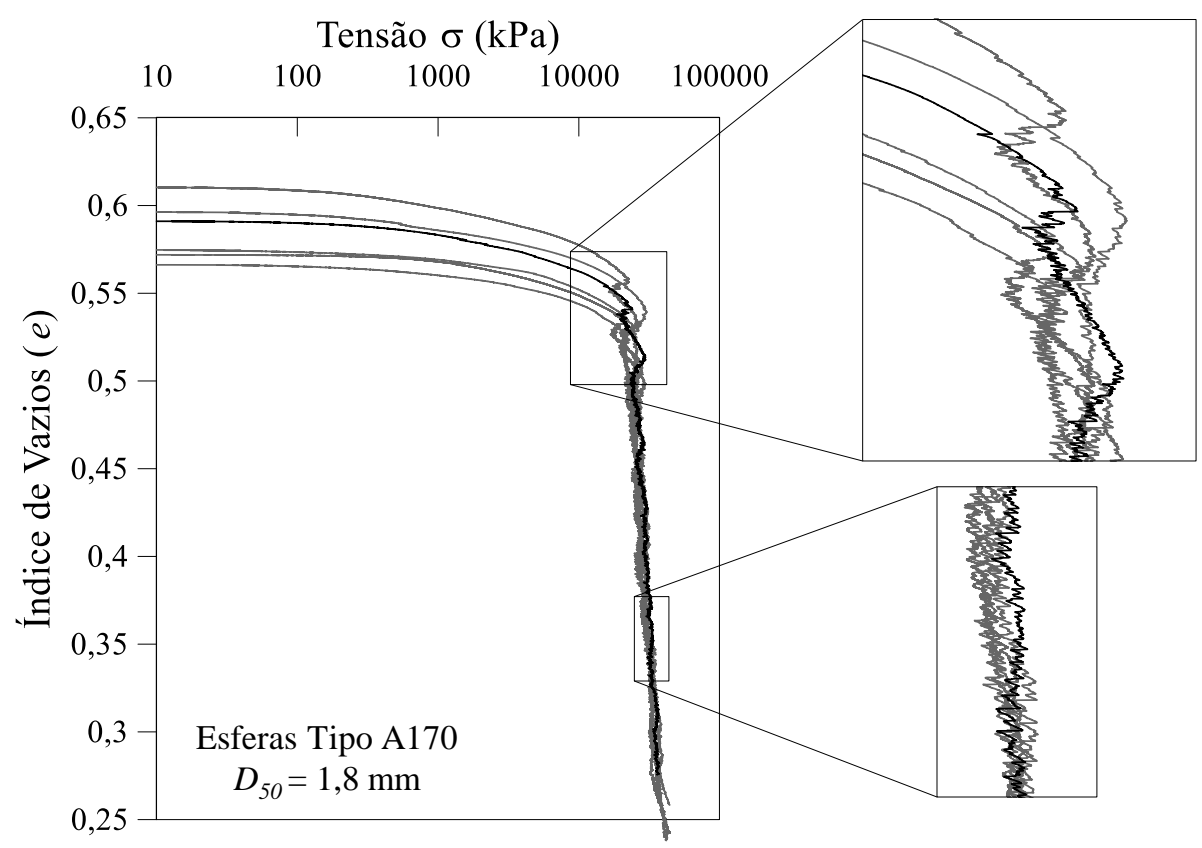

Figura 4.25. Compressibilidade de microesferas tipo A170. 


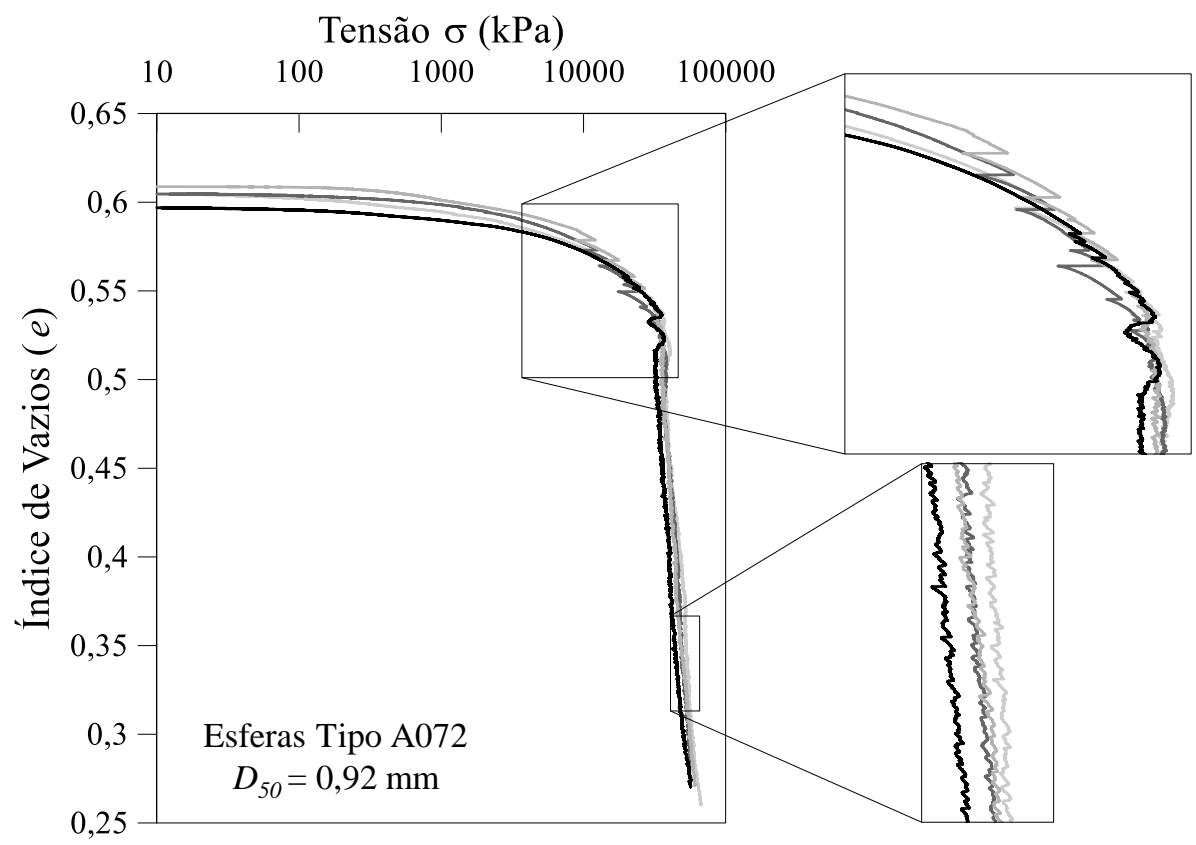

Figura 4.26. Compressibilidade de microesferas tipo A072.

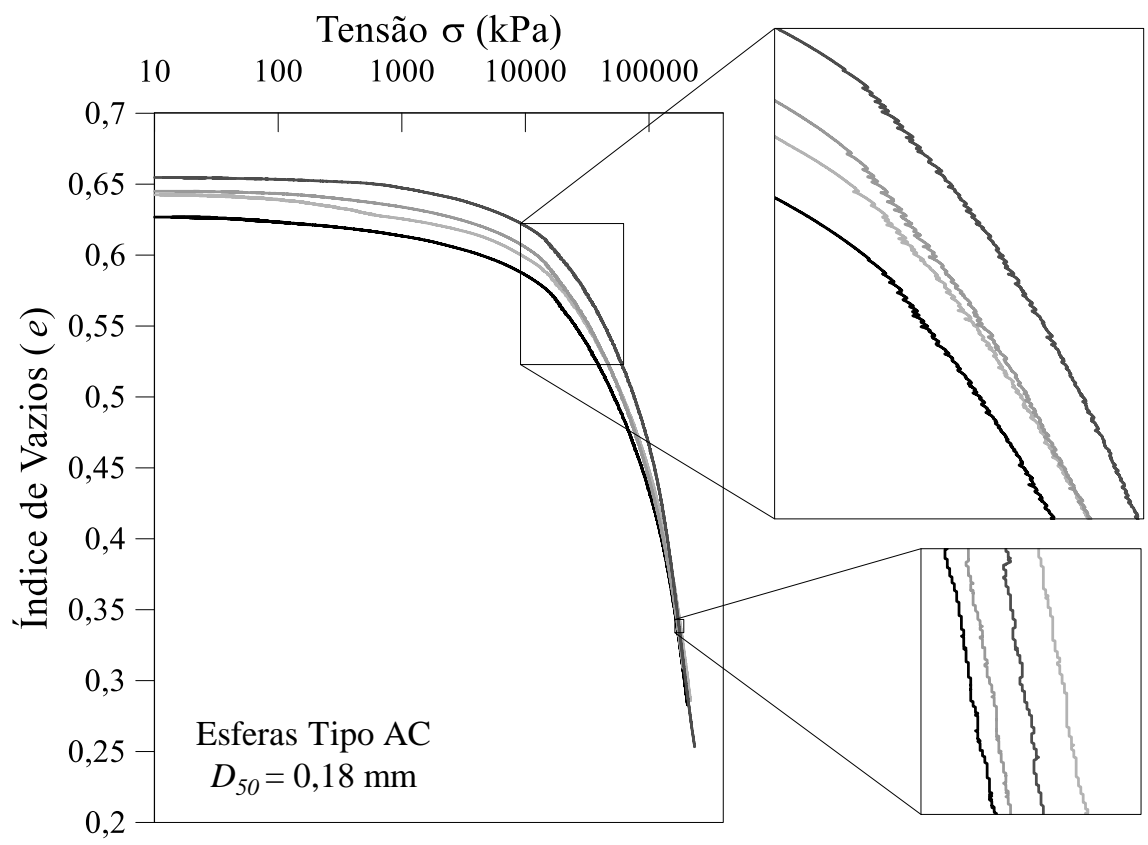

Figura 4.27. Compressibilidade de microesferas tipo AC.

A intensidade de quebra diminui com o aumento do nível das tensões, devido às mudanças na granulometria ocasionadas pelas quebras, que produzem um material cada vez mais fino. Além disso, quando a curva tangencia a NCL, a estrutura do material é cada vez mais fechada, provocando diminuições de vazios cada vez menores, como pode ser observado no zoom da região da NCL das curvas de compressibilidade.

Curvas de compressibilidade com níveis de tensão muito elevados (> 50MPa) são apresentadas na Figura 4.28, nas quais se observa que para aos materiais de diâmetro maior 
existe uma mudança de comportamento. A inclinação da NCL diminui consideravelmente, o que significa que o material chega a um estado muito rígido (fechamento quase total de vazios), onde para um pequeno incremento de deformação a tensão deve aumentar consideravelmente. Neste último regime de comportamento, o intertravamento é o mecanismo dominante, capaz de enrijecer todo o sistema de partículas.

Observa-se que o ponto de inflexão, onde se percebe a mudança de comportamento, vaise deslocando a depender do diâmetro da partícula. No caso dos materiais usados nesta pesquisa, fica claramente definida a transição para os materiais de maior diâmetro, enquanto para o material menor o nível de tensões ainda não é suficiente para chegar neste regime. Além disso, as mudanças de comportamento sempre acontecem de uma forma mais suave para os materiais de menor diâmetro, já que a dissipação de energia por quebra de grão ocorre de forma gradual e não abrupta, como nas partículas maiores.

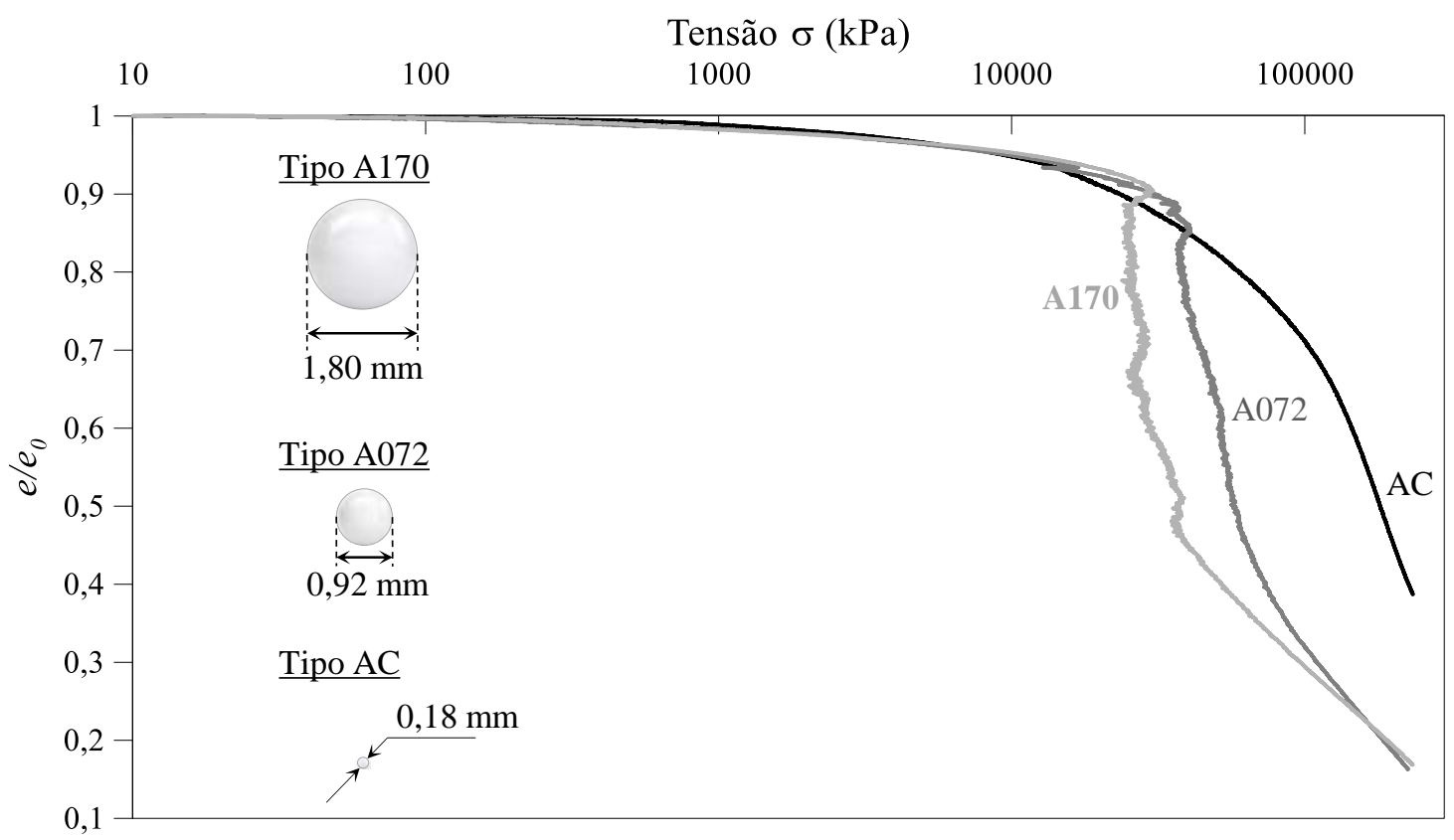

Figura 4.28. Compressibilidade a níveis altos de tensão confinante.

\subsubsection{Emissões Acústicas}

Durante a realização dos ensaios de compressibilidade, foram monitoradas as emissões acústicas dos mesmos. Os resultados destes monitoramentos são apresentados em termos de energia, amplitude, duração e contagem, os quais foram definidos no capítulo anterior. $\mathrm{Na}$ Figura 4.29, observam-se as medições de emissões acústicas, para um ensaio feito com esferas tipo A170, o qual ilustra o resultado típico destes monitoramentos. Destes gráficos, pode-se ter uma ideia qualitativa do significado físico de cada uma das medições 
proporcionadas pelo monitoramento acústico. Evidencia-se uma coerência entre os picos das leituras de contagem, duração e energia, com os pontos de relaxação de tensões por quebra de partículas. Não obstante, para a interpretação dos resultados, neste estudo, foi escolhida a energia. Esta medição acústica proporciona informações mais representativas do fenômeno físico, pois o processo de quebra é um processo com dissipação de energia. Além disso, a energia é uma conjugação da duração, da contagem (número de eventos) e da amplitude.

A Figura 4.30 mostra as curvas de compressibilidade, para os três materiais de trabalho, e as respectivas medições de energia das emissões acústicas. Para os materiais A170 e A072, os picos de energia são bastante evidentes e coerentes com os pontos de relaxação de tensões.

No caso do material AC, o processo de quebra não é tão evidente, o que é comprovado nas medidas de energia, as quais não mostram picos. Observando as séries de dados de energia dos três materiais (ver Figura 4.30), confirma-se que para tamanhos de partículas maiores, tem-se maiores capacidades de dissipação de energia. As energias obtidas para os materiais A170 e A072, são relativamente similares, sendo A170 levemente superior. Isto concorda com as curvas de compressibilidade, nas quais estes dois materiais estão próximos. No caso do material AC, as magnitudes baixas coincidem com a suavidade da curva de compressibilidade. Isto não significa que não existe quebra de partículas, mas que o processo acontece de forma gradativa e sem mudanças abruptas no comportamento.

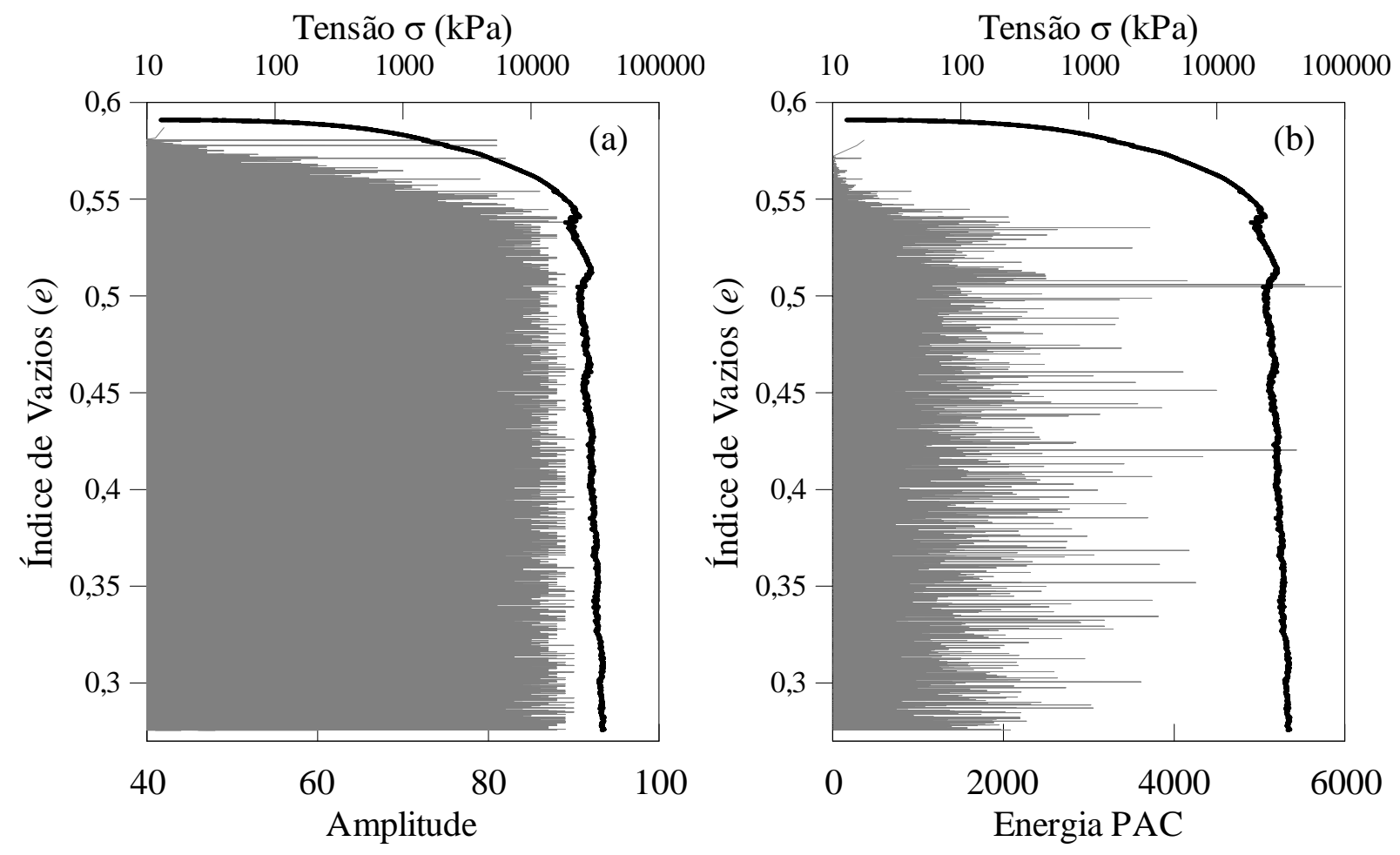




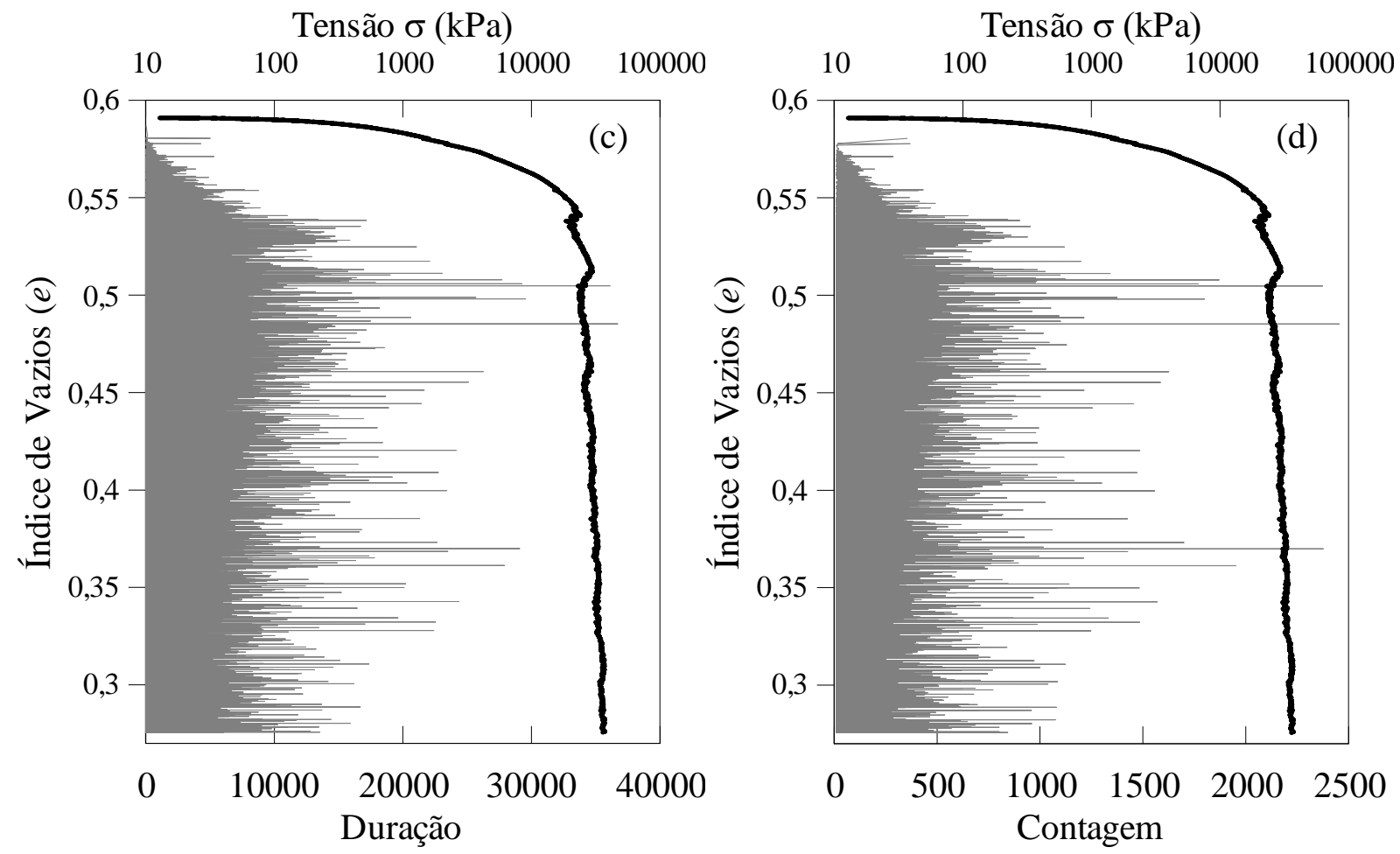

Figura 4.29. Medições obtidas da técnica de EA para as microesferas A170.

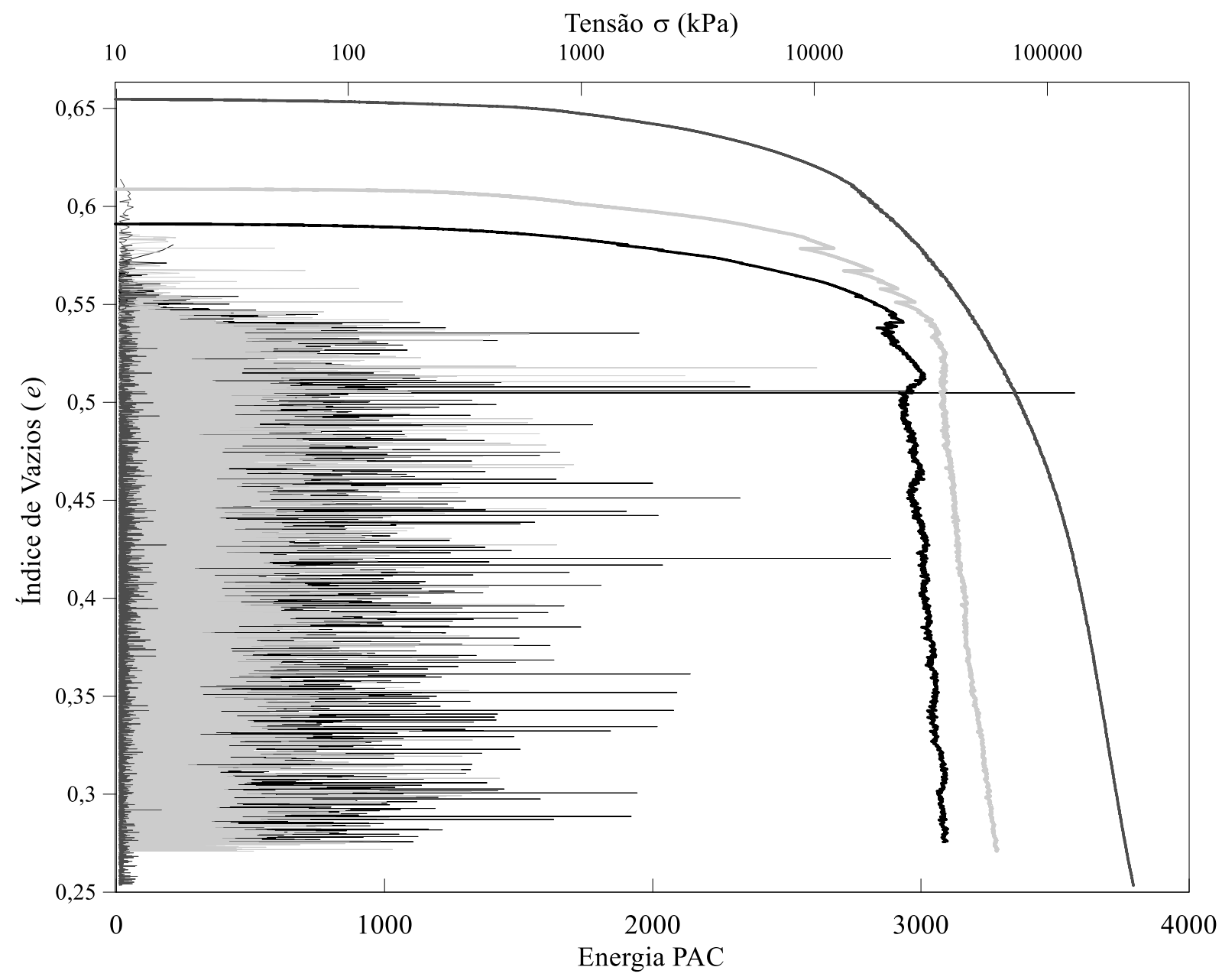

Figura 4.30. Energia PAC com a variação do tamanho de partícula. 
Outra forma usada para a interpretação dos dados obtidos de emissões acústicas é mostrada na Figura 4.31. Neste caso, é usada a energia acumulada para a realização das análises. Mostra-se que a inclinação das curvas de energia acumulada está relacionada com o tamanho do material, sendo uma medida da capacidade de dissipação de energia. Esta figura ilustra que para partículas de tamanho maior, as inclinações são maiores.

Outra influência do tamanho é o momento de medição inicial de energia, no qual, a curva acumulada de energia sai de zero e começa a inclinar-se. Este momento de chegada da energia inicial é mais rápido no caso de materiais de tamanho maior, e está relacionado com a tensão na qual a curva de compressibilidade tangencia a NCL, correspondente ao início da quebra.

Deve-se ressaltar que as leituras dos quatro (4) sensores colocados nas laterais do corpo de prova não são plenamente iguais. Não obstante, existe uma correspondência nos picos de energia e na forma da curva de energia acumulada. Esta discordância se deve ao fato de a montagem experimental não ser totalmente padronizada. Fatores como, quantidade de vaselina colocada na parede (para diminuir atrito), quantidade de cola no sensor (para fixar sensor acústico na parede), entre outras, podem afetar as leituras. O que deve ser destacado é que as leituras feitas mostram total coerência com os fenômenos micromecânicos e que os regimes de comportamento são claramente demarcados com ajuda das emissões acústicas.

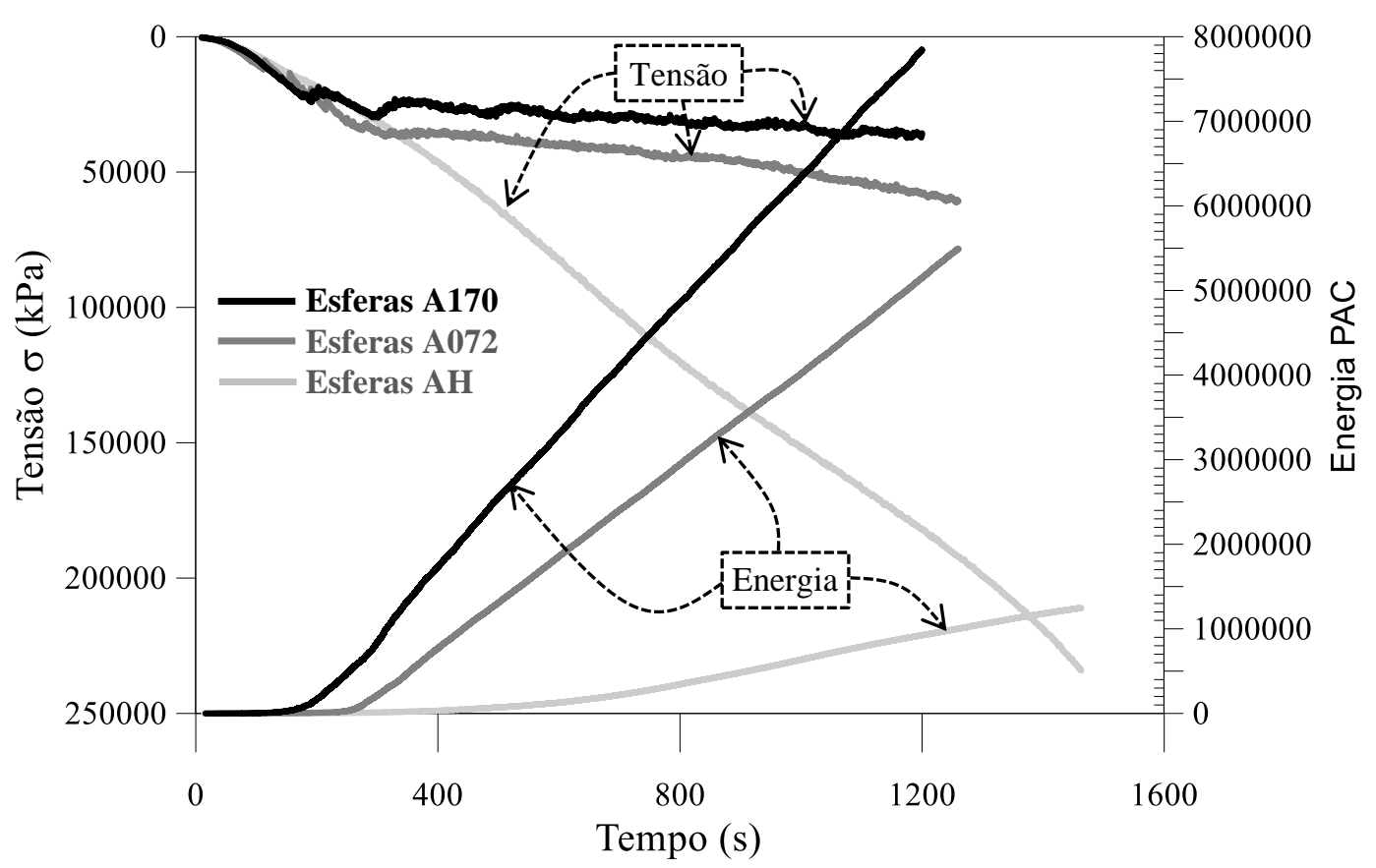

Figura 4.31. Variação da energia PAC com o tipo de partícula. 
Mudanças do comportamento são claramente observadas para os três materiais de trabalho mediante o registro de emissões acústicas. Na Figura 4.32, Figura 4.33 e Figura 4.34, são apresentados os resultados da energia PAC e da tensão, em função do tempo, para três níveis de tensão. No primeiro, o processo de quebra ainda está começando; no segundo, a NCL está bem definida; e no último, as tensões são as mais elevadas conseguidas com o equipamento no laboratório ( 235MPa).

Quando a curva de compressibilidade está na fase de recompressão, onde o comportamento macroscópico é assumido elástico não linear, os processos dominantes são devidos ao rearranjo das partículas. Nesta fase, não se tem registros de emissões acústicas. Posteriormente, se chega a um nível de tensões que leva ao começo do processo de quebra, onde são registradas as primeiras leituras de ruído no sistema. Esse processo continua até formar claramente a NCL, ressaltando que a energia acumulada durante esta fase aumenta de forma linear. Isto significa que os processos de quebra se dão a taxas mais ou menos constantes ao interior do material. Por último, quando o material está muito denso e o sistema é cada vez mais rígido, se observam aumentos consideráveis da energia liberada, definindo-se claramente uma nova fase de equilíbrio de emissões acústicas (correspondente com um novo comportamento do material). 


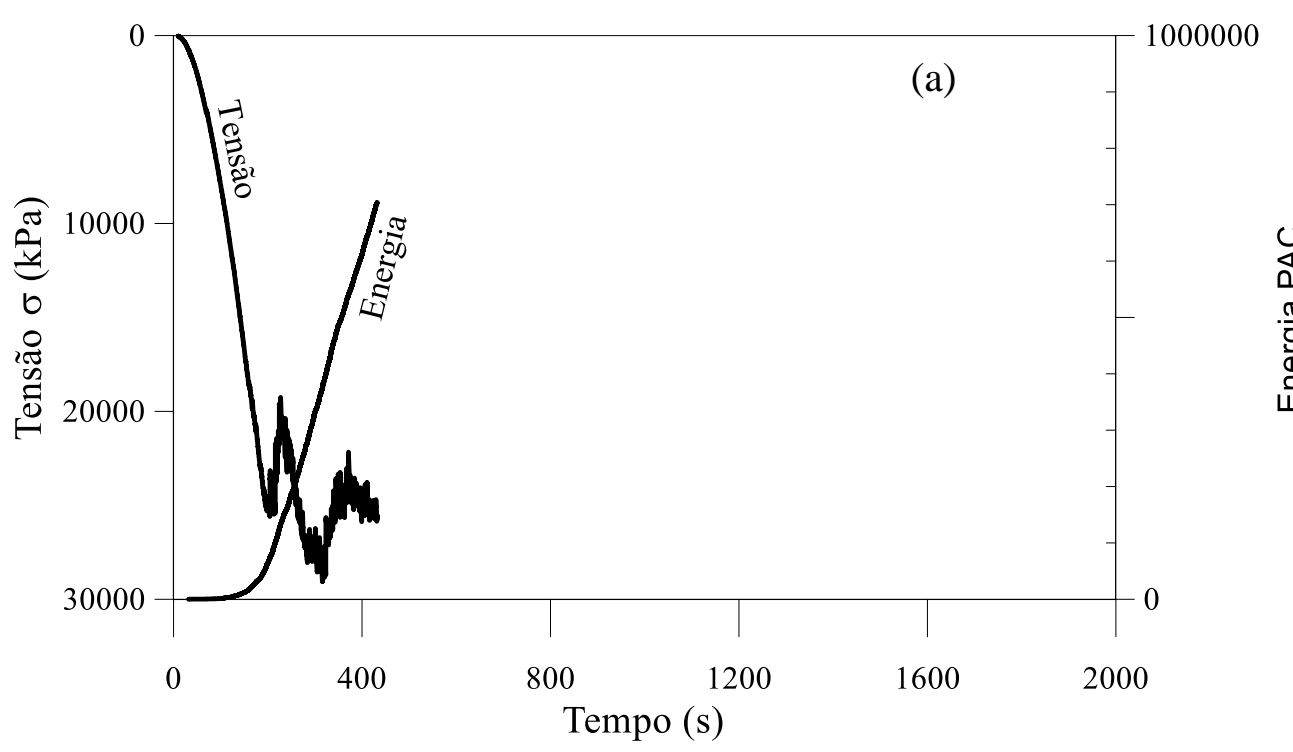

0
$\frac{1}{2}$
$\frac{0}{5}$
$\frac{0}{0}$
$\frac{1}{山}$
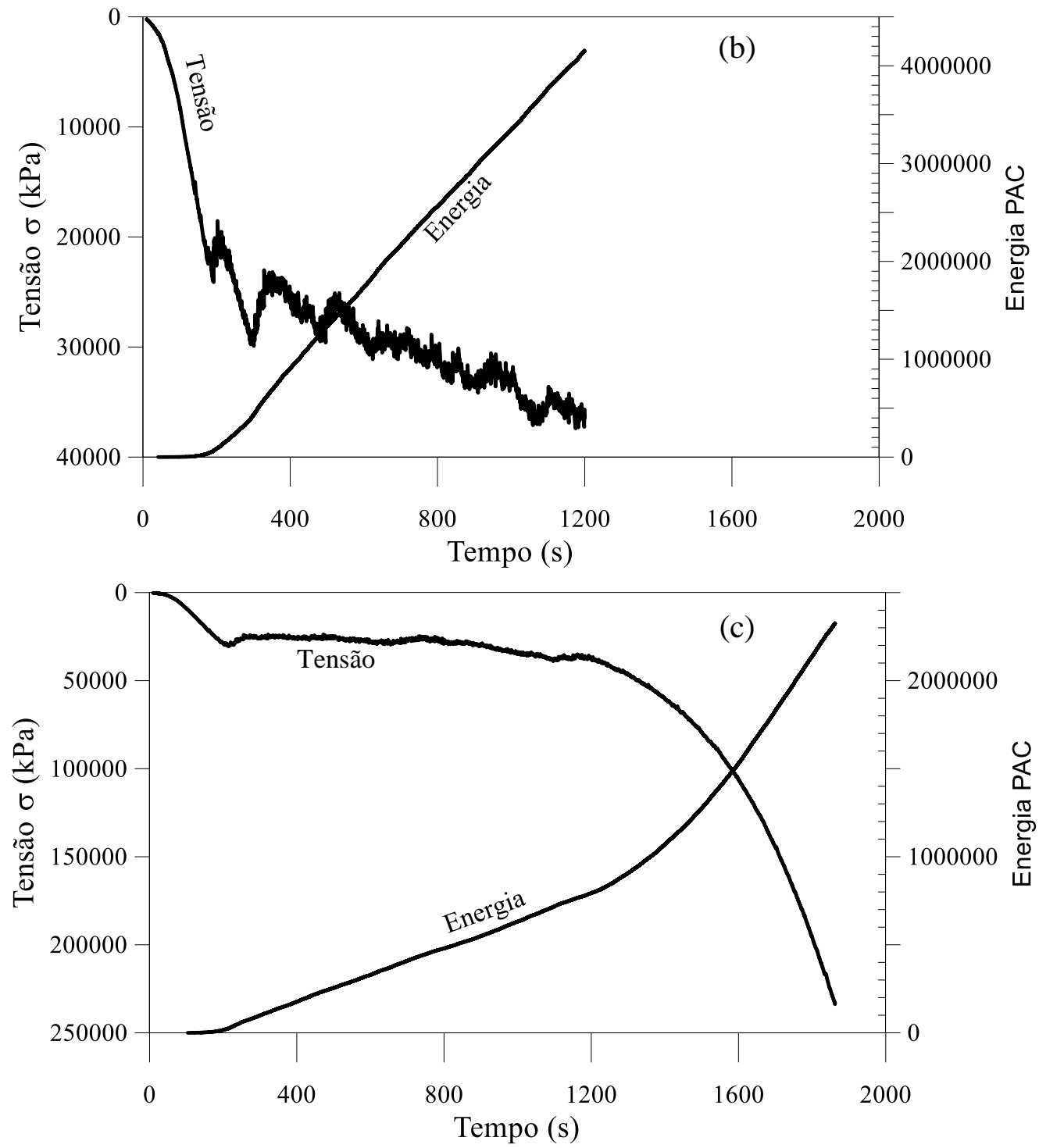

Figura 4.32. Relação entre a compressibilidade e as emissões acústicas para o material A170. 

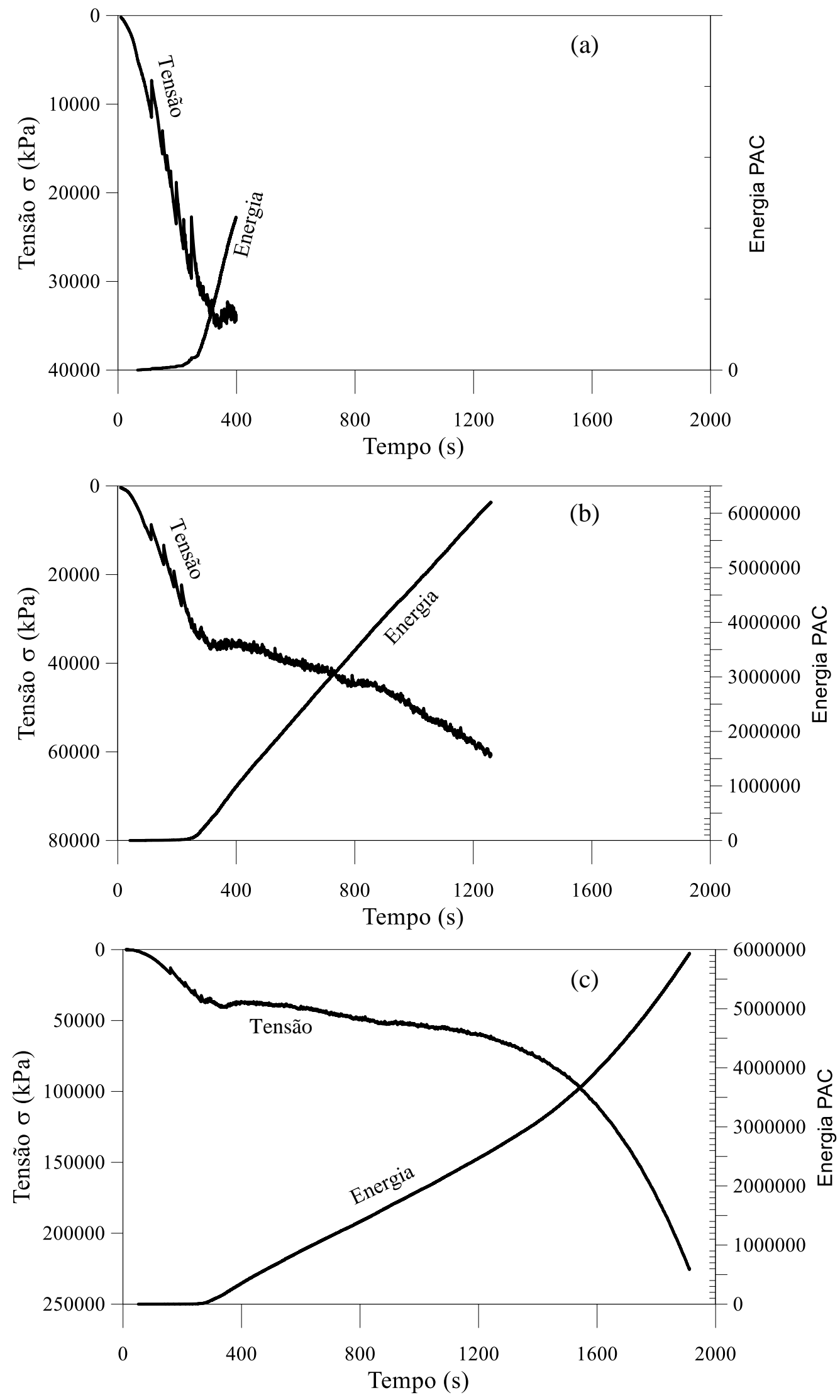

Figura 4.33. Relação entre a compressibilidade e as emissões acústicas para o material A072. 


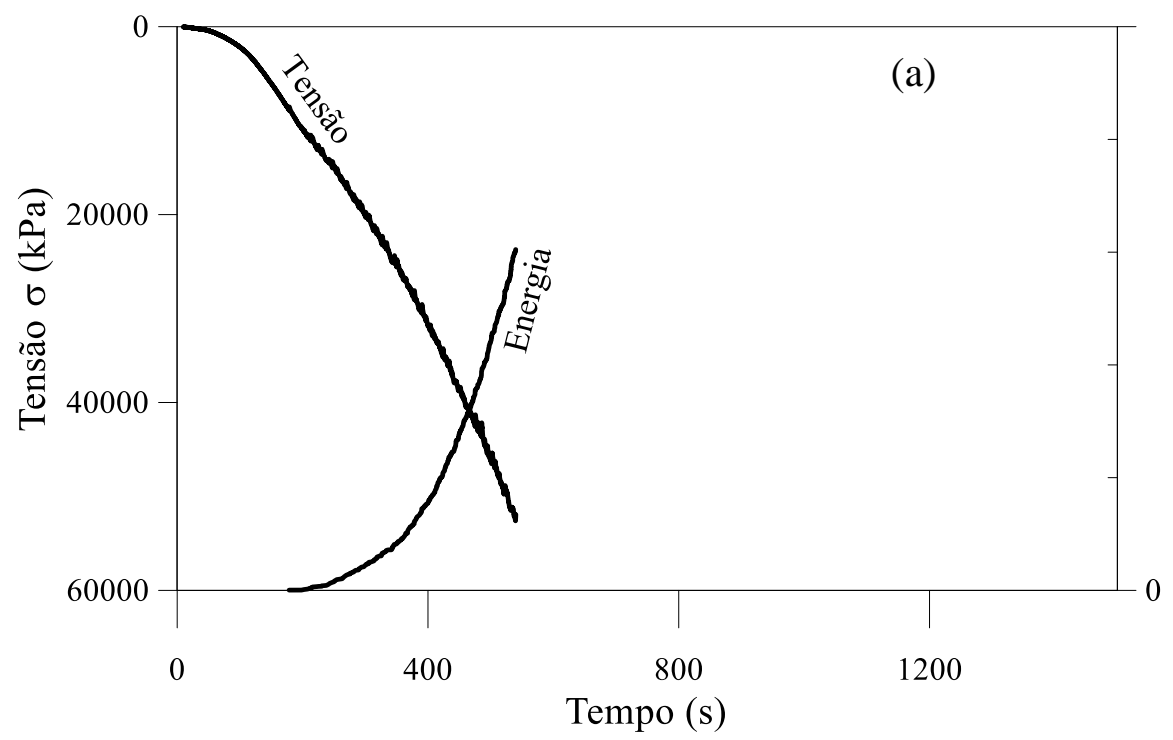

0
$\frac{1}{0}$
$\frac{\pi}{6}$
$\frac{0}{0}$
$\frac{\omega}{4}$

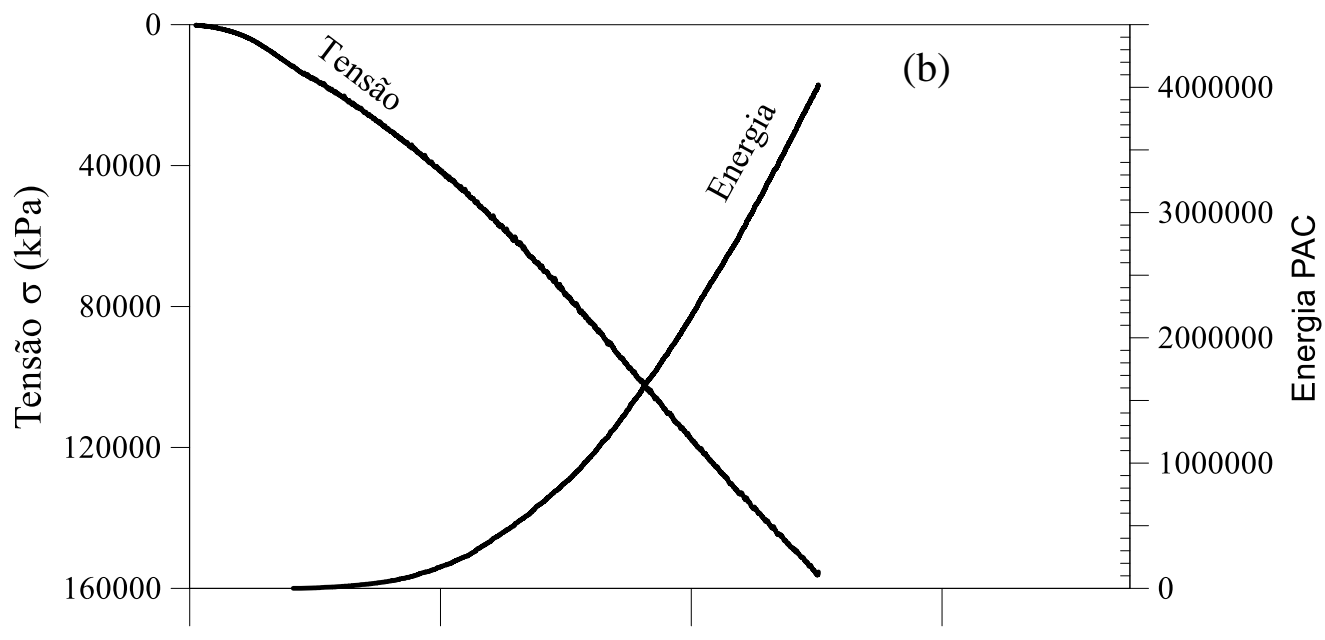

$0 \quad 400$

800

1200

Tempo (s)

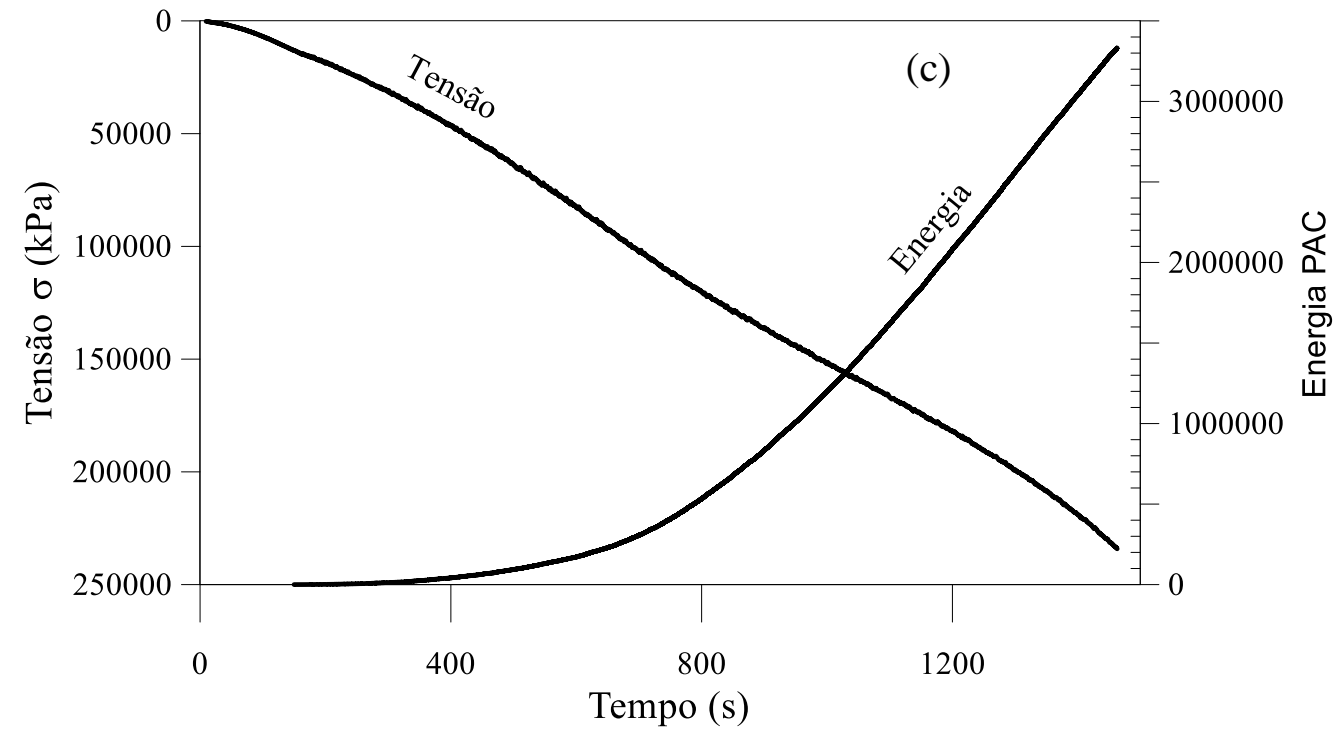

Figura 4.34. Relação entre a compressibilidade e as emissões acústicas para o material AC. 


\subsubsection{Avaliacão da quebra de partículas}

Para a avaliação da quebra das partículas, foram feitas as curvas de compressibilidade parando em quatro níveis de cargas, entre os valores extremos da curva. Para cada um destes níveis, foi feita a análise granulométrica. Além disso, foi feita avaliação dos tamanhos dos grãos para uma curva de compressibilidade que tinha como critério de parada $20 \%$ de deformação vertical, e para a curva que foi carregada até a capacidade máxima da prensa $(450 \mathrm{kN})$. Assim, para cada material, tem-se seis (6) níveis de referência que auxiliam o entendimento da evolução do processo de quebra.

Na Figura 4.35 e Figura 4.36, ilustra-se o processo de quebra para os níveis de carga para os materiais A170 e A072, respectivamente. Nas imagens percebe-se a evolução da quebra das partículas na superfície superior para cada um destes estados de carga. Nos dois primeiros não se observam quebras superficiais, mas nos últimos níveis é evidente o fenômeno de fragmentação. No caso do material AC (de menor diâmetro), não foram apresentadas imagens porque não é possível perceber a quebra a olho nu.

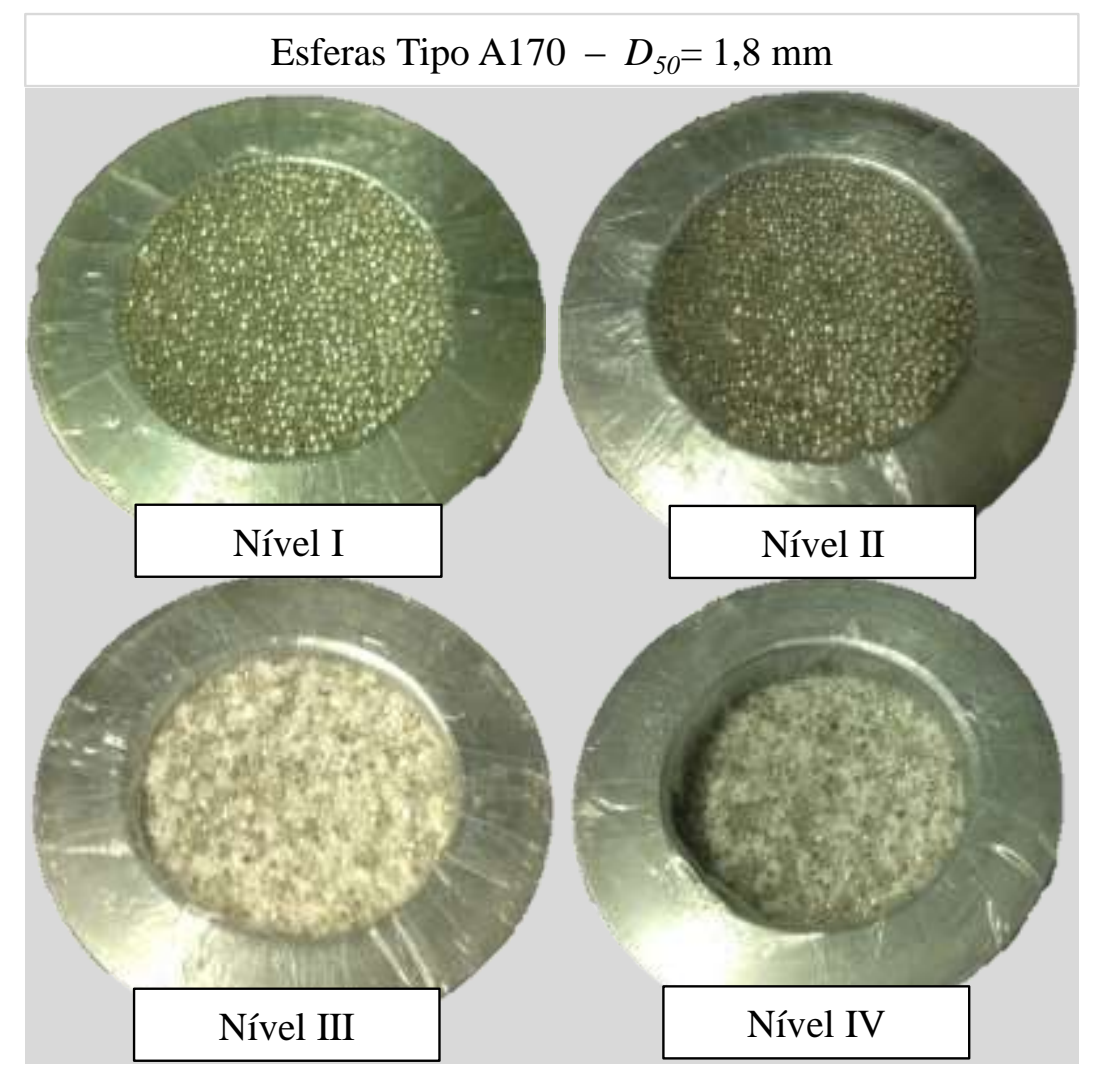

Figura 4.35. Imagens das microesferas após compressão confinada, para vários níveis de tensão- A170. 


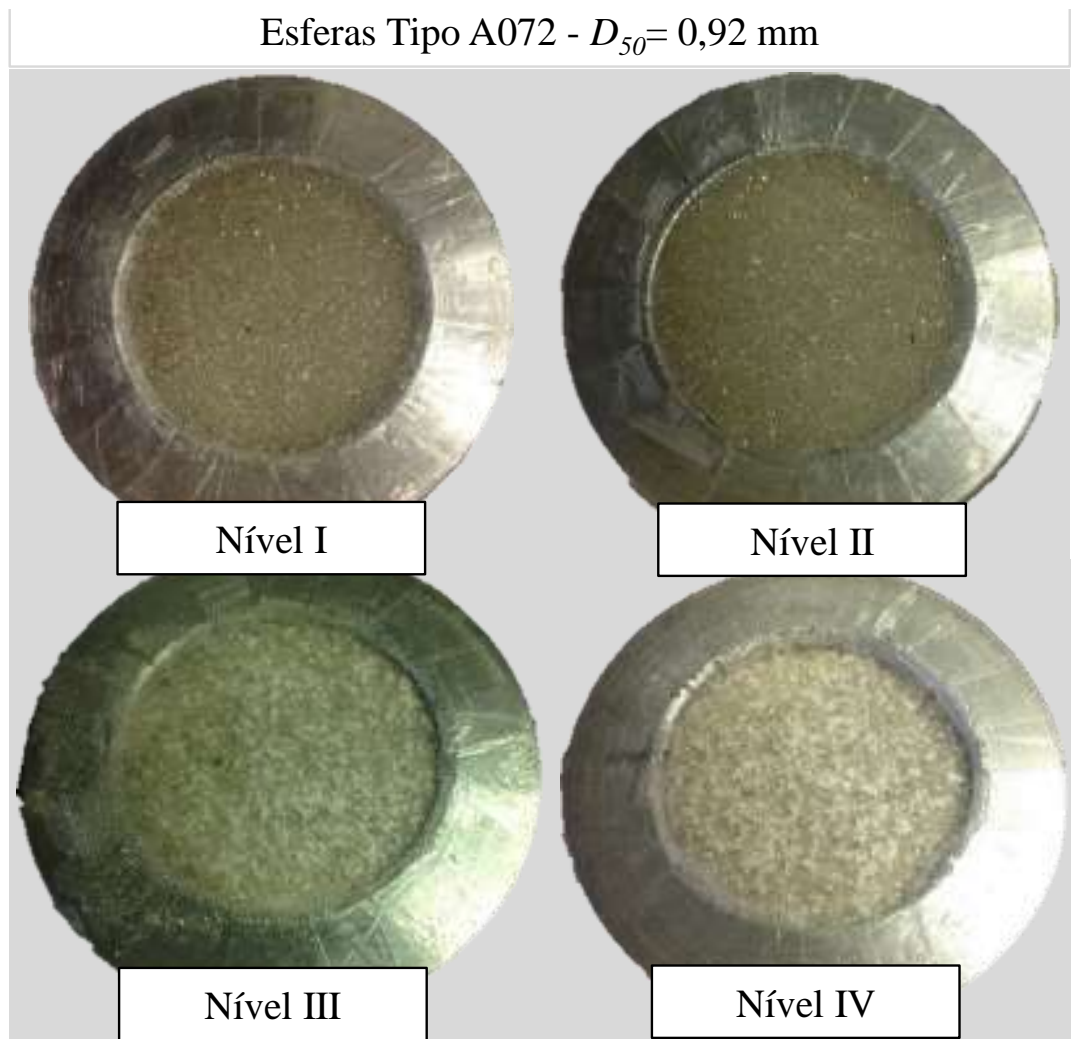

Figura 4.36. Imagens das microesferas após compressão confinada, para vários níveis de tensão- A072.

Na Figura 4.37, Figura 4.38 e Figura 4.39, mostram-se as curvas de compressibilidade dos materiais A170, A072 e AC, respectivamente, para os diferentes níveis de tensão. Observa-se que as condições iniciais (índice de vazios) foram mais ou menos iguais, dentro das limitações dos procedimentos laboratoriais. Para cada um dos gráficos é apresentado o nível de tensão máximo ao qual o material foi submetido, escolhidos com para obter os pontos chaves de mudanças de comportamento. Além disso, são apresentados os registros acústicos em termos de energia PAC, ilustrando o começo dos eventos de quebra e a intensidade do fenômeno para cada um dos níveis avaliados.

As granulometrias após compressão são apresentadas na Figura 4.40, Figura 4.41 e Figura 4.42, para os materiais A170, A072 e AC, respectivamente. A evolução do tamanho da partícula fica bastante explícita nestes gráficos. Observa-se que para o material de maior diâmetro a quebra ocorre com maior intensidade para todos os níveis avaliados. Materiais menores só apresentam mudanças significativas de granulometrias sob níveis altos de tensões.

Baseando-se apenas na gradação do material a longo de todos os carregamentos, a avaliação com a curva granulométrica fica bastante subjetiva. Por isto a necessidade de avaliar diferentes índices de quebra, para entender melhor o processo degradação dos grãos no comportamento do material granular. 

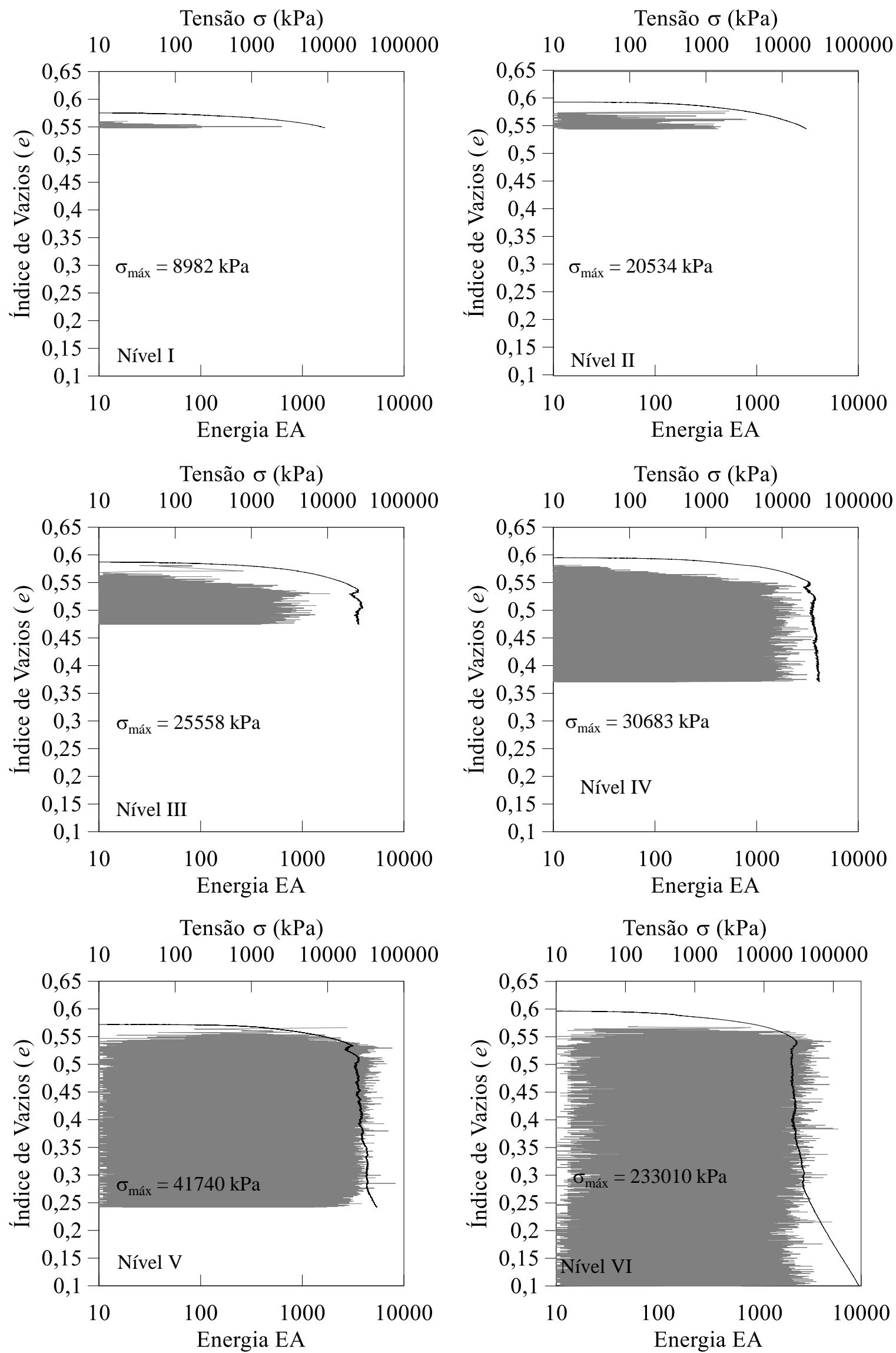

Figura 4.37. Curva de compressibilidade para vários níveis de tensão. Esferas A170. 
Tensão $\sigma(\mathrm{kPa})$

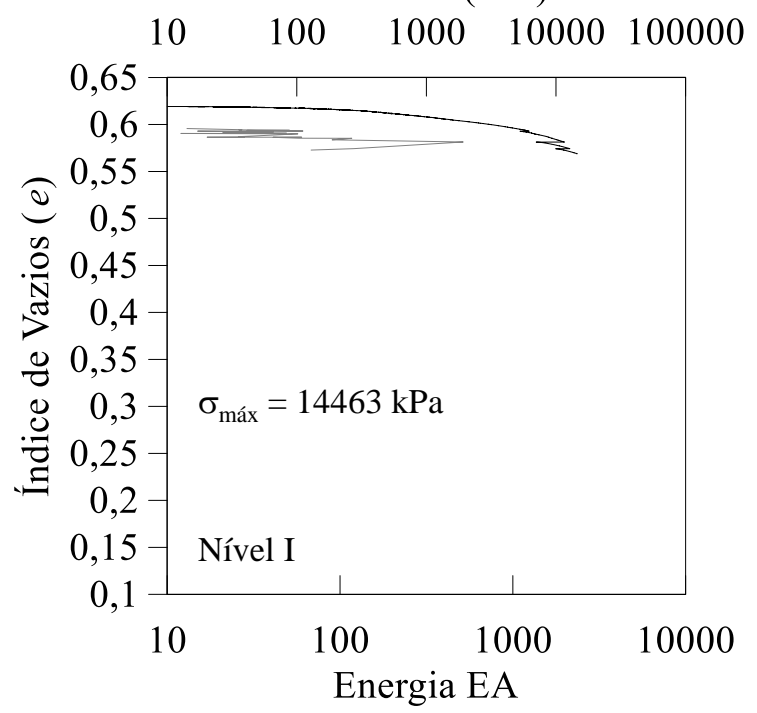

Tensão $\sigma(\mathrm{kPa})$

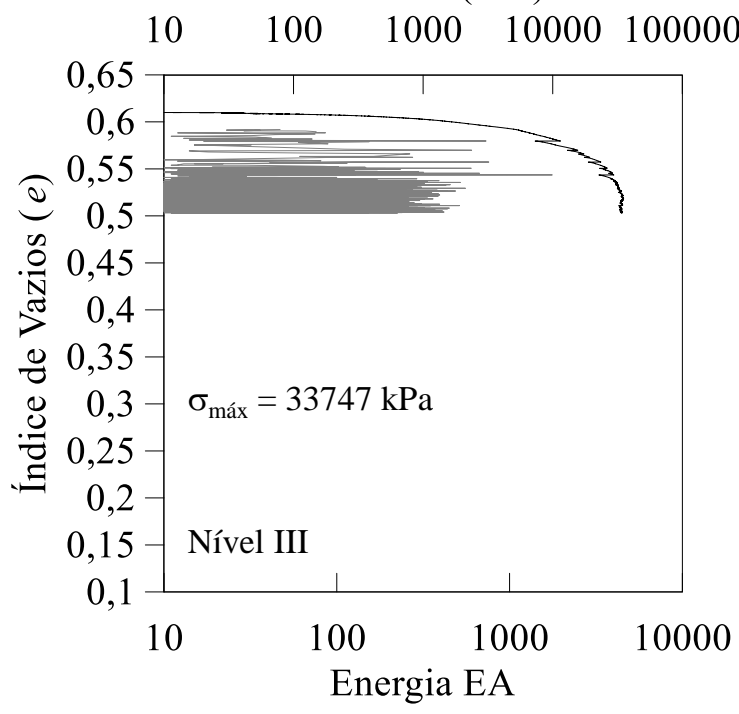

Tensão $\sigma(\mathrm{kPa})$

$\begin{array}{lllll}10 & 100 & 1000 & 10000 & 100000\end{array}$

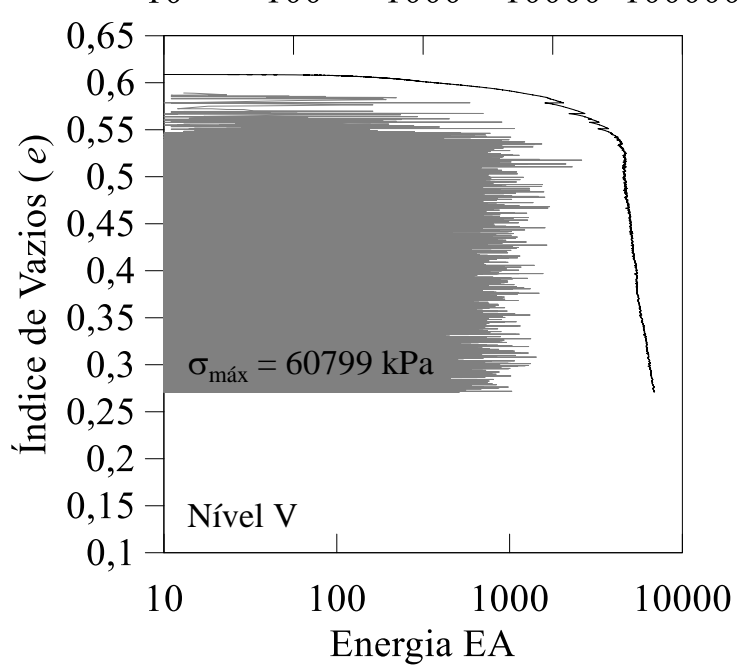

Tensão $\sigma(\mathrm{kPa})$

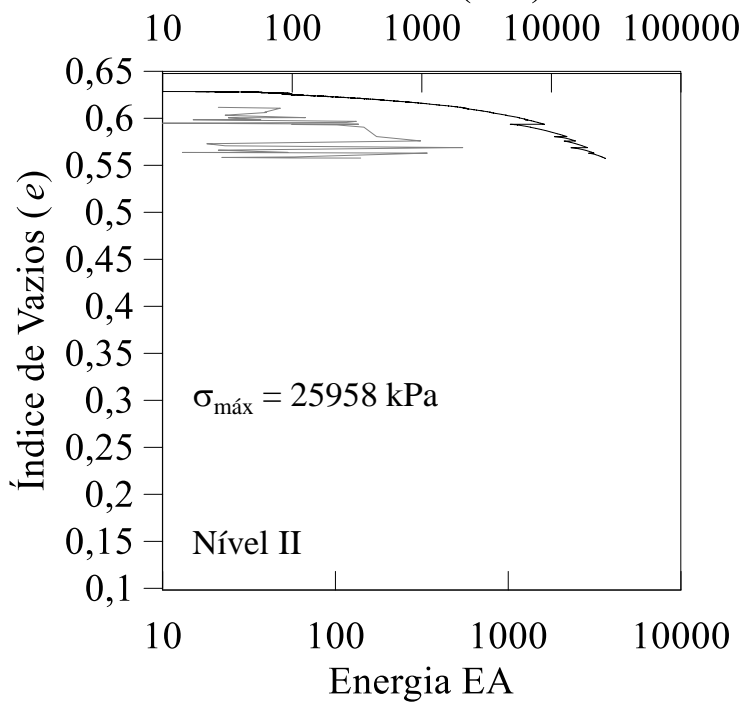

Tensão $\sigma(\mathrm{kPa})$

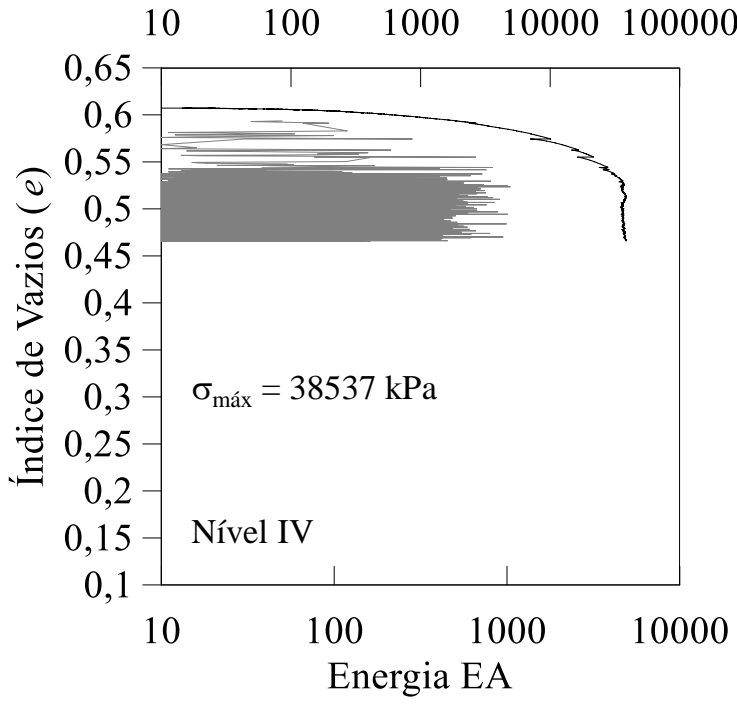

Tensão $\sigma(\mathrm{kPa})$

$\begin{array}{llll}10 & 100 & 1000 & 10000100000\end{array}$

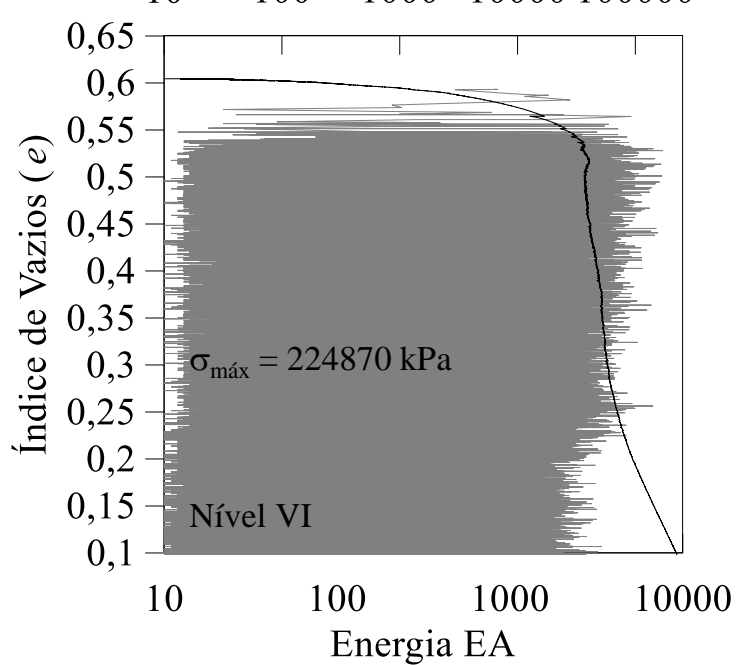

Figura 4.38. Curva de compressibilidade para vários níveis de tensão. Esferas A072. 

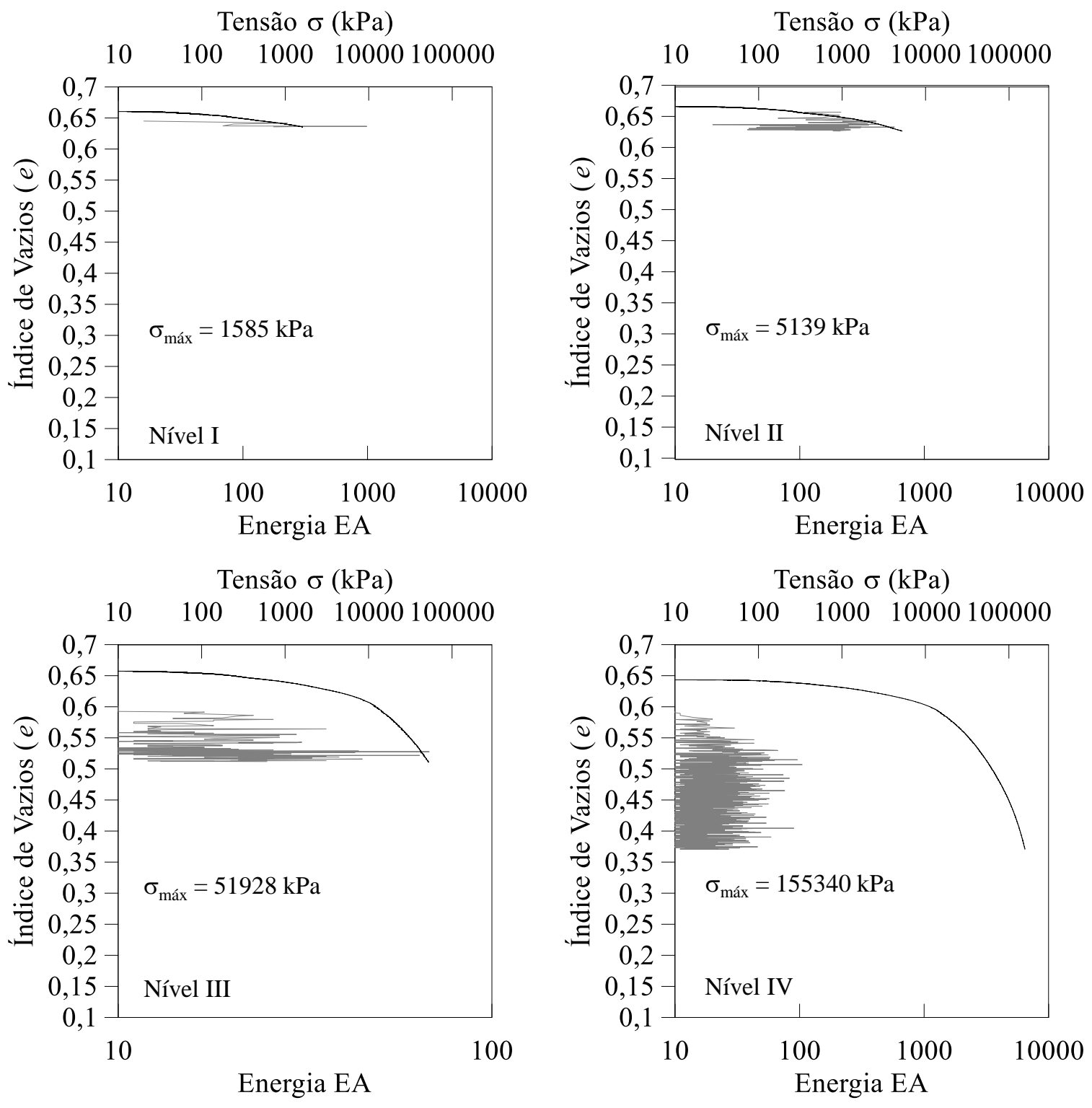

Tensão $\sigma(\mathrm{kPa})$

$10 \quad 100 \quad 1000 \quad 10000100000$

Tensão $\sigma(\mathrm{kPa})$
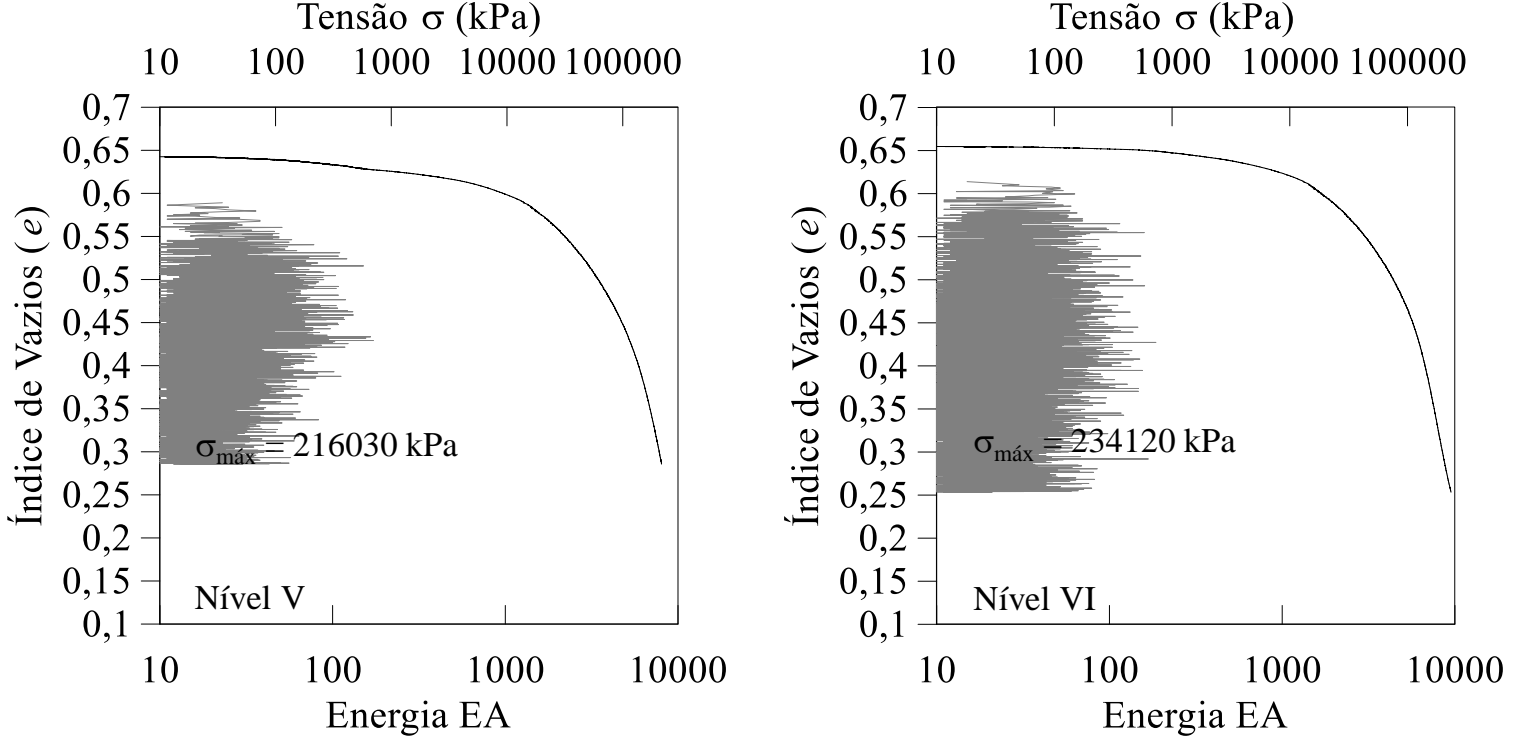

Figura 4.39. C urva de compressibilidade para vários níveis de tensão. Esferas AC. 


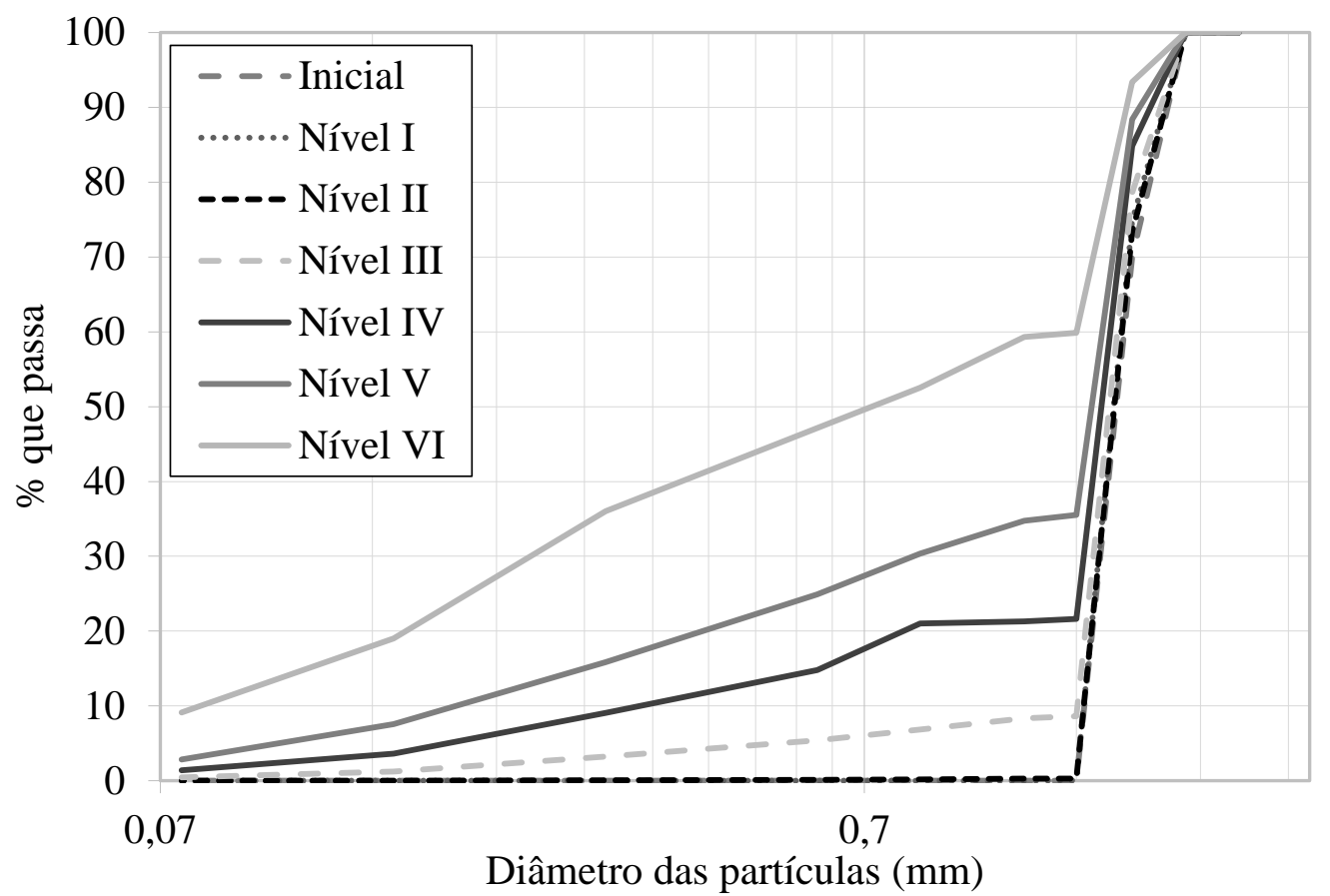

Figura 4.40. Curva granulométrica para vários níveis de tensão. Esferas A170.

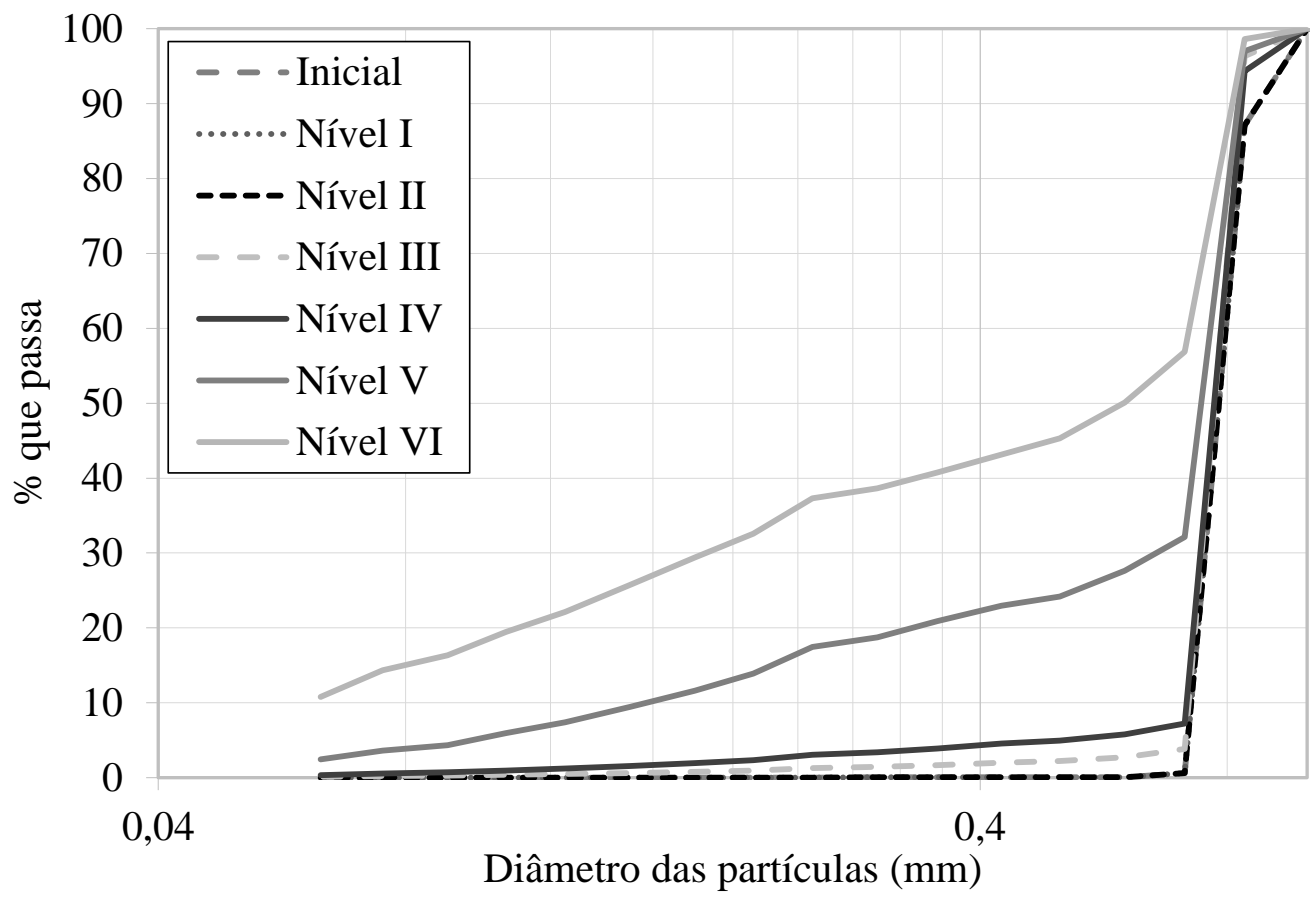

Figura 4.41. Curva granulométrica para vários níveis de tensão. Esferas A072.

Foram calculados os índices de quebras mais relevantes encontrados na literatura, o quais foram apresentados em detalhe no capítulo anterior. Os índices de quebra em função do nível de tensões, para os diferentes materiais, são apresentados na Figura 4.43, Figura 4.44 e Figura 4.45. A curvas de compressibilidade usadas nesta análise possuem condições de atrito nas paredes similares (uso do sistema plástico-vaselina). 


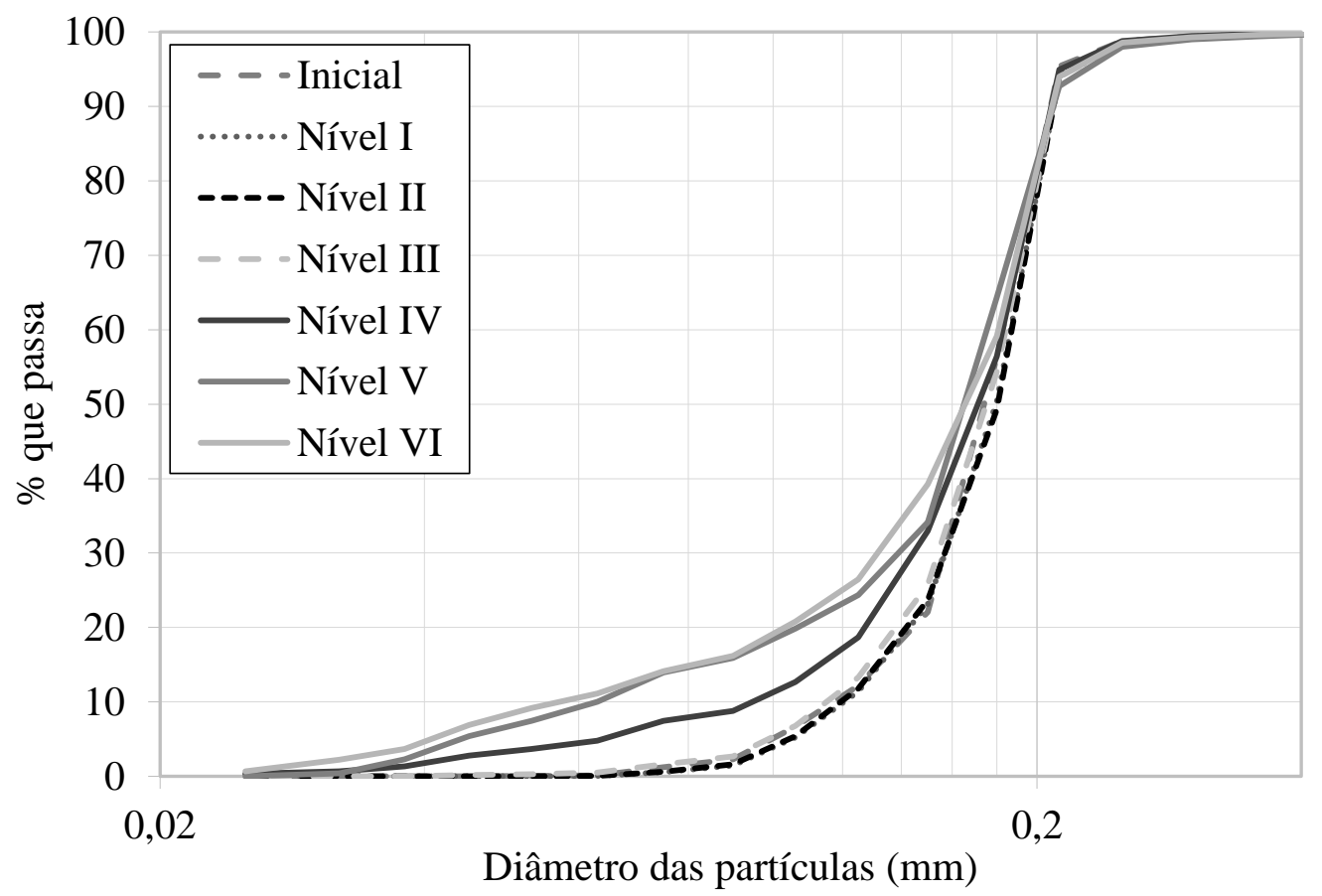

Figura 4.42. Curva granulométrica para vários níveis de tensão. Esferas AC.

No caso das propostas de índice de quebras de Lee \& Farhoomand (1967) e Lade et al (1996), o cálculo é feito mediante a relação de diâmetros correspondentes a uma porcentagem que passa pré-fixada $\left(B=D_{15 \text { inicial }} / D_{15 \text { final }}\right.$ e $\left.B_{10}=1-D_{10 f} / D_{10 i}\right)$. Neste trabalho foram também testados outros diâmetros para entender a sua importância na avaliação do fenômeno de quebra. Com base nos resultados obtidos para todos os materiais, conclui-se que o uso de diâmetros correspondentes uma porcentagem passante superior a $20 \%$ dificulta a interpretação do processo de fragmentação.

Em termos gerais, as tendências de todos os índices são semelhantes. Tem-se uma fase inicial onde a quebra é pouco significativa, correspondente ao trecho de recompressão da curva de compressibilidade. Posteriormente o processo de quebra começa e evolui de forma exponencial até atingir um valor máximo. Esta fase corresponde à transição entre o trecho de recompressão e a NCL. O valor máximo de quebra corresponde aos pontos onde a NCL está perfeitamente definida. Por último, o material é submetido a níveis de tensão extremadamente altas, onde existem poucas deformações para um aumento significativo das tensões (material com pouquíssimos vazios). Nesta fase se presume que o índice de quebra continua aumentando de forma linear com a tensão. 

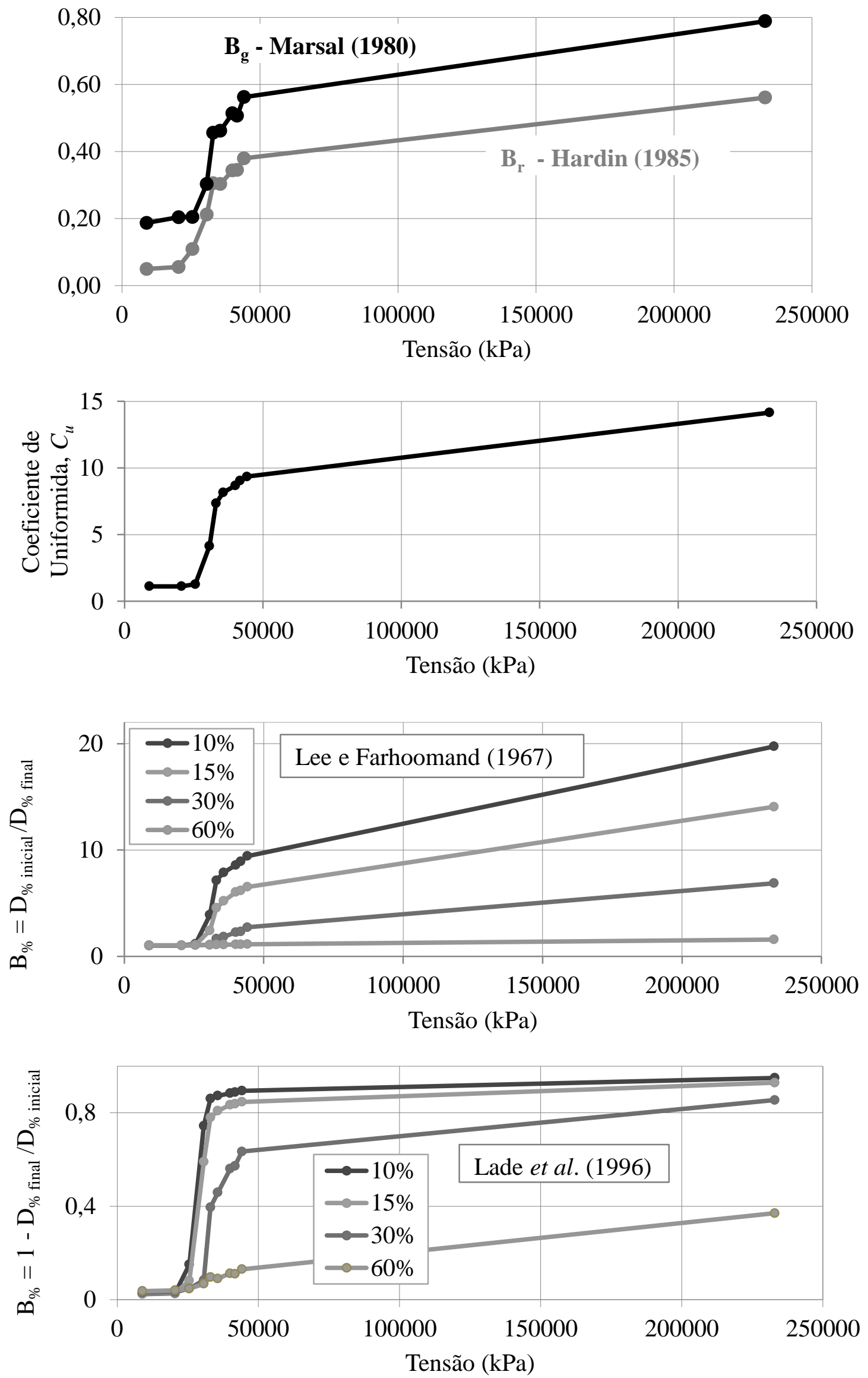

Figura 4.43. Índices de quebra para o material A170. 

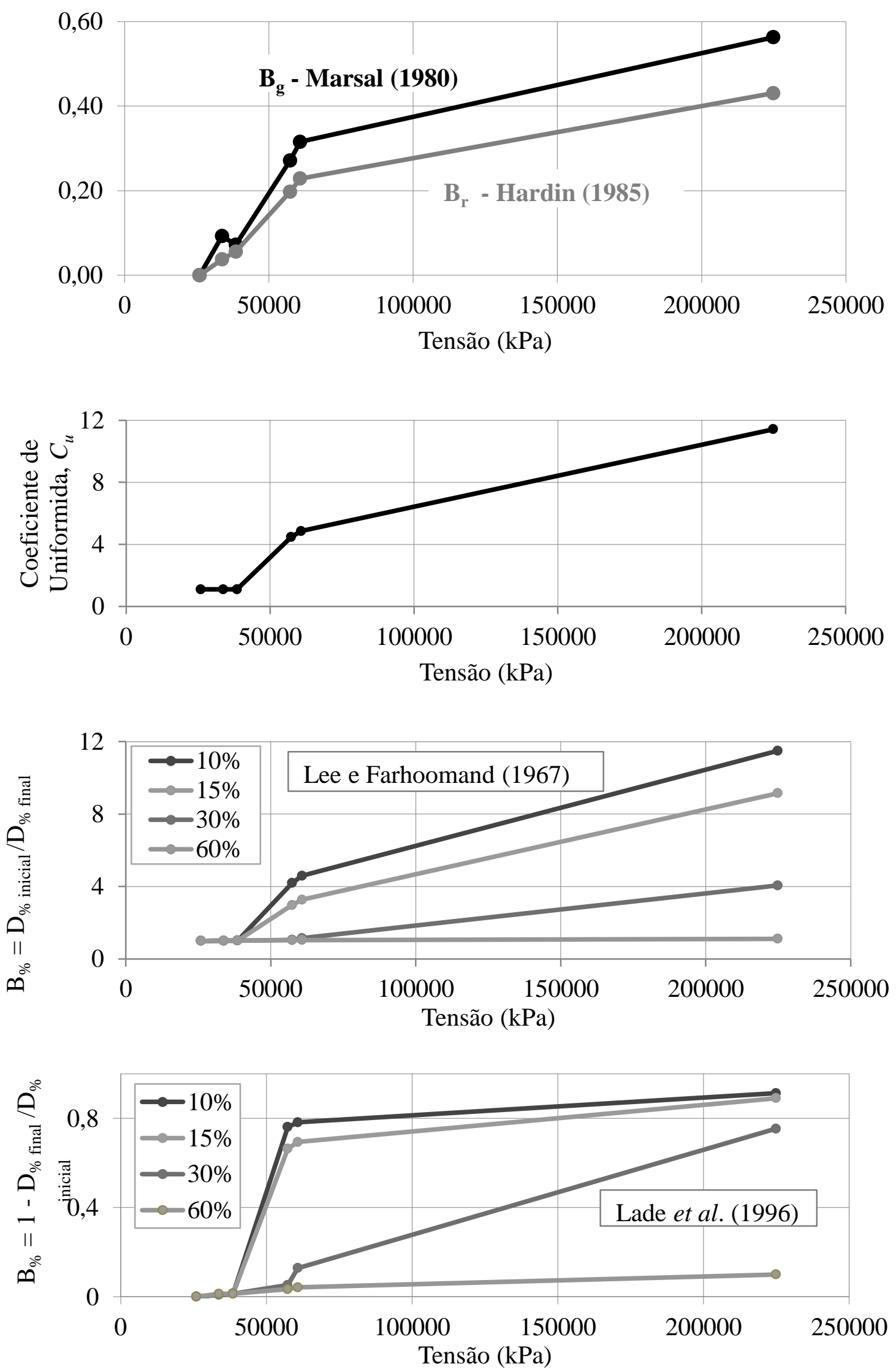

Figura 4.44. Índices de quebra para o material A072. 

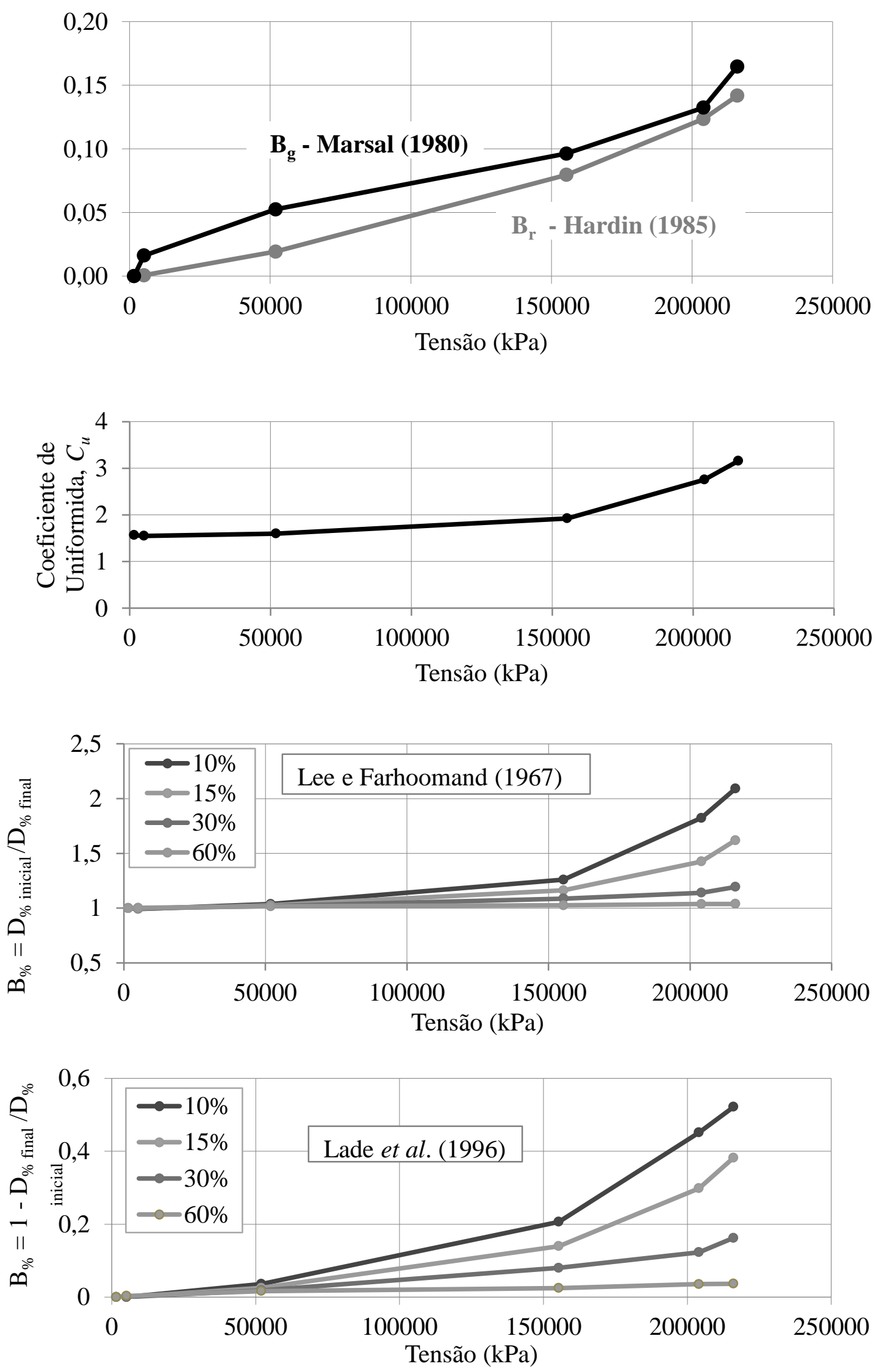

Figura 4.45. Índices de quebra para o material AC. 
Na Figura 4.46 são apresentados os índices de quebra relativo (Hardin, 1985) para os diferentes materiais. Observa-se a concordância dos resultados com os processos descritos anteriormente das informações de compressibilidade e emissões acústicas. Desta forma observa-se claramente que o efeito da quebra é mais intenso para as partículas de maior diâmetro.

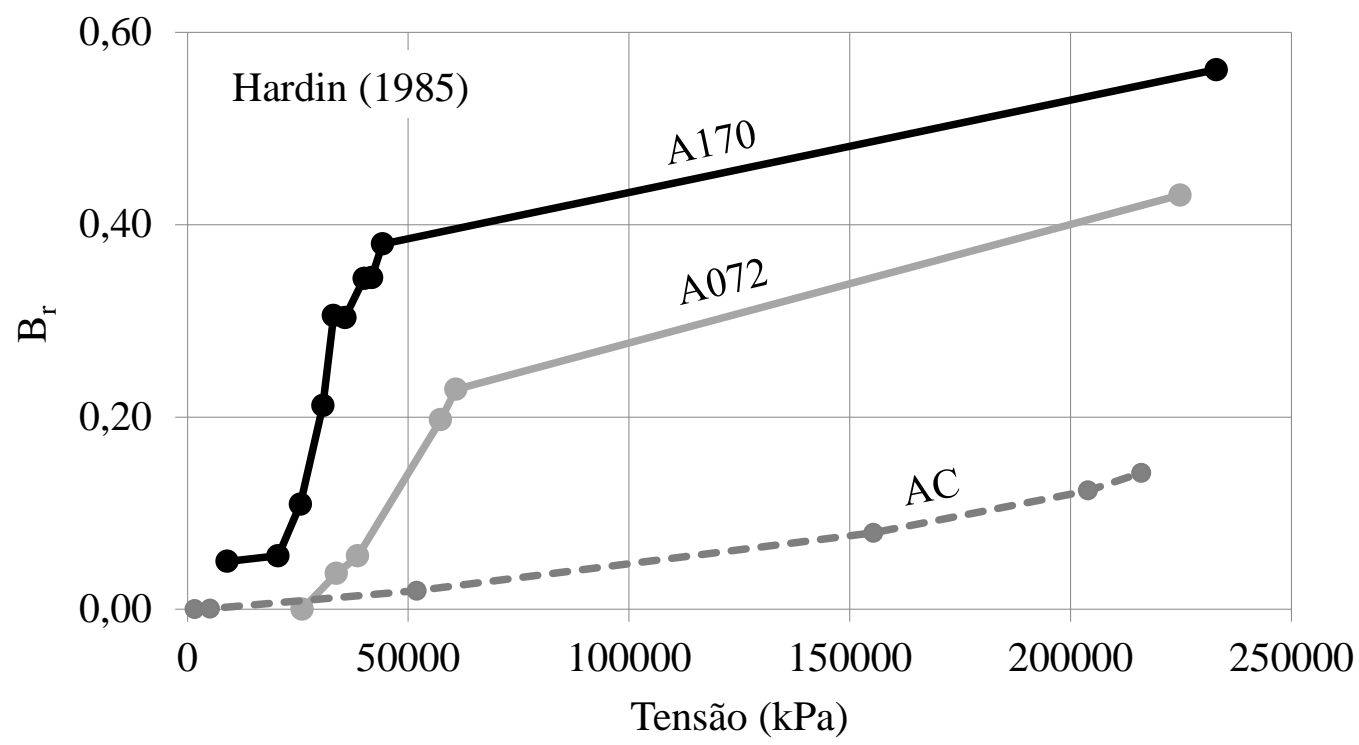

Figura 4.46. Índices de quebra em função do tipo de material.

Entre os índices avaliados os mais satisfatórios são aqueles que levam em consideração a curva completa no processo de cálculo. Para entender melhor o porquê deve-se observar com cuidado os casos onde se tem pouca quebra, como no do material AC, já que degradações são tão leves (poucas mudanças na curva granulométrica) que a avaliação pontual não proporciona suficiente informação. Na Figura 4.45 observa-se que para os níveis baixos de tensão, onde se tem pouca quebra, os índices $B_{r}$ e $B_{g}$ mostram claramente as mudanças. O índice de maior aceitação internacionalmente é o proposto por Hardin (1985) que trabalha com a relação de áreas de material retido e proporciona resultado de fácil interpretação porque varia entre 0 , no caso de não haver quebra, e 1 , para o caso de quebra total.

\subsubsection{Análise de imagens}

Visando avaliar a evolução da forma das partículas foram feitas análises de imagens do material original e resultante do processo de fragmentação. No caso de material A170, foram feitas análises individuais das diferentes frações, separadas previamente mediante peneiramento. Na Figura 4.47 são mostradas as granulometrias para as quais foram feitas 
análises de imagens. Para a avaliação da forma foi usada a relação de aspecto, a qual foi definida no capítulo anterior. A apresentação dos dados utiliza a curva de probabilidade acumulada de relação de aspecto, funcionando de maneira semelhante à curva granulométrica. Neste caso, o valor na ordenada deve ser interpretado como a porcentagem de material com relação de aspecto inferior ao valor correspondente na abscissa. No caso do material A170 os resultados são apresentados na Figura 4.48, onde se encontra a distribuição acumulada do material original e as distribuições de cada uma das frações do material resultante da fragmentação.

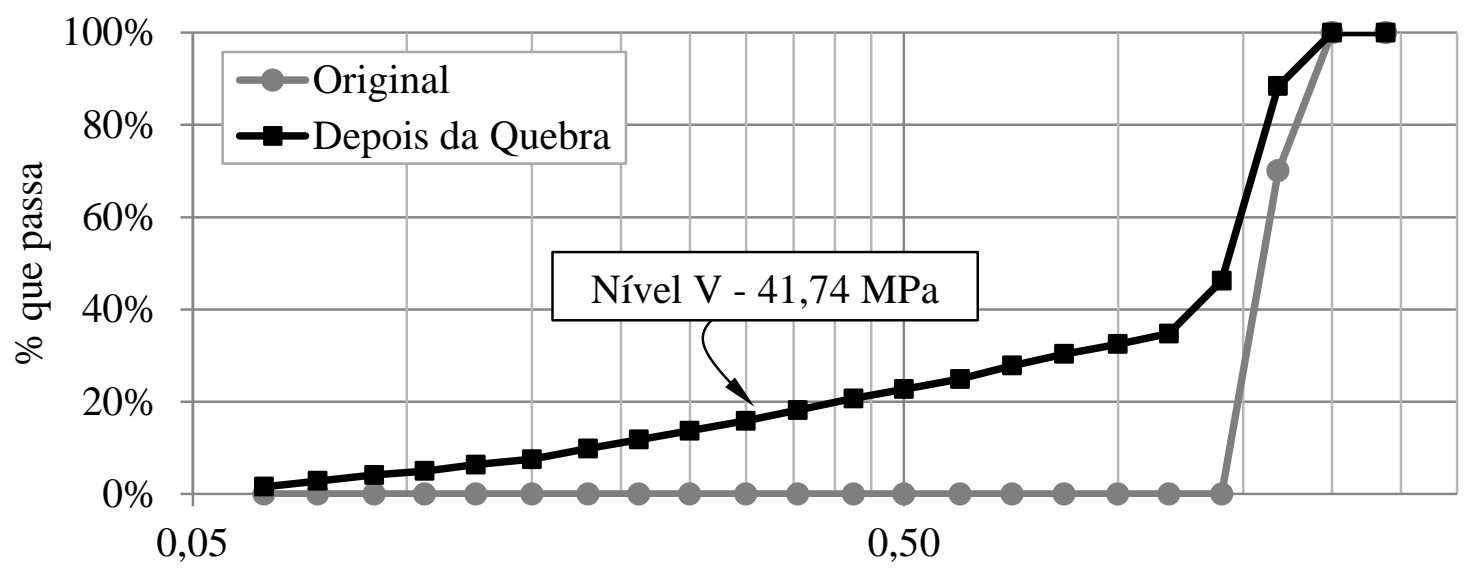

Diâmetro (mm)

Figura 4.47. Granulometria do material A170 para os quais foram feitas analise de imagens.

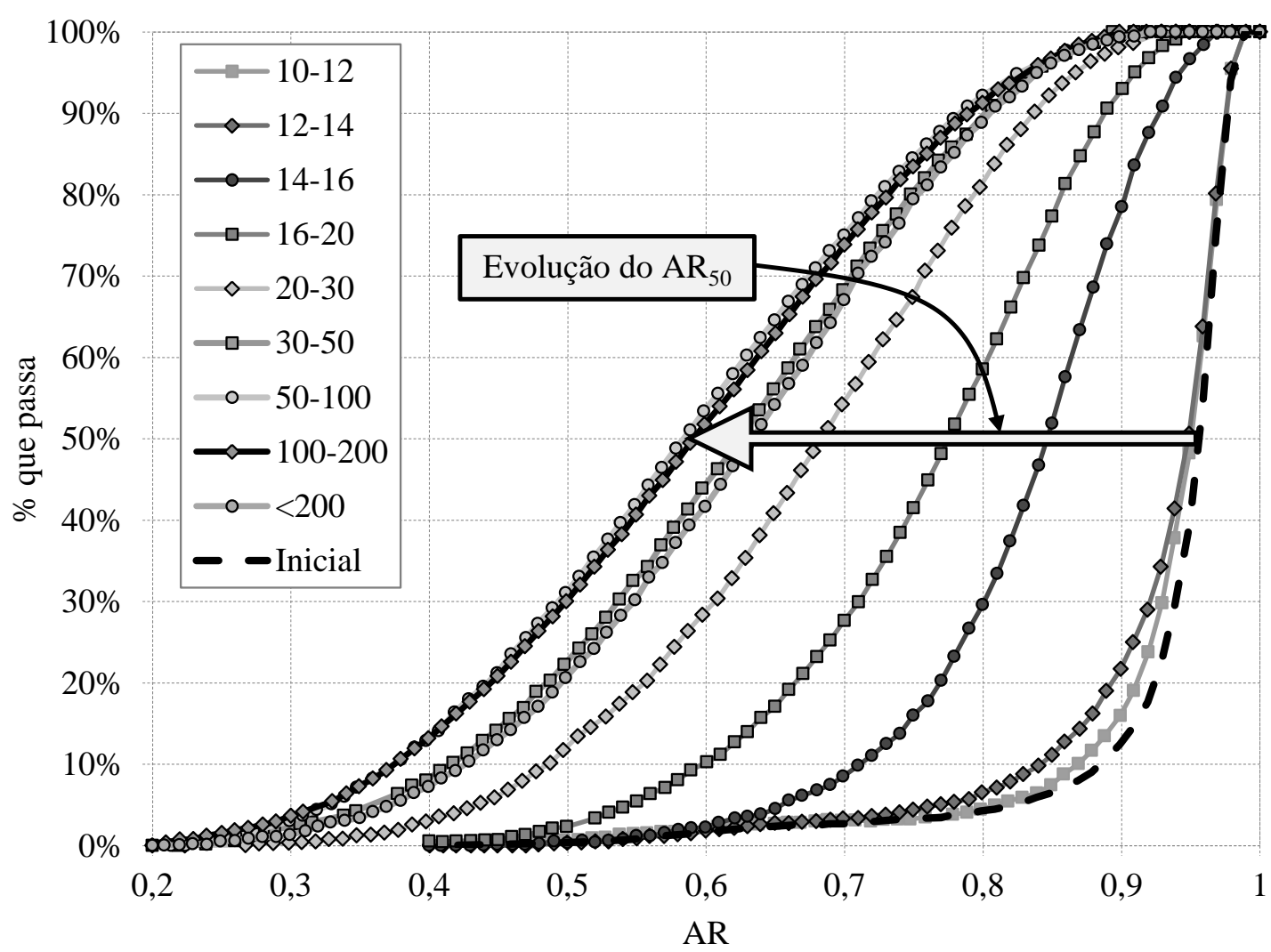

Figura 4.48. Distribuição acumulada da relação de aspecto para o material A170. 
Mesmo que a relação de aspecto seja uma caraterística simplista da forma da partícula, este resultado proporciona uma descrição estatística muito útil para o entendimento do comportamento. Para o material de trabalho (vidro) observa-se que mesmo para as frações mais finas, que passaram por vários processos de quebra, é pequena a percentagem de material quebrado com relações de aspecto inferiores a 0,4 (material alongado). Predominam mais as relações de aspecto superiores a 0,6, o que parece estar intimamente ligado à natureza do mineral.

Para entender melhor a evolução da quebra é apresentada a Figura 4.49, na qual se plota para cada uma das frações a relação de aspecto correspondente a uma determinada porcentagem de material passante. A primeira linha corresponde aos valores de relações de aspecto média (50\%) para cada uma das frações, mostrando que mesmo que o material seja submetido a muitos processos de quebra, em média esta relação não será inferior a 0,6.

As outras duas linhas são para porcentagens de $15 \%$ e $30 \%$ de material passante, podendo ser interpretadas como os valores mínimos que apresenta a relação de aspecto para o $85 \%$ e $70 \%$ do material, respectivamente. Observa-se ainda que as frações que atingem relações de aspecto mais baixas, ou seja, partículas mais alongadas, se concentram na faixa de diâmetro entre 0,300 e 0,075mm (peneiras ASTM \#50 a \#200). Na Tabela 4.4 são apresentados os valores da relação de aspecto para as diferentes frações de materiais.

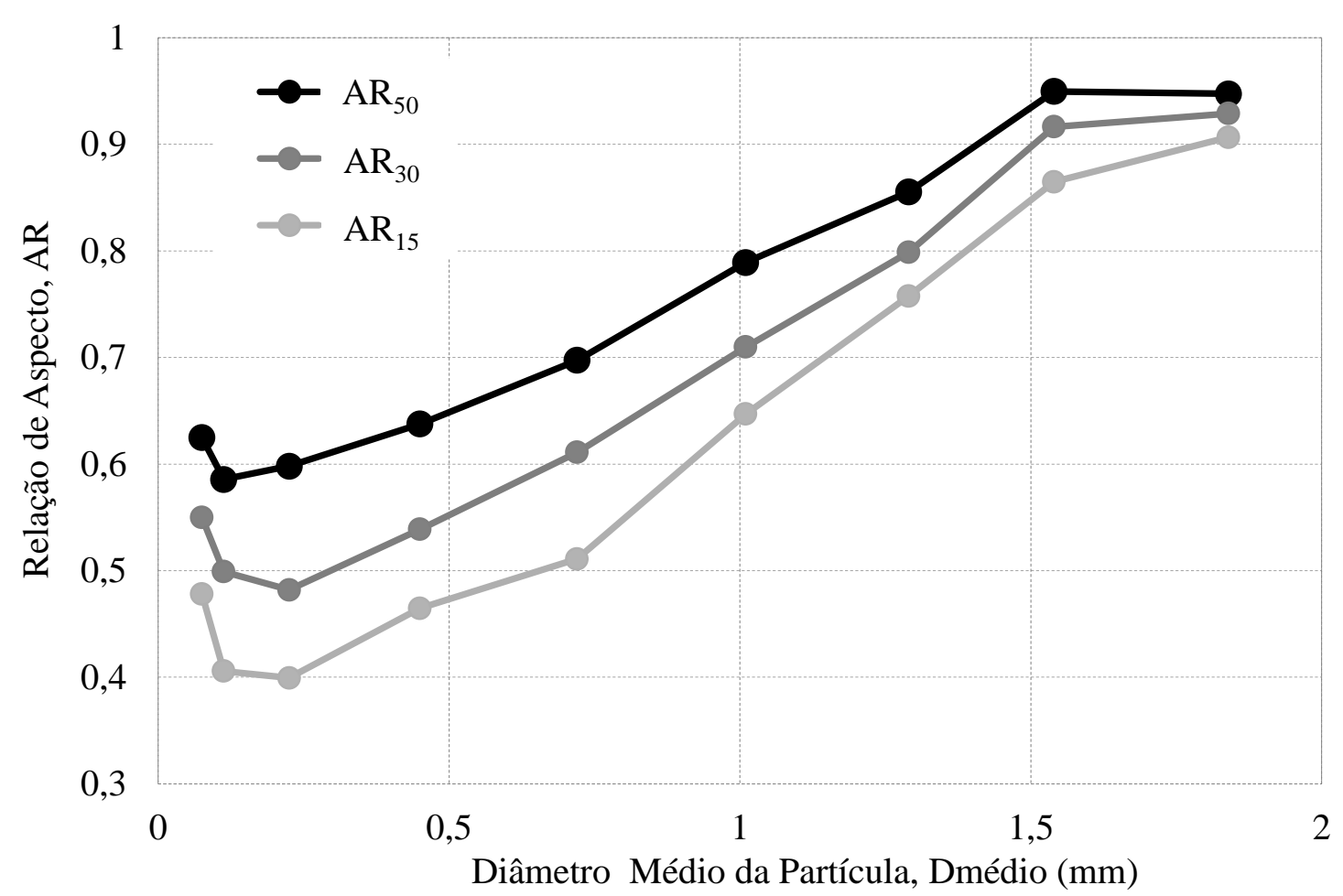

Figura 4.49. Relação de Aspecto em função do tamanho da partícula. 
Tabela 4.4. Evolução da relação de aspecto do material A170.

\begin{tabular}{|c|c|c|c|c|c|c|c|}
\hline \multirow{2}{*}{$\begin{array}{c}\text { Faixa } \\
\text { ASTM }\end{array}$} & \multirow{2}{*}{$\begin{array}{c}\text { Dédio } \\
(\mathrm{mm})\end{array}$} & \multicolumn{3}{|c|}{ Material Original } & \multicolumn{3}{|c|}{ Material Quebrado } \\
\cline { 3 - 8 } & $\mathrm{AR}_{15}$ & $\mathrm{AR}_{30}$ & $\mathrm{AR}_{50}$ & $\mathrm{AR}_{15}$ & $\mathrm{AR}_{30}$ & $\mathrm{AR}_{50}$ \\
\hline $10-12$ & 1,84 & 0,907 & 0,938 & 0,963 & 0,907 & 0,929 & 0,947 \\
\hline $12-14$ & 1,54 & 0,907 & 0,938 & 0,963 & 0,865 & 0,917 & 0,950 \\
\hline $14-16$ & 1,29 & - & - & - & 0,758 & 0,799 & 0,855 \\
\hline $16-20$ & 1,01 & - & - & - & 0,647 & 0,710 & 0,789 \\
\hline $20-30$ & 0,72 & - & - & - & 0,511 & 0,611 & 0,697 \\
\hline $30-50$ & 0,45 & - & - & - & 0,465 & 0,539 & 0,638 \\
\hline $50-100$ & 0,225 & - & - & - & 0,399 & 0,482 & 0,598 \\
\hline $100-200$ & 0,113 & - & - & - & 0,406 & 0,499 & 0,586 \\
\hline$<200$ & 0,075 & - & - & - & 0,478 & 0,550 & 0,625 \\
\hline
\end{tabular}

A estabilização da relação de aspecto em um valor limite é uma evidencia experimental de como os processos na natureza possuem um ponto de equilíbrio, podendo estar relacionados com alguns estados limites do comportamento macroscópico. Um aspecto relevante dominado pela evolução da forma é o intertravamento dos grãos, o qual repercute explicitamente na resposta macro do material. Este tipo de evidência experimental fornece informações valiosas para a elaboração de modelos que possam quantificar a fábrica em função da distribuição de tamanhos e de forma do material, submetido a diferentes processos de carregamento.

A Figura 4.50 apresenta algumas imagens do material A170 usadas para análise da forma das partículas. A evolução da quebra é apresentada de cima para baixo, onde as primeiras correspondem a materiais com tamanho e forma originais e as últimas aos grãos resultantes de vários processos de quebras. Nas imagens são observadas claramente superfícies côncavas características de quebra de material quartzoso devido à semelhança da composição mineralógica do vidro.

Deve ficar claro que apesar de esta técnica ser totalmente bidimensional, o número de imagens é o suficientemente grande para poder diminuir esta limitação mediante tratamento estatístico dos dados. Nesta pesquisa, devido a limitações de tempo de uso do equipamento QICPIC, não foi possível realizar análises mais detalhadas das informações que podem ser obtidas. Aspectos como angularidade, convexidade, entre outros, podem ser levantados com facilidade com estas ferramentas, sendo analisados de forma estatística para um melhor beneficio. 


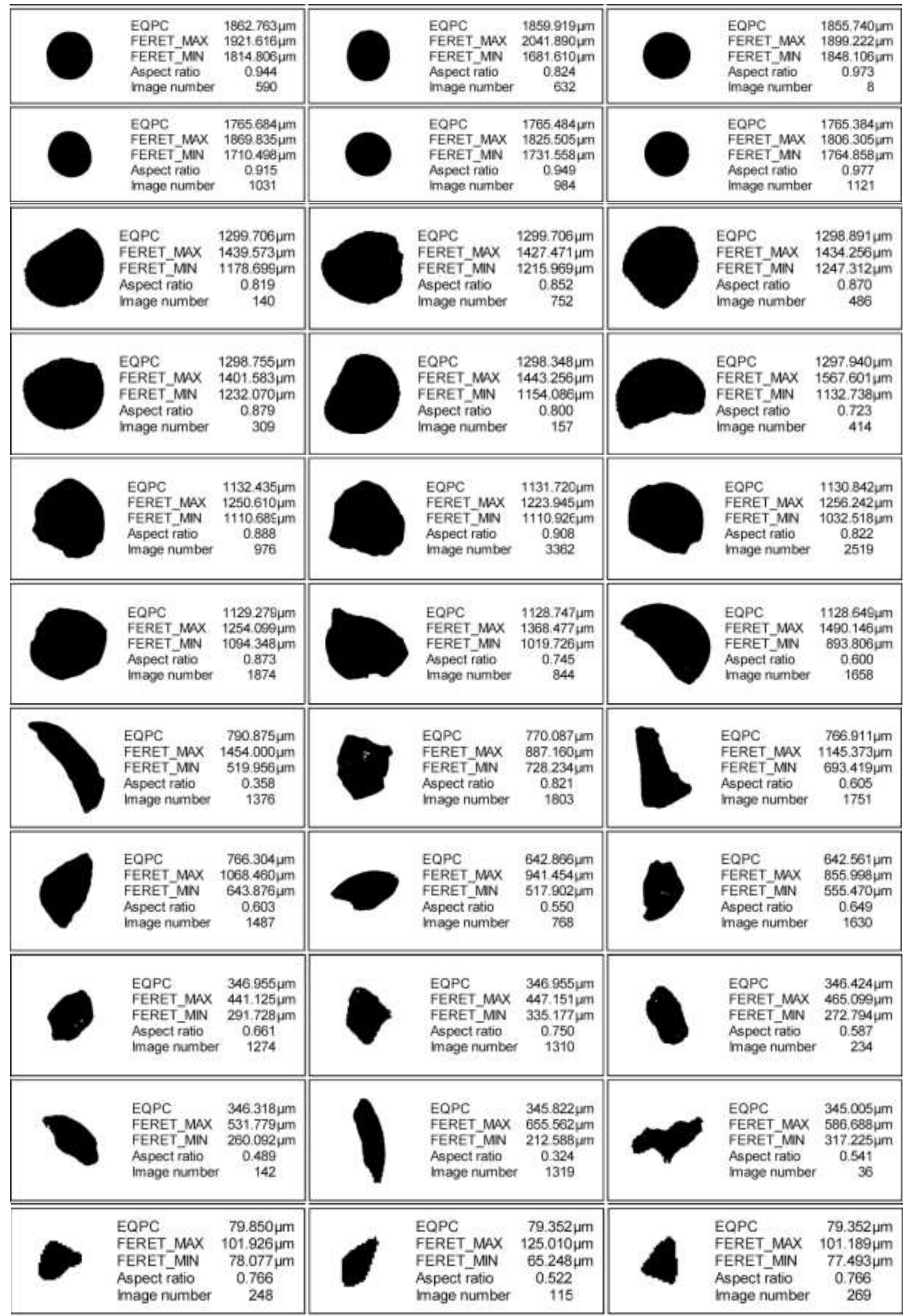

Figura 4.50. Algumas imagens do material A170. 
Para os materiais A072 e AC foram feitas análises do material quebrado sem dividir por frações, devido a limitações de tempo de uso do equipamento. Assim, os resultados obtidos são representados por uma única curva de distribuição acumulada. As curvas granulométricas usadas nesta análise para o material A072 e AC são apresentadas na Figura 4.51 e na Figura 4.52, respectivamente. Deve ser ressaltado que o nível de tensão escolhido para representar a curva de material quebrado, foi aquele para o qual a NCL ficou bem definida. No caso do material AC esta condição só foi alcançada no nível de carga máximo da prensa.

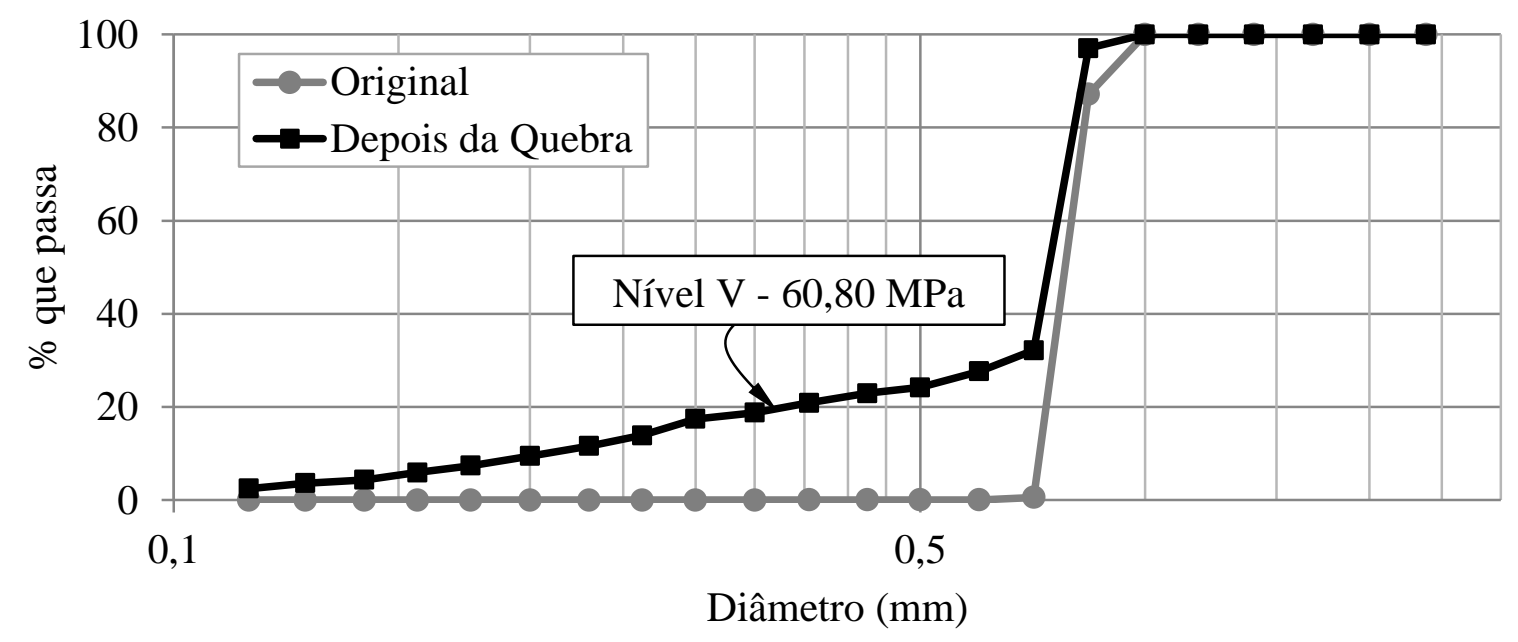

Figura 4.51. Granulometria do material A072 para os quais foram feitas analise de imagens.

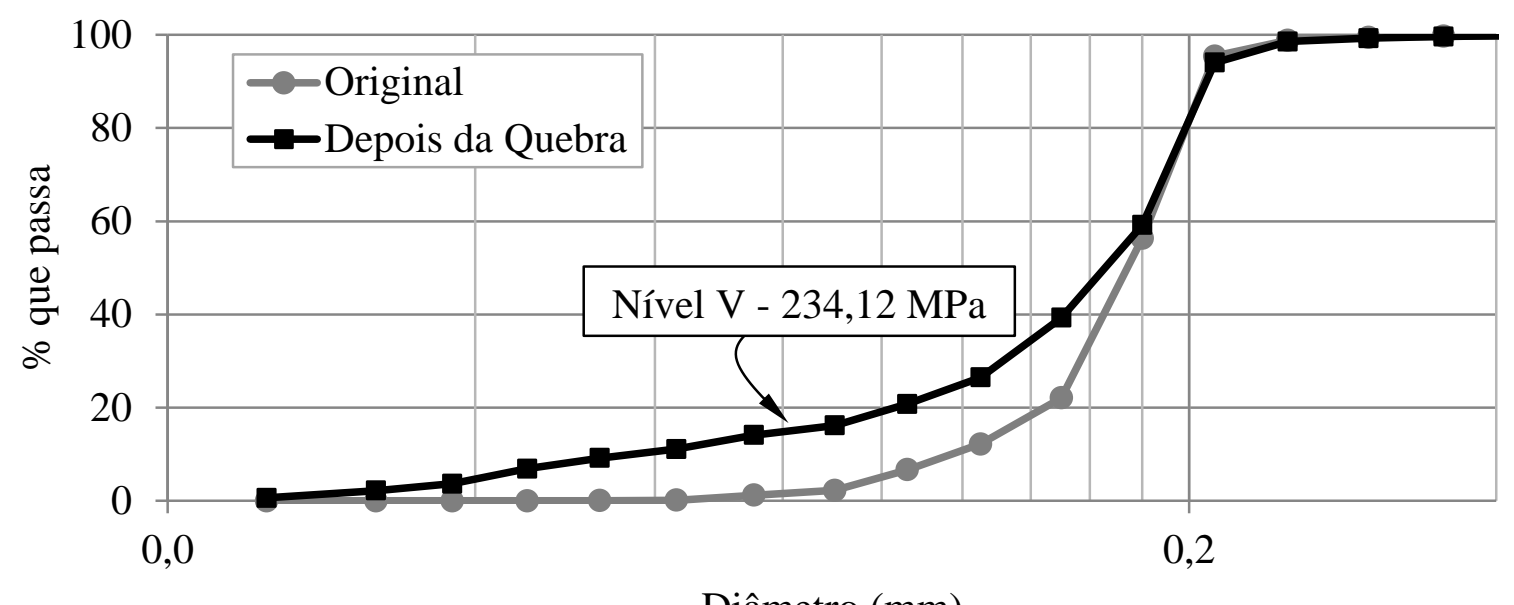

Figura 4.52. Granulometria do material AC para os quais foram feitas analise de imagens.

As distribuições acumuladas da relação de aspecto para o material A072 e AC são apresentadas na Figura 4.53 e na Figura 4.54, respectivamente. Observa-se que no caso do material A072 a quebra foi significativa e as relações de aspecto dominantes são superiores a 0,7, como no caso do material A170. No material AC, em termos de valores médios, a relação de aspecto do material praticamente permaneceu constante. 


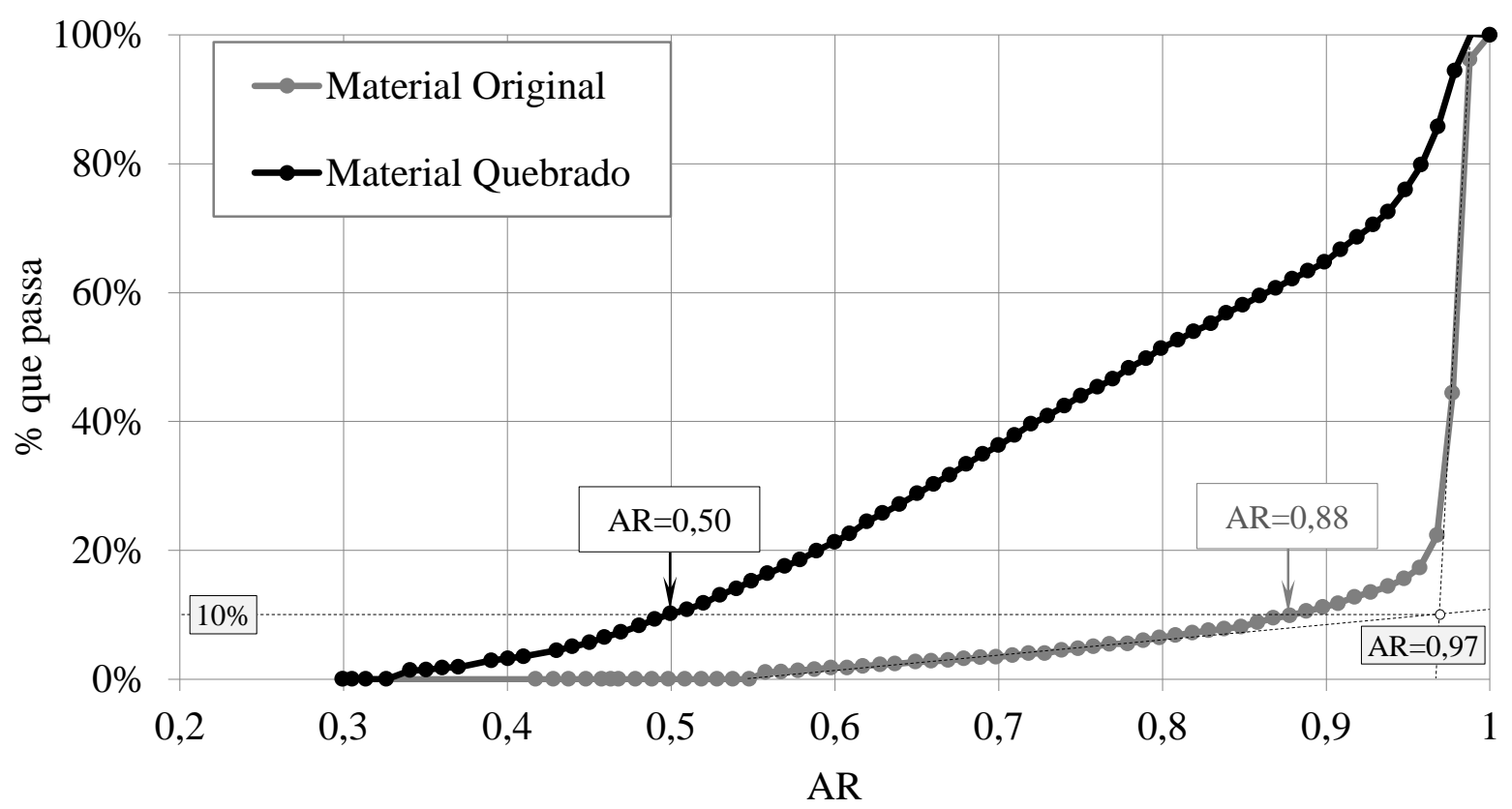

Figura 4.53. Distribuição acumulada da relação de aspecto para o material A072.

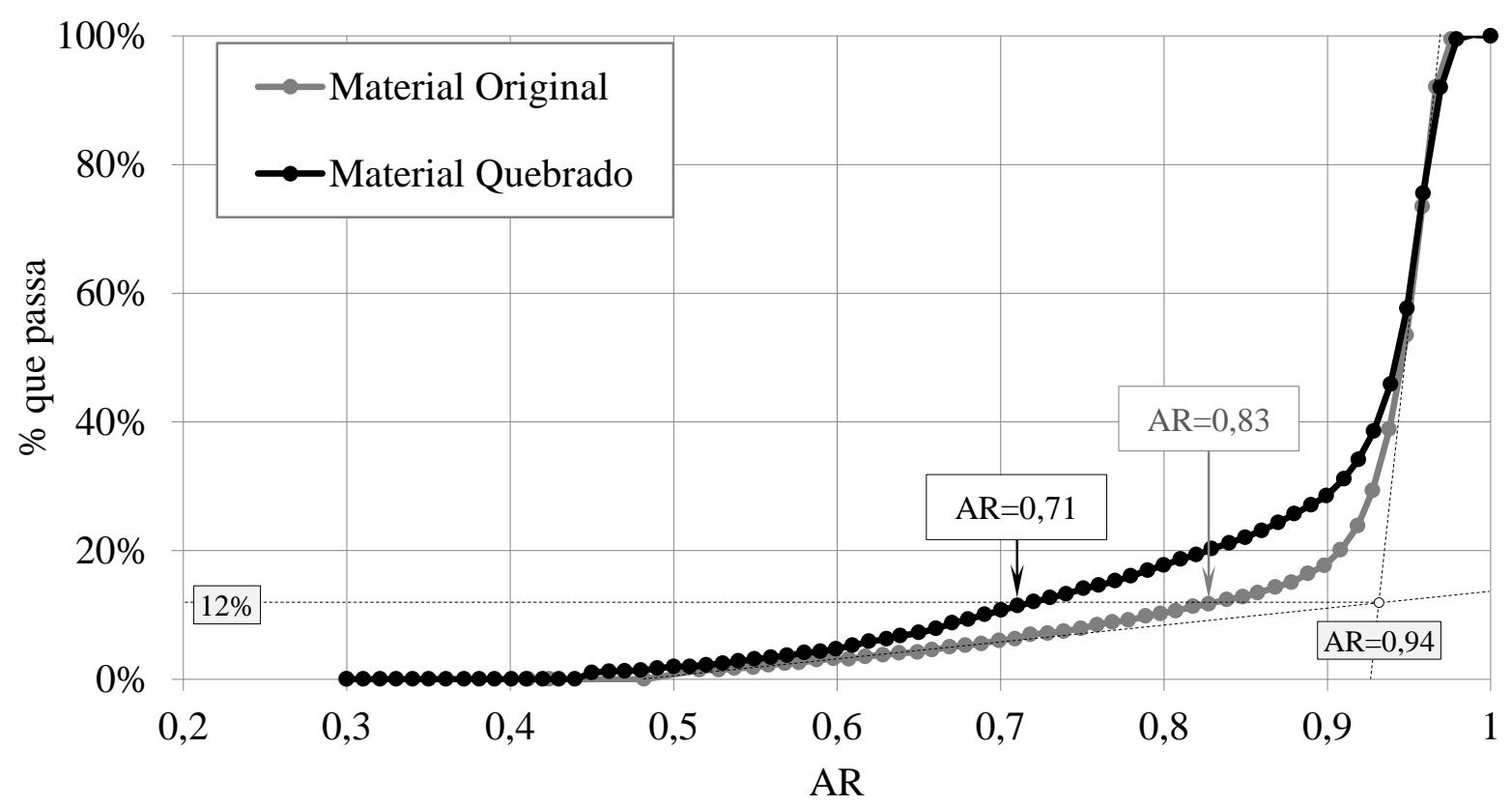

Figura 4.54. Distribuição acumulada da relação de aspecto para o material AC.

Com estes gráficos de distribuição acumuladas é possível determinar a quantidade de material com relação de aspecto superior a um valor de interesse. No caso do material A072 original, $90 \%$ do material (10\% de material que passa) tem relações de aspecto superiores a 0,9 . Quando este material é carregado (quebrado) a porcentagem de material com $A R \geq 90 \%$ diminui para 35\% (ver Figura 4.53). No caso do material AC, para uma relação de aspecto de 0,9 , a porcentagem passa de $80 \%$ para o material original para $70 \%$ nas partículas quebradas (ver Figura 4.55). 
Outra característica importante das curvas de distribuição acumuladas é a existência de um ponto de inflexão bem definido, o qual pode ser considerado com um ponto referência para avaliar as mudanças do comportamento da forma do grão ao longo do carregamento. Este ponto separa as partículas em dois grupos, no primeiro encontram-se as partículas com relações de aspeto mais uniformes (AR maiores do que o valor do ponto de inflexão), correspondentes ao trecho da curva com maior inclinação. O segundo grupo de partículas, corresponde aos grãos com diferentes formatos, sem a prevalência de um valor especifico (formas dispersas). No caso teórico de relação de forma única com todas as partículas totalmente esféricas, o ponto de inflexão corresponderia a uma relação de aspecto unitária para todo o material $(\mathrm{AR}=1$ e fração passante $=0 \%)$. $\mathrm{O}$ outro caso extremo seria uma distribuição equitativa, quando existe a mesma quantidade de partículas para cada relação de aspecto, no qual a curva teria uma única inclinação, correspondente a 45 graus (em escala decimal). Assim, a evolução do ponto de inflexão poderia ser usado como variável da evolução da forma do material.

\subsubsection{COMPRESSÃO CONFINADA - MATERIAL CIMENTADO}

\subsubsection{Compressibilidade}

Para este tipo de amostra foram geradas curvas de compressibilidade para diferentes níveis de cimentação, sendo avaliada sua influência no comportamento em compressão confinada. As porcentagens adicionadas de epóxi foram calculadas em relação ao peso das microesferas, sendo correspondentes a $5 \%, 8 \%$ e $10 \%$.

$\mathrm{Na}$ Figura 4.56, mostram-se as curvas de compressibilidade para os materiais cimentados, além de colocar como referência a curva das partículas não cimentadas. Observase o deslocamento das curvas de compressibilidade para a direita, com o aumento do teor de agente cimentante. Esta característica do ponto de vista micromecânico deve-se à restrição dos movimentos entre partículas pelo agente cimentante, o que em termos macroscópicos, corresponde a um aumento da rigidez do material. Além disso, no material cimentado, a transição que passa do trecho de recompressão para a NCL é feita de uma forma mais suave que no caso do material solto.

As curvas de compressibilidade para materiais cimentados apresentam o formato típico da literatura, no qual para porcentagens baixas o material mostra estruturação e com o aumento do cimento entre partículas, o comportamento tende ao de um material denso (rochas brandas). 


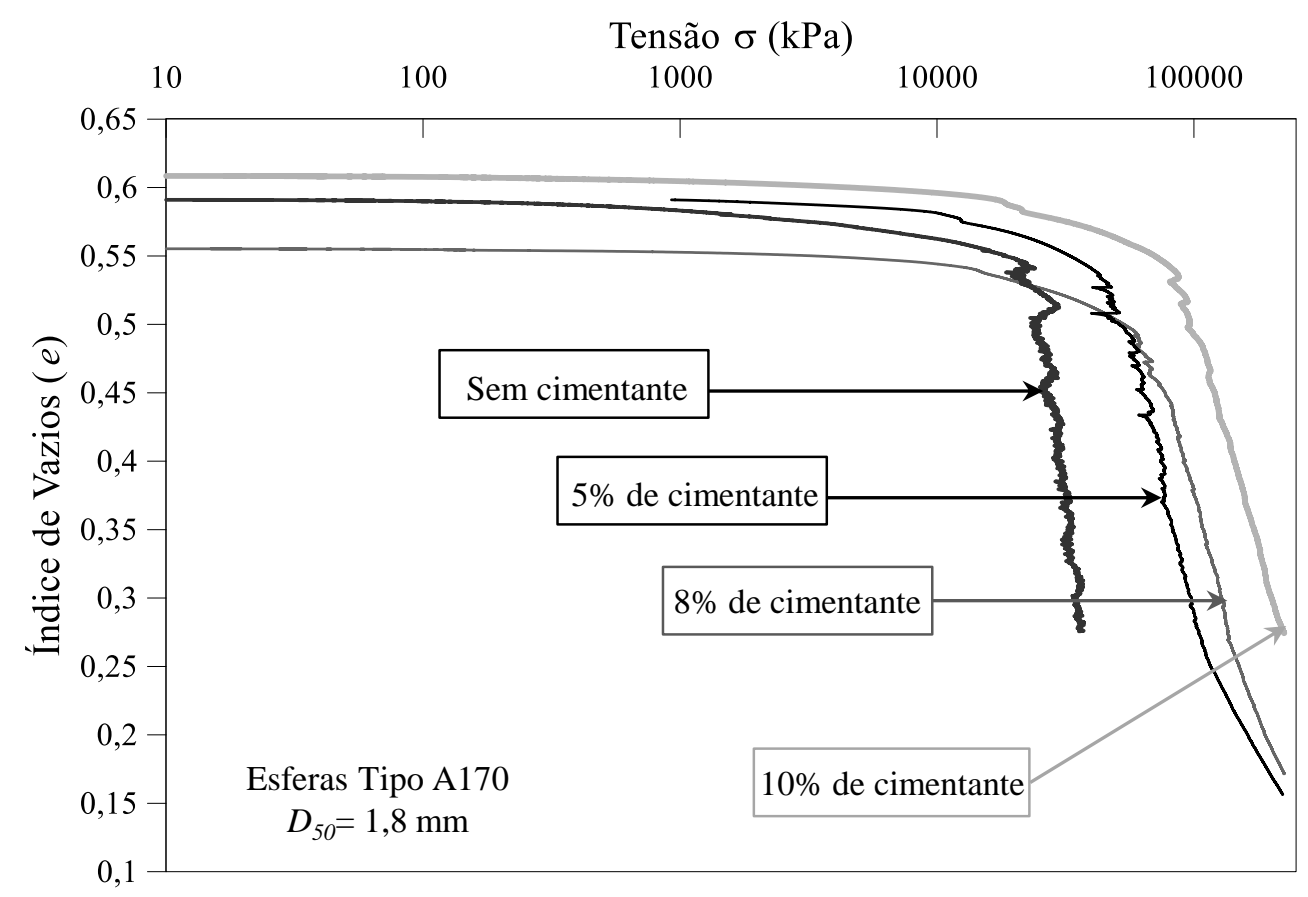

Figura 4.56. Curvas de compressibilidade para materiais cimentados.

Para observar melhor os efeitos do agente cimentante no comportamento macroscópico as curvas de compressibilidade foram normalizadas, usando como referência o índice de vazios para $10 \mathrm{kPa}$. Os resultados para todos os materiais são apresentados na Figura 4.57. Os efeitos do deslocamento da curva e a evolução da mesma são influenciados tanto pelo tipo de partícula como pela quantidade de epóxi utilizada. Para estes materiais a fase da transição do trecho de recompressão para a NCL apresenta um comportamento diferente ao do material solto. Neste caso, existe inicialmente uma quebra da cimentação sem a ocorrência da quebra das partículas. Quando o material perde todas essas conexões do epóxi, o fenômeno de quebra de grão começa a dominar o comportamento e começa a definir a NCL. Para os materiais A170 e A072 este processo de desestruturação ocorre claramente para 5\% e 8\% de epóxi, mostrando a definição da NCL (linha tracejada).

No caso do $10 \%$ de epóxi para esses dois tipos de esferas, o material é suficientemente rígido para não definir bem todas as fases de comportamento, com os níveis alcançados no experimento. $\mathrm{O}$ mesmo ocorre com o material AC, para o qual os efeitos de deslocamento da curva de compressibilidade são mais fortes, ao ponto de não se observar claramente a totalidade da transição entre a recompressão e a NCL.

O tamanho da partícula afeta substancialmente o comportamento, como foi ressaltado para materiais soltos. No caso de materiais cimentados, observa-se que o deslocamento da 
curva de compressibilidade para as diferentes porcentagens de cimento é menor para as partículas de menor diâmetro.
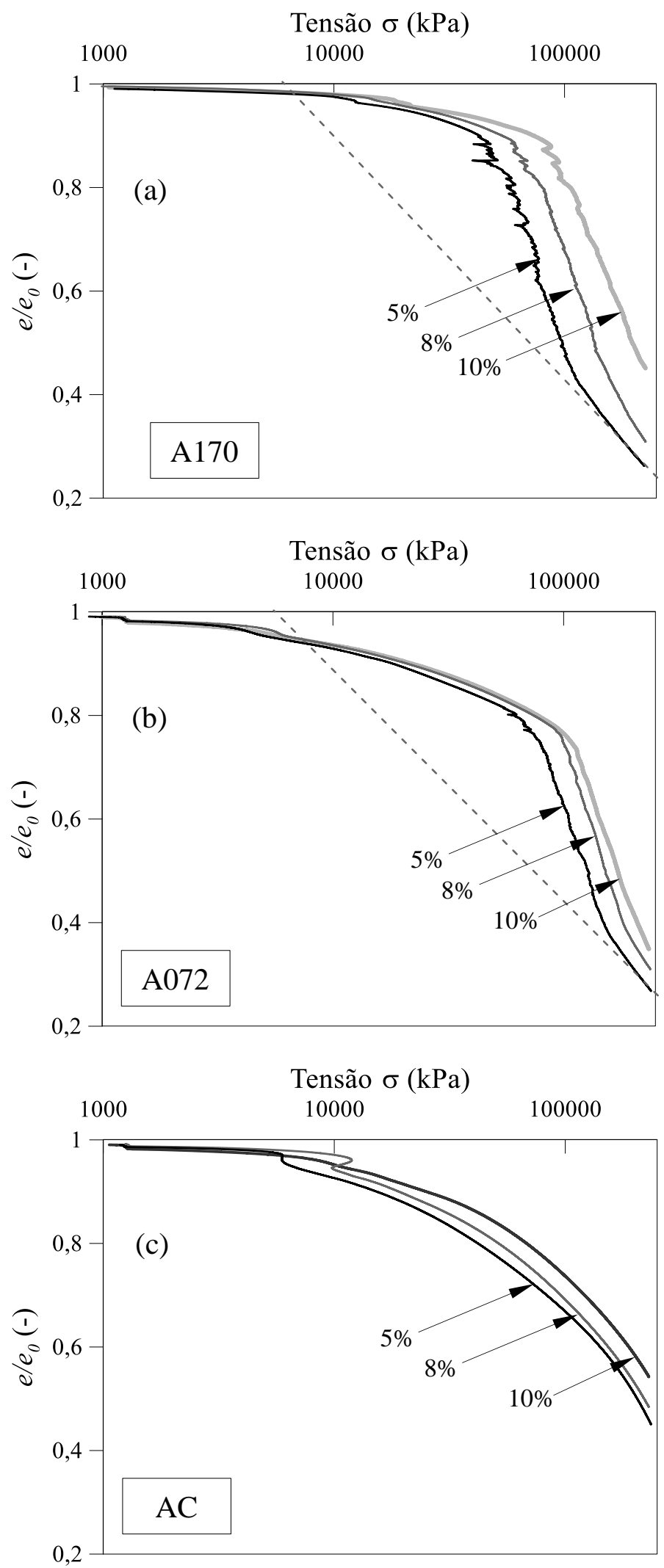

Figura 4.57. Curvas de compressibilidade normalizadas do material cimentado. 


\subsubsection{Emissões Acústicas}

Na Figura 4.58 são analisadas as diferenças dos resultados de ensaios de compressão comfinada, para material cimentado e material solto. Nestas figuras são incluídas as energias obtidas da emissão acústicas, para auxiliar na interpretação dos mecanismos. Observa-se que a liberação de energia em materiais cimentados é menor que em materiais soltos. Isto se deve às cimentações entre partículas, as quais enrijecem o sistema, fazendo que o processo de liberação de energia seja mais suave.
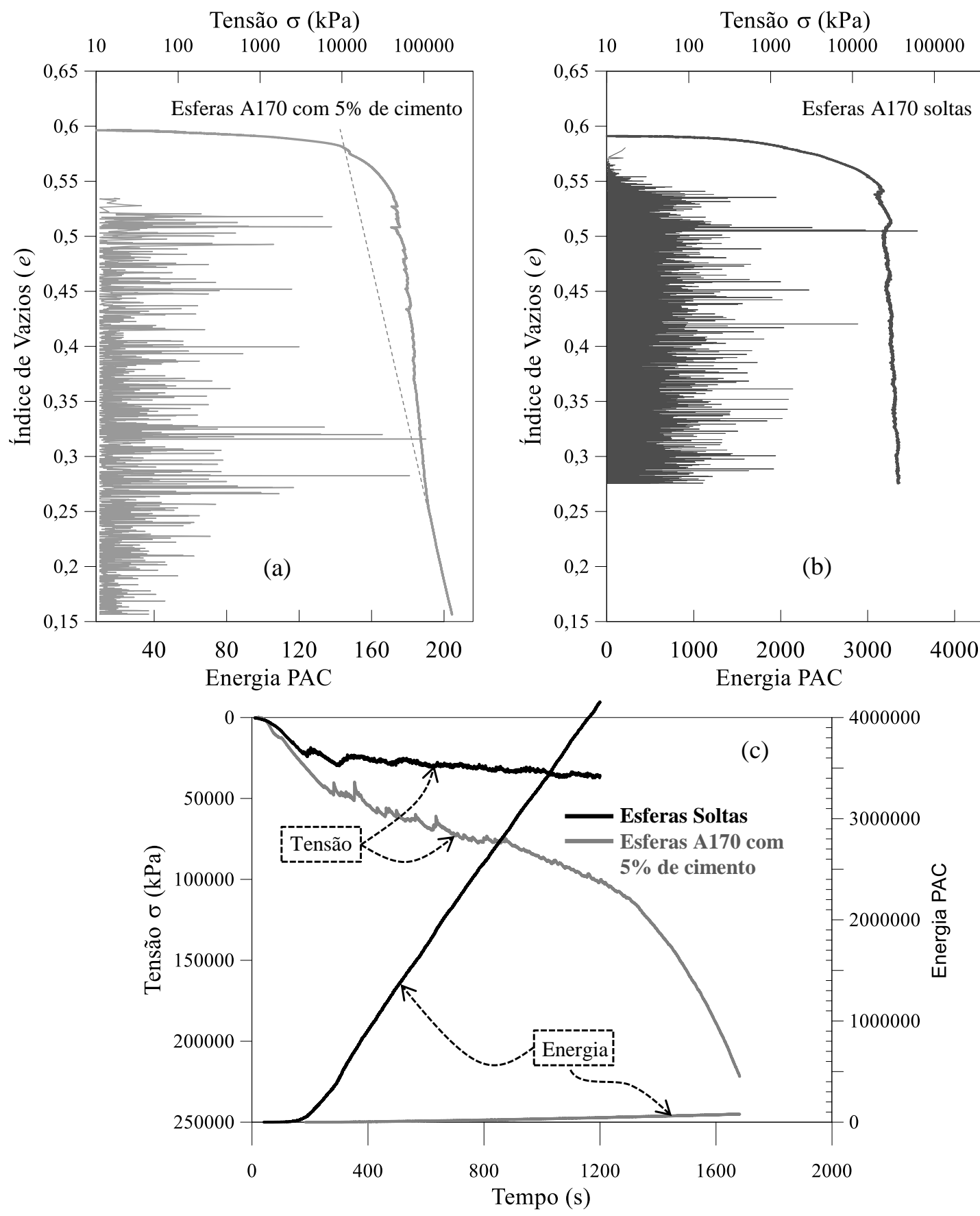

Figura 4.58. Diferenças entre as emissões acústicas para material solto e cimentado. 
A Figura 4.58-c mostra mais claramente a diferença de magnitude da energia liberada numa amostra solta em relação a um corpo de prova cimentado, como é evidenciado nas curvas de energia acumulada. Não obstante, existe total coerencia entre os resultados da curva de compressibilidade com os eventos acústicos, tendo pico de energias com os locais de relaxação de tensões (quebra de cimentação ou de partícula). Além disso, a curva de energia acumulada continua sendo uma excelente ferramenta para definir as diferentes fases de comportamento que acontecem no material.

A Figura 4.59 mostra as diferentes curvas de energias acumuladas para os diferentes materiais sob as diferentes condições de cimentação. Para o material A170, onde as diferenças de comportamento para as diferentes dosagens de cimento são bem definidas, observa-se uma clara tendência na resposta das curvas acumuladas. A Figura 4.59-a mostra que a inclinação da linha de energia aumenta com a diminuição da porcentagem de cimento. Isto é bastante logico, já que com o aumento da estruturação a liberação de energia é maior. Não obstante, para os outros materiais a sequência obtida das curvas de energia acumulada não respeita necessariamente esta ordem.

Para interpretar melhor isto, deve-se ressaltar as limitações da instrumentação, onde as condições da fronteira do corpo de prova não eram perfeitamente iguais. A cada ensaio os sensores eram colados nas paredes com uma resina que não necessariamente possuíam a mesma espessura, além do mais o sistema para a diminuição do atrito lateral (plásticovaselina) pode apresentar diferenças significativas (espessura da vaselina, p.ex.). Todo isto provoca alterações nas ondas recebidas das emissões geradas pelas quebra de partículas e/ou das conexões de cimento. Quando as diferenças de comportamento são fortes, este efeito não chega a influenciar muito a interpretação das emissões acústicas. Deve ser ressaltado que mesmo que não exista uma coerência com a ordem das magnitudes, a forma da curva de energia acumulada não tem alterações e pode ser usada para a identificação das diferentes fases de comportamento.

Os materiais cimentados podem apresentar três fases da curva de compressibilidade. A primeira é o trecho de recompressão com características similares ao que acontece no material solto. A segunda é a fase de desestruturação, na qual o processo dominante é a quebra das cimentações entre partículas. A última fase corresponde à definição novamente da NCL, onde os processos de quebras de partículas dominam o fenômeno, de forma similar ao que ocorre nas partículas soltas. Estas fases são facilmente identificáveis na curva de energia acumulada. 


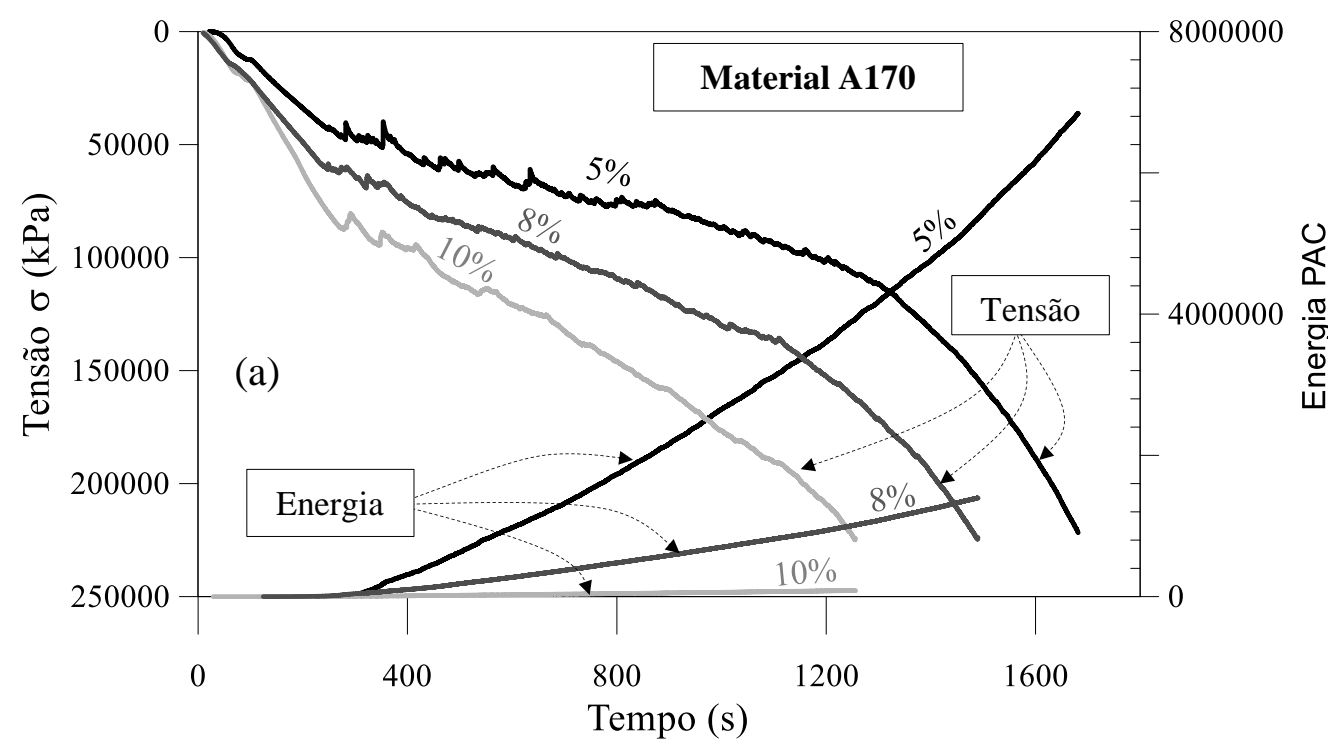

0
$\frac{1}{2}$
$\frac{\pi}{0}$
$\frac{0}{0}$
$\frac{1}{4}$
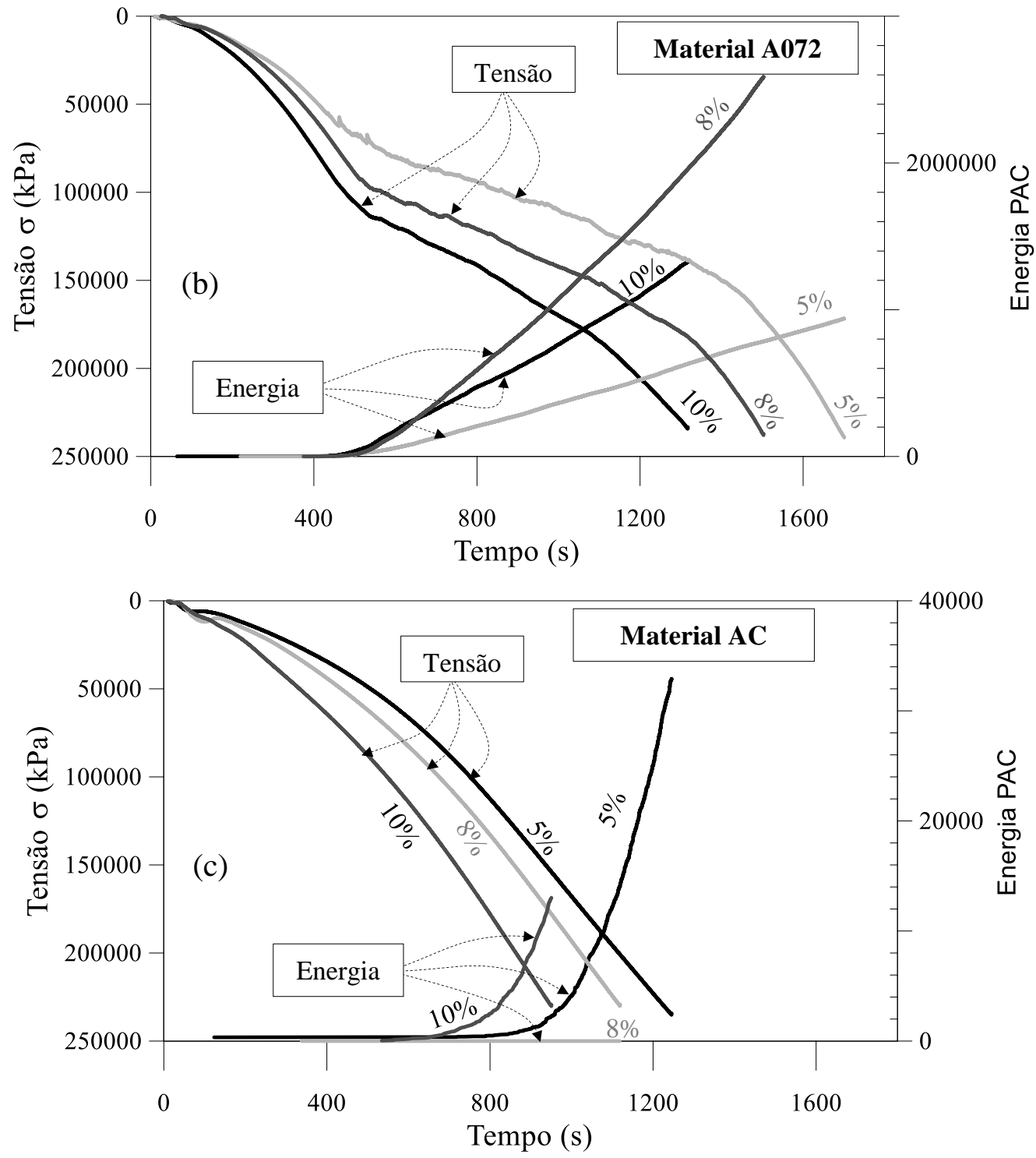

Figura 4.59. Compressibilidade e as emissões acústicas com a porcentagem de cimento. 
A fase da recompressão, onde não existe liberações significativas de ruídos, é definida pelo trecho inicial quase horizontal da curva de energia acumulada define. Posteriormente, a energia aumenta até definir um comportamento linear, correspondendo à segunda fase, a qual pode ser longa ou curta dependendo da intensidade da estruturação. Por último, a energia continua aumentando e se observa uma mudança na inclinação, correspondente ao trecho onde fica definida a NCL.

Na Figura 4.60, Figura 4.61 e Figura 4.62 são apresentados os resultados da energia acumulada para cada um dos materiais sob as diferentes condições de cimentação. Para todas as curvas são ilustradas as duas últimas fases mediante linhas tracejadas, de modo que fica clara a mudança de comportamento.

Os resultados dos materiais A170 e A072 para 5\% e 8\% de cimento apresentam claramente as três fases de comportamento, podendo usar o ponto de inflexão (intercepto das linhas tracejadas) para definir uma referência na qual o material muda de comportamento. Observa-se que na segunda fase em alguns resultados está melhor definida do que em outros, o que se deve ao fato de o material ser mais ou menos estruturado.

Para os corpos de prova com 10\% de epóxi para os materiais A170 e A072 e para todos os corpos de prova com esferas AC, observa-se que a curva de energia acumulada não desenvolve a terceira fase de comportamento. A linha tracejada corresponde à segunda fase de comportamento. Isto pode acontecer porque durante o ensaio não foram alcançados níveis de tensões suficientes para o desenvolvimento da última fase, ou porque a quantidade de cimentante é tal que dificilmente se chegara numa ruptura da partícula (similar a uma rocha branda).

A técnica de emissões acústicas mostra resultados bastante coerentes com os fenômenos estudados. Com esta ferramenta podem-se identificar claramente os momentos de maior liberação de energia, além detectar claramente qual são as diferentes fases de comportamento desenvolvidas pelo material. 

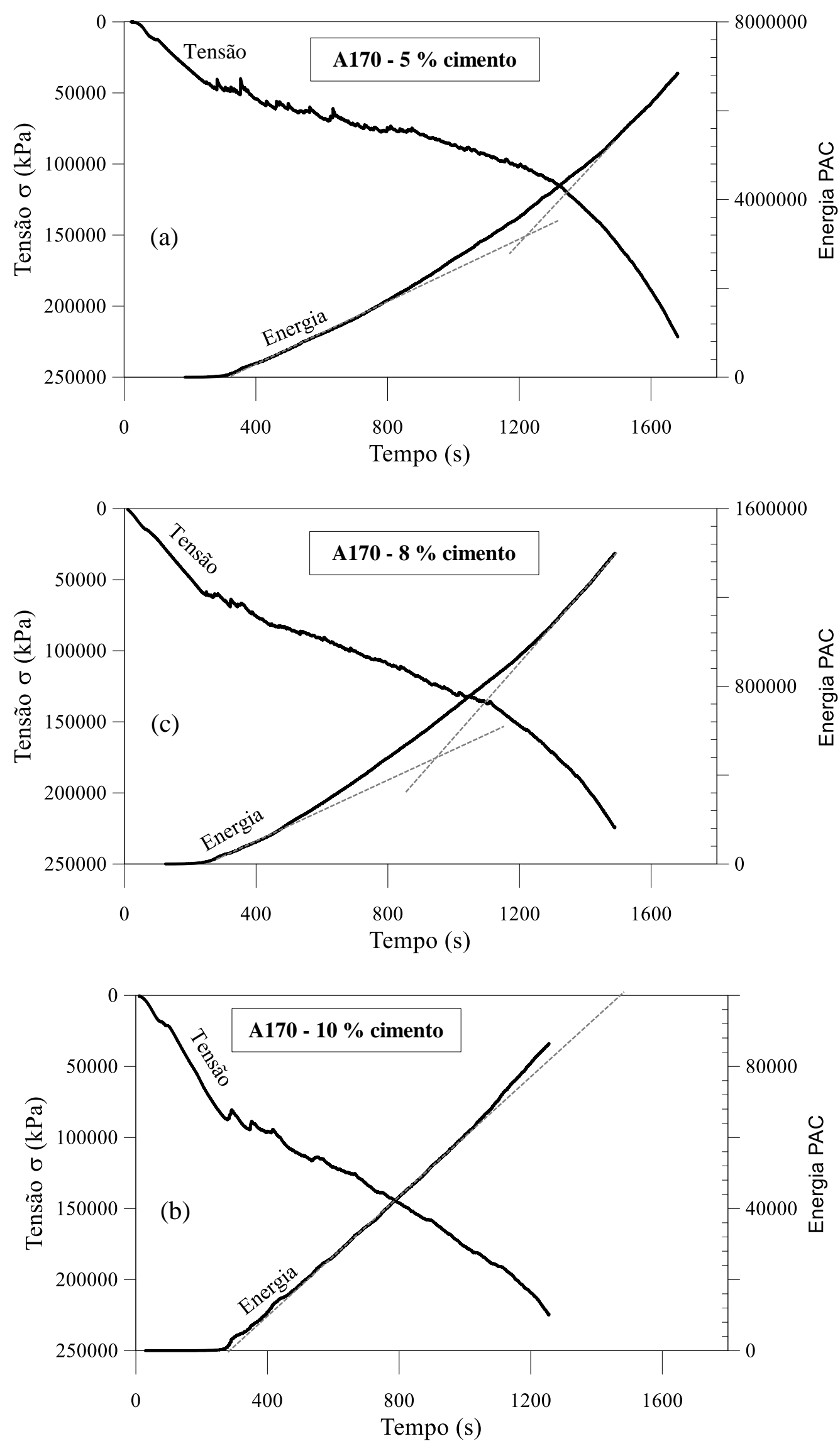

Figura 4.60. Relação entre a compressibilidade e as emissões acústicas para o material A170 cimentado. 

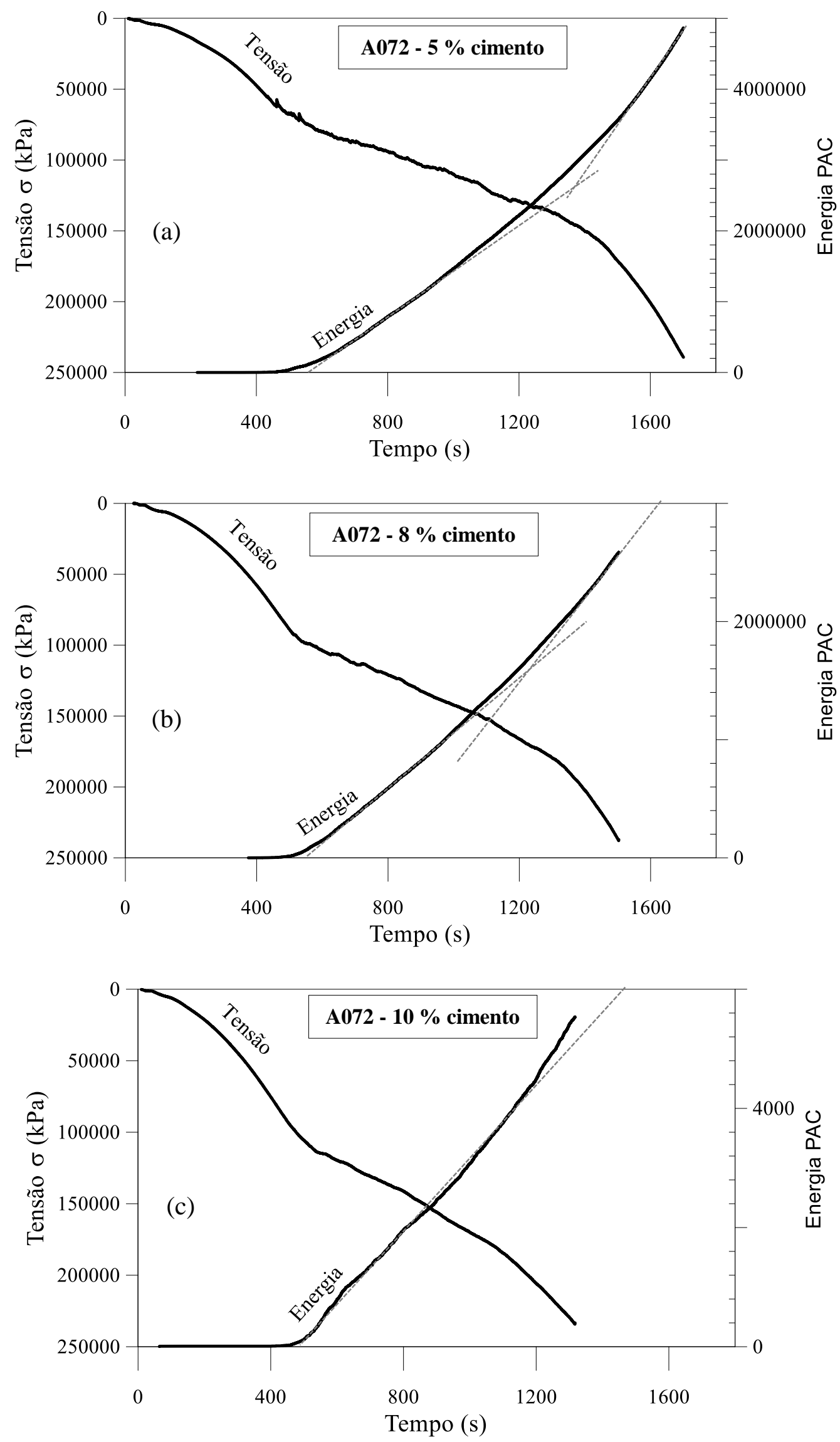

Figura 4.61. Relação entre a compressibilidade e as emissões acústicas para o material A072 cimentado. 

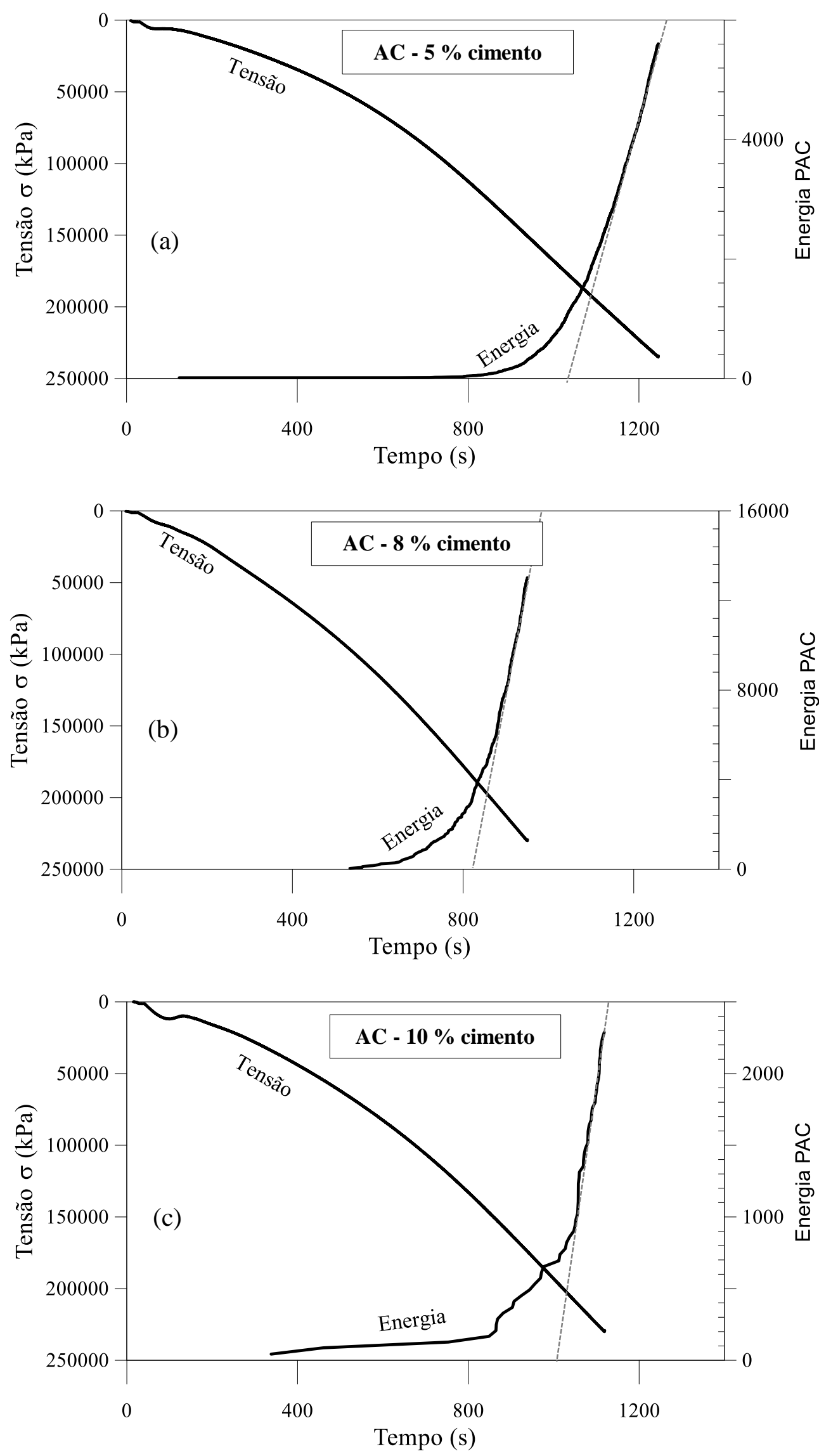

Figura 4.62. Relação entre a compressibilidade e as emissões acústicas para o material AC cimentado 


\subsection{SIMULAÇÕES NUMÉRICAS}

As simulações numéricas com o Método dos Elementos Discretos (DEM) foram realizadas apenas para materiais soltos, tendo como principal objetivo a avaliação do potencial do DEM para a representação qualitativa do comportamento macroscópico de matérias que apresentam quebra de partículas.

As características principais a avaliar foram a capacidade de reprodução da curva de compressibilidade e a evolução das curvas granulométricas, além de verificar a coerência dos eventos de quebra registradas numericamente via DEM com os obtidos das emissões acústicas reais.

As condições das simulações foram descritas em detalhes no Capítulo 4, mostrando dimensões e condições de contorno assumidas. As propriedades do material e do critério de quebra são apresentados na Tabela 4.5.

Tabela 4.5. Propriedade usadas para a simulação

\begin{tabular}{|l|c|}
\hline Propriedade & Valor \\
\hline Densidade do Material & $1500 \mathrm{~kg} / \mathrm{m}^{3}$ \\
\hline Ângulo de Atrito & $10^{\circ}$ \\
\hline Módulo de Young & $10 \mathrm{MPa}$ \\
\hline Coeficiente de Poisson & 0,3 \\
\hline Velocidade de compressão & $0,01 \mathrm{~m} / \mathrm{s}$ \\
\hline Módulo de Weibull, $\mathrm{m}$ & 1 \\
\hline Tensão Caraterística, $\sigma_{0}$ & $20 \mathrm{MPa}$ \\
\hline
\end{tabular}

Na Figura 4.63 mostra-se a evolução da quebra das partículas mediante imagens, onde pode ser observado quatro (04) níveis de compressão do material com diferentes estados de quebra das partículas. Observa-se claramente o funcionamento do critério de quebra, mostrando a subdivisão da partícula original em quatorze partículas novas. Na fase final do ensaio, o material apresenta também quebras no interior do corpo de prova, e o fenômeno acontece de uma forma mais uniforme. Isto é coerente com a verificações experimentais, nas quais ao final do ensaio o material apresentava quebra generalizada.

Na Figura 4.64 é apresentada a curva de compressibilidade obtida da simulação de elementos discretos. Em termos gerais, o resultado mostra que esta ferramenta consegue reproduzir qualitativamente o comportamento macroscópico do material, mostrando a potencialidade do método. Pode-se concluir que o resultado é aceitável, mesmo que neste 
trabalho não se tenha tentado ajustar perfeitamente aos ensaios experimentais por falta de tempo e de meios para calibrar os parâmetros microscópicos.
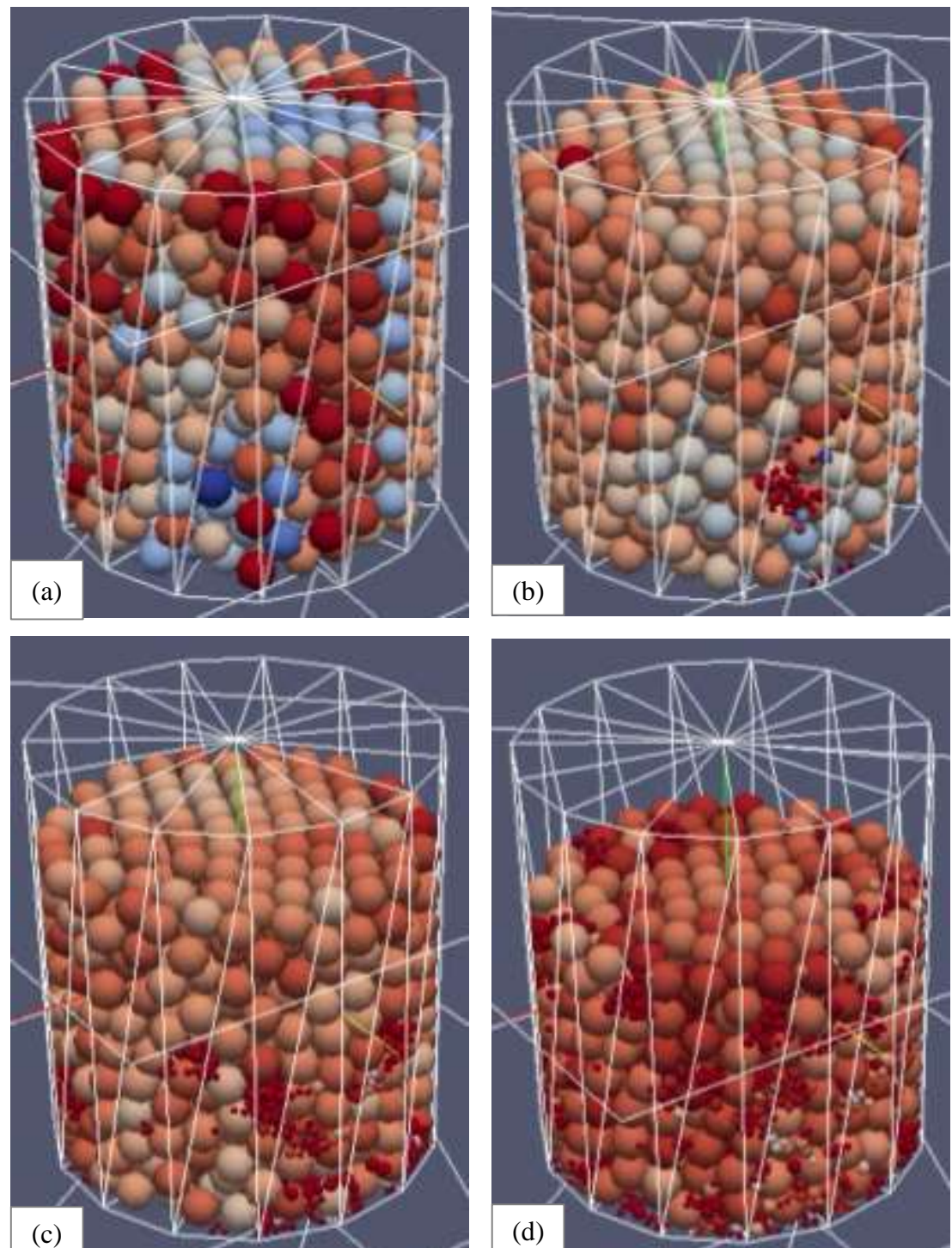

Figura 4.63. Resultado da simulação do ensaio de compressão confinada, com o método de elementos discretos, ilustrando a evolução do fenômeno de quebra.

O número de eventos ao longo da simulação é também apresentado na Figura 4.64, mostrando coerência com os resultados experimentais. A coincidência qualitativa dos picos e da distribuição dos eventos, validam o método que foi implementado para simular o fenômeno de quebra. A curva de eventos acumulados é apresentada na Figura 4.65, mostrando uma tendência linear semelhante à observada nas curvas experimentais de energia acumulada, indicando a fase na qual o material entra define a NCL. Assim, modelos com calibrações mais acertadas, para a obtenção de resultados similares aos experimentais, podem ser usados como ferramentas para a avaliação quantitativa dos mecanismos microscópicos e macroscópicos do material. 


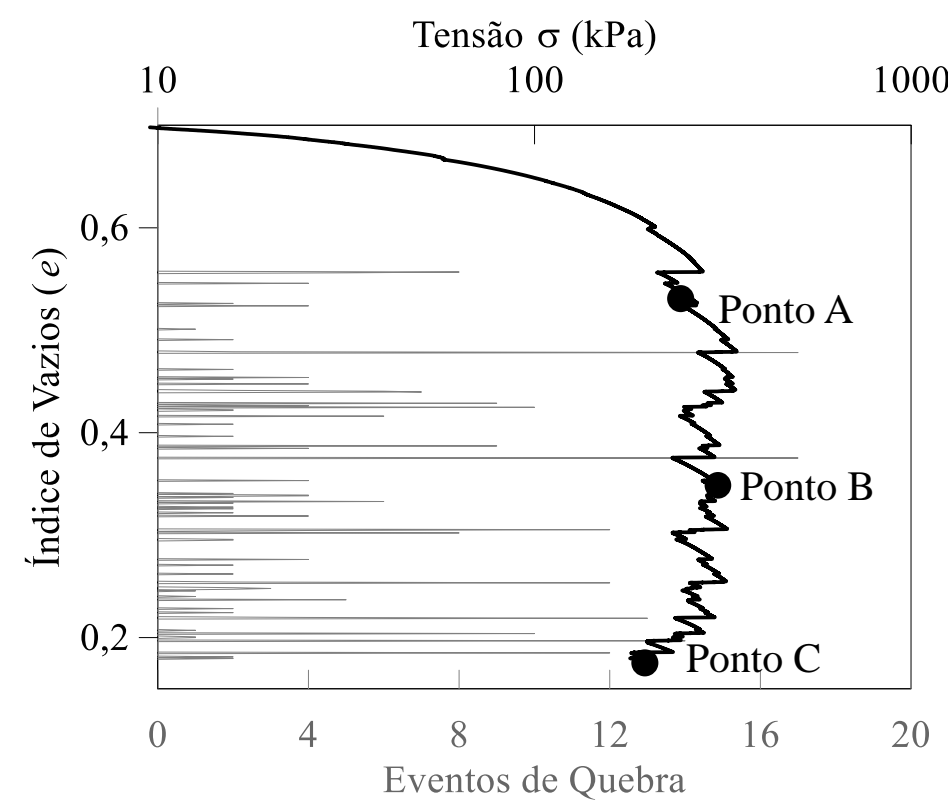

Figura 4.64. Curva de compressibilidade obtida da simulação com MED.

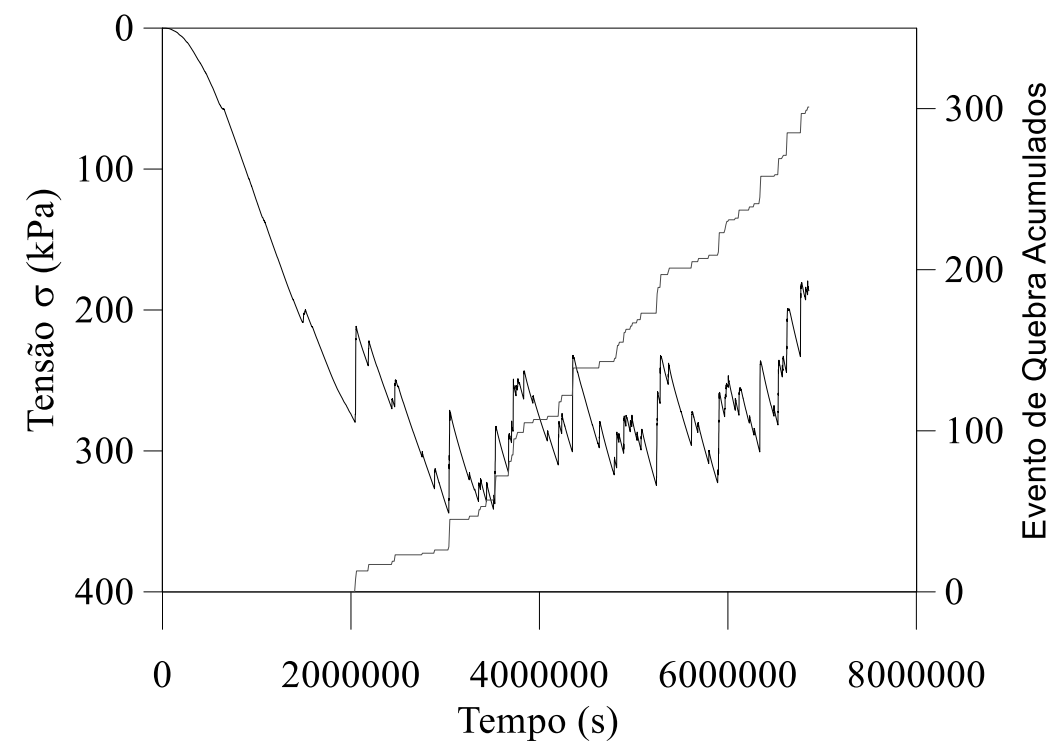

Figura 4.65. Evolução da tensão e dos eventos de quebra ao longo do ensaio.

Na Figura 4.66 são apresentadas as curvas granulométricas para três níveis de confinamento (A, B e C, segundo a Figura 4.64). Observa-se a que a evolução em termos gerais acontece de forma semelhante á observada nos ensaios reais, não obstante, com a metodologia implementada existe uma perda de massa na hora que é realizada cada substituição de uma partícula mãe pelas filhas. Por uma questão de tempo não foi possível a implementação da correção deste problema. Existe na literatura algumas formas para a correção destes problema. Ciantia et al. (2015) apresentam uma metodologia baseada na geometria fractal que deu resultados bastantes satisfatórios para tal correção. 
De uma forma geral pode-se concluir que a ferramenta DEM tem muito potencial para facilitar o entendimento de vários fenômenos micromecânicos. Mostrou-se que com as implementações feitas neste trabalho pode-se avaliar de uma forma acurada o fenômeno de quebra. Por uma questão de tempo não foi possível realizar um trabalho numérico mais detalhado da parte de quebra, nem uma implementação acurada do efeito da cimentação. Não obstante, deve-se ressaltar que a ferramenta é muito satisfatória para o estudo micromecânico de materiais granulares.

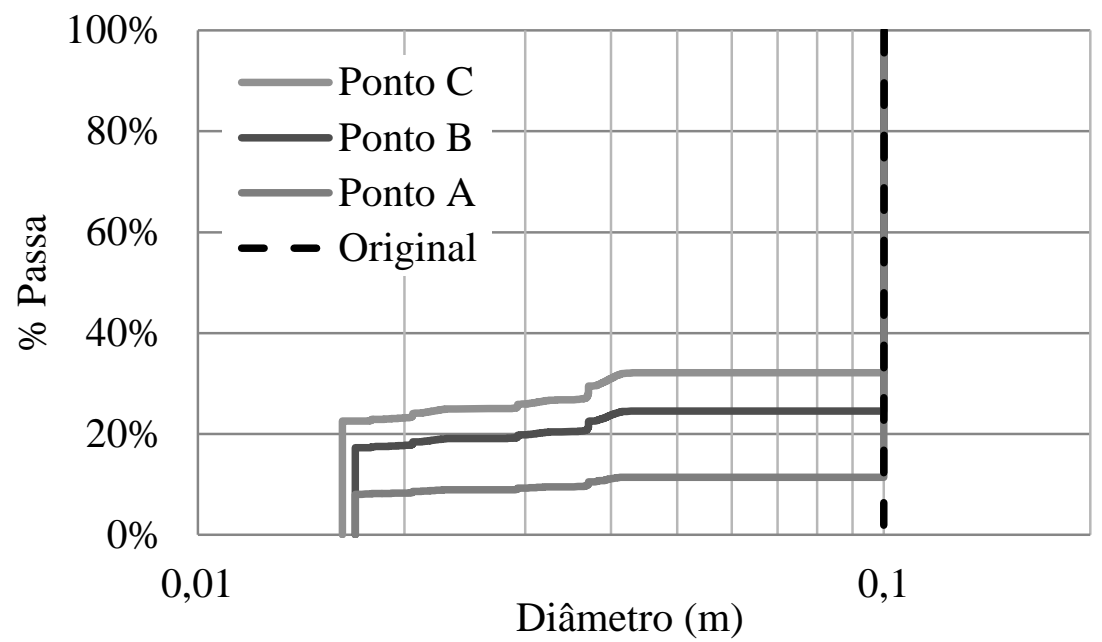

Figura 4.66. Evolução da curva Granulométrica com o processo de quebra. 


\section{CONCLUSÕES E SUGESTÕES}

Para alcançar o objetivo deste trabalho, que era avaliação da influência das características microestruturais de solos granulares em seu comportamento geomecânico macroscópico, foram realizados principalmente ensaios experimentais de compressão confinada, com a finalidade de abordar os fenômenos de fragmentação de partículas e desestruturação de cimentações. Este capítulo apresenta as conclusões obtidas durante esta pesquisa e também as sugestões para trabalhos futuros na continuação deste tema.

\subsection{CONCLUSÕES}

- A abordagem estatística da quebra da partícula individual usando a distribuição de Weibull é bastante satisfatória para o estudo deste fenômeno.

- A inclusão do efeito do tamanho da partícula no fenômeno de quebra individual apresenta algumas limitações. Normalmente são avaliados para uma quantidade pequena de diâmetros, sem ter uma tendência bem definida. Há algumas propostas na literatura, mas ainda não se possui uma formulação generalizada.

- O equipamento adaptado para a avaliação da quebra da partícula individual foi bastante satisfatório apesar das limitações que este possuía.

- A metodologia de diminuição de atrito usada durante os ensaios de compressão confinada possibilitou a obtenção de resultados bastante uniformes.

- A velocidade de deformação tem pouca influência no resultado macroscópico da curva de compressibilidade do material testado, mas pode melhorar significativamente a qualidade das emissões acústicas. No caso de materiais onde as emissões acústicas não são tão intensas, recomenda-se a avaliação da velocidade de deformação ideal.

- Para o entendimento da compressibilidade de materiais granulares é necessário entender bem os mecanismos de quebra presentes nas partículas.

- Para a formação completa de uma curva de compressibilidade típica de um material granular devem existir processos de fragmentação do grão.

- A técnica captação de emissões acústicas usada neste trabalho fornece dados relevantes que apoiam as análises dos resultados. 
- Várias medidas internas são obtidas com as emissões acústicas, não obstante, a energia PAC é suficiente para as interpretações dos fenômenos de compressibilidade, porque os mecanismos internos dos materiais estão relacionados com processos energéticos.

- No caso da avaliação da compressibilidade de material solto, as emissões acústicas refletem claramente os pontos de início dos processos internos e dos tipos de comportamentos.

- Estados de tensões muito elevados induzem um comportamento diferente, no qual a estrutura do material é bastante fechada e se observa um aumento de rigidez considerável.

- O início da quebra das partículas em termos gerais não depende das condições iniciais de índice de vazios. Normalmente, para cada tipo de partícula, o processo começou mais ou menos no mesmo nível de tensão.

- A evolução da quebra é bem representada por qualquer dos índices de quebra propostos na literatura. Não obstante, se recomenda usar as propostas que levam em consideração a curva granulométrica completa.

- Existem pontos de mudanças de comportamentos que foram observados em todas as avaliações experimentais, podendo ser correlacionadas entre si. Por exemplo, os pontos de inflexão da curva de evolução do índice de quebra devem estar relacionados com os pontos de inflexão nas curvas de energia acumulada das emissões acústicas.

- O processamento de imagens dinâmicas usado para avaliação da forma das partículas é uma ferramenta muito potente para o entendimento da evolução da forma das partículas devido ao processo de carregamento.

- A distribuição da relação de aspecto é uma ferramenta bastante útil para a representação da forma das partículas, podendo ser utilizada para incluir esta variável de forma quantitativa nos modelos de comportamento macroscópicos.

- Os corpos de provas fabricados com materiais cimentados reproduziram os comportamentos típicos de rochas brandas encontradas na natureza, como o arenito. Assim, foi possível a avaliação controlada das diferentes características micromecânicas relativas à cimentação, variando-se a quantidade de agente cimentante (epóxi) empregada. 
- As emissões acústicas são uma ferramenta bastante útil para a obtenção dos pontos que limitam os diferentes comportamentos dos materiais cimentados. Novamente a curva de energia acumulada proporciona esta informação.

- As informações experimentais levantadas neste trabalho ajudarão a melhorar modelos constitutivos macroscópicos, podendo avaliar a possibilidade de incluir caraterísticas micromecânicas, associadas com a energia de dissipação dos processos de quebra e desestruturação.

- A implementação numérica da quebra de grãos, via Método dos Elementos Discretos (DEM) no programa YADE, apresentou resultados satisfatórios para os objetivos delineados neste trabalho.

- As curvas de comportamento obtidas mediante as simulações via DEM são coerentes do ponto de vista qualitativo com os resultados experimentais, mostrando assim o potencial desta ferramenta para a geração de dados micromecânicos que ajudem a melhorar o entendimento macroscópico.

\subsection{SUGESTÕES PARA FUTURAS PESQUISAS}

Em complementação aos resultados obtidos neste trabalho são feitas as seguintes sugestões para pesquisas futuras:

- Realização de ensaios de compressão confinada com medida da tensão horizontal, de modo a se obter uma melhor descrição do estado de tensão ao qual é submetido o material.

- O item anterior permite ainda avaliar o coeficiente de empuxo no repouso $\left(K_{0}\right)$, o qual pode servir de base para calibrações de importantes parâmetros mecânicos macroscópicos (p.ex. coeficiente de Poisson) e microscópicos (p.ex. coeficiente de rigidez tangente).

- Avaliar a quebra de grãos durante a preparação de corpos de prova de materiais granulares, principalmente quando sujeitos a processos dinâmicos de compactação comuns em diversas obras de engenharia (p.ex. pavimentação rodoviária).

- Realizar ensaios de cisalhamento e de compressão triaxial para avaliar a influência das trajetórias nos comportamentos micromecânicos de quebra e cimentação. 
- Potencializar o uso de sistemas de emissões acústicas para obter a localização tridimensional das diferentes fontes de ruído no interior do material.

- Fazer avaliações mais detalhadas da evolução da forma das partículas.

- Realizar calibrações do modelo de quebra no programa YADE para obter uma melhor reprodução quantitativa e qualitativa dos ensaios experimentais.

- Realizar simulações com o efeito da cimentação da partícula que ajudem a entender os processos de desestruturação.

- Aperfeiçoar modelos constitutivos macroscópicos a partir das observações realizadas e propostas nesta tese.

- A proposta feita neste trabalho para a calibração da expressão usada para a evolução da resistência da partícula individual com o tamanho deve ser validada com uma quantidade maior de dados. 


\section{REFERÊNCIAS BIBLIOGRÁFICAS}

Alonso, E.E. \& Gens, A. (2010). Unsaturated soils. The 5th International Conference on Unsaturated Soil, . CRC Press, 1532.

Alonso-Marroquín, F. (2008). Spheropolygons: a new method to simulate conservative and dissipative interactions between 2d complex-shaped rigid bodies. EPL (Europhysics Lett., 83(1): 14001.

Alonso-Marroquín, F. \& Wang, Y. (2009). An efficient algorithm for granular dynamics simulations with complex-shaped objects. Granul. Matter, 11(5): 317-329.

ASTM International. (2006). Standard test method for one-dimensional consolidation properties of saturated cohesive soils using controlled-strain loading. D4186-06,.

Åström, J. a. \& Herrmann, H.J. (1998). Fragmentation of grains in a two-dimensional packing. Eur. Phys. J. B, 5(3): 551-554.

Bagi, K. (2003). Statistical analysis of contact force components in random granular assemblies. Granul. Matter, 5(1): 45-54.

Barreto, D., Gaudray, G., Shire, T. \& O’Sullivan, C. (2013). Quantifying stress-induced anisotropy using inter-void constrictions. Géotechnique, 63(1): 85-91.

De Beer, E.E. (1963). The scale effect in the transposition of the results of deep-sounding tests on the ultimate bearing capacity of piles and caisson foundations. Géotechnique, 13(1): 39-75.

Ben-Nun, O. \& Einav, I. (2010). The role of self-organization during confined comminution of granular materials. Philos. Trans. A. Math. Phys. Eng. Sci., 368(1910): 231-47.

Biarez, J. \& Hicher, P.-Y. (1994). Elementary Mechanics of Soil Behaviour: Saturated Remoulded Soils.

Bono, J.P. De. (2013). Discrete element modelling of cemented sand and particle crushing at high pressures. The University of Nottingham.

Burland, J.B. (1990). On the compressibility and shear strength of natural clays. Géotechnique, 40(3): 329-378.

Cantor, D., Estrada, N. \& Azéma, E. (2015). Split-cell method for grain fragmentation. Comput. Geotech., 67: 150-156.

Cheng, Y.P., Nakata, Y. \& Bolton, M.D. (2003). Discrete element simulation of crushable soil. Géotechnique, 53(7): 633-641.

Cheng, Y.P., White, D.J., Bowman, E.T., Bolton, M.D. \& Soga, K. (2001). The observation of soil microstructure under load. Powders and Grains, 69-72.

Cho, G.C., Dodds, J. \& Santamarina, J.C. (2006). Particle shape effects on packing density, stiffness, and strength: natural and crushed sands. J. Geotech. Geoenvironmental Eng., 132(5): 591-602. 
Chuhan, F.A., Kjeldstad, A., Bjørlykke, K. \& Høeg, K. (2003). Experimental compression of loose sands: relevance to porosity reduction during burial in sedimentary basins. Can. Geotech. J., 40(5): 995-1011.

Ciantia, M.O., Arroyo, M., Calvetti, F. \& Gens, A. (2015). An approach to enhance efficiency of dem modelling of soils with crushable grains. Geotechnique, (2): 91-110.

Ciantia, M.O., Arroyo, M. \& Gens, A. (2014). Particle failure in dem models of crushable soil response. Numerical Methods in Geotechnical Engineering, . CRC Press, 345-350.

Contreras, R.F. (2010). Estudio del fracturamiento de materiales granulares sometidps a esfuerzos de corte mediante monitoreo de la tecnica de emisión acústica. Universidad de Los Andes.

Coop, M.R. \& Atkinson, J.H. (1993). The mechanics of cemented carbonate sands. Géotechnique, 43(1): 53-67.

Cuccovillo, T. \& Coop, M.R. (1999). On the mechanics of structured sands. Géotechnique, 49(6): $741-760$.

Cundall, P. a. \& Strack, O.D.L. (1979). A discrete numerical model for granular assemblies. Géotechnique, 29(1): 47-65.

Daniell, C.M. \& McDowell, G.R. (2001). Fractal compression of soil. Géotechnique, 51(2): 173176.

Donzé, F.-V., Richefeu, V. \& Magnier, S.-A. (2009). Advances in discrete element method applied to soil , rock and concrete mechanics. Electron. J. Geotech. Eng., 8: 1-44.

Engin, H.K., Jostad, H.P. \& Rohe, A. (2014). On the modelling of grain crushing in hypoplasticity. Numerical Methods in Geotechnical Engineering, 33-38.

Evans, T.M., Mojarrad, H., Cunningham, C. \& Tayebali, A.A. (2009). Grain size distribution effects in 2 d discrete numerical experiments. 2009 International Foundation Congress and Equipment Expo, . ASCE, 58-65.

Feda, J. (1982). Mechanics of Particulate Materials.

Fernandes, F., Syahrial, A.I. \& Valdes, J.R. (2010). Monitoring the oedometric compression of sands with acoustic emissions. Geotech. Test. J., 33(5): 102501.

Fonseca, J., O’Sullivan, C., Coop, M.R. \& Lee, P.D. (2013a). Quantifying the evolution of soil fabric during shearing using directional parameters. Géotechnique, 63(6): 487-499.

Fonseca, J., O'Sullivan, C., Coop, M.R. \& Lee, P.D. (2013b). Quantifying the evolution of soil fabric during shearing using scalar parameters. Géotechnique, 63(10): 818-829.

Fraser, H.J. (1935). The systematic packing of spheres-with. J. Geol., XLIII(8): 785-909.

Galindo-Torres, S.A. \& Pedroso, D.M. (2010). Molecular dynamics simulations of complexshaped particles using voronoi-based spheropolyhedra. Phys. Rev. E, 81(6): 1-9.

Ghanbarian, B. \& Daigle, H. (2015). Fractal dimension of soil fragment mass-size distribution - a 
critical analysis. Geoderma, 245-246: 98-103.

Gili, J. a. \& Alonso, E.E. (2002). Microstructural deformation mechanisms of unsaturated granular soils. Int. J. Numer. Anal. Methods Geomech., 26(5): 433-468.

Gili, J.A. (1988). Modelo microestrutctural para medios Granulares no saturados. Universidad Politecnica de Catalunya.

Hagerty, M.M., Hite, D.R., Ullrich, C.R. \& Hagerty, D.J. (1993). One dimensional high pressure compression of granular media. J. Geotech. Eng., 119(1): 1-18.

Hardin, B.O. (1985). Crushing of soil particles. J. Geotech. Eng., 111(10): 1177.

Hardy, H. (1981). Applications of acoustic emission techniques to rock and rock structures: a state-of-the-art review. Acoustic Emissions in Geotechnical Engineering Practice, ASTM International, 100 Barr Harbor Drive, PO Box C700, West Conshohocken, PA 19428-2959, pp. 4-4-89.

Harireche, O. \& Mcdowell, G.R. (2002). Discrete element modelling of yielding and normal compression of sand. Géotechnique, 52(4): 299-304.

Ibañez, J.P. (2003). Modelagem constitutiva para solos com ênfase em solos não saturados. Pontifícia Universidade Católica do Rio de Janeiro.

Ibañez, J.P. (2008). Modelagem micro-mecânica discreta de solos residuais. Pontifícia Universidade Católica do Rio.

Ismail, M.A., Joer, H.A., Sim, W.H. \& Randolph, M.F. (2002). Effect of cement type on shear behavior of cemented calcareous soil. J. Geotech. Geoenvironmental Eng., 128(6): 520-529.

Jaeger, J.C. (1967). Failure of rocks under tensile conditions. Int. J. Rock Mech. Min. Sci. Geomech. Abstr., 4(2): 219-227.

Jiang, M.J., Leroueil, S. \& Konrad, J. (2005). Yielding of microstructured geomaterial by distinct element method analysis. J. Eng. Mech., 131(11): 1209-1213.

Jiang, M.J., Leroueil, S. \& Konrad, J.M. (2004). Insight into shear strength functions of unsaturated granulates by dem analyses. Comput. Geotech., 31(6): 473-489.

Jiang, M.J., Li, T., Hu, H.J. \& Thornton, C. (2014a). Dem analyses of one-dimensional compression and collapse behaviour of unsaturated structural loess. Comput. Geotech., 60: $47-60$.

Jiang, M.J., Sun, Y.G., Li, L.Q. \& Zhu, H.H. (2012a). Contact behavior of idealized granules bonded in two different interparticle distances: an experimental investigation. Mech. Mater., 55: $1-15$.

Jiang, M.J., Sun, Y.G. \& Xiao, Y. (2012b). An experimental investigation on the mechanical behavior between cemented granules. Geotech. Test. J., 35(5): 104408.

Jiang, M.J. \& Yan, H. (2007). Micro-contact laws of bonded granular materials for dem numerical 
analyses.

Jiang, M.J., Yu, H. \& Leroueil, S. (2007). A simple and efficient approach to capturing bonding effect in naturally microstructured sands by discrete element method. Int. J. Numer. Methods Eng., 69(6): 1158-1193.

Jiang, M.J., Zhang, F. \& Sun, Y. (2014b). An evaluation on the degradation evolutions in three constitutive models for bonded geomaterials by dem analyses. Comput. Geotech., 57: 1-16.

Jong, G.D.J. de \& Verruijt, A. (1969). Étude photo-élastique d'un empilement de disques. Cah. Groupe Français Rhéologie, 2(1): 148-161.

Ke, T.-C. \& Bray, J. (1995). Modeling of particulate media using discontinuous deformation analysis. J. Eng. Mech., 121(11): 1234-1243.

Koerner, R., McCabe, W. \& Lord, A. (1981). Acoustic emission behavior and monitoring of soils. Acoustic Emissions in Geotechnical Engineering Practice, ASTM International, 100 Barr Harbor Drive, PO Box C700, West Conshohocken, PA 19428-2959, pp. 93-93-49.

Koerner, R.M., Lord, A.E. \& Deutsch, W.L. (1984). Determination of prestress in granular soils using ae. J. Geotech. Eng., 110(3): 346-358.

Lade, P. V., Yamamuro, J.A. \& Bopp, P.A. (1996). Significance of particle crushing in granular materials. J. Geotech. Eng., 122(4): 309-316.

Lambe, T.W. \& Whitman, R. V. (1969). Soil Mechanics.

Lee, K.L. (1965). Triaxial compressive strength of saturated sands under seismic loading conditions. University of California.

Lee, K.L. \& Farhoomand, I. (1967). Compressibility and crushing of granular soil in anisotropic triaxial compression. Can. Geotech. J., 4(1): 68-86.

Leroueil, S. \& Vaughan, P.R. (1990). The general and congruent effects of structure in natural soils and weak rocks. Géotechnique, 40(3): 467-488.

Lim, W.L. \& McDowell, G.R. (2005). Discrete element modelling of railway ballast. Granul. Matter, 7(1): 19-29.

Liu, M.D. \& Carter, J.P. (2002). A structured cam clay model. Can. Geotech. J., 39(6): 13131332.

Lo, K.Y. \& Roy, M. (1973). Response of particulate materials at high pressures. Soils Found., 13(1): 61-76.

Lobo-guerrero, S. (2006). Evaluation of crushing in granular materials using the discrete element method and fractal theory. .

Lobo-Guerrero, S. \& Vallejo, L.E. (2006). Dem as an educational tool in geotechnical engineering. GeoCongress 2006: Geotechnical Engineering in the Information Technology Age, . ASCE, 1-6. 
Mandelbrot, B. (1982). The Fractal Geometry of Nature.

Marsal, R.J. (1980). Contribuciones a la mecánica de medios granulares. Comisión Federal de Electricidad.

Matsuoka, H. \& Liu, S. (1998). Simplified direct box shear test on granular materials and its application to rockfill materials. J. Japanese Geotech. Soc. soils Found., 38(4): 275-284.

Matuttis, H.-G. \& Chen, J. (2014). Understanding the Discrete Element Method. John Wiley \& Sons (Asia) Pte. Ltd, Singapore.

Mcdowell, G. \& Ferellec, J. (2010). Modelling realistic shape and particle inertia in dem. Géotechnique, 60(3): 227-232.

McDowell, G.R. \& Bolton, M.D. (1998). On the micromechanics of crushable aggregates. Géotechnique, 48(5): 667-679.

McDowell, G.R., Bolton, M.D. \& Robertson, D. (1996). The fractal crushing of granular materials. J. Mech. Phys. Solids, 44(12): 2079-2101.

McDowell, G.R. \& Harireche, O. (2002). Discrete element modelling of soil particle fracture. Géotechnique, 52(2): 131-135.

Mejía, A.M. (2009). Emisiones Acústicas en suelos granulares Cargados. .

Mesri, G. \& Vardhanabhuti, B. (2009). Compression of granular materials. Can. Geotech. J., 46(4): 369-392.

Michlmayr, G., Cohen, D. \& Or, D. (2012). Earth-science reviews sources and characteristics of acoustic emissions from mechanically stressed geologic granular media - a review. Earth Sci. Rev., 112(3-4): 97-114.

Miura, N. \& O-hara, S. (1979). Particle-crushing of a decomposed granite soil under shear stresses. Soils Found., 19(3): 1-14.

Nakata, A.F.L., Hyde, M. \& Hyodo, H. (1999). A probabilistic approach to sand particle crushing in the triaxial test. Géotechnique, 49(5): 567-583.

Nakata, Y. (2005). Macro and micro mechanical behaviour of crushable soil under compression. Geomechanics, . American Society of Civil Engineers, Reston, VA, 585-599.

Nakata, Y., Hyodo, M., Hyde, A. f. 1., Kato, Y. \& Murata, H. (2001a). Microscopic particle crushing of sand subjected to high pressure one-dimensional compression. Soils Found., 41(1): 69-82.

Nakata, Y., Kato, Y., Hyodo, M., Hyde, A.F.L. \& Murata, H. (2001b). One-dimensional compression behaviour of unuformly granded sand related to single particle crushing strength. Soils Found., 41(2): 39-51.

Neves, C.E.V. (2009). Comportamento de materiais granulares usando o método dos elementos discretos. Universidade de Brasília. 
O'Sullivan, C. (2008). Particle-based discrete element modelling: a geomechanics overview. The12th International Conference International Association for Computer Methods and Advances in Geomechanics (IACMAG), . International Association for Computer Methods and Advances in Geomechanics, Goa, India, 498-505.

O’Sullivan, C. (2011). Particulate Discrete Element Modelling.

O’Sullivan, C. (2014). Advancing geomechanics using dem. Geomechanics from Micro to Macro, CRC Press, pp. 21-32.

Oda, M., Konishi, J. \& Nemat-Nasser, S. (1980). Some experimentally based fundamental results on the mechanical behaviour of granular materials. Géotechnique, 30(4): 479-495.

Ortigão, J.A.R. (2007). Introdução à mecanica dos solos dos estados críticos.

Pestana, J.M. \& Whittle, A.J. (1995). Compression model for cohesionless soils. Géotechnique, 45(4): 611-631.

Potyondy, D.O. \& Cundall, P. a. (2004). A bonded-particle model for rock. Int. J. Rock Mech. Min. Sci., 41(8): 1329-1364.

Rowe, P.W. (1962). The stress-dilatancy relation for static equilibrium of an assembly of particles in contact. Proc. R. Soc. A Math. Phys. Eng. Sci., 269(1339): 500-527.

Sadd, M.H., Adhikari, G. \& Cardoso, F. (2000). Dem simulation of wave propagation in granular materials. Powder Technol., 109(1-3): 222-233.

Sheng, D. (2011). Review of fundamental principles in modelling unsaturated soil behaviour. Comput. Geotech., 38(6): 757-776.

Shi, G. \& Goodman, R.E. (1985). Two dimensional discontinuous deformation analysis. Int. J. Numer. Anal. Methods Geomech., 9(6): 541-556.

Shi, G. \& Goodman, R.E. (1989). Generalization of two-dimensional discontinuous deformation analysis for forward modelling. Int. J. Numer. Anal. Methods Geomech., 13(4): 359-380.

Šmilauer, V., Catalano, E., Chareyre, B., Duriez, J., Gladky, A., Kozicki, J., Scholtès, L., Sibille, L., Stránský, J. \& Thoeni, K. (2011a). Yade Reference Documentation.

Šmilauer, V., Catalano, E., Chareyre, B., Duriez, J., Gladky, A., Kozicki, J., Scholtès, L., Sibille, L., Stránský, J. \& Thoeni, K. (2014). Yade Documentation.

Šmilauer, V. \& Chareyre, B. (2011). Yade DEM Formulation.

Šmilauer, V., Gladky, A., Kozicki, J., Modenese, C. \& Stránský, J. (2011b). Yade : Using and Programming.

Tanimoto, K. \& Tanaka, Y. (1986). Yielding of soil as determined by acoustic emission. Soils Found., 26(3): 69-80.

Tapias, M., Gili, J.A. \& Alonso, E.E. (2012). Scale effects in rockfill behaviour. Géotechnique Lett., 2(July-September): 155-160. 
Thornton, C. (2000). Numerical simulations of deviatoric shear deformation of granular media. Géotechnique, 50(1): 43-53.

Toll, D.G., Lourenço, S.D.N., Fisher, P.C., Gallipoli, D., Congreve, A. \& Augarde, C.E. (2012). Formation and evolution of water menisci in unsaturated granular media. Géotechnique, 62(3): 193-199.

Torregroza-Aldana, L.M. (2007). Estudio de la fracturacion de las particulas empleando el Metodo de los Elementos Discretos. Universidad de Los Andes.

Turcotte, D.L. (1986). Fractals and fragmentation. J. Geophys. Res., 91(B2): 1921.

Tyler, S.W. \& Wheatcraft, S.W. (1992). Fractal scaling of soil particle-size distributions: analysis and limitations. Soil Sci. Soc. Am. J., 56: 362.

Wang, Y.-H. \& Leung, S.-C. (2008). A particulate-scale investigation of cemented sand behavior. Can. Geotech. J., 45(1): 29-44.

White, H.E. \& Walton, S.F. (1937). Particle packing and particle shape. J. Am. Ceram. Soc., 20(1-12): 155-166.

Yamamuro, J. a., Bopp, P. a. \& Lade, P. V. (1996). One-dimensional compression of sands at high pressures. J. Geotech. Eng., 122(2): 147-154.

Zhu, H.P., Zhou, Z.Y., Yang, R.Y. \& Yu, A.B. (2007). Discrete particle simulation of particulate systems: theoretical developments. Chem. Eng. Sci., 62(13): 3378-3396.

Zuluaga, R.A.G. (2011). Uma nova abordagem simples para simular o comportamento de solos em condições unidimensionais. Universidade de Brasília. 